\title{
INTER LINKED
}

A New Approach to Urban Expansion in Papamoa

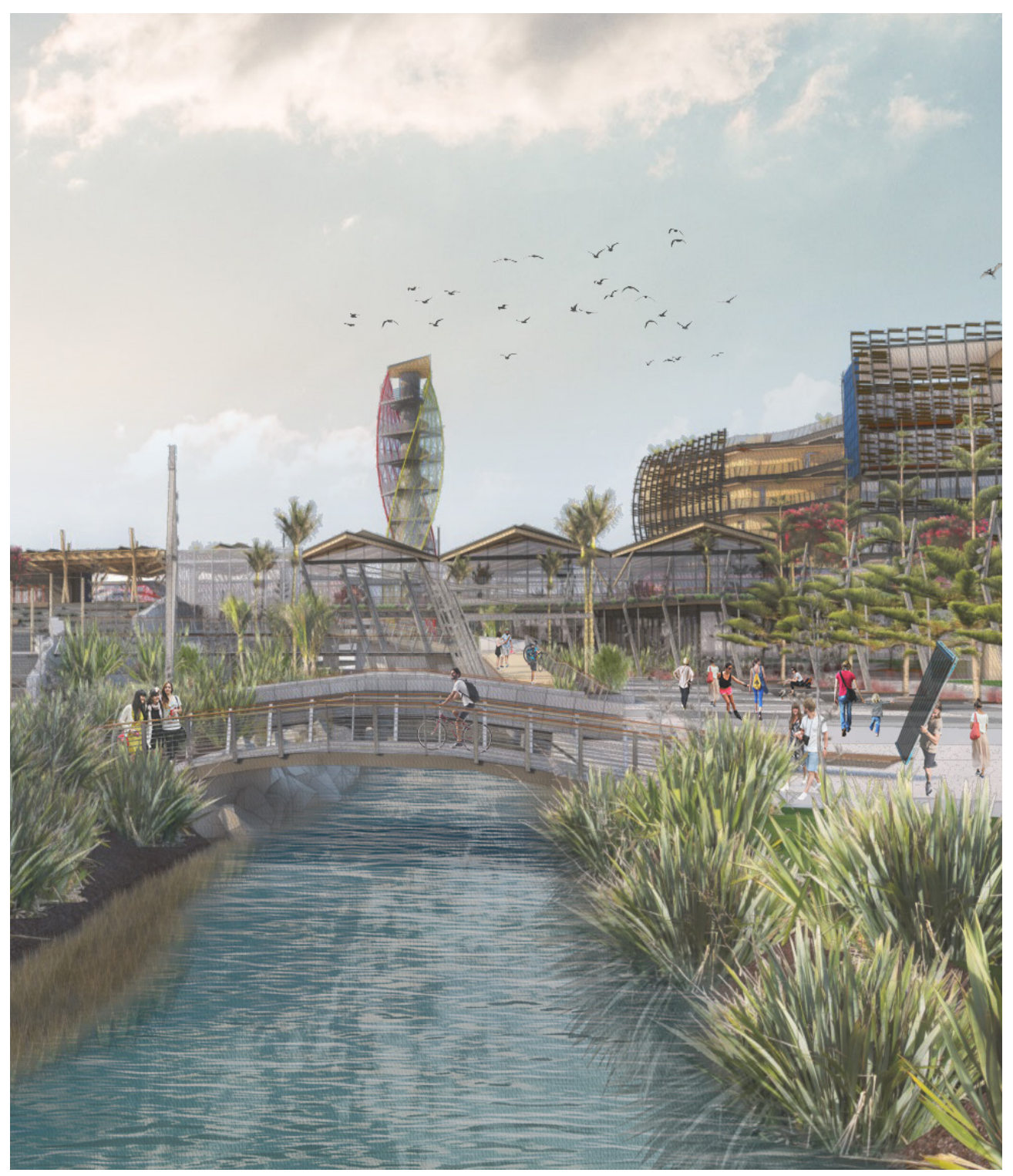


$-\therefore-7$ 


\section{INTER LINKED}

\section{A New Approach to Urban Expansion in}

Papamoa

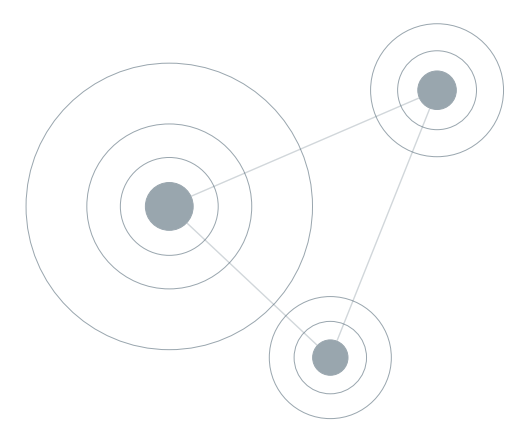

Kerry McKechnie Hinton

Supervisor: Guy Marriage

A 120 point thesis submitted in partial

fulfilment of the requirements for the degree of

Master of Architecture (Professional)

\section{Victoria University of Wellington \\ School of Architecture}


Acknowledgements

$<$ Figure 1 - Papamoa Beach at Domain Road

IV

inter linked 
I would like to thank my supervisor, friends and family for all their support.

To Guy and the Dream Team, thank you for putting up with my antics. Guy, your knowledge and guidance has been invaluable.

Mum and Dad, thank you for providing an escape and letting me periodically take over the house. Mum, thank you for dealing with my last minute proofing requests. I promise you will never have to read this again.

To the Archi Crew, its been a great five years full of all-nighters and poor decisions, I could not have done it without you.

To my friends outside of architecture, thank you for humouring me through the many late nights and providing a welcome escape from study.

And to Mabel, thank you for always listening to my rambles and providing an excuse to travel as part of my'research'.

Let it be done. 
Abstract 
New Zealand cities are prone to poor urban planning and have a strong tendency to expand out into widespread suburbs, consuming the fertile farmland and natural landscapes that reside at the fringes of urban development.

These types of greenfield development are rampant throughout New Zealand. Posed as the solution to housing issues and a growing population, these developments nullify and alienate the surrounding context. Low-density urban planning is particularly damaging with its maze of curving cul-de-sacs and dead-end streets resulting in an overly complex network with little to no central framework or hierarchy. This lack of internal infrastructure puts a significant strain on static infrastructure such as roads and public transport, which struggle to meet the needs of the end user.

The aim of this research is to develop an alternative strategy for urban growth in Papamoa. Located in the Bay of Plenty, Papamoa is a regional community within the Tauranga city limits, currently experiencing unprecedented growth.

Current projections show development in Papamoa will exhaust current land reserves by as early as 2028 , requiring the development of additional land to the south in order to sustain demand. This research aims to respond to this issue by increasing density within the existing sprawl, specifically focusing on the site of Papamoa Plaza, the original retail centre of the area. By reducing the need for greenfield development and enabling better connectivity across the region, a shift in focus of the use of public space can revitalise the existing urban centre to the benefits of connectivity within urban design.

Case studies and literature were reviewed in order to assess their viability within the New Zealand context and to identify key design elements that would be used. Criteria and guiding principles were developed using Assemblage Theory and Space Syntax. Existing developmental framework and growth trends were analysed during the research, then initial design goals and strategies were identified. Using this information, several schemes and approaches were developed. These were evaluated using 'Space Syntax' to establish levels and patterns of connectivity. A selection process of the most viable schemes was explored in detail. These were then broken into key components that were progressively developed to generate a range of different options, which were then reflected upon, assessed and, from this, the final scheme emerged. 
Preface 
Childhood trips to the beach were a quintessential part of life growing up in the Bay of Plenty. For my family Papamoa was always the place to go to - it was no more than $\mathbf{4 5}$ minutes from home and the quieter eastern end that we frequented allowed us to avoid the crowds of the Mount Maunganui beach, who would probably have disapproved of unruly dogs and the many sand battles that occurred.

Over the course of my visits, spanning over two decades, Papamoa has changed substantially. No longer is it the quiet rural beach hidden away at the end of the coastal strip. Even as a child I have held a fascination with construction and development and observed, with interest, the infill of the 1990s inch its way up the coast transforming the once sleepy beachside community into the heaving suburbs of today.

It has been an amazing experience watching the area evolve and move through different capacities of change, growth and decay as areas stagnate and investment moves onto the next stage.

However it has not been without its downsides as the rapid influx of people has brought with it straining infrastructure and a changing of attitudes amongst the community. What has surprised myself, and I think most people in the area, is the sheer rate of growth over the past decade. Demand has soared as people clamber for what is left of the kiwi getaway bach at the beach dream, whilst developers continue to squeeze as many houses as possible onto ever decreasing sections.

While growth and change are inevitable, and not something that I as a designer want to shy away from, I feel there must be a better approach to the planning and development in response to the challenges faced. This research will look toward developing alternative strategies for coping with this growth with a focus on designing for the user and the community rather than the developer. 
MVotiti Island
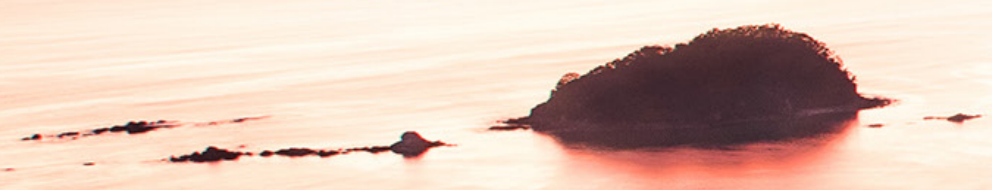

\section{Mount Maunganui}

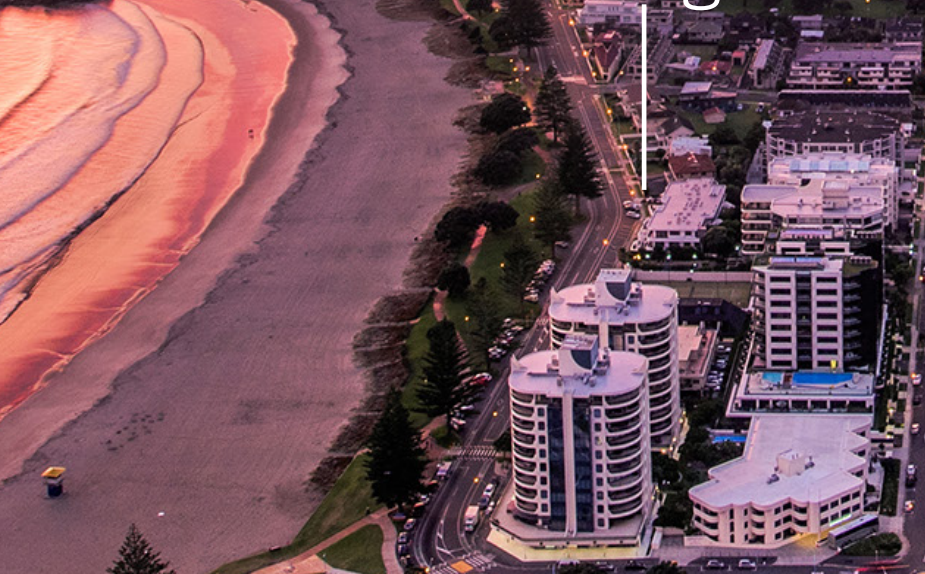

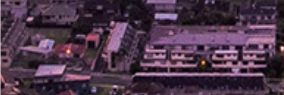
$5-\quad \forall-\ldots$ $\operatorname{lin}^{2}$

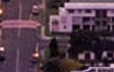




\section{Site}

Papamoa Hills

Tauranga CBD

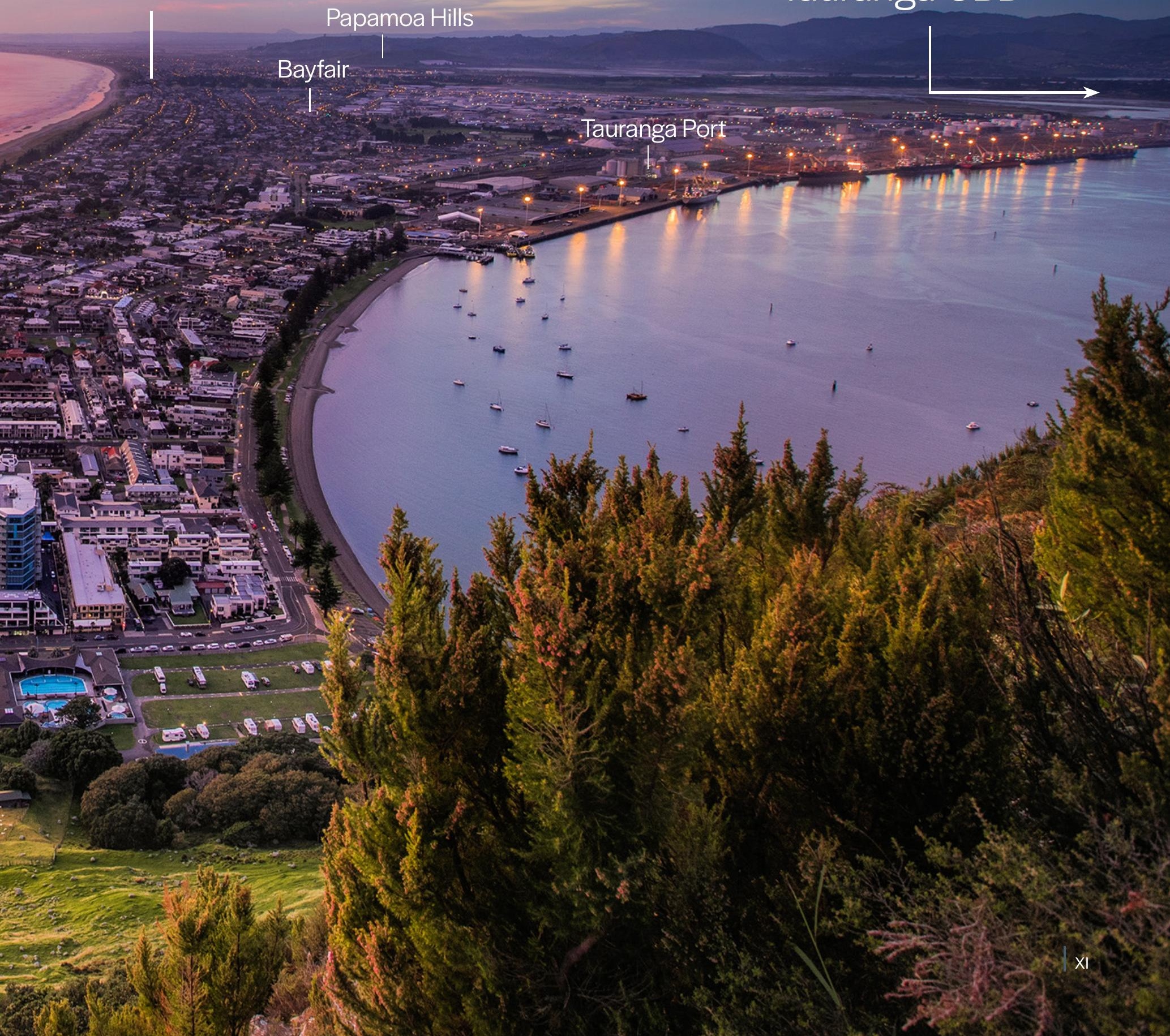


1.0

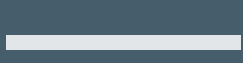

$c$

0

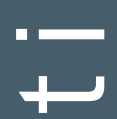

0

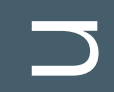

$\overline{0}$

0

$\stackrel{ \pm}{ \pm}$ 


\section{Contents}

Acknowledgements -........ IV

Abstract -............... VI

Preface _............... VIII

\subsection{Introduction}

Research Question _........ 4

Problem Statement _.......... 6

Aims \& Objectives _.......... 8

Scope of Research _. . . . . . . . _ 11

Methodology _............... 12

2.0 Site 22

Demographics \& Climate - . - . - 26

Existing Centres ............. 28

Site $\ldots \ldots \ldots 32$

\subsection{Site Assessment 44}

Existing Site Assessment - . . . . . 46

Transit-Oriented Development - . - 56

3.1 Preliminary Design _ . . . . . . 62

Design Phase 1 ........... 66

Design Phase 2 ........... 76

Design Phase 3 ........... 86
4.0 Masterplanning $\quad 94$

Destination Based Planning-- 107

Grade Separation . . . . . . 108

4.1 The Approach _. - - - 114

4.2 The Plan _.......... 128

5.0 The Parts 138

140

The Plaza _.......... 150

The Terraces _.......... 158

The Tower _. . . . . . . . . _ 174

5.1 The Assemblage _... . . 184

6.0 Conclusion 190

198

Figure List _.......... 202

Appendix 206 
Research Question 
How can an assemblage of urban structures be interlinked to bring vibrancy, vitality and flow to a tired stagnating suburb? 


\section{Problem Statement}

Tauranga City is New Zealand's 5th largest city and one of its fastest growing urban areas. Rapid growth is the success story of Tauranga. Its temperate climate, stunning scenery and multitude of beaches makes it an ideal as a place to live and an attractive alternative to a gridlocked Auckland (TCC, 2018c).

However, the city is poorly placed to accommodate this growth. According to Tauranga City Councils Draft Urban Strategy the city has grown by almost 50,000 people in the past 20 years and is predicted to reach 200,000 residents by 2063 (TCC, 2018C).

This is an issue as Tauranga is a city built around the suburb. To date over $80 \%$ of Tauranga's new housing and population growth has been accommodated by green field development on the city's fringes.

Between the years of 2001 and 2013 Tauranga's urbanised land area has expanded by $25 \%$, while the population increased $27 \%$. By comparison Auckland's land area expanded by $11 \%$ in the same period with a similar population increase of $23 \%$ (Nunns, 2016).

This highlights Tauranga's trend toward maintaining the same low-density suburban nature that the city has employed since its inception. Typical characteristics of development in this area are a lack of neighbourhood centre, a disjointed public transit system and a focus on the car rather than the community.

One of the areas hardest hit by this growth is the beachside suburb of Papamoa, located to the east of the central city. In Papamoa sprawling housing developments can be attributed to a range of issues including stagnation, community division and infrastructure strain.
As a result, home ownership rates are decreasing and the number of rental households experiencing housing stress is increasing. At the last census nearly $90 \%$ of renters could not affordably purchase a home priced at $\$ 500,000$ and the median home price in July 2018 was $\$ 635,000,9.1$ times the median income (TCC, n.d.-b).

This research seeks to bring vibrancy back to a tired and stagnating suburb through the intensification and interlinking of regional centres via strong transportation links focusing on Papamoa. This will centre on the site of Papamoa Plaza and Fashion Island, the original retail heart of the suburb.

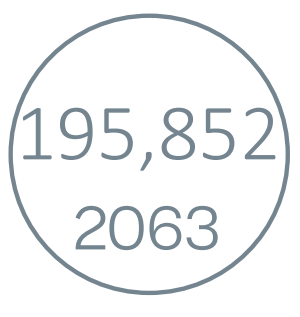

Population
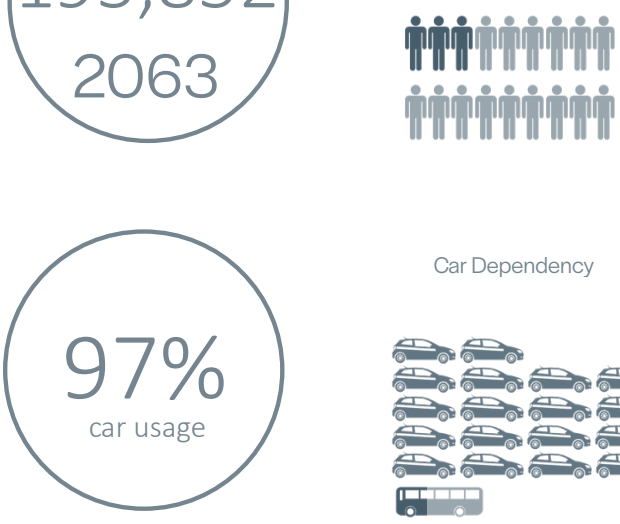

Car Dependency
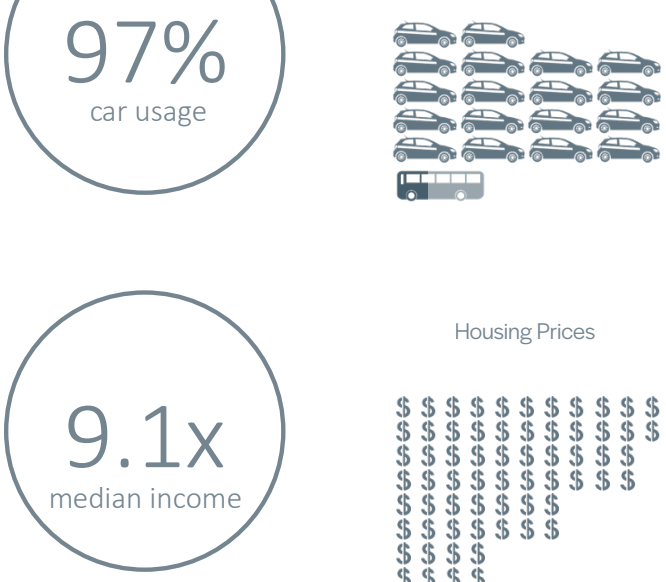

Housing Prices

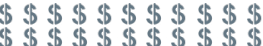

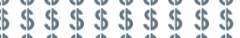

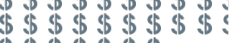

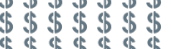

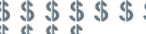

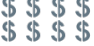




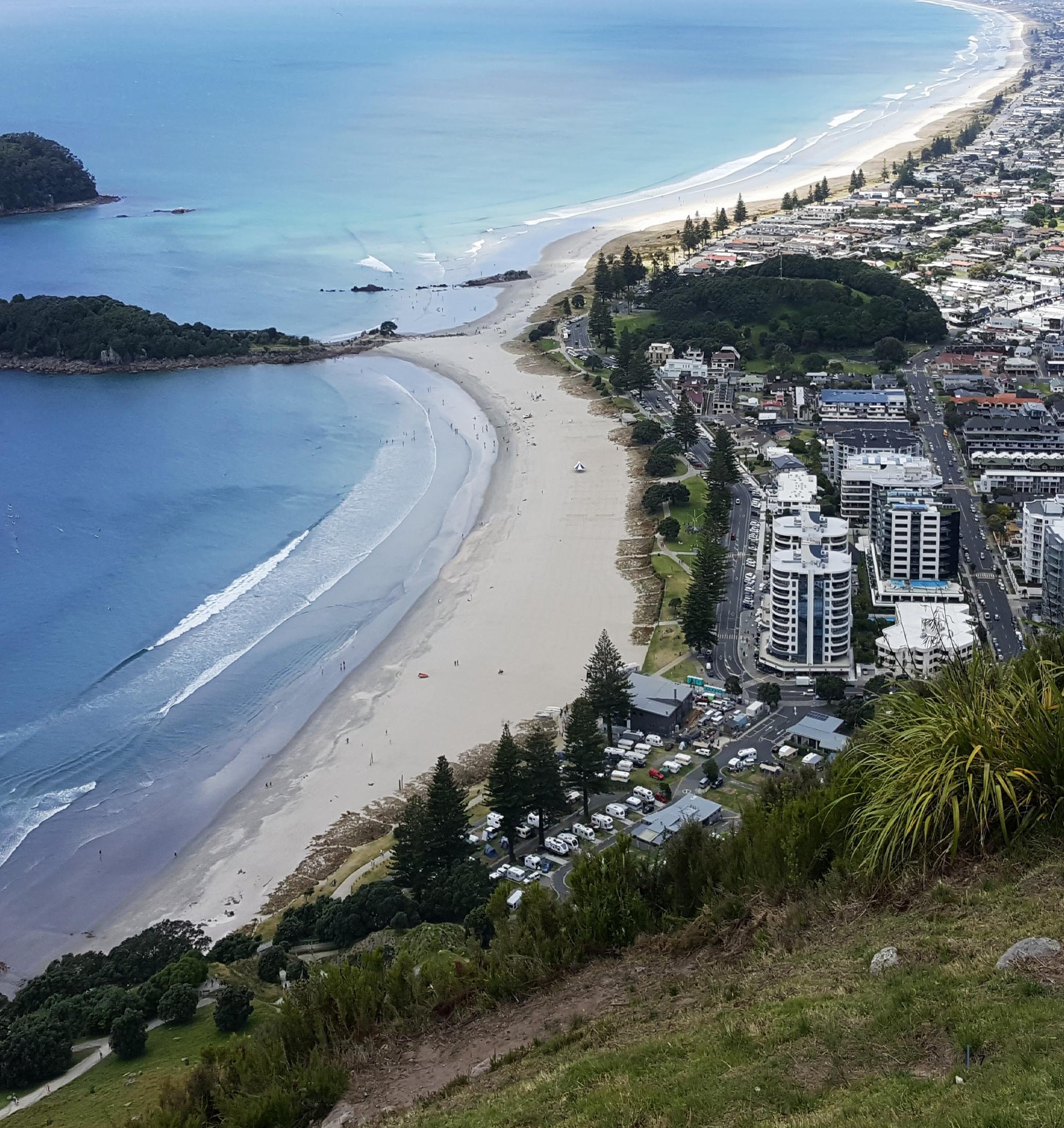




\section{Aims \& Objectives}

Current projections show development in Papamoa will exhaust current land reserves by as early as 2028 .

This research seeks to develop an alternative strategy for urban growth in Papamoa by reducing the need for greenfield development. This will enable better connectivity across the region, refocusing the use of public space to revitalise existing urban centres, and exploring the benefits of connectivity within urban design.

\section{Objectives}

To intensify the chosen site in order to facilitate a successful and vibrant town centre in Papamoa

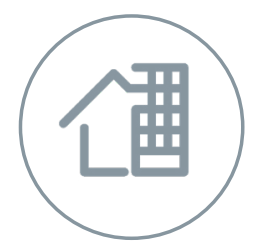

Intensification

To provide and integrate a multimodal public transportation system within the existing development.

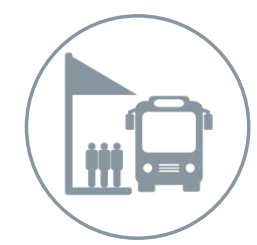

Transportation

To re-orientate the site and create new quality links between the coast and the Papamoa Hills, connecting the site the with its context.

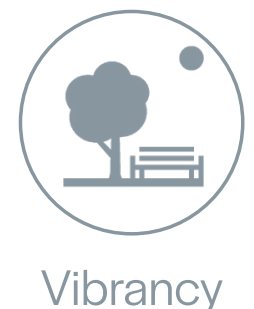

Vibrancy 
Guiding Principles

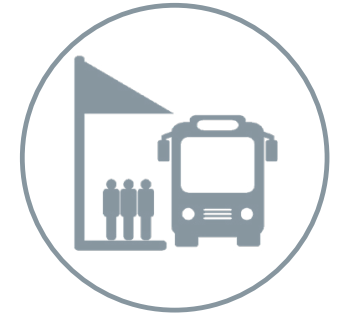

Quality Public Transit

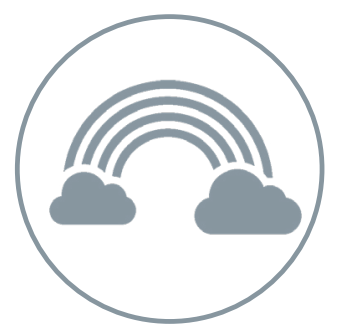

Neighbourhood centres and Vibrant

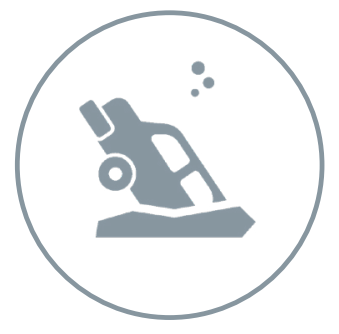

Car use management

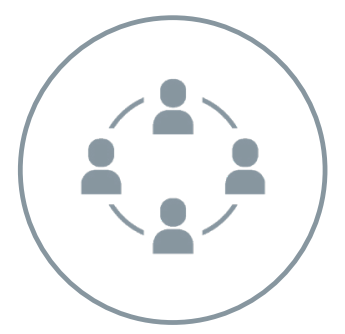

Community

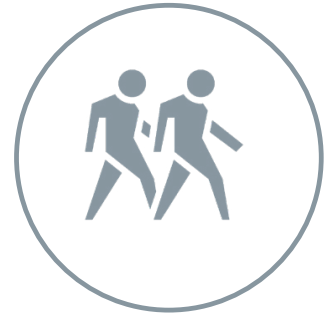

Active Transit

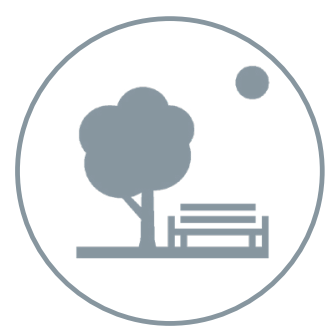

Quality Public Spaces

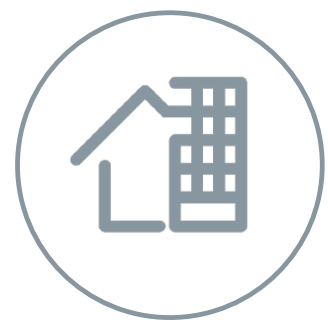

Mixed Use

neighbourhoods

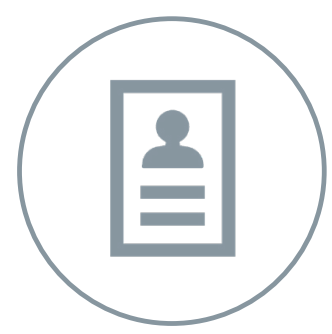

Collective Identity 


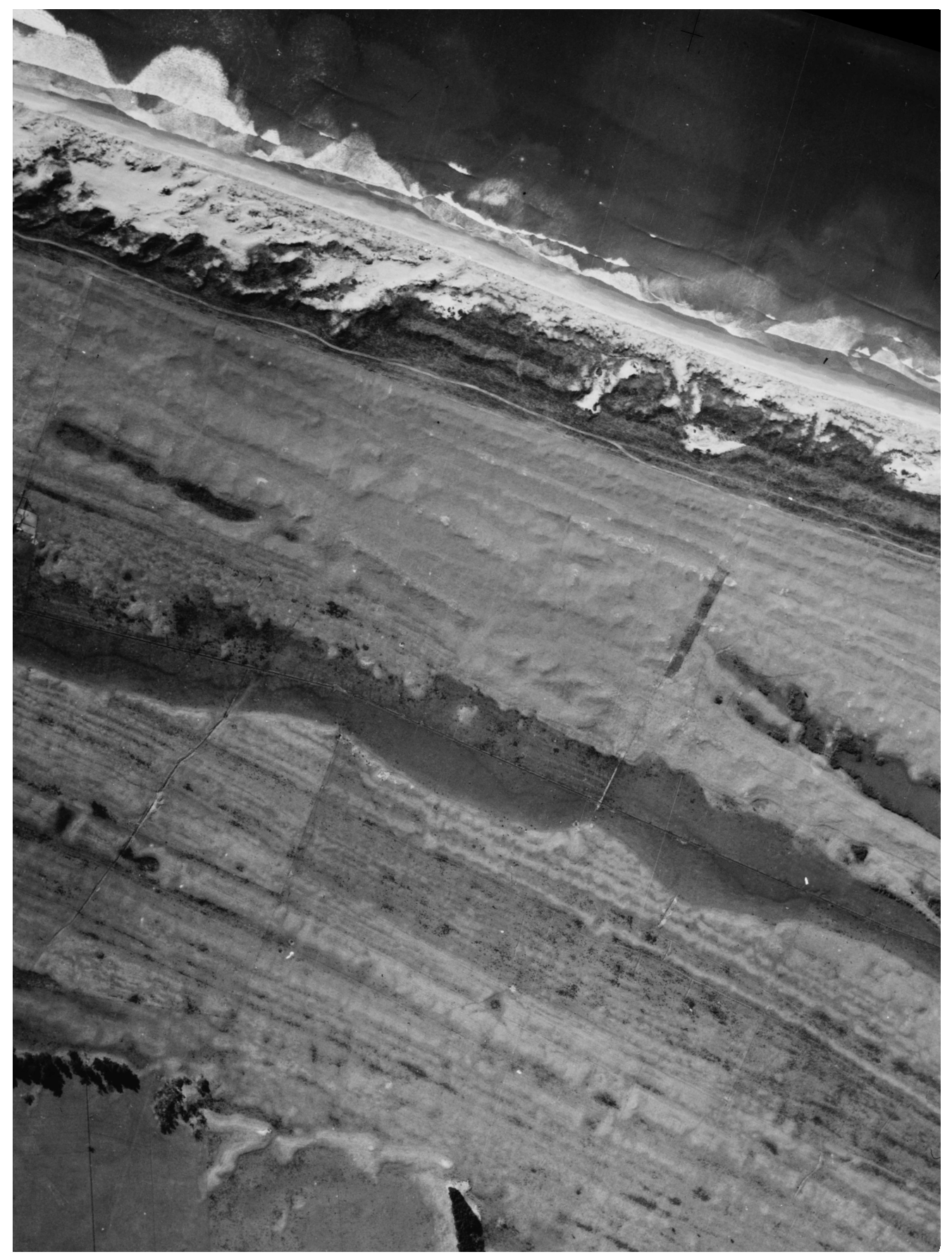

^ Figure 4 - Papamoa Beach 12 April 1939. Retrieved from http://retrolens.nz. Copyright creative commons 3.0 New Zealand. 
"Cities are the largest and most complex artefacts that humankind makes. We have learned long and hard lessons about how we can damage them by insensitive interventions. But the growth of knowledge limps painfully along through a process of trial and error in which the slow time scale of our efforts and the even slower timescale of our understanding, make it almost impossible to maintain the continuity of experience and study which we might hope, in time, would give rise to a deeper, more theoretical understanding of cities".

(Hillier, 2007, p 111)

The scope of this research began at the regional scale, developing a regional transit system based on the principles of Transit Oriented Development. However, as development progressed it became apparent that a reduced scope was required in order to develop the key research objectives to a satisfactory level. As a result, the scope was refocused to the site of the current Papamoa Plaza and Fashion Island developments in Papamoa.

The brief of this project was something that developed organically over time as 'assemblage' was employed to develop the scheme in response to regional conditions and site-specific factors. This looked to the sites history and the needs of the community, both now and moving into the future, in order to develop an assemblage that could meet the needs of the rapidly growing community.
Despite the initial change in scope, the overall size of the project remained relatively large due to the need to explore a range of different factors and design areas. Due to this, the project remains largely within the masterplan scale. Key areas such as the public scale and the transport hub are developed to a higher level of detail in order to bring elements of realism to the scheme and enable testing of the research's core principles. However, the research makes no attempt to venture into the realm of detailed design.

Elements such as community engagement, costings and implementation were also considered out of scope, considering the time elements of this research. 
Methodology

5th March 2018

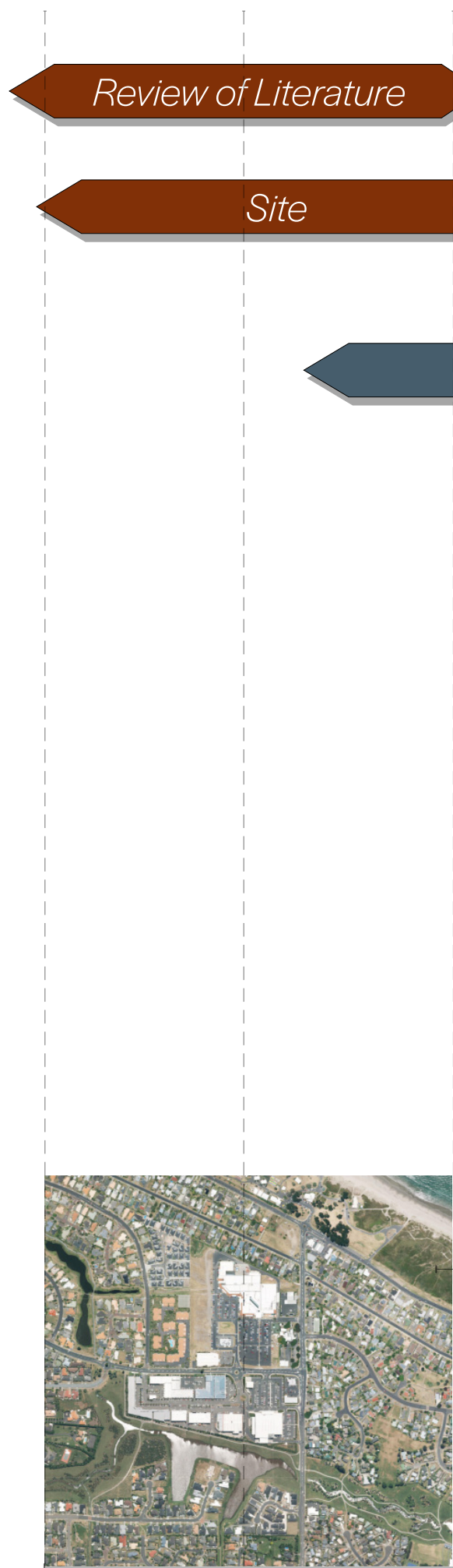

Design Review One

\section{Site Assessment}

Space Syntax - Depth Map

\section{Transport}

T.O.D.

Case Studies

Space Syntax - Depth Map

\section{Preliminary Design}

Design Phase 1

Reflection

Design Phase 2

Reflection

Design Phase 3

Reflection
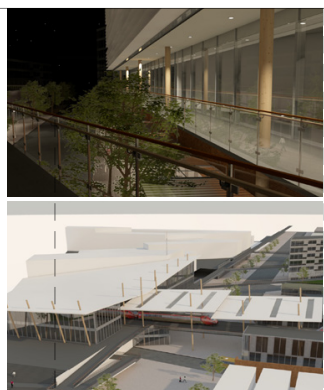


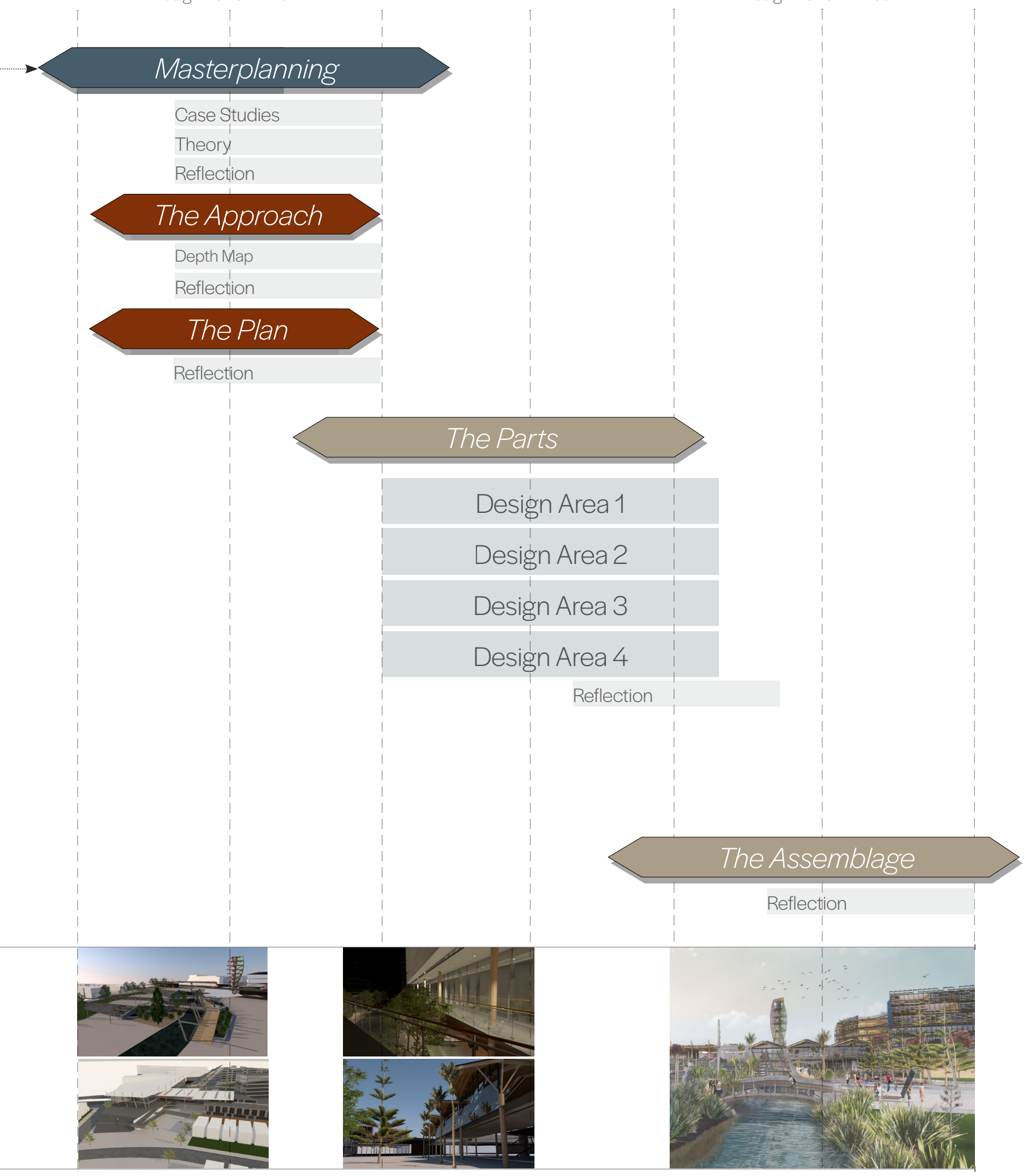


This research employs the principles of 'assemblage' as an approach regarding the concept of urban design as a system of components. Assemblage is a theory created by Gilles Deleuze in the late twentieth century. This follows a theoretical framework that seeks to analyse and describe a wide range of systems constructed from an equally diverse range of components.

\section{Application}

This theory applies well to the urban context and is becoming increasingly used in theoretical debate. It is described as a system whose properties emerge from the interconnections, interactions, flow and synergies between different components. When we apply this to the city, the components represent the places, the neighbourhoods and the buildings. These objects are the result of the productive processes of assemblage and inform how we view and interact with the city. It is from these that we form relationships and synergies with the urban landscape (Dovey \& Ristic, 2017).

The main issue when using this theory is that there is no singular interpretation of application. This becomes apparent when we contextualise the theory to a specific time and place. For the purposes of this research I will be simplifying my usage of the theory and applying it primarily to connectivity and the establishment of relationships between varying urban structures as this is the primary drive of this work. This will use the broad Deleuzian conception of Assemblage established in 'Dialogues II' described as "a multiplicity constituted by heterogeneous terms and which establishes liaisons, relations between them" (Deleuze, Parnet, Habberjam, \& Tomlinson, 2007, p. 52), (McFarlane, 2011a, p. 207) .
The primary driver of assemblage in this interpretation is that of a co-functioning system. It never affiliates, instead components interact via symbiosis. When applying this to urban structures this means that the forms, processes and resulting relationships are less defined by the properties of the individual components, instead they are more likely affected by the arrangement and formations in which they engage. It is through the individual components that the overall assemblage can be stabilised or destabilised depending on the relationships established (McFarlane, 2011a).

Colin McFarlane uses assemblage to explain the relationships and consequence of composition. McFarlane develops this in his paper, 'The city as assemblage: dwelling and urban space', where he proposes that the formation of the city should be considered as a process of gathering. He argues that the concept of assemblage is particularly applicable to the generative nature of the city. "Generative" is defined as the momentum of historical and political processes that combine to encompass the "eventful, disruptive, atmospheric, and random juxtapositions that characterise urban space" (McFarlane, 2011b).

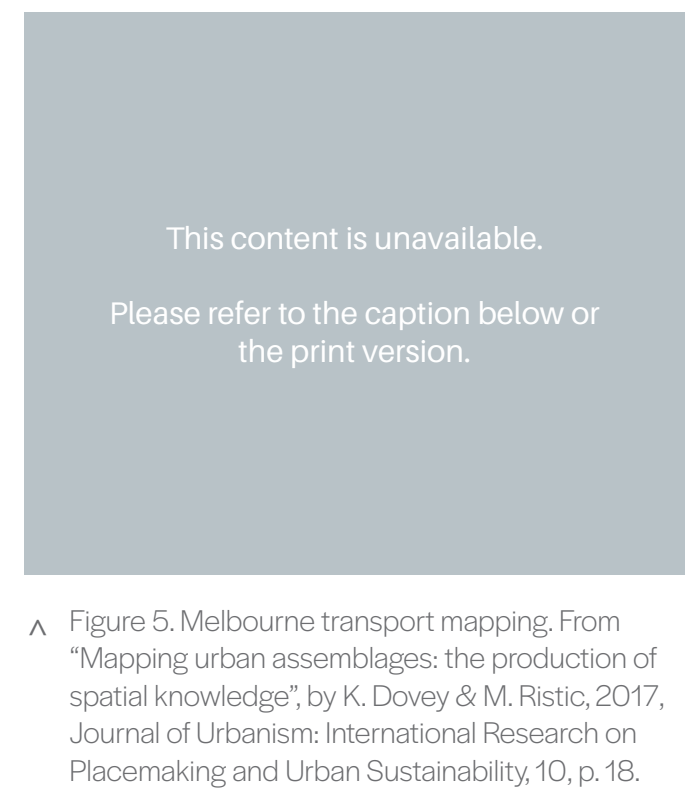




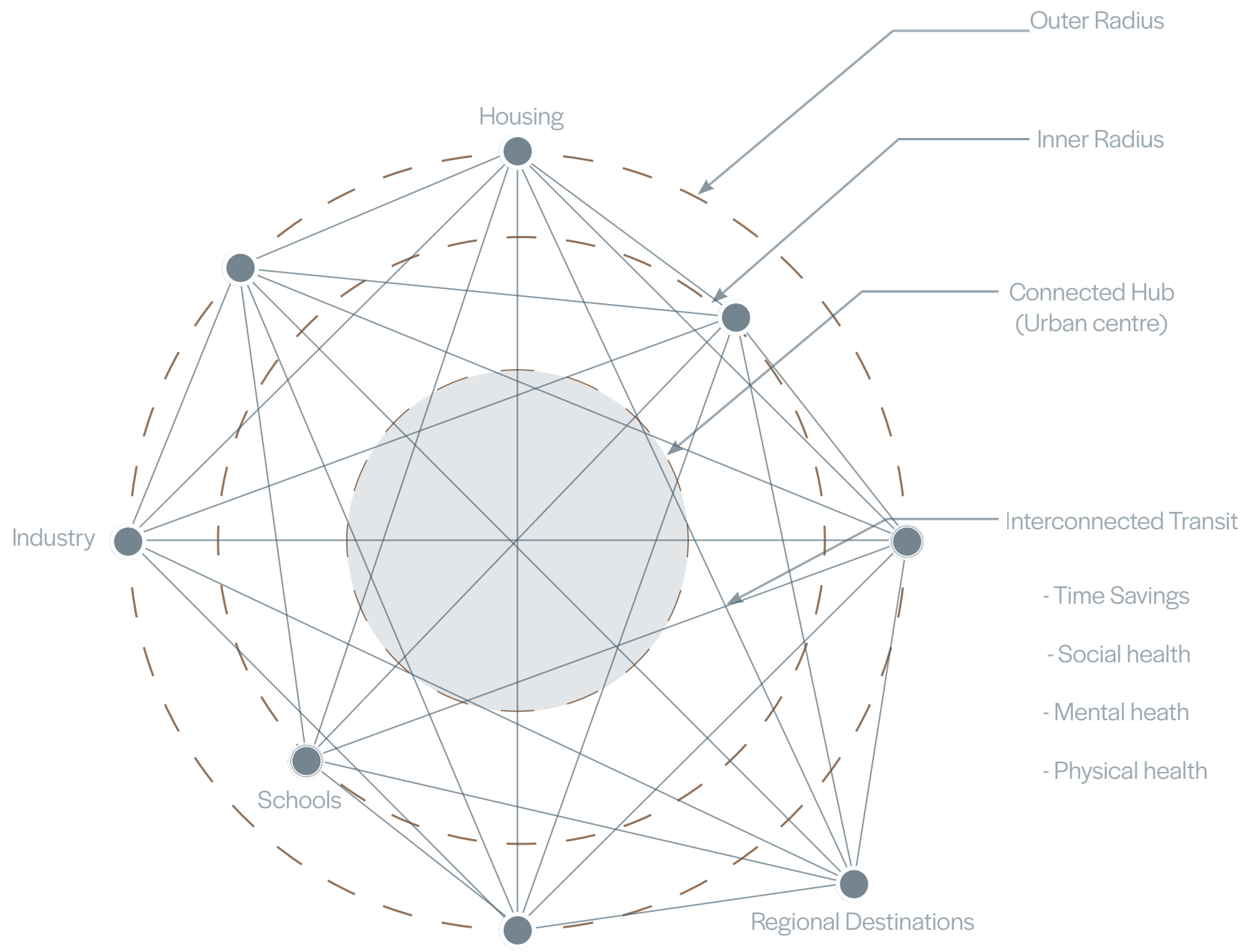

$\wedge$ Figure 6 - Assemblage Theory Visualisation

"The Deleuzian ontology is one that seeks to understand morphogenetic processes through which forms come into being. Unlike a 'system' that implies hierarchy, assemblage thinking assumes what is often called a 'flat ontology'

(Dovey \& Ristic, 2017, p. 3).

Kim Dovey and Mirjana Ristic's paper, 'Mapping urban assemblages: the production of spatial knowledge', discusses assemblage applied as a process of mapping transport modes within Melbourne, Australia (figure 5). This stems from the work of James Corner who discusses the use of mapping to understand "the various hidden forces that underlie the workings of a given place" (Dovey \& Ristic, 2017, p. 17). This focuses on how urban mapping, used in conjunction with assemblage, can be used to expand the spatial knowledge of a given location (Corner, 1999). 
The Melbourne example investigates levels of access across various transport modes between different areas of the city. This uses urban mapping as a means to compare types of 20 minute accesses across the city and illustrates travel data, including connectivity, mobility and walkability.

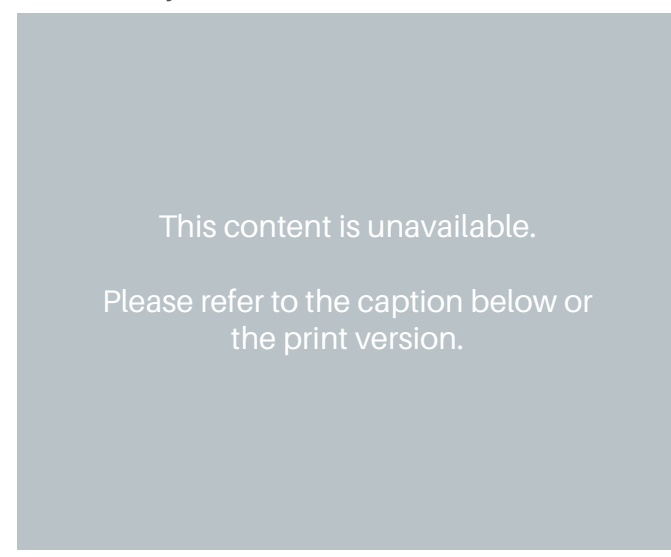

$\wedge$ Figure 7-Fitzroy Case Studies. From Mapping urban assemblages: the production of spatial knowledge. by K. Dovey \& M. Ristic, 2017, Journal of Urbanism: International Research on Placemaking and Urban Sustainability, 10 (1), p.20

Assemblage is explored to analyse the interconnected nature of the city, through a mapping exercise of the primary functions present in the suburb of Fitzroy (figure 7,8). This employs Jane Jacobs' arguments regarding the necessity of co-functionality within the makeup of our cities, noting the issues created through the modernist segregation of the city and the impact that this has on the urban environment, disrupting the connectivity and synergies of urban living (Jacobs, 1993).

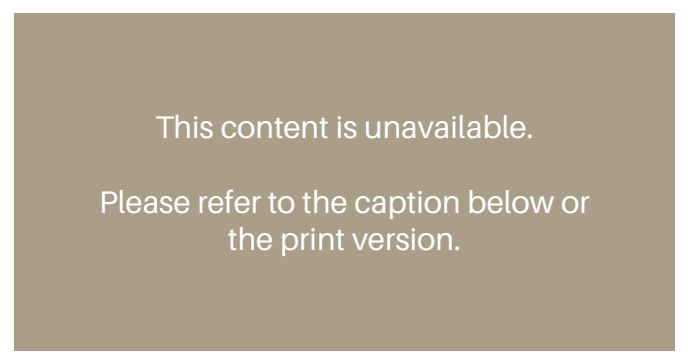

$\wedge$ Figure 8-Urban functions. From Mapping urban assemblages: the production of spatial knowledge. by K. Dovey \& M. Ristic, 2017, Journal of Urbanism: International Research on Placemaking and Urban Sustainability, 10 (1), p.20
This argument is well established in urbanism, however many of our cities still lack this synergistic flow and the connectivity required to make this work, as is the case with the Papamoa site.

The mapping process used for the Fitzroy case study is adapted from an approach developed by a Netherlands based research team and organises urban functions into three primary categories, housing, work and amenity (Dovey \& Ristic, 2017).

For the purpose of this research, amenity refers to places such as retail and other urban attractors outside of work and home. Amenity will also refer to location-based destinations such as parks and beaches. This system of organising urban functions enables the identification of multiplicities acting within the urban context and represents the mixing of categories, identifying areas of higher connectivity (Dovey \& Ristic, 2017).

\section{Conclusion}

In this research I intend to focus my investigations primarily on connectivity with emphasis on transport and access to amenity, which will be dictated by my target population. By utilising assemblage as a key framework and process to organise and assess the design concepts, a comprehensive understanding of the way design changes can facilitate urban mobility and assist in the choice between design schemes will be achieved.

The goal of this is to establish connectivity and vibrancy within an existing suburb that is experiencing the consequences of segregated design and stagnation due to poor urban planning. This will be applied primarily at the suburban scale and will employ the theories discussed, in conjunction with design precedents, and evaluated using connectivity analysis such as space syntax and depth map software. 


\section{Methodology}

Space Syntax

Definitions:

Axial line - "The axial line is defined as the longest straight line representing the maximum extension of a point of space. It can be objectively created"

("Axial line Space Syntax_Online Training Platform," n.d.).

Segment - "The segment is the section of axial line or street or path lying between two intersections"

("Segment Space Syntax_Online Training Platform," n.d.)

Convex space - "Convex space is one in which no straight line drawn between any two points goes outside the space"

("Convex space Space Syntax_Online Training Platform," n.d.).

Isovist points - "An isovist is a set of all points visible from a given vantage point in space and with respect to an environment. The shape and size of an isovist is liable to change with position" ("Isovist Space Syntax_Online Training Platform," n.d.).

Space syntax is a system of analysing spatial layouts, a programme developed by Bill Hillier and UCL. It works based on the idea that space can be broken down into a system of nodes which can then be mapped and modelled.

This is particularly useful for measuring human activity and patterns within buildings and urban areas and can be used to predict things such as connectivity and integration. When applied to urban planning it gives designers a means, through mapping, to simulate the effects of different design decisions, allowing different schemes to be assessed in rapid succession and their long-term consequences to be explored and compared prior to construction (Hillier, 2007).
The potential of Space syntax was initially founded in solving problems associated with small scale design and planning, it is increasingly being used for larger projects in space-based master planning as a means of solving issues in the urban environment, and as a tool for planning new suburbs and even cities.

Hillier points its success towards the programmes ability to generate syntactic models of the city, which allows planners to work across all urban scales within the same model. This ability enables planners to map movement networks across both the larger city-wide scale and simultaneously identify smaller micro movements and features within individual districts. This facilitates the identification of wider transportation networks alongside localised land use analysis (Hillier, 2007).

Space Syntax is founded on two fundamental principles. The first is the link between space and human activity, suggesting that space is not necessarily secondary to human activity but, instead, the two are intrinsically linked. The second takes the view that space is influenced by the relationships that it has with the wider network of spaces around it ("Overview Space Syntax_Online Training Platform," n.d.). This uses a network analysis to measure to what degree each element of the network is integrated with the wider system. This is calculated by the number of axial links that one must pass through to reach their destination (Pafka, Dovey, \& Aschwanden, 2018). 
The concept itself is comprised of four components:

'Representations of Space'- using twodimensional mapping techniques to represent spatial elements and then assessing the spaces created, this focuses on how people experience the space that they inhabit and move through.

'Analysis of spatial relations'- is used to understand the relationships between spatial elements and the differences that occur from varying configurations of these elements. These measures represent the two elements of the human journey which are established as, firstly, the choice of destination and, secondly, the route taken to get to the destination.

'Interpretive models' interpret the data collected and represent it visually through colour maps so that it can be analysed and explored.

'Theory'. This explores the links between theory and the relationships between spatial and social patterns to identify commonalities and patterns in results across models and test what happens to spatial layouts when objects are altered, placed or removed entirely.

("Overview Space Syntax_Online Training Platform," n.d.)

\section{Limitations}

However, there are limitations as to how Space Syntax can be applied. In the article 'Limits of space syntax for urban design: Axiality, scale and sinuosity', recently published by the University of Melbourne, several limitations of the analysis are discussed. This focuses primarily on issues relating to the level of reductionism and determinism that the authors have identified within space syntax literature. This concern is based on the suggestion that "urbanity can be explained by one basic universal principle" (Pafka et al., 2018). However, Space Syntax is composed of an array of different methodologies which cater to different needs, it is not a "one size fits all" solution and requires understanding before it is used (Pafka et al., 2018).

The three primary approaches used are

Gamma (figure 9a), Isovist (figure 9b) and Axial analysis (figure 9c). Gamma identifies relationships between different cells or

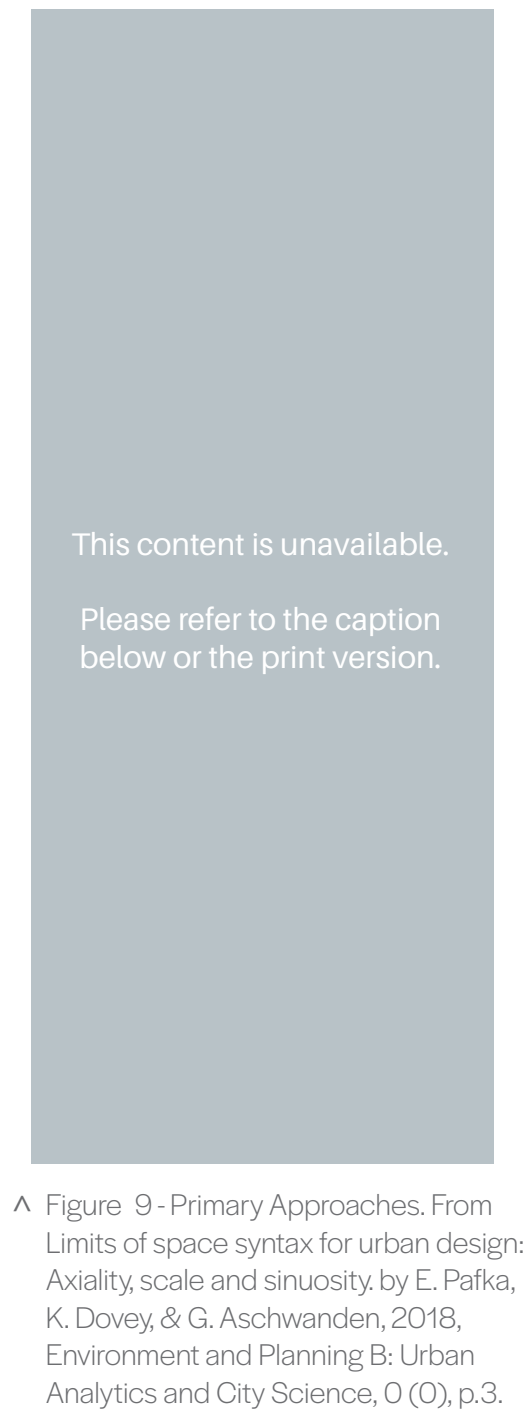

rooms and is generally more suited toward building and architectural scales. Isovist works by identifying and analysing the area of space visible in the horizontal from any given vantage point ("Isovist Space Syntax_Online Training Platform," n.d.). This is useful at both the architectural 
and urban scales. However, for wider scale connectivity studies, Axial analysis is more appropriate. This is because it uses axial lines in the plan view to analyse the number of straight axis required to navigate the urban environment, the lower the number better the connection. This follows the theory that the most integrated pathways are those with the least number of turns required to access all other pathways within a given network (Pafka et al., 2018).

Axial analysis can be applied at a multitude of scales and is the best suited for this research. However, there are also limitations that must be considered. The main point of contention is brought about by the nature of axial analysis, which is a topological measure rather than metric. This means it disregards physical and spatial distance in its calculations. Ratti argues that this is an issue as it relies on the basis that people are more inclined to move in a straight line than they are to choose the shortest distance, suggesting that while the theory may hold ground for newcomers and tourists, it may not accurately portray the paths taken by locals who are familiar with the area (Pafka et al., 2018)(Ratti, 2004).

Hillier counters this, noting that while Ratti is correct in his observation that space syntax does discount metric data, the issue is that by trying to marry metric and topological data within a configurative model of space can may end up reducing the accuracy and reliability overall. By including metric data directly within the model, the overall result is immediately skewed toward the geometric centre of the model, which will identify smaller link roads adjoining the centre as more integrated than the major lines that are more removed from the geometric centres. It will also make the model more sensitive to the boundaries of the model, to the extent that the location of which boundaries are set will skew the location of the centre of integration producing an
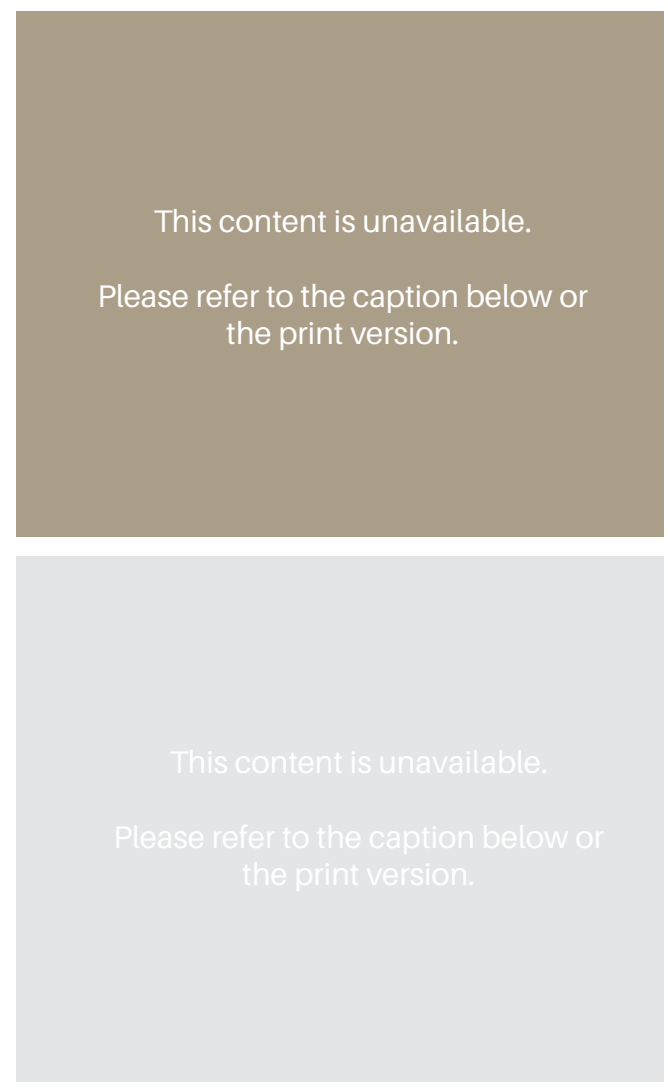

$\wedge$ Figure 10 -Primary Approaches. From The architectures of seeing and going:or, are cities shaped by bodies or minds? And is there a syntax of spatial cognition? by B. Hillier,2003, (Proceedings) 4th International Space Syntax Symposium. : London., O (0), p.6.3.

inaccurate depiction of the area analysed (figure 10), which is why topological data is favoured (Hillier \& Penn, 2004).

This highlights the necessity of using Space Syntax in conjunction with other theory and metrics. Issues may occur where Space Syntax is used as standalone design tool, as it is difficult to determine if the flow through a space will lead to occupied and vibrant spaces, or whether it will simply become a movement conduit of people travelling from A to B. However, for the purposes of this research the work will be conducted in principle with other case studies, theory and knowledge bases that will be used to guide it. 
There are also contentions in the way that Space Syntax and Axial Analysis discard three-dimensional information relating to both changes in elevation and building heights which can affect pedestrian movement and spatial use. However, the site in question is flat and issues relating to building height and its impact will be assessed using other means, such as solar studies, in addition to the axial analysis.

\section{Conclusion}

Axial analysis has been identified for use in this research due to its ability to identify points of integration within urban areas. It is particularly useful because of the correlations that have been drawn between points of high integration and higher flows of movement, density and greater mixes in terms of land use. This enables the identification of nexus points in the community and allows schemes to be tailored to facilitate this type of activity, which has been shown to encourage higher levels of street-life and vibrancy within public spaces. In previous studies locations with the highest levels of integration have been shown to be the social hearts of our suburbs and cities, where the most public life and intensive activity is found (Pafka et al., 2018).

This research will use Space Syntax as an evaluation tool to assess the potential of different schemes to meet the research objectives and design a new vibrant heart for the Papamoa Community and wider Tauranga region. This will use UCL Depth Map as the primary evaluation tool, by using axial analysis to identify connectivity and integration of spaces across the urban scale and has been identified as the most suitable for the purpose of this research. 

2.0

$\stackrel{\oplus}{\infty}$ 


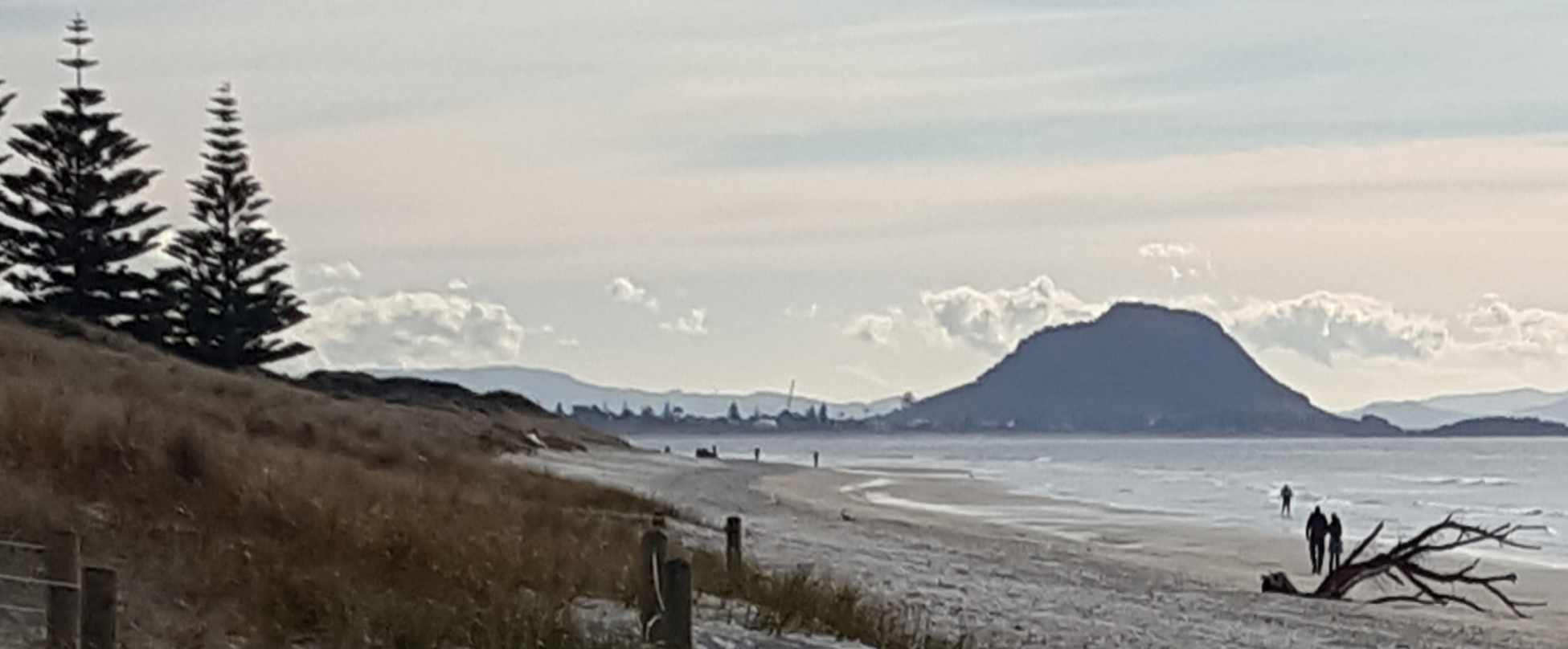

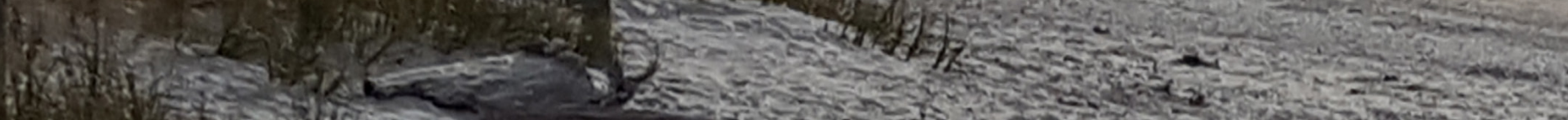

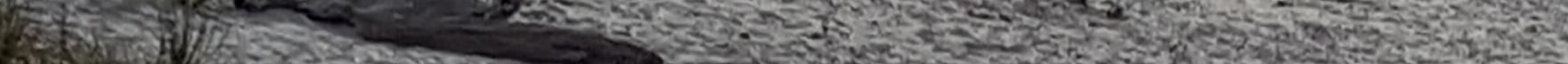

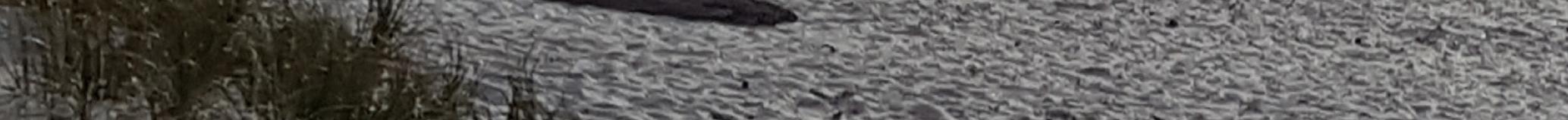

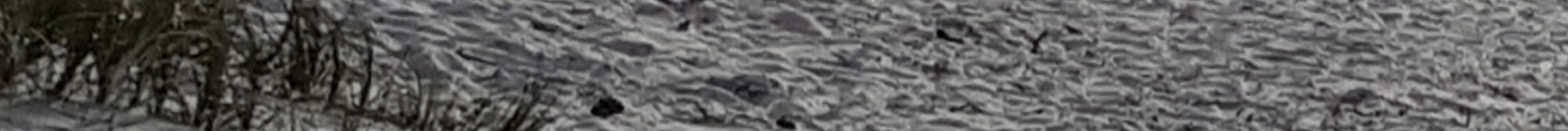

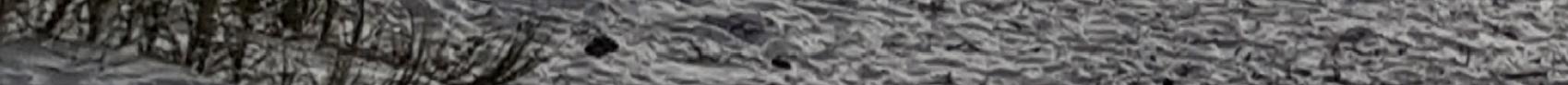

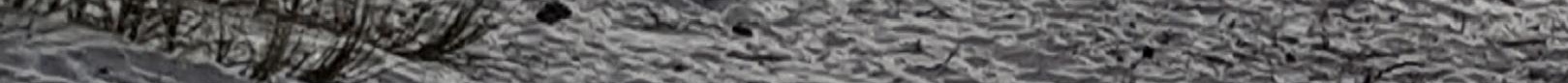
19. 1 H

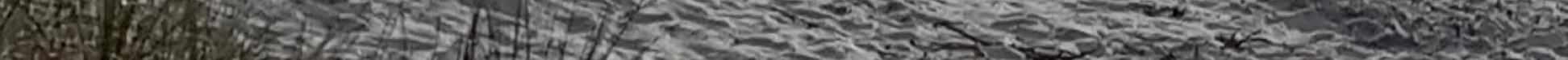

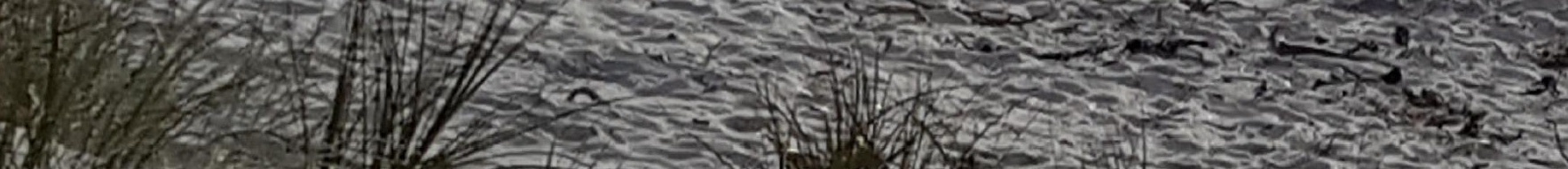

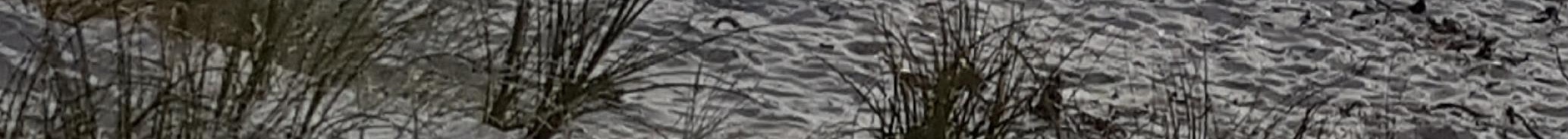

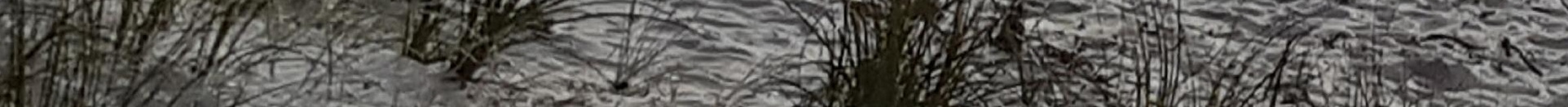

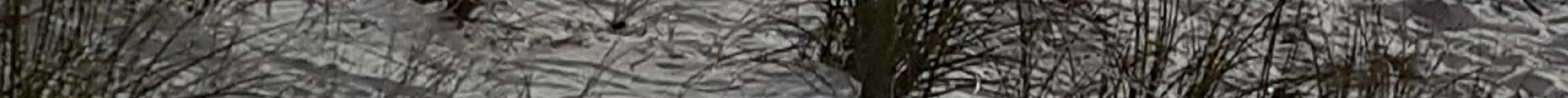

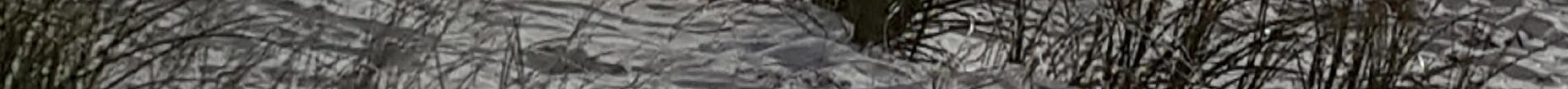

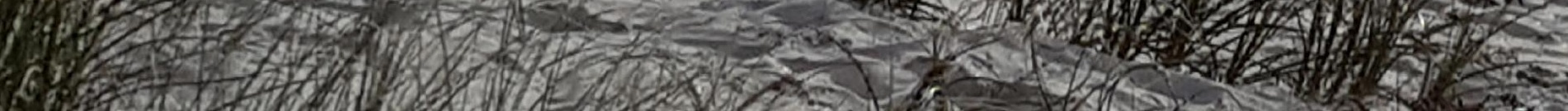

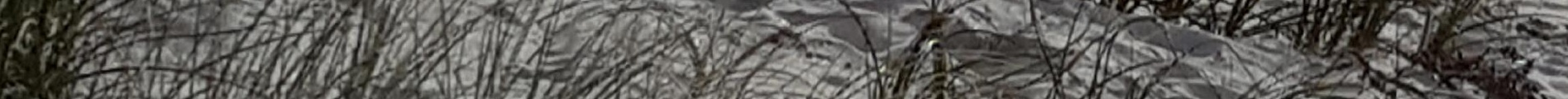

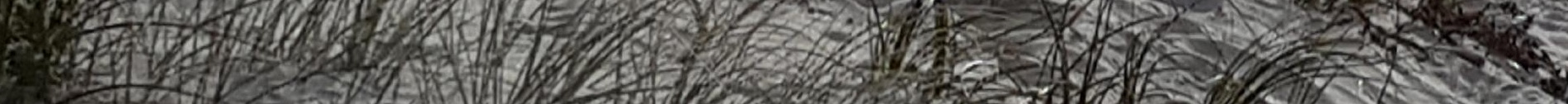

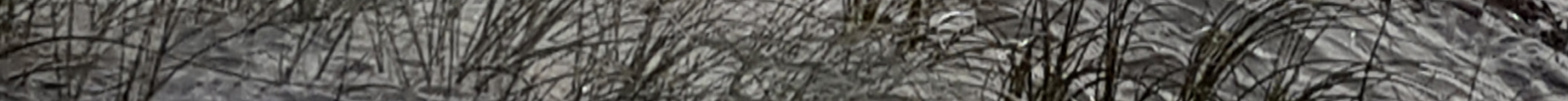

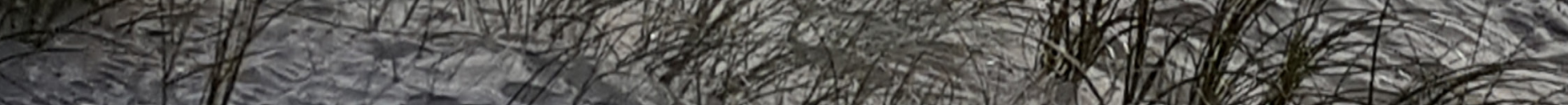

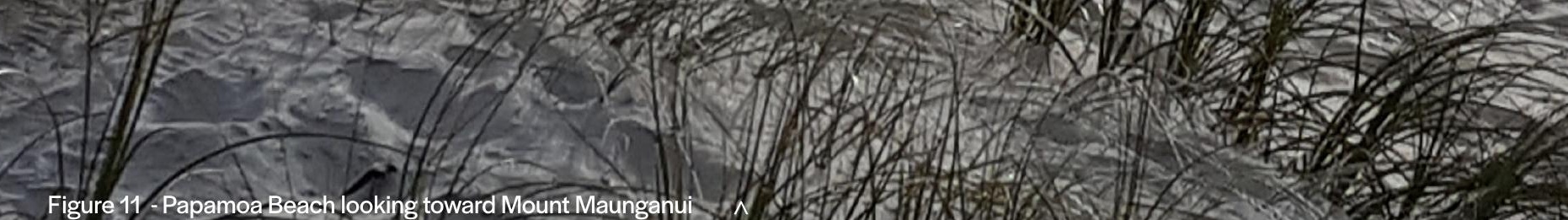
- 


\section{Papamoa Hills}

View from Papamoa Hills - photoe 
raphed by author 


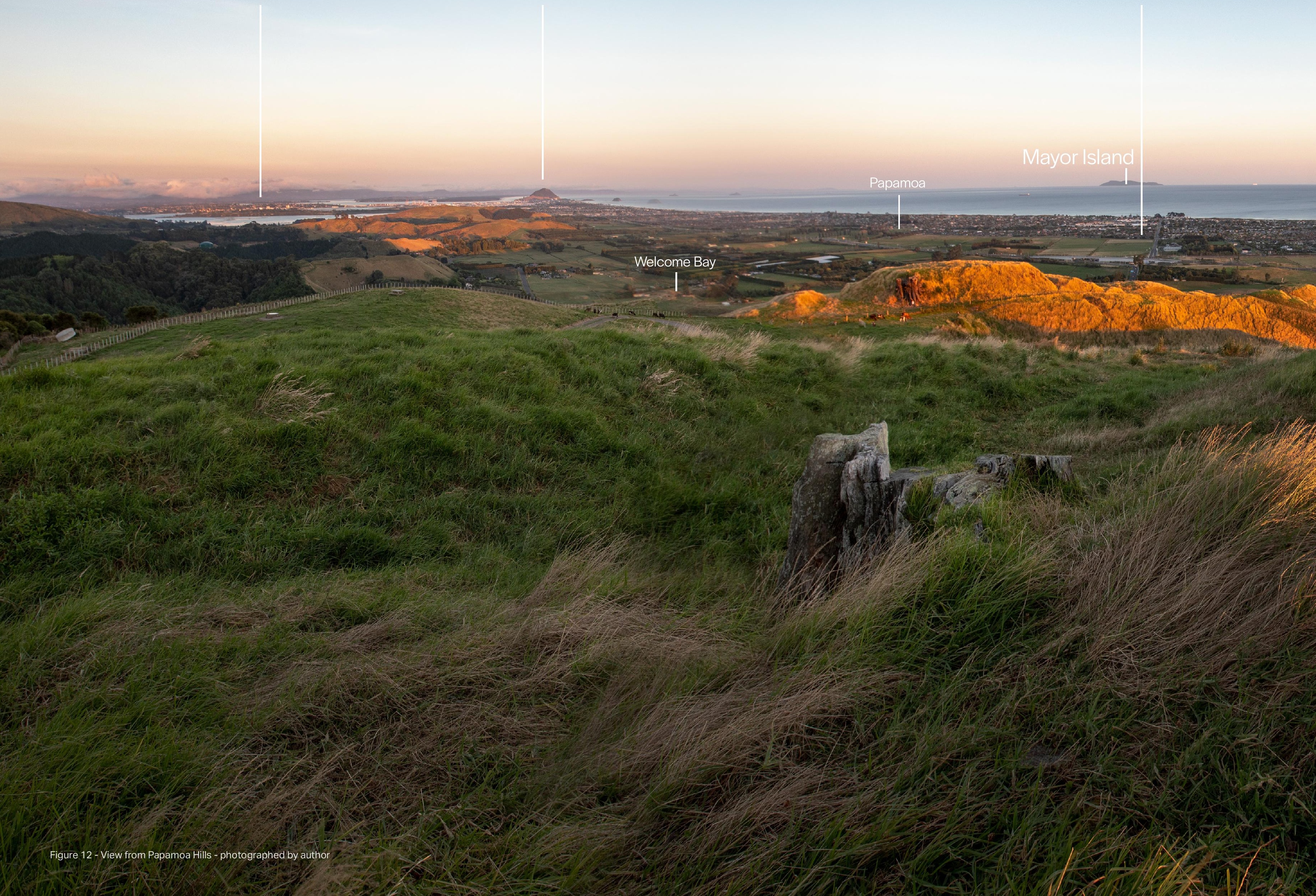


Tauranga is New Zealand's sixth largest local authority in terms of population and, according to the 2018 census, has a resident urban population of 136,713 people (Motion, 2019). Growth between the 2006 and 2013 census has been approximately 1,558 people per year which is significantly higher than the national growth average and by 2063 the population is expected to reach 198,374 . The largest proportion of this growth has been in Papamoa (TCC, 2018C).

Compared to the national average, Tauranga has higher percentages of European and Maori at $83 \%$ and $17 \%$ respectively, while the national average sits at $74 \%$ and $15 \%$. This relates to a higher than average proportion of Tauranga's population being born in New Zealand, Australia and the UK meaning proportions of Pacific, Asian and MELAA are significantly lower than average. However, considering the current levels of migration, this is likely to change and the amount of Asian, Māori and Pacific peoples are expected to increase, while levels of European will decrease, providing a more balanced ethnic profile for the city and encouraging diversity and cultural growth (TCC, 2018c).

The region is well known for warm temperate climates with a mean temperature of 16.2 and an average daily high of 22.2 degrees. The area is one of the sunniest areas of New Zealand, receiving between 2,200 and 2,500 hours of sunshine per year. Average rainfall is $1,938 \mathrm{~mm}$ although this can fluctuate (TCC, 2018c).

This makes the area particularly appealing to those looking to retire, affecting the region's age profile which is predicted to grow older. Predictably the fastest growing proportion is those aged $65+$, reinforcing Tauranga's reputation as a destination for retirees. The fastest decrease is the age group 30-44, however there is a consistent decline in younger populations due to issues such as housing affordability and difficulty in finding skilled work (TCC, 2018c).

According to the 2013 census the average household income in Tauranga was $\$ 55,800$ and the median personal income $\$ 27,100$. This is inclusive of beneficiary payments which are affected by Tauranga's above average proportion of retirees (Cox \& Pavletich, n.d.). This is creating issues in housing affordability as more people begin to move into the area, generally with the ability to pay more, increasing demand and prices for housing. This has recently been reported at a median of $\$ 623,000$, making Tauranga the 8th least affordable city in the world to buy a house according to the latest Demographia housing survey (Cox \& Pavletich, n.d.). 


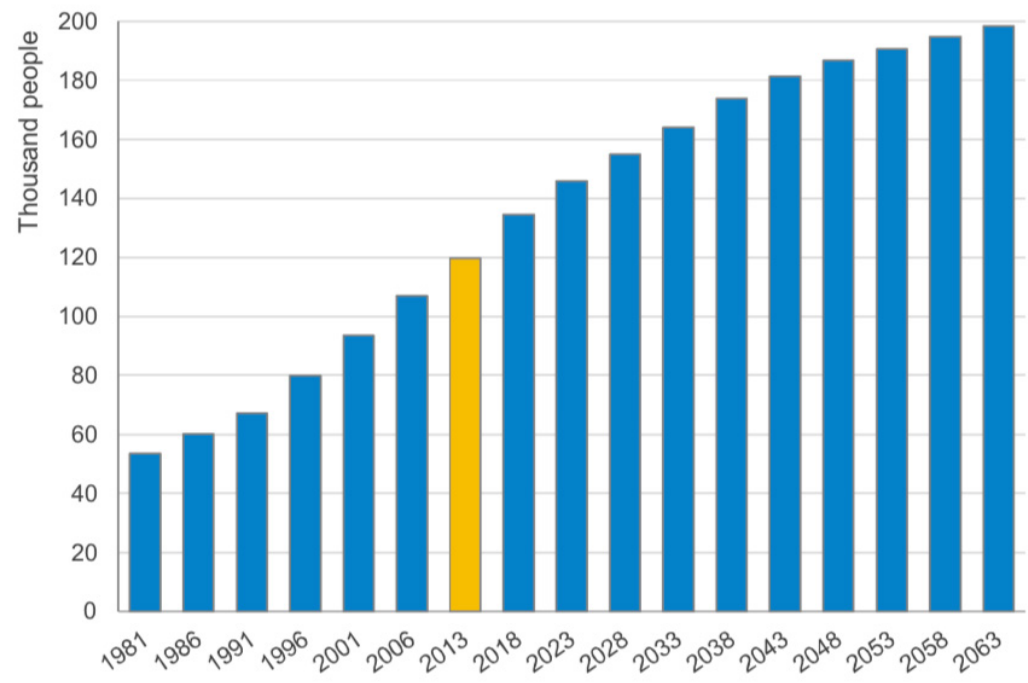

Figure 13 - Population change of Tauranga 1982-2063. Tauranga City

Council, 2018, Tauranga Statistical Information Report May 2018. p. 3.

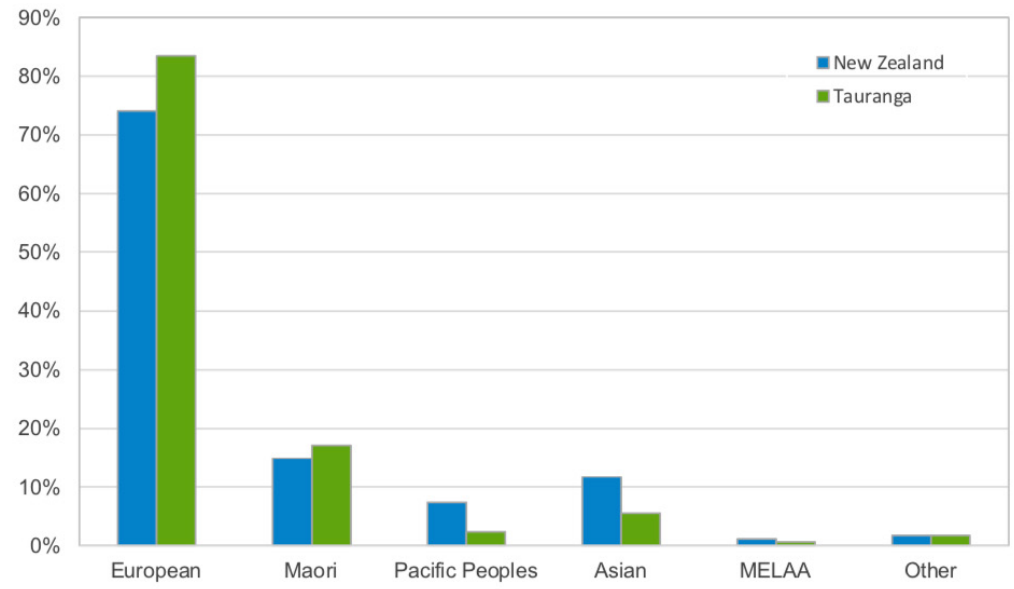

Figure 14 - Ethnic Profile of Tauranga 2013. Tauranga City Council, 2018,

Tauranga Statistical Information Report May 2018. p.12.

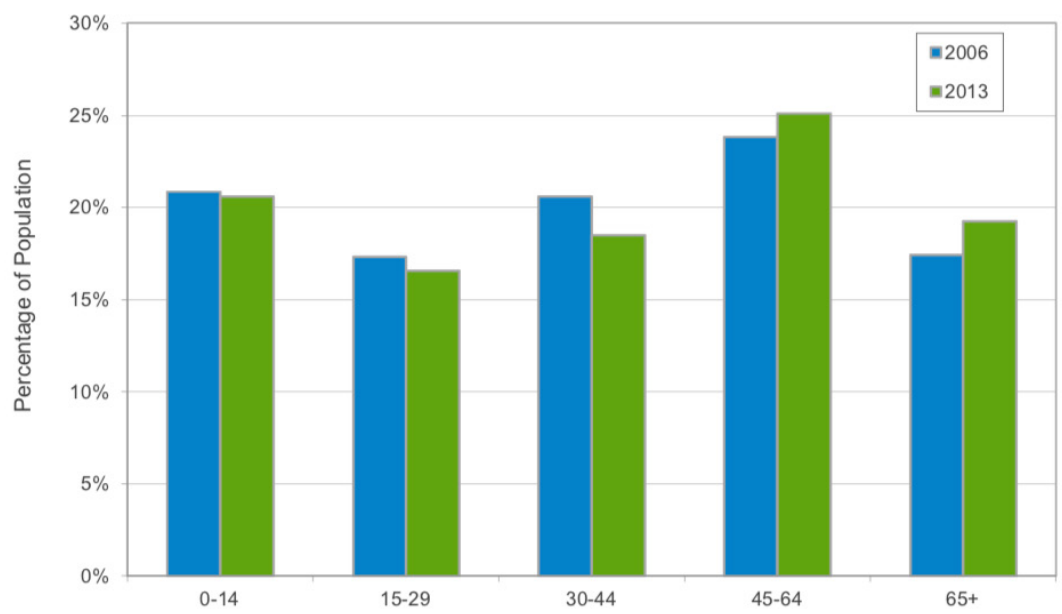

Figure 15 - Distribution of Tauranga population by age group, 2006 - 2013. Tauranga City Council, 2018, Tauranga Statistical Information Report May 2018. p. 23. 


\section{Existing Centres}

Situated around a stunning harbour, the Tauranga region is located on the western coast of the Bay of Plenty, dominated by the remnants of an ancient volcanic area. Within the region there are two primary urban centres, Tauranga CBD and Mount Maunganui.

\section{Tauranga}

Tauranga is the main CBD, yet it gives the impression that it is a town that has not quite caught up to its city status. It is an interesting mix of old and new as the provincial town attempts to become the city. The area is relatively low rise with the main shopping area situated on the eastern side of the Tauranga peninsula overlooking the waterfront.

The main streets are pleasant enough, however the central area lacks the vibrancy and destination feel of the Mount. It is let down by several factors, namely a lack of destinations and attractions that are normally commonplace in main centres.

This is further hindered by poor transport links and difficult integration with the city's waterfront which is severed from the main city by the rail corridor.

This corridor has the potential to be turned into something beneficial for the city through the integration of passenger rail services. It would provide a transport link right to the heart of Tauranga and has the potential for expansion across the region. However, the current emphasis appears to prioritise freight services to the port, who highlight capacity issues when the discussion of passenger rail is raised.

With almost half a billion dollars' worth of resource consents underway, significant promise is beginning to emerge. A host of projects including a new inner-city university campus for Waikato University and a series of street and waterfront redevelopments show that progress is heading in the right direction (Hall, 2018).

\section{Mount Maunganui}

By contrast the Mount is a very different experience, dominated by the iconic Mount Maunganui, a large lava dome and former Maori Pā, it is an area renowned for its vibrant atmosphere and beach culture.

Compared to the Tauranga CBD, the Mount is a condensed area. Situated on a narrow isthmus that links Mount Maunganui to the mainland the main shopping area consists of a singular street packed full of cafés, bars and boutique shopping. This helps to concentrate activity and creates the vibrant and dynamic environment that the Mount is renowned for. The isthmus is bordered on one side by the harbourside, family-friendly beach of Pilot Bay and the Mount Main Beach on the other, a location well known for its surfing.

The area is a popular holiday destination for locals and tourists alike, with the adjacent cruise ship terminal and an abundance of camping and holiday homes, the population is known to soar during holiday periods.

Aside from a shopping and holiday destination the Mount is seeing significant growth in apartment living and commercial offices, including Zespri who are constructing a headquarters on Maunganui Road, indicating significant growth.

By seeking to assimilate positive characteristics of both centres, capturing the vibrancy of the Mount Maunganui precinct and learning from the missed opportunities of Tauranga Central, I aim, with this research, towards a positive solution for a revitalised Papamoa Plaza. 


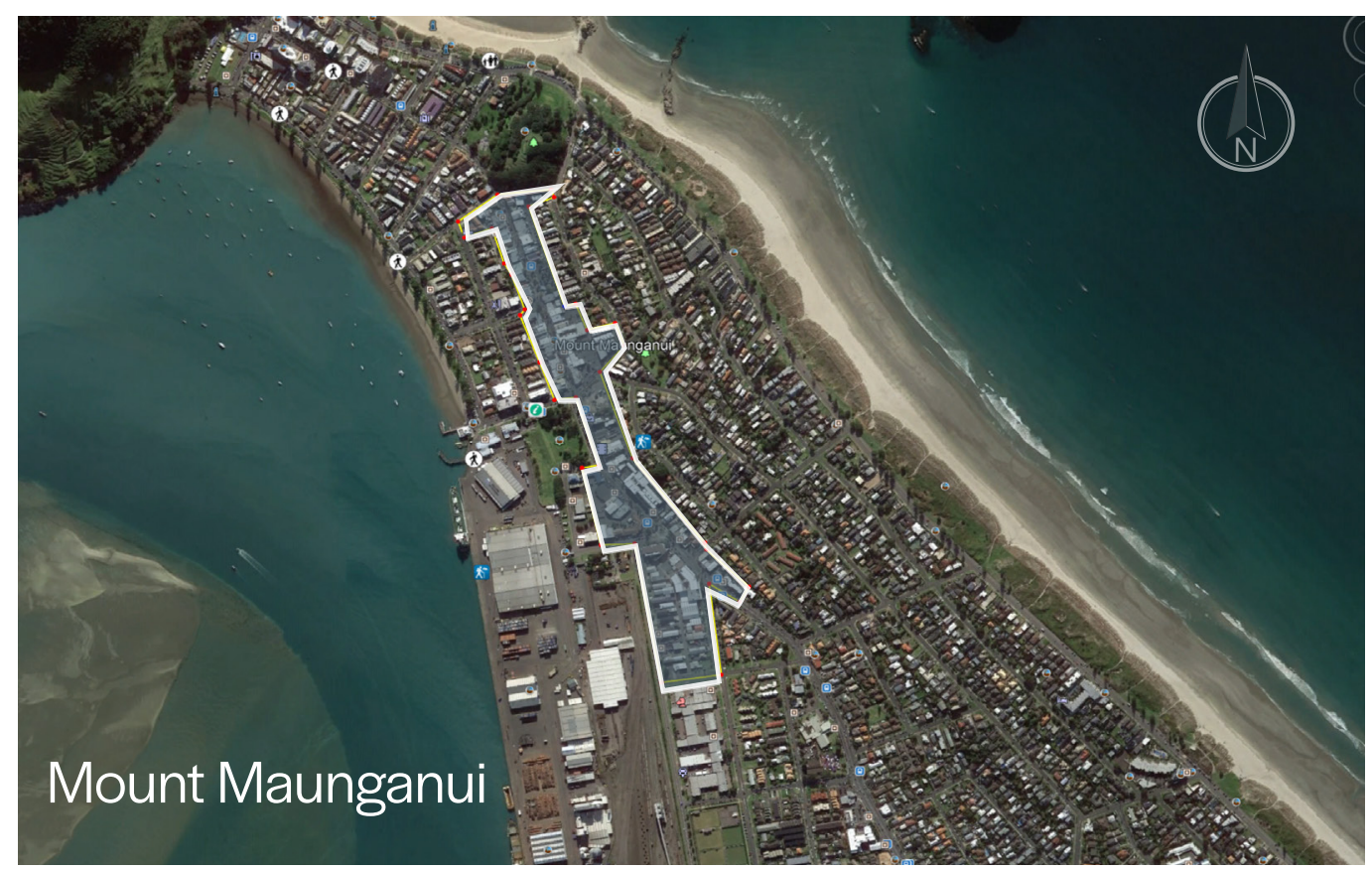

$\wedge$ Figure 16 - Mount Maunganui aerial view. Retrieved from Google earth. Copyright Google 2018.

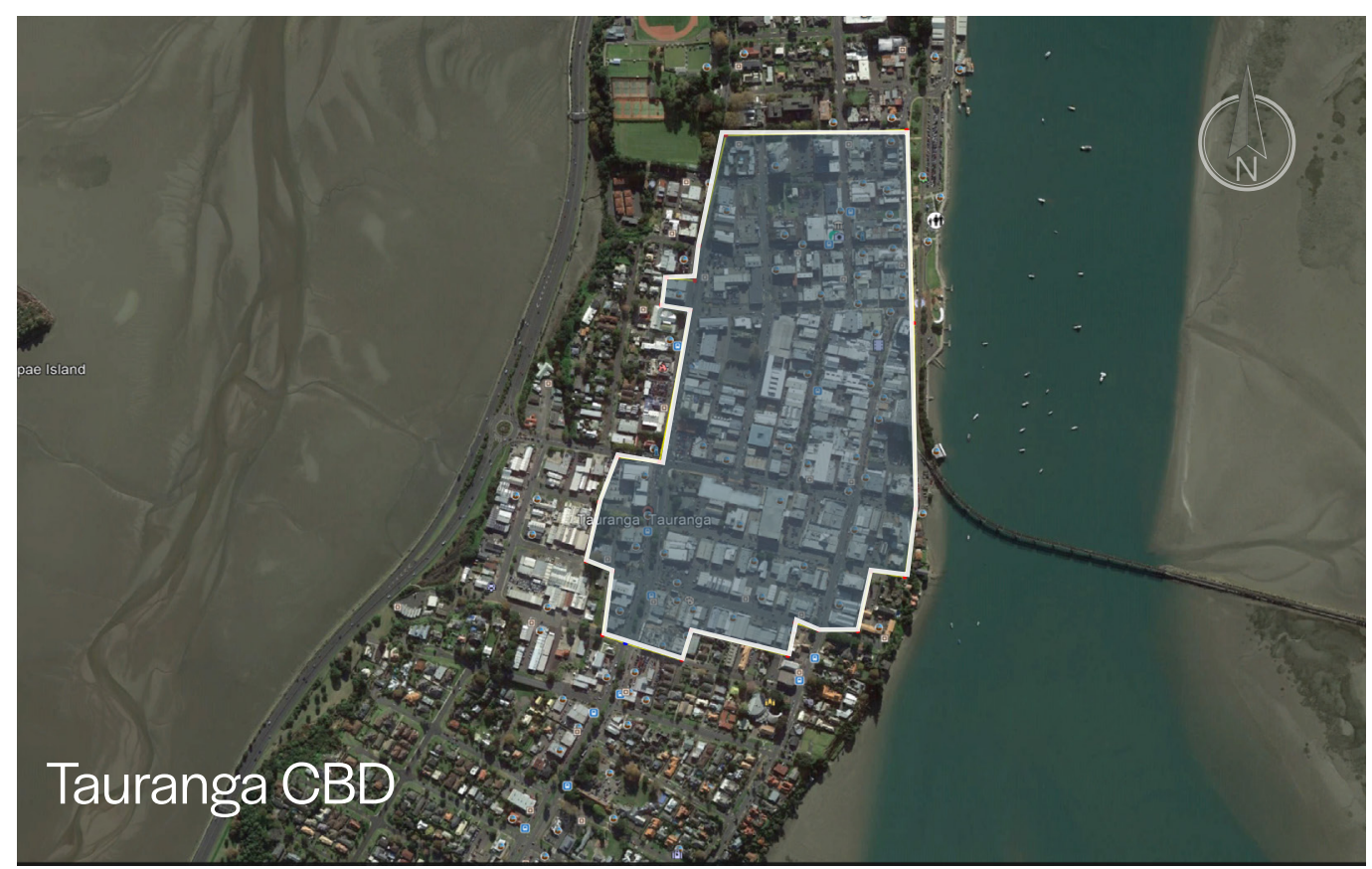

^ Figure 17 - Tauranga aerial view. Retrieved from Google earth. Copyright Google 2018. 
Tauranga
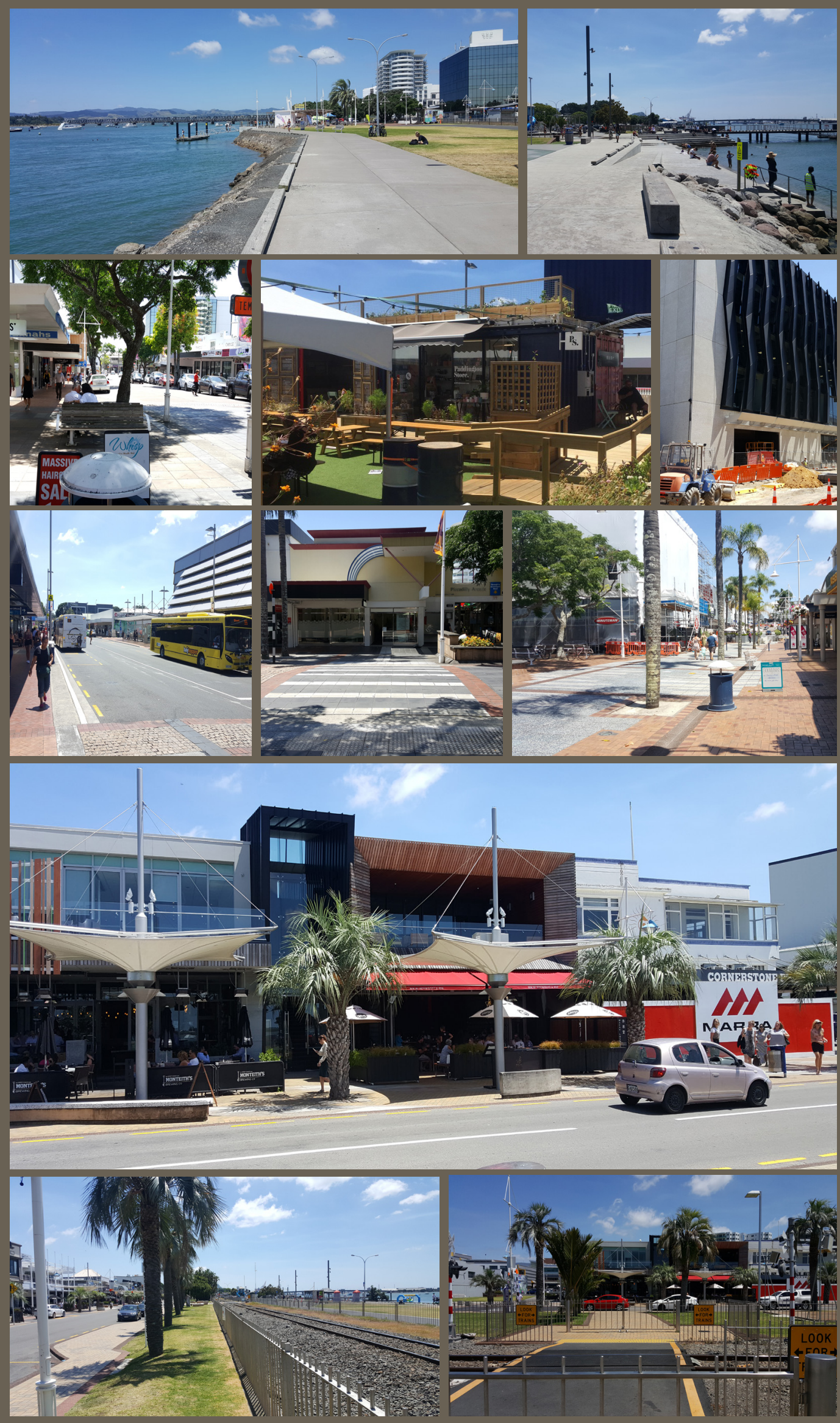

$\wedge$ Figure 18 - Tauranga Central site observation (author) 
Mount Maunganui
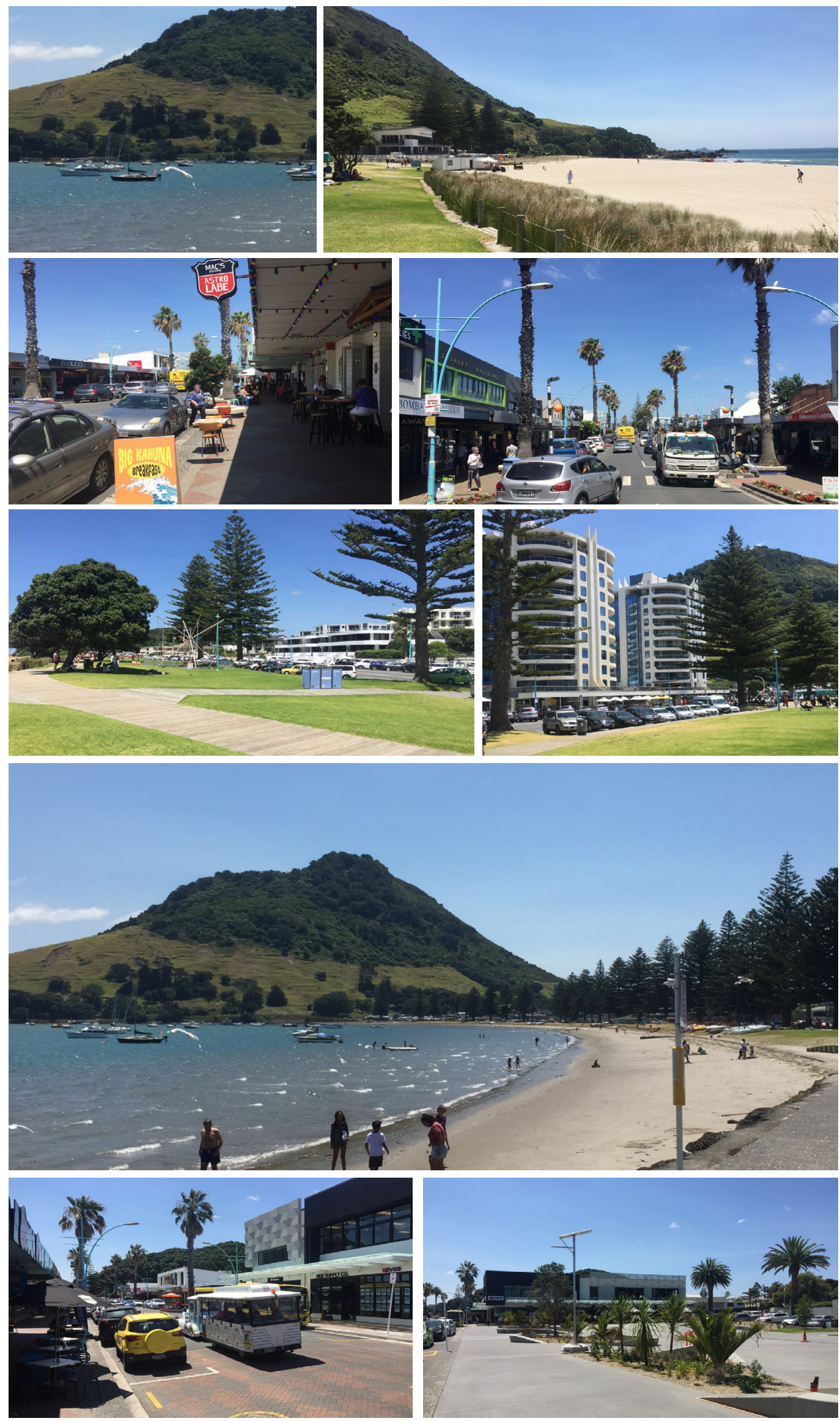

$\wedge$ Figure 19 - Mount Maunganui site observation (author) 
Papamoa is largest suburb of Tauranga and one of the fastest growing areas in New Zealand. Situated in the North Island's Bay of Plenty this area is well known for extensive sandy white beaches and a temperate climate. The area gets its name from its historical land use during Maori settlement of the area where the fertile plains were used to cultivate vegetables and food for the local tribes. "Papa" meaning flat and "moa" meaning raised, which refer to the raised plantations that used to exist there.
Reliance on the car as the primary means of transit and a propensity for low density greenfield development has led to significant sprawl in the area in recent years, causing strain on infrastructure. Statistics show that Tauranga's urban population grew 27\% between 2001 and 2013 while its urbanised land area grew by $25 \%$ within the same period indicating a strong inclination toward greenfield development rather than the intensification of existing suburbs and town centres (Nunns, 2016).

Tauranga New Zealand

Population - 137,900 people

5th largest urban area in New Zealand New Zealand's largest port 


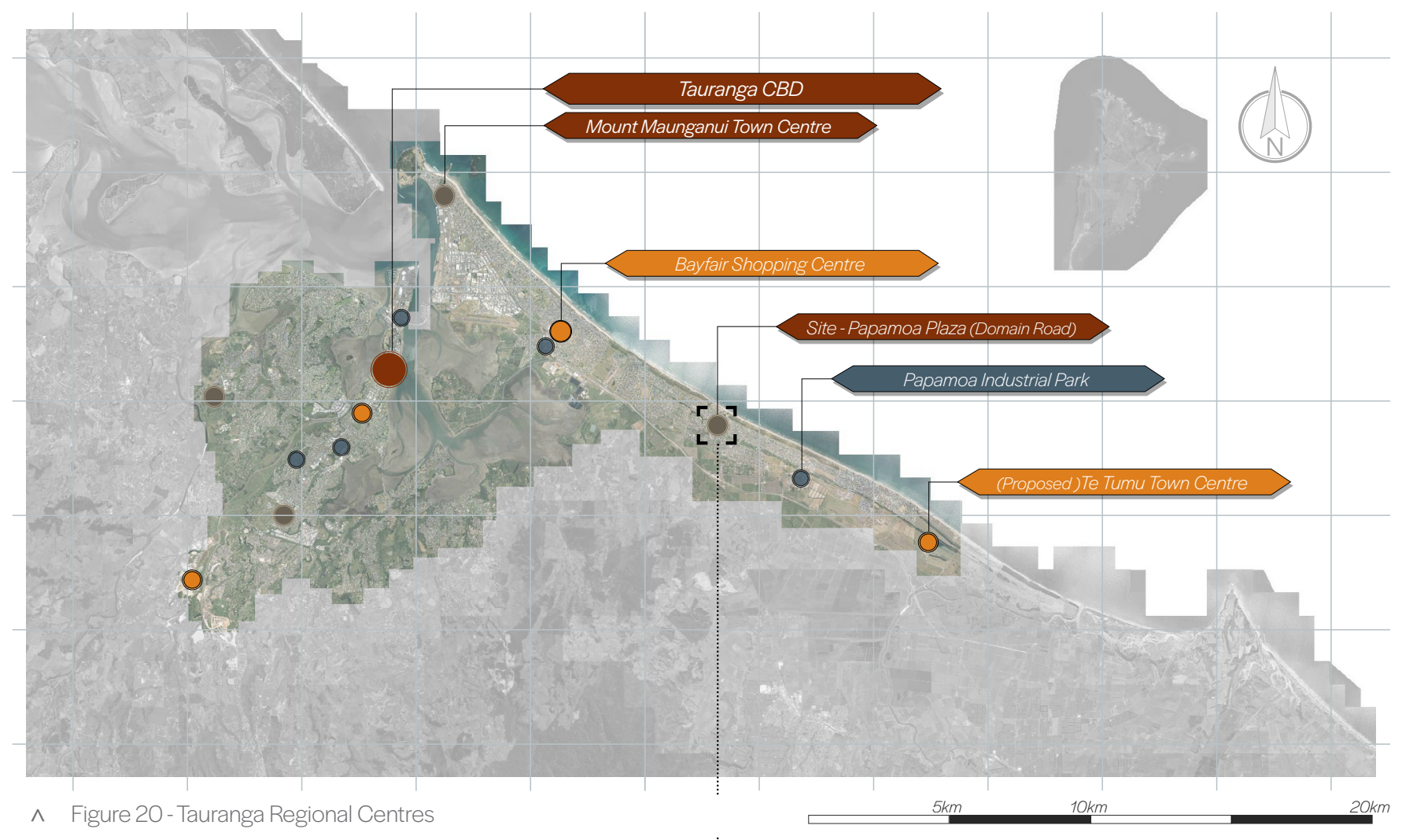

$\wedge$ Figure 20 - Tauranga Regional Centres

City Centre

Sub Regional Centre

Town Centre

Sub Regional Centre 


\section{Site}

Papamoa Beach Road

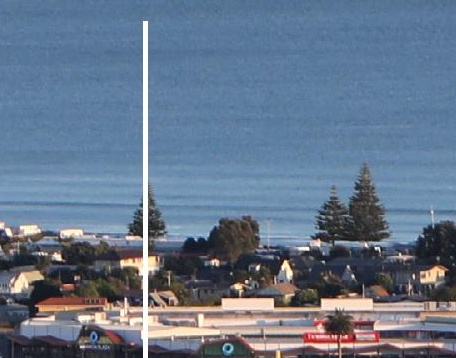

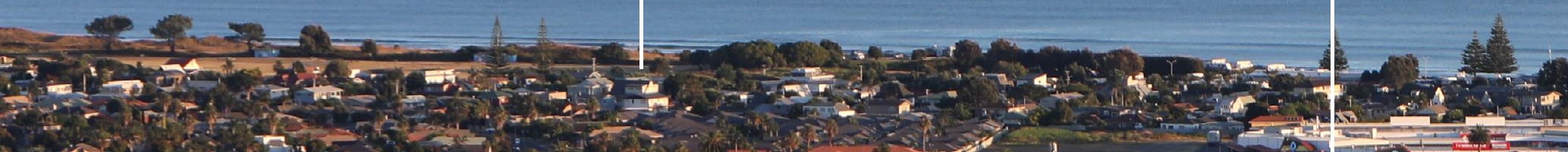

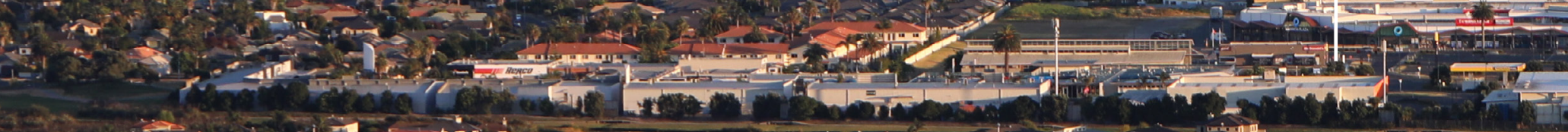
$y_{10}=0$

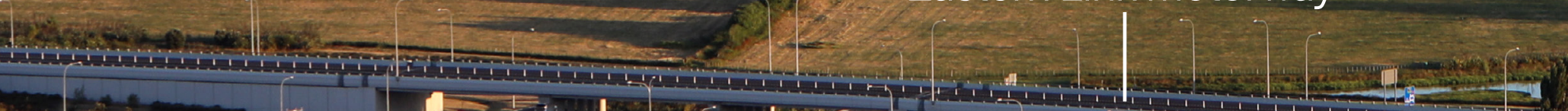

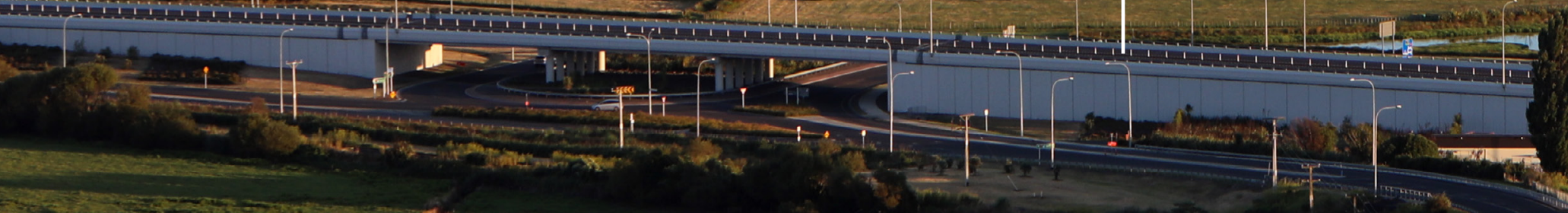

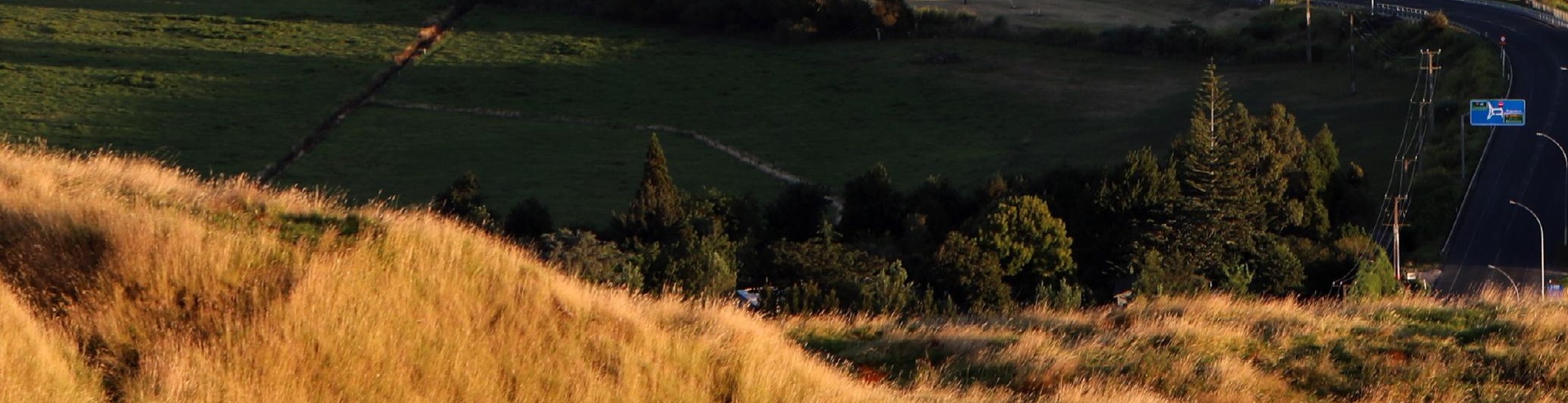




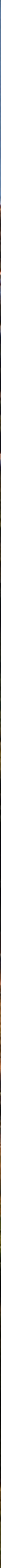




\section{Site Features}

The site selected is located on Domain Road in Papamoa East. This is currently occupied by a large shopping centre comprised of a covered mall, a library and community centre and a range of big box outlet stores and warehouse type shopping.

The site lies close to the beach and offers the potential for high level integration with the surrounding communities through the existing pedestrian network and green links. However, in its current configuration it makes use of neither of these assets.

The practice of staged development and differing land ownership has created fragmented growth across the site due to being developed by multiple parties. This has resulted in a disjointed, contradictory and car focused development that discourages pedestrians, and forms an almost impenetrable wall of buildings around the site perimeter.
Currently people mainly arrive via private cars, encouraged by extensive carparking. Public transport is provided by three bus routes, however patronage to date has been consistently low.

Issues to consider prior to any design on the site include flood potential, liquefaction and rising sea level. The site location is on the remains of Papamoa's secondary dune and elevation of approximately $7 \mathrm{~m}$ above sea level leaves the site relatively resistant up to 2.5 degrees warming (Level, Impacts, \& Central, n.d.).

The wider drainage scheme required as part of the Wairakei growth spine has helped to alleviate most of the flooding risk with the diversion of surface water into the reinstated Wairakei Stream to the South of the site, however certain areas of the site including the central carpark are still prone to surface flooding in extreme conditions. 


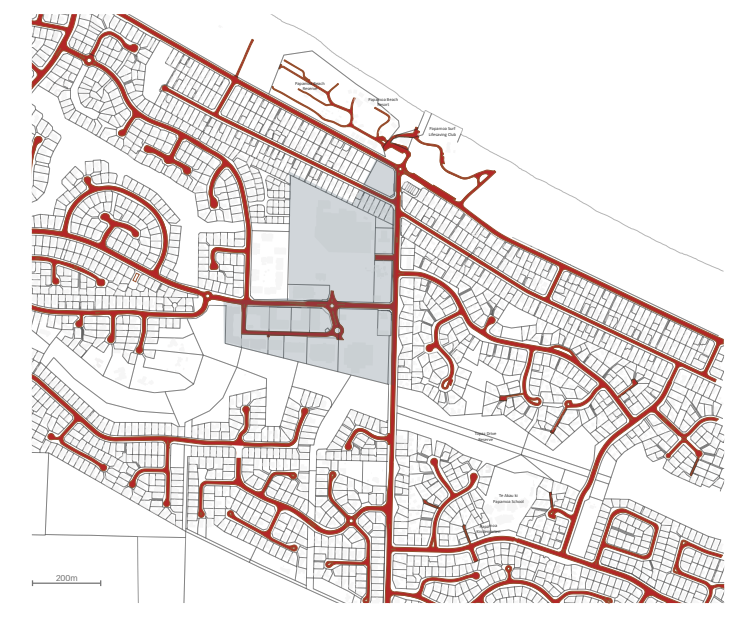

Existing Roads

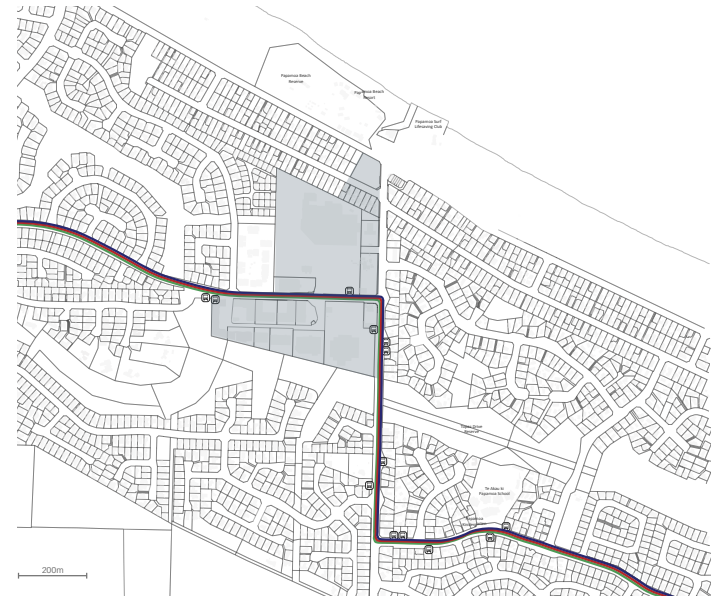

Bus Routes

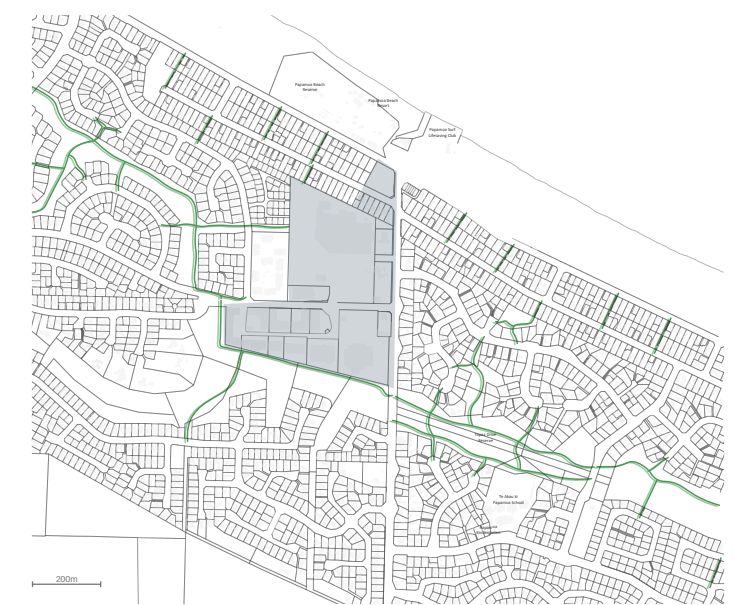

Pedestrian Links

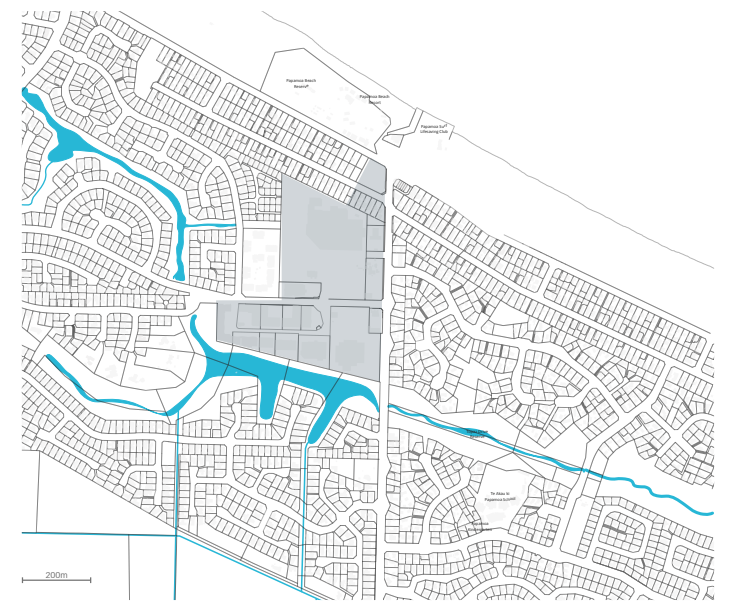

Site Hydrology

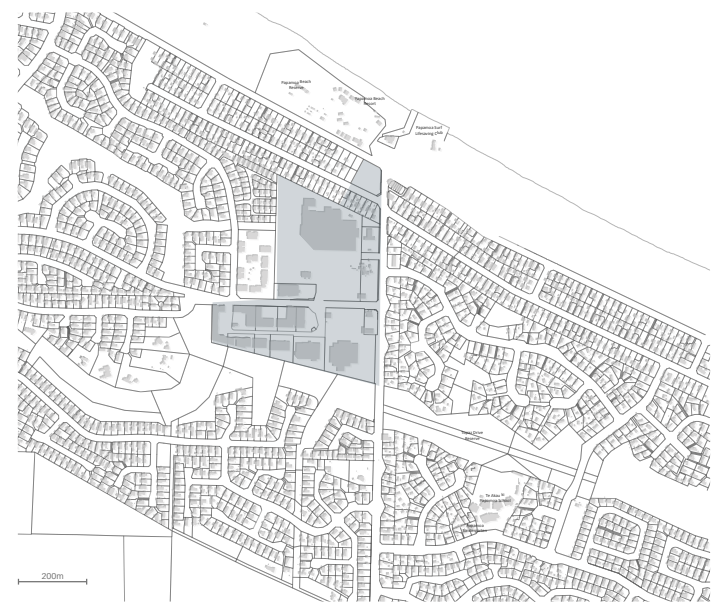

Built Area

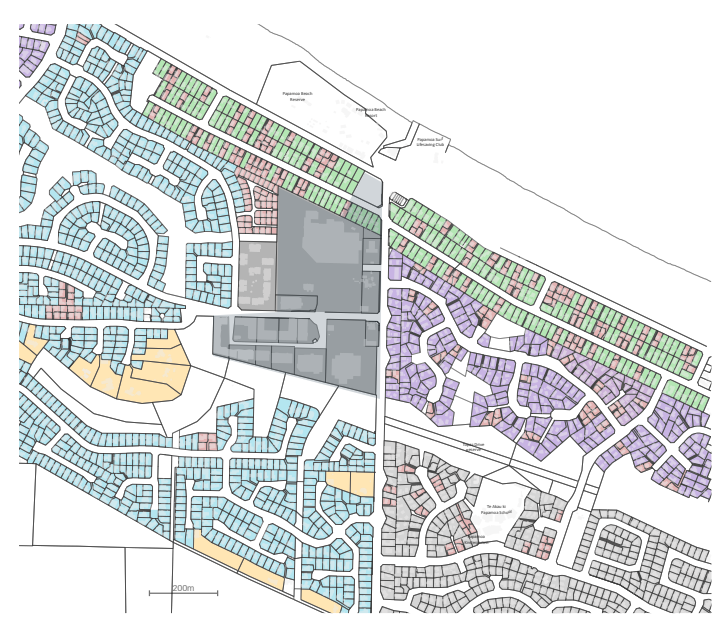

Housing Development 1970

1980

1990

2000

Infill of existing plots

lifestyle blocks 
Existing Site
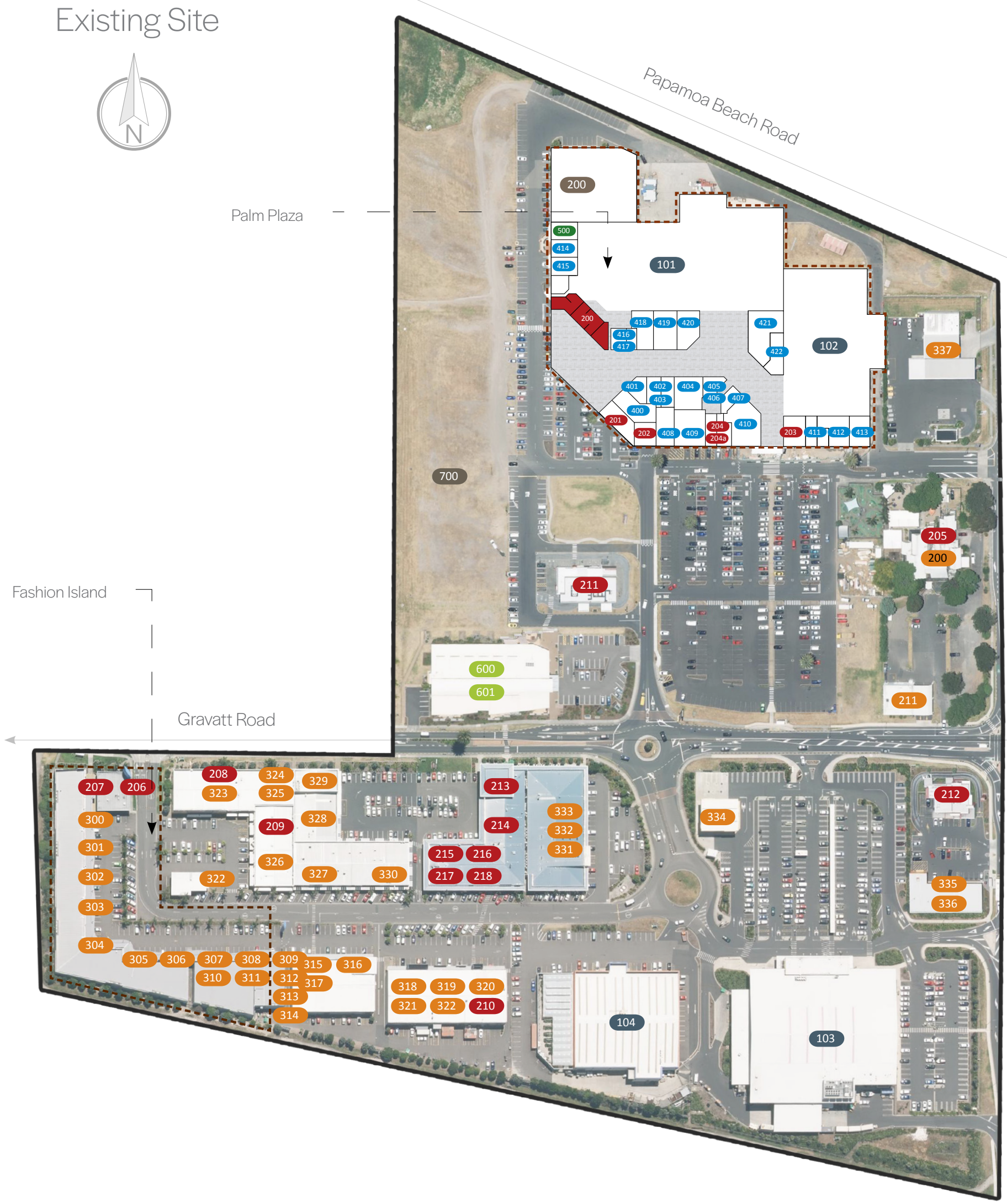

$\wedge$ Figure 23 - Existing Site Layout \& Tenancy Mix 


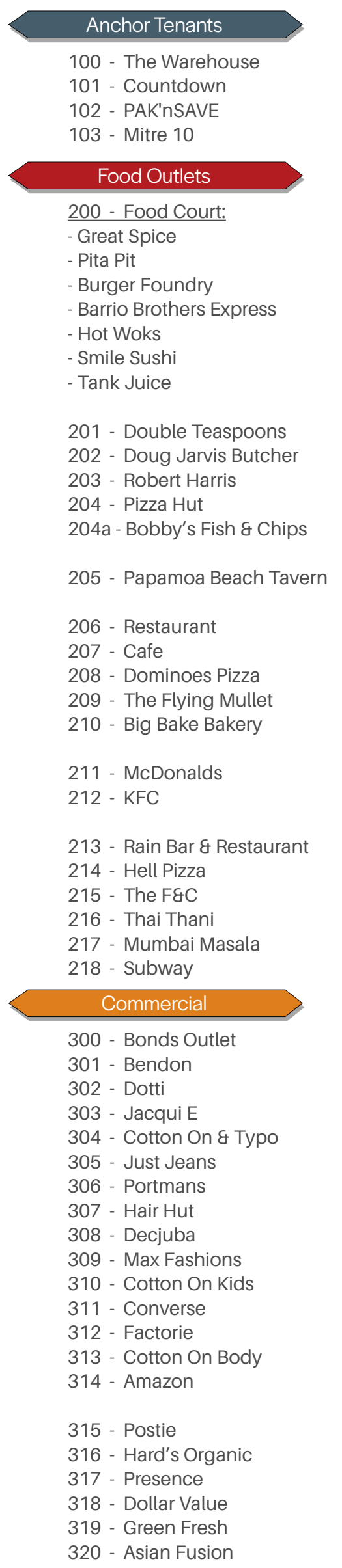

Commercial

321 - Papamoa Liquor Centre

322 - TAB

323 - Spark Mobile

324 - Repco

325 - Number One Shoes

326 - LJ Hooker

327 - Refresh Beauty \& Salon

328 - Snap Fitness

329 - ASB Bank

330 - ANZ Bank

331 - BNZ

332 - Physio \& General Practise

333 - Papamoa Pharmacy

334 - PAK'nSAVE Fuel

335 - Thirsty Liquor

336 - Westpac

337 - Z Palm Beach

Commercial - Palm Plaza

400 - Acquisitions

401 - 2 degrees

402 - EMPTY

403 - EMPTY

404 - 123 Mart

405 - Porcelain Skin Clinic

406 - Dorje

407 - Vivo Hair \& Beauty

408 - EMPTY

409 - Eves Real Estate

410 - My Pharmacy

411 - Hollywood Nails \& Cutz 4 U

412 - EMPTY

413 - Postshop \& Kiwibank

414 - EMPTY

415 - EMPTY

416 - Spark

417 - EMPTY

418 - Stirling Sports

419 - Backdoor Surf

420 - Merric

421 - Paper Plus

422 - Flight Centre

\section{Palm Plaza - Management}

500 - Palm Plaza Management

\section{Community Facilities}

600 - Papamoa Community Centre 601 - Papamoa Library

\section{Future Development}

700 - Future Development / Overflow Parking 


\section{Site Development Timeline}

Prior to occupation by Europeans, Papamoa existed as fertile coastal dune plains, punctuated by waterways and wetlands. Settlement by Maori began here around 1400 and the area was rich in agriculture and fisheries which supported the local iwi, including Ngāi Te Rangi, Ngāti Ranginui and Ngāti Pūkenga, and the Waitaha iwi, who built their settlements around the kumara cycle and soil fertility leaving a trail of kāinga, garden beds and swamp pā along the coastal strip now being consumed by growing subdivisions (TeAra, 2018).

Coastal fringe development of small beachside baches began from the 1920s onward and has grown sporadically since the 1930's where the area began to be cultivated and farmed following waterway diversions and the draining of existing wetland areas to allow access the fertile soils.
Growth continued along the coastal edge as communities grew from the 1960s to 1970s. During this time the area was still considered rural and separate from the larger centres of Mount Maunganui and Tauranga, attracting those looking for somewhere different to settle and helping to build Papamoa East's reputation as an alternative community.

In the late 1980s where Mount Maunganui officially became part of Tauranga and growth began to push its way up the coast. The rapid growth of the 1990's saw the construction of Palm Plaza on the domain road site in 1997 (Taonga, 2018).

Growth intensified with the construction of the "Fashion Island" outlet shopping on the southwest corner of the site in 2005 and the construction of the Mitre 10 and PAK'nSAVE stores in 2011, as the backfilling of housing along the coastal strip toward the Mount intensified. 

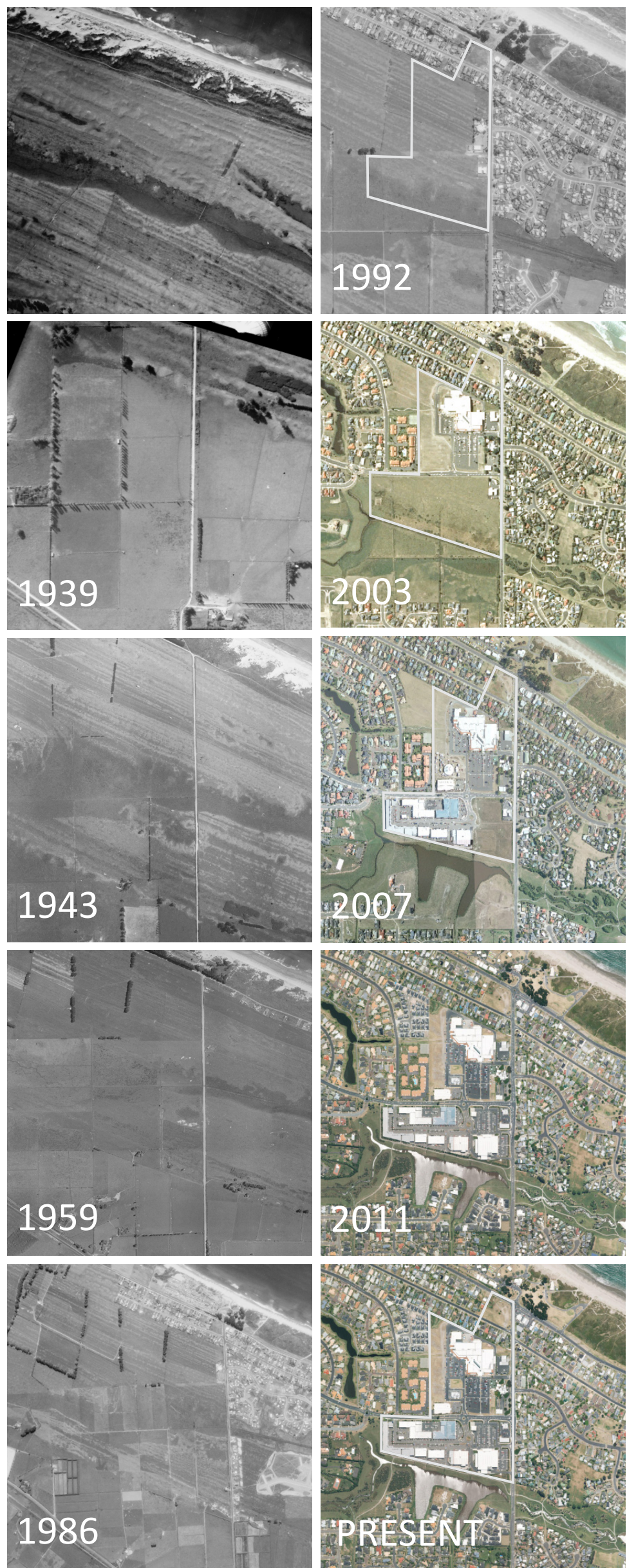

^ Figure 24 - Site development timeline. Papamoa Beach 12 April 1939. Retrieved from http://retrolens.nz. Copyright creative commons 3.0 New Zealand 


\section{Current Housing Density}

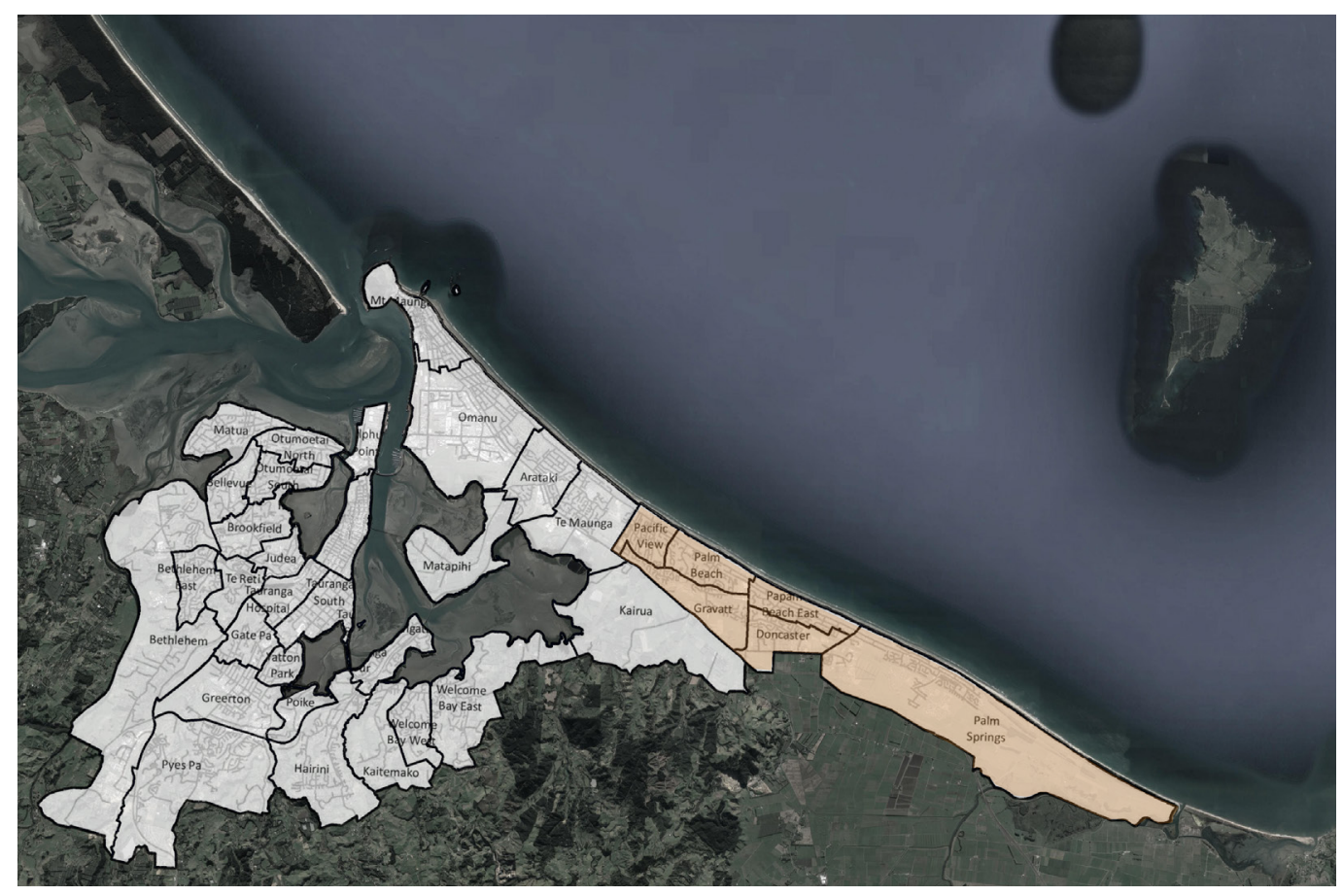

$\wedge \quad$ Figure 25 - Tauranga Suburbs

Following the 2013 Census Tauranga had 50,085 dwellings, an increase of $11.4 \%$ since 2006. Greenfield urban growth areas remain the primary means of urban expansion. Of the new housing built $87 \%$ were accommodated in greenfield development, $12 \%$ as infill and $1 \%$ in rural. Rapid population growth and rising housing unaffordability has encouraged the council to provide additional homes to keep up with growth, which has primarily been facilitated through fringe development to the North and East in suburbs such as Papamoa (TCC, n.d.-b).

However high levels of urban expansion, particularly greenfield development, creates challenges. Despite being New Zealand's 5th largest city Tauranga is also one of the smallest in terms of available land. Currently the city has a total land area of 13,440 hectares following an extension of the urban boundaries in 2008. However, due to growth demands, areas in Papamoa including the current Wairakei and the proposed Te Tumu growth areas are predicted to only last the next 10-15 years (BPT, 2016) (TCC, 2018c).
This is concerning considering that the current average density in Tauranga is around 15 dwellings per hectare and over $7 \%$ of housing consents in 2018 were for standalone dwellings (TCC, n.d.-b). While there will likely be the option to expand the urban boundary, this will require the conversion of existing agricultural land and will impact growing capacity within the region.

This development methodology contradicts TCC's own urban strategies, which look toward compact city design and have highlighted the need for varying typologies and scales to make efficient use of infrastructure in Papamoa. This is highlighted as the purpose of the current Wairakei Residential Zone in Papamoa, which seeks to provide an "intensified urban character", of which the current development to date does not appear to reflect (TCC, n.d.-a, secs. 14B, 14F). 


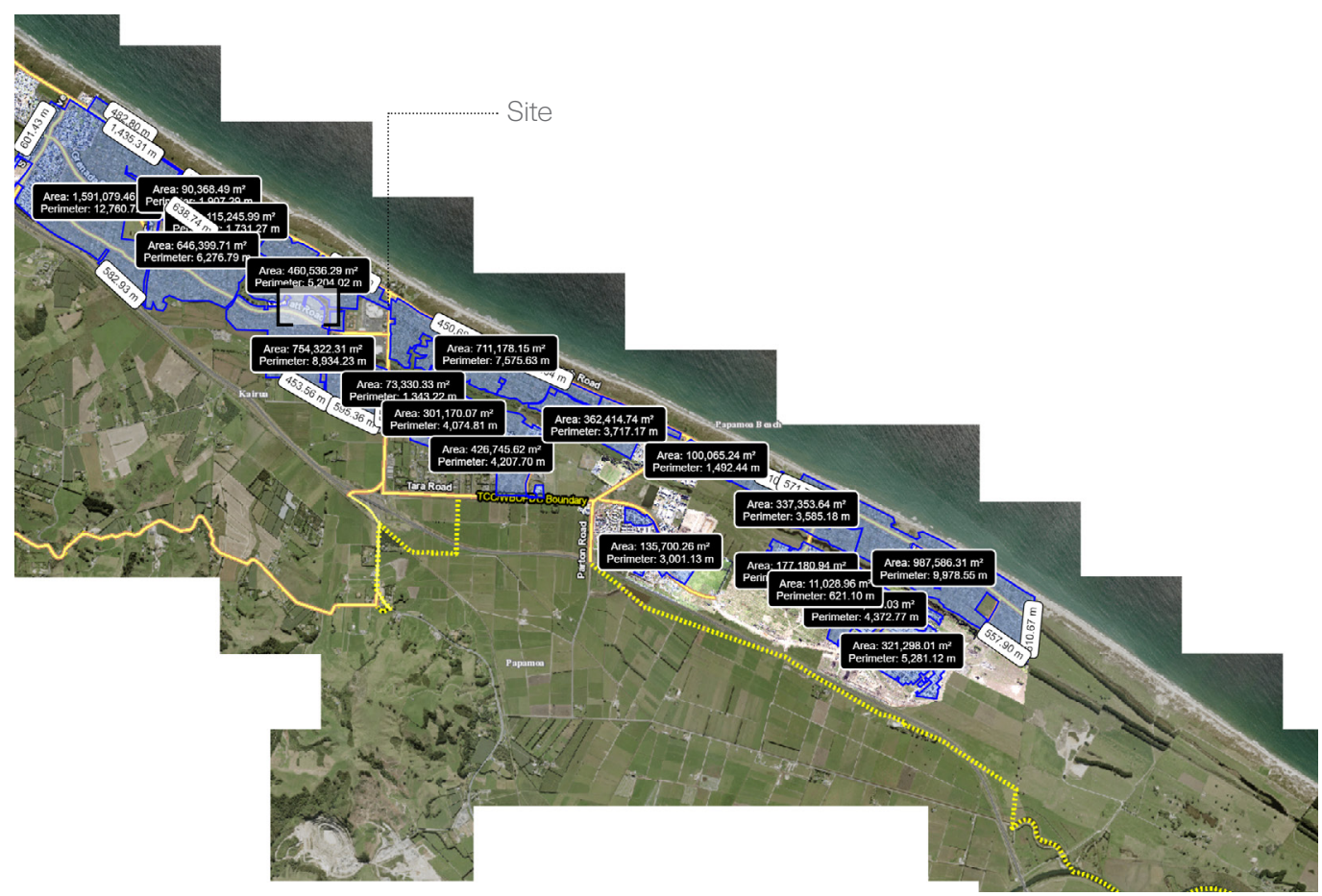

$\wedge$ Figure 26 - Mapi Papamoa Density Measurement. by Tauranga City Council and LINZ. n.d. retrieved from https://mapi.tauranga.govt.nz/Html5/index.html?viewer=Mapi. Copyright creative commons 3.0 New Zealand

\section{Density Analysis}

In order to understand the extent of the problem an analysis into the average density in the areas surrounding the site was undertaken. This analysed the housing from Sandhurst Drive on the western boundary of Papamoa up to the current growth area to the east. This found the density of the housing surrounding the site to be lower than the city average at approx 11 dwellings per hectare.

- This analysis uses the population estimates of Stats NZ and TCC for the 2018 data set as the 2018 Census is not available at this time.

- This analysis only surveyed areas developed as of August 2018

- Commercial areas lifestyle blocks and schools were excluded from this study due to their large land use and potential to affect results.

- Retirement homes where residents are not in individual homes have been considered commercial buildings for the purposes of this analysis.

\section{Areas Analysed}

Projected Dwellings 2018:

Palm Springs 2378

Doncaster 1130

Papamoa Beach East 1301

Gravatt 1248

Palm Beach $\quad 1492$

Pacific View 1337

Projected Dwellings 2018:

TOTAL

8886

Projected Dwellings 2028:

TOTAL

13101

(TCC 2016)

\section{Area Density}

$=$ N.O Dwellings

Site Area (Hectares)

$=\underline{8886}$

790.30

Dwellings Per Hectare $=11.24$ 
This chapter evaluates the current layout in order to assess the viability of intensifying the site in its current form to meet the research objectives.

An exploration of initial ideas were carried out in order to establish a framework from which to proceed.

A range of different design schemes were then explored. These were built around the research objectives, which were developed toward creating an integrated solution for the site.

(1)

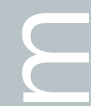

$\omega$

( )

(1)

( )

U

$<$

(1)

$+$

г r.

$\infty$ 


\section{Existing Site Assessment}

This investigation looked at the opportunities within the current site arrangement and how the existing configuration could be reconfigured or adapted to encourage better connectivity across the site.

This was evaluated using 'Depth Map" in order to identify existing connectivity and areas of conflict within the original layout. This exercise uses an axial analysis to identify levels of connectivity across a twodimensional plan file.

Refer to the following analysis on pages 48-51 for further information.
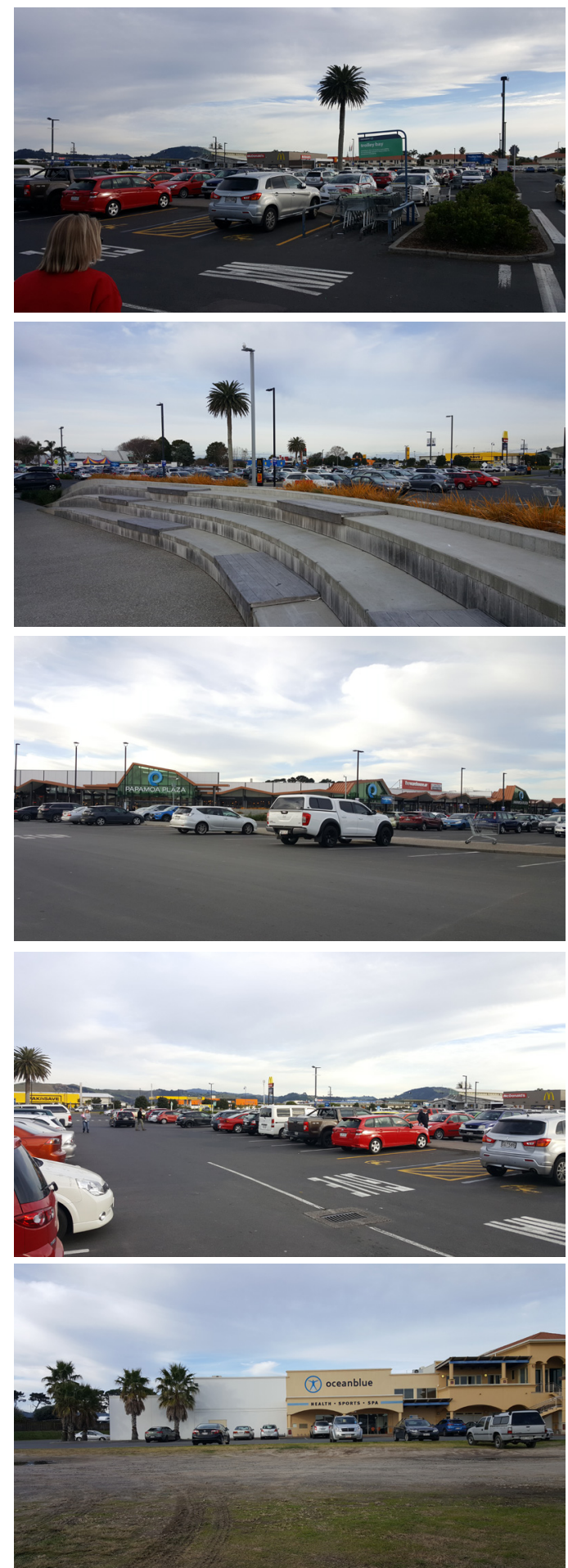

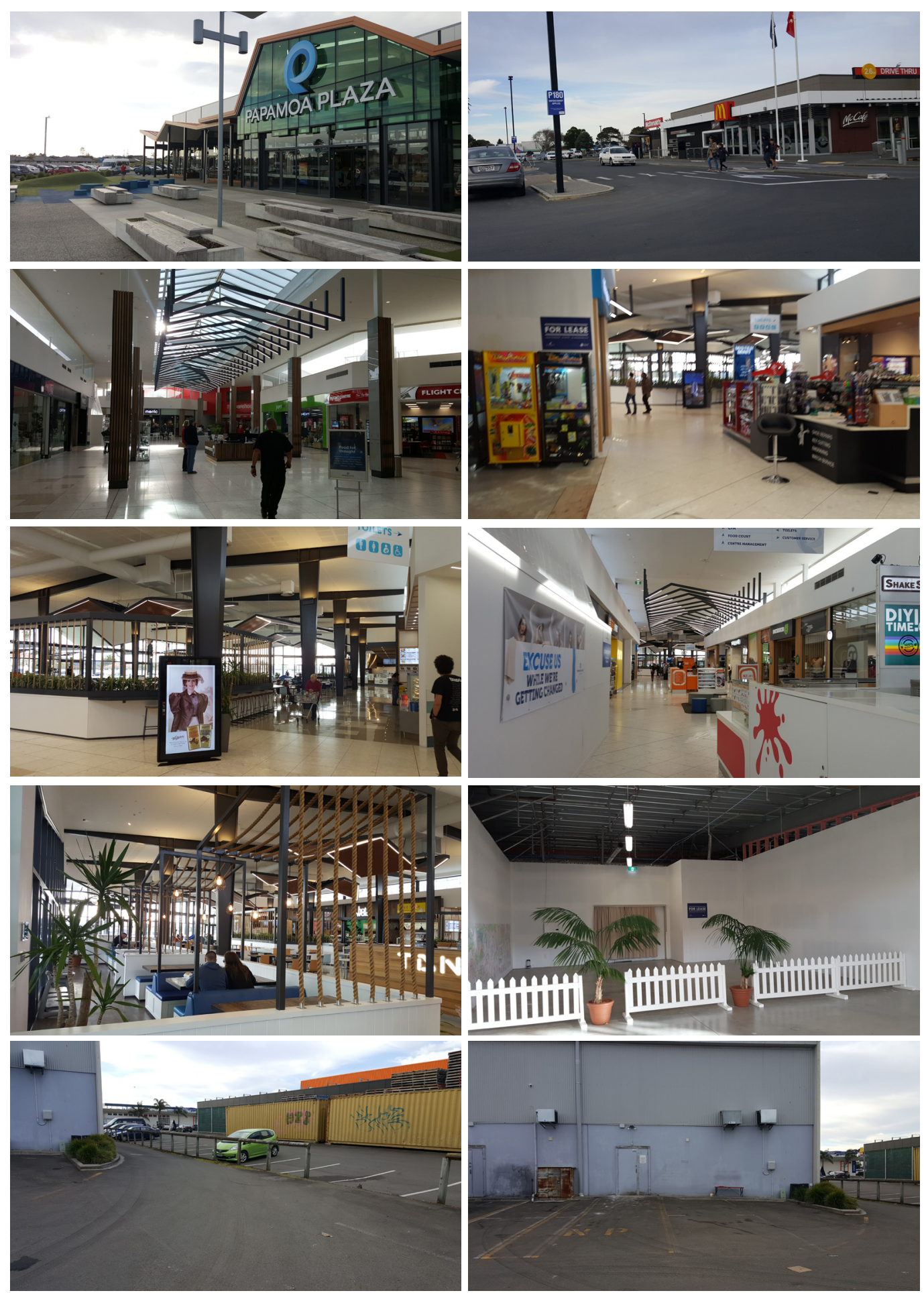

$<$ Figure 27-Existing Site \& Mall (author) $\wedge$ 
Connectivity Analysis Of Existing Site

The results shown in (figures 28 and 29) are consistent with my initial evaluations of the site. These highlight a consistent lack of connectivity (shown in blue) across the site and very minor connections along the existing Gravatt Road access. This is primarily due to the disjointed nature of the pedestrian network across the site and physical barriers imposed by the owners of individual sites impairing the user's ability to navigate between destinations.

Further investigations will look at the strategic removal of barriers and the potential to increase connectivity. This will also look at better utilisation of the existing site and foster points of convergence within the site to facilitate more vibrant and accessible public spaces. 



\section{Existing Site - Connectivity analysis}

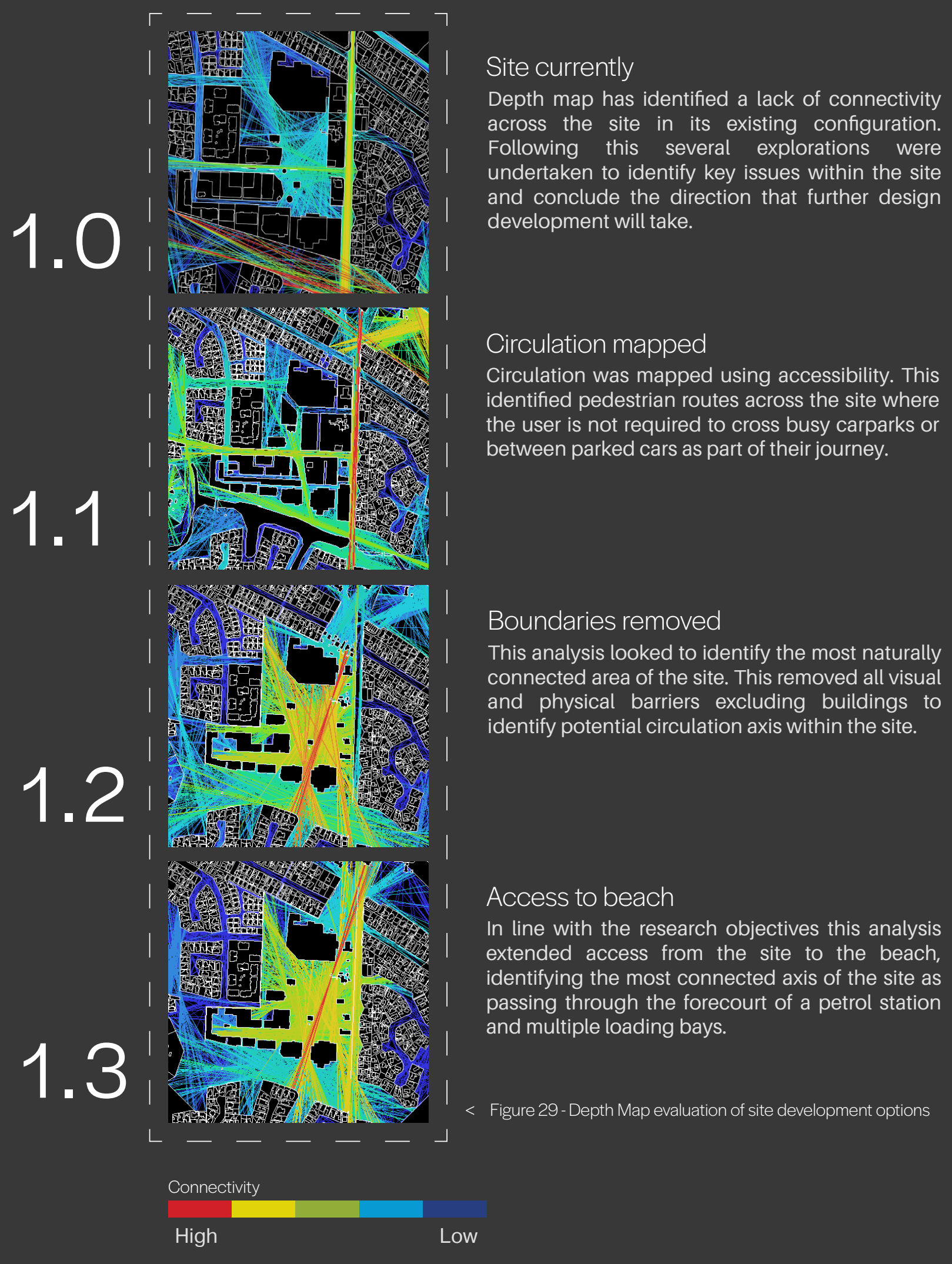



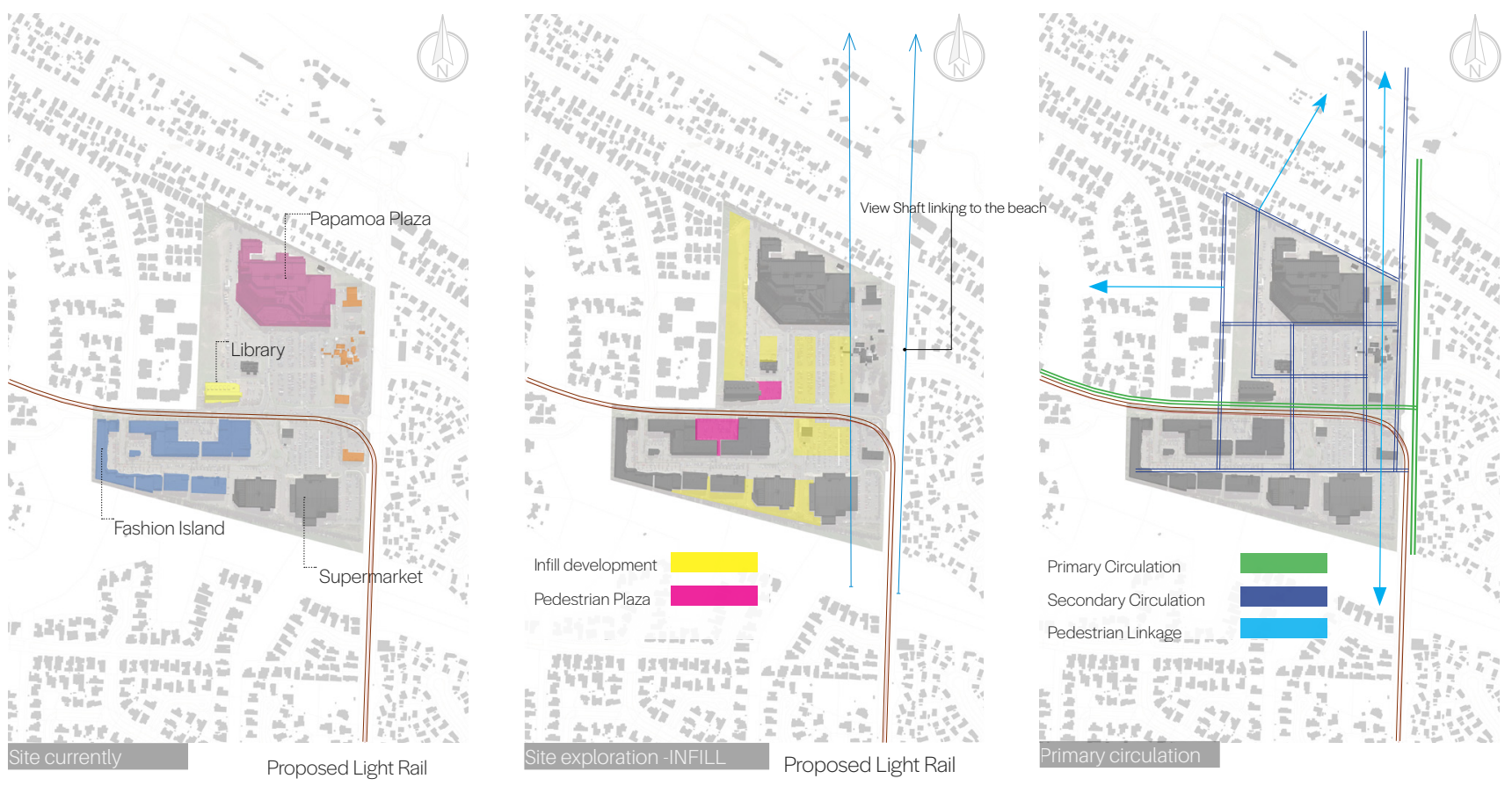

$\wedge$ Figure 30 - Exploration of several development options of the current site

This exercise looked to identify the potential for redevelopment of the site utilising its current configuration.

Depth map identified barriers, including fencing and roads, that had a detrimental effect on connectivity across the site. The exercise looked at the removal of strategic barriers to encourage connectivity, including opening the development area to the north of the site to provide a link back to the beach.

This identified the most connected axis of the current site, shown in exercises 1.2 and 1.3, linking between the beach and the waterway to the south of the site, passing through the current Z Petrol station and loading areas of both the mall and Mitre 10. While this shows there is potential for increased activity along this link it remains difficult to integrate this with the areas to the west of the site due to the positioning of existing structures.

\section{Critical Evaluation}

Various iterations of how the site may be reconfigured were attempted based on these findings. However repeated issues occurred when attempting to integrate the site with the surrounding suburb.

Taking this and the objectives of this research under consideration it was concluded that there is a greater potential for exploration and analysis if the site were to be considered as a blank slate and not limited by the current configuration. 


\section{Existing Ring Road System}

Mount Maunganui

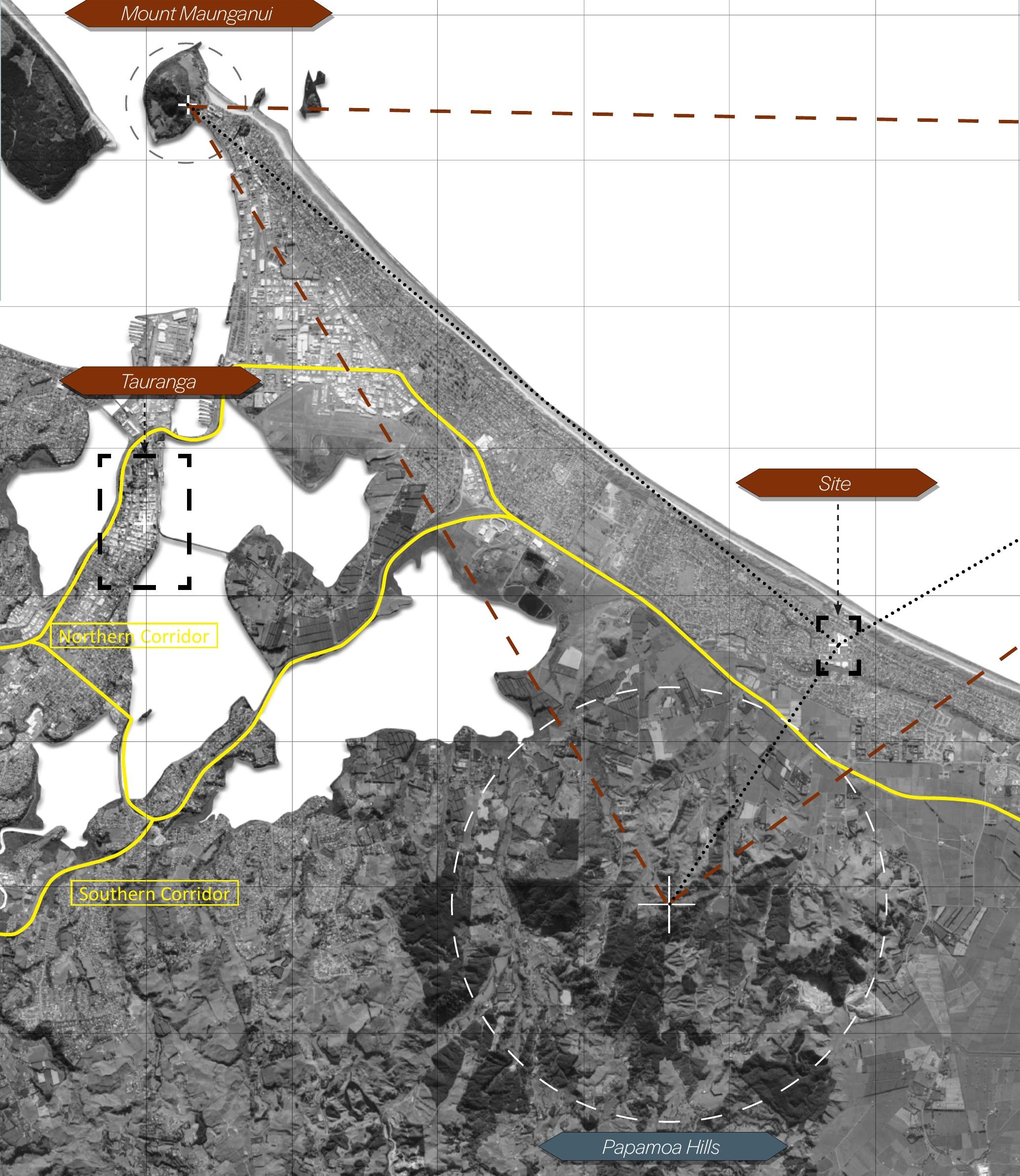




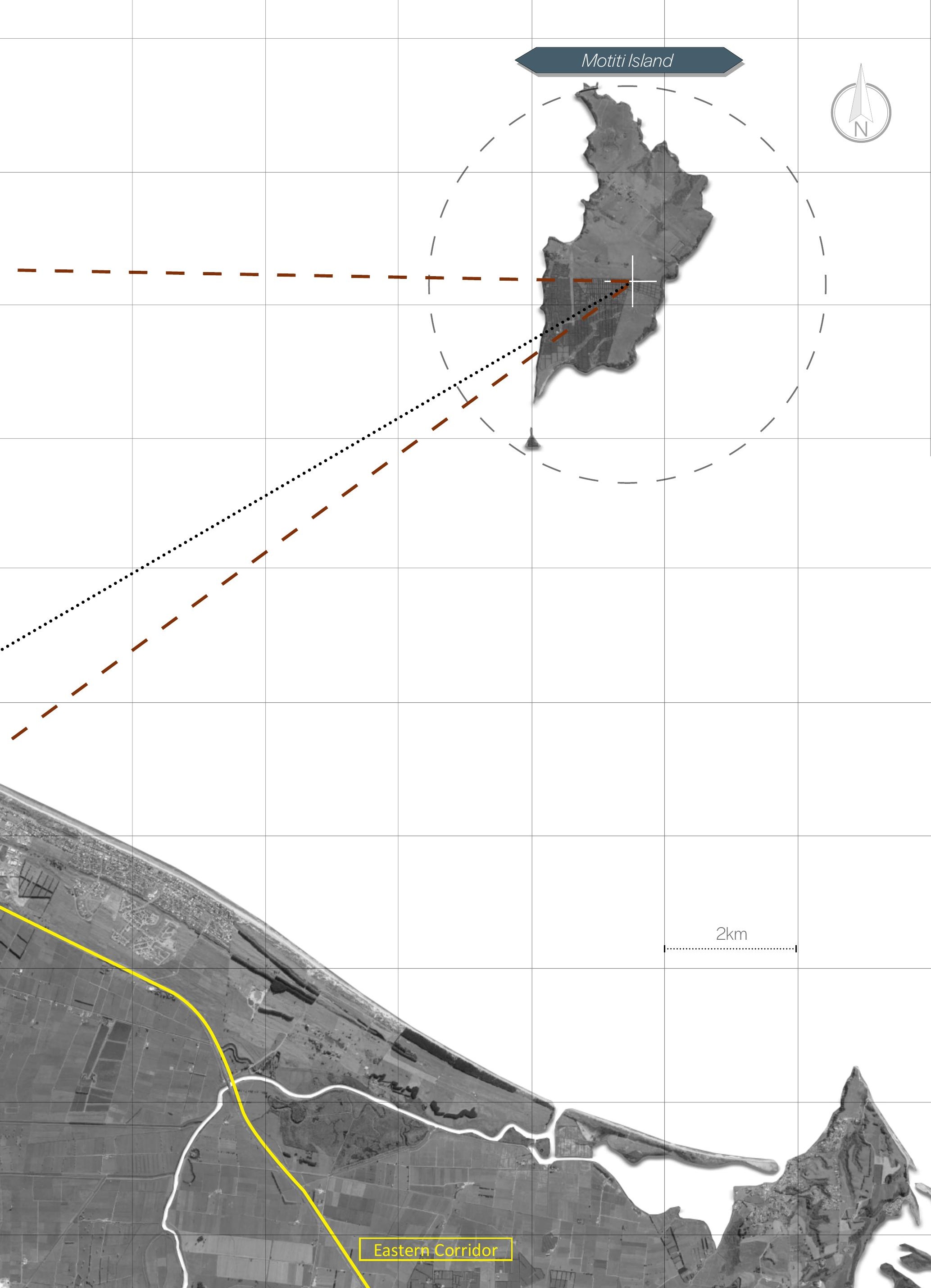




\section{Case Study - G:link}

\section{Gold Coast}

The Gold Coast G:link is a new light rail transit system connecting the main centres of the Gold Coast, Australia running from Helensville to Broadbeach South (City of Gold Coast, 2018).

The project, which began construction in 2012, consists of a $20 \mathrm{~km}$ dual track system running every 7.5 minutes on peak and between 10 and 15 minutes off peak. Stage 1 and 2 have been completed and discussions have begun on stage 3 which would continue to Coolangatta connecting Gold Coast Airport (G:link, 2018), (City of Gold Coast, 2018).

Previously the only other transport method was by car or bus, leading to significant congestion due to the disjointed nature of development along the coast and constrained geography. The introduction of light rail has provided significant additional capacity to the network and increased public transport usage up to $25 \%$ in its first year (L, 2015).

The advantages of this system in the confined geography of the Gold Coast are clear. It bypasses regular traffic through dedicated right of ways and signal priority at intersections and the $43.5 \mathrm{~m}$ tram used by the Gold Coast can carry up to 309 people, far exceeding the capacity and reliability of a bus on the same route $(\mathrm{L}$, 2015).

For the purposes of my research this is a particularly useful case study to contrast against Papamoa and Tauranga, all sharing similar geographical constraints and associated issues regarding congestion and low public transport use.
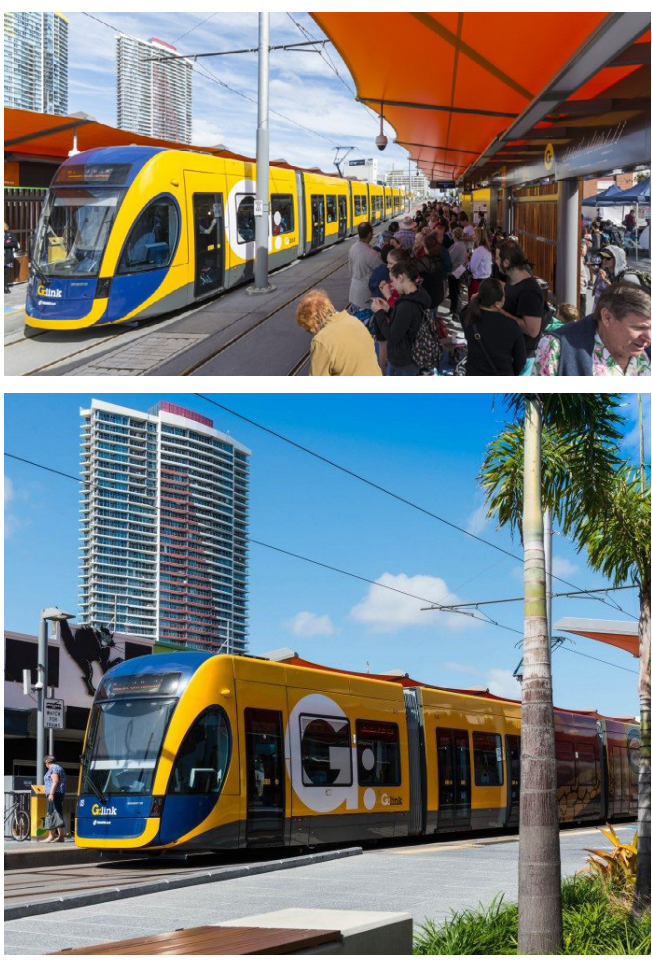

$\wedge$ Figures 32 \& 33 - G:link. provided courtesy of the Department of Transport and main roads Queensland. n.d. retrieved from https://ridetheg.com.au. Copyright by G:link 2019

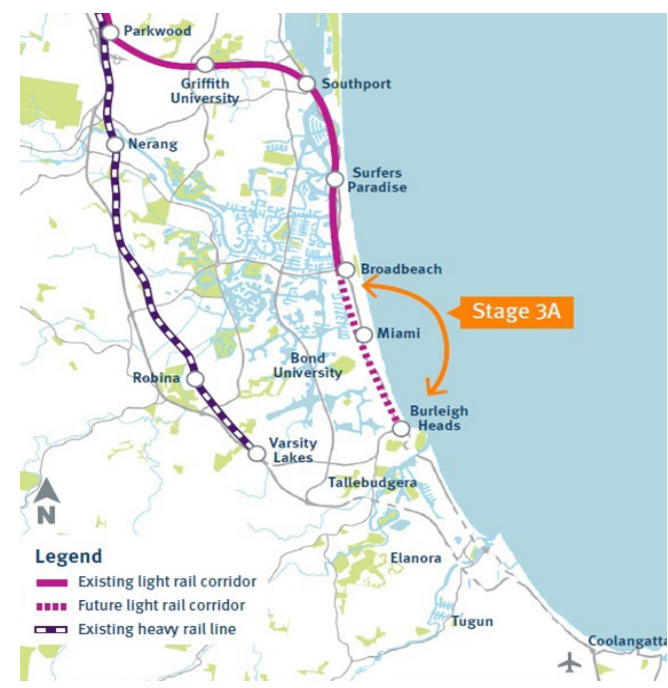

Figure 34 - Future stages. provided courtesy of the Department of Transport and main roads Queensland. n.d. retrieved from https://tinyurl.com/y4xgghyv. Copyright Department of Transport and main roads Queensland 2019 

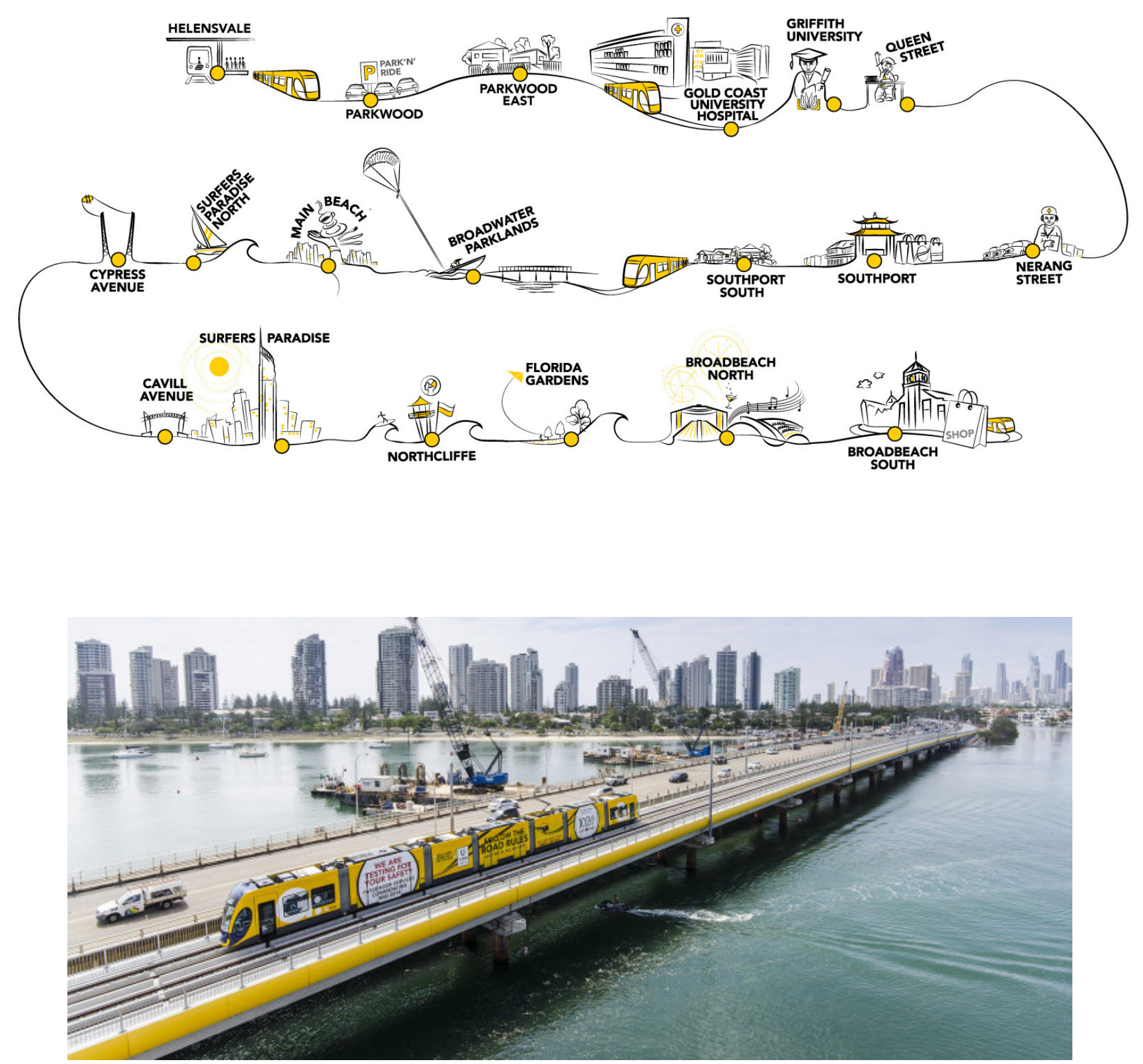

Figure 35 - Current route \& Stations. provided courtesy of the Department of Transport and main roads Queensland. n.d. retrieved from https://tinyurl.com/y2kyazld. Copyright by G:link2019

$\wedge$ Figure 36 - Bridge crossing. provided courtesy of the Department of Transport and main roads Queensland. n.d. retrieved from https://www.mcconnelldowell.com/projects/gold-coast-light-railaustralia. Copyright by G:link 2019 


\section{Transit-Oriented Development}

Following my experiences in Singapore and Taiwan I was impressed with the ease of which public transport could be used and the levels of integration it had with the surrounding urban environment. This experience highlighted the potential for similar systems to be implemented in fast growing areas of New Zealand such as Tauranga.

This research seeks to establish a system similar in nature to those developed in the Gold Coast, Australia and Singapore following the principles of Transit-Oriented Development.

Tauranga's existing transport system relies exclusively on private cars and buses. The region does have a limited network of regional rail, however the current system prioritises freight access from the Tauranga port and would require significant investment through double tracking in order to operate commuter services. Currently Tauranga's public transport is one of the most under-utilised in the country with under $1 \%$ of people using the cities bus system to commute (TCC, 2018c). The site has three bus routes that run every thirty minutes on peak and every hour at all other times, however these are prone to delays due to Tauranga's growing traffic issues which has increased by $5.7 \%$ compared to the national increase of $3.9 \%$ (Hunter, 2018b).
Options such as Bus Rapid Transit (BRT) and a metro styled underground train system were considered. However, while BRT would work in the intermediate, it did not offer the necessary capacity in the long term as the region grows when compared to other options. Metro was also ruled out due to a high-water table, sandy and swampy ground conditions along the Papamoa Coast and a large initial outlay for tunnelling and installation.

Taking this into consideration light rail was selected as the most viable option capable of servicing the greatest amount of people. Light rail is a reliable, high-capacity public transit system that can operate within its own right of way system (NZTA, 2018). This is ideal for Tauranga where current public transport is frequently caught in traffic congestion.

\section{System Selected}

Light rail is more easily integrated into new and existing urban environments and is quieter and more pedestrian friendly than heavy rail. It is also capable of moving people at greater frequencies and capacities than comparable bus systems and provides significantly faster loading and off-loading of passengers, making it ideally situated as a high frequency spine for a redeveloped public transit system in Tauranga (NZTA, n.d.). 
Existing Transport Spine

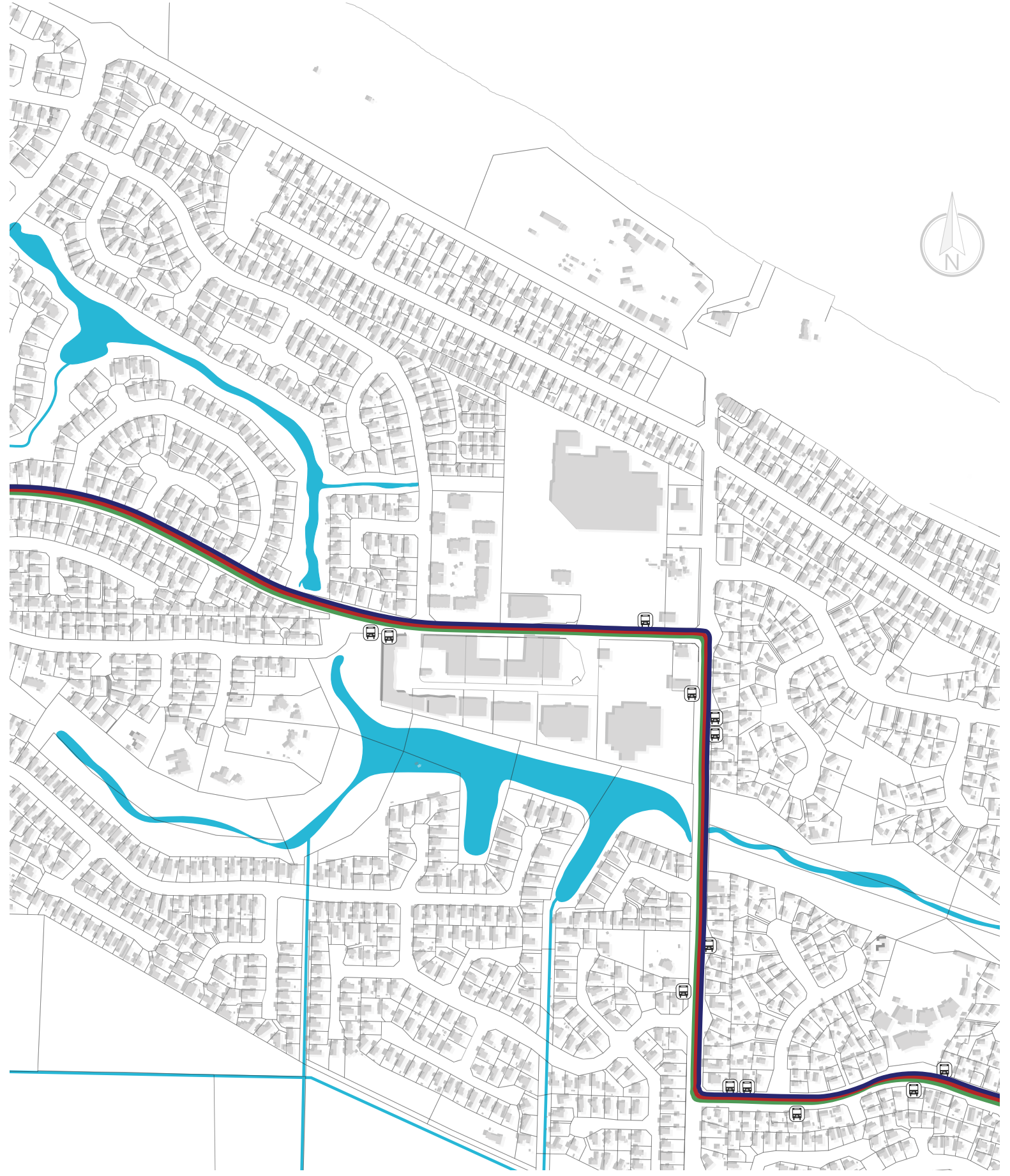

Figure 37 - Existing Site Transport Routes 


\section{Fixed Route vs. Flex-route}

Consideration over fixed and flexible transit routes were considered as a part of this process. Feng Qiu's paper highlighted the advantages of both. Fixed-route transit is cost effective and reliable, while flexiroute transit is convenient and adaptable to the needs of the user (Qiu, Li, \& Haghani, 2015). For these reasons the proposed system will be a combination of both, it will utilise light rail as a frequent fixed-route mass transit spine system, populated by a series of transit hubs that will in turn be serviced by more flexible transit options capable of meeting the needs of each community.

The permanence of light rail and transport hubs will encourage investment and sustainable development around the hubs, while the flexi-route transit within the local communities will ensure the system remains responsive to the needs of the community (Qiu et al., 2015).

The proposed system will look to implement a combined multi-modal transit system. The existing bus network will be replaced by a dedicated mass rapid transit light rail system. This will provide frequent and reliable connections along the coastal strip into Mount Maunganui and the Tauranga CBD.

This system is envisaged as a regional link between the primary centres, including a direct link through to Tauranga along Cameron road and on to the Northern Suburbs. It would also include a spur line to connect to Mount Maunganui. This would operate as a high frequency system with transit operating in both directions at frequencies of every 10-15 min. The light rail units will be similar to those used in the Gold Coast's G:Link and those proposed for Auckland's Dominion Road Airport link, offering a capacity of up to 309 people during peak periods which allows for population growth (Goldlinq, n.d.).

The system will be designed to allow easy and convenient transfer between modes and increase accessibility for residents throughout the region, looking to reduce the region's dependency on the private car which currently sits at $97 \%$, the highest in the country (NZ Herald, 2016).

\section{Evaluation of Site Transit Routes}

Three route options were proposed. All three routes maintain a minimum 40 metre turning radius to reduce track noise (Incorporated, 2012). These utilise the excess width of Gravatt Road to accommodate light rail from the west and either used an alignment down Domain Road or divert onto the Wairakei stream exclusion zone, which offers access up the centre of the suburb.

The blue and green routes were dismissed as they run down the existing green network which is prone to flooding and would also be compromised as an urban park if light rail were to be introduced here.

For these reasons the red option was selected. This option provides the best integration with the site and by aligning the trams down Domain Road provides access to Te Okura Drive and the future Te Tumu town centre. It also aligns the transport corridor to better capture residential growth to the south of the Expressway. 


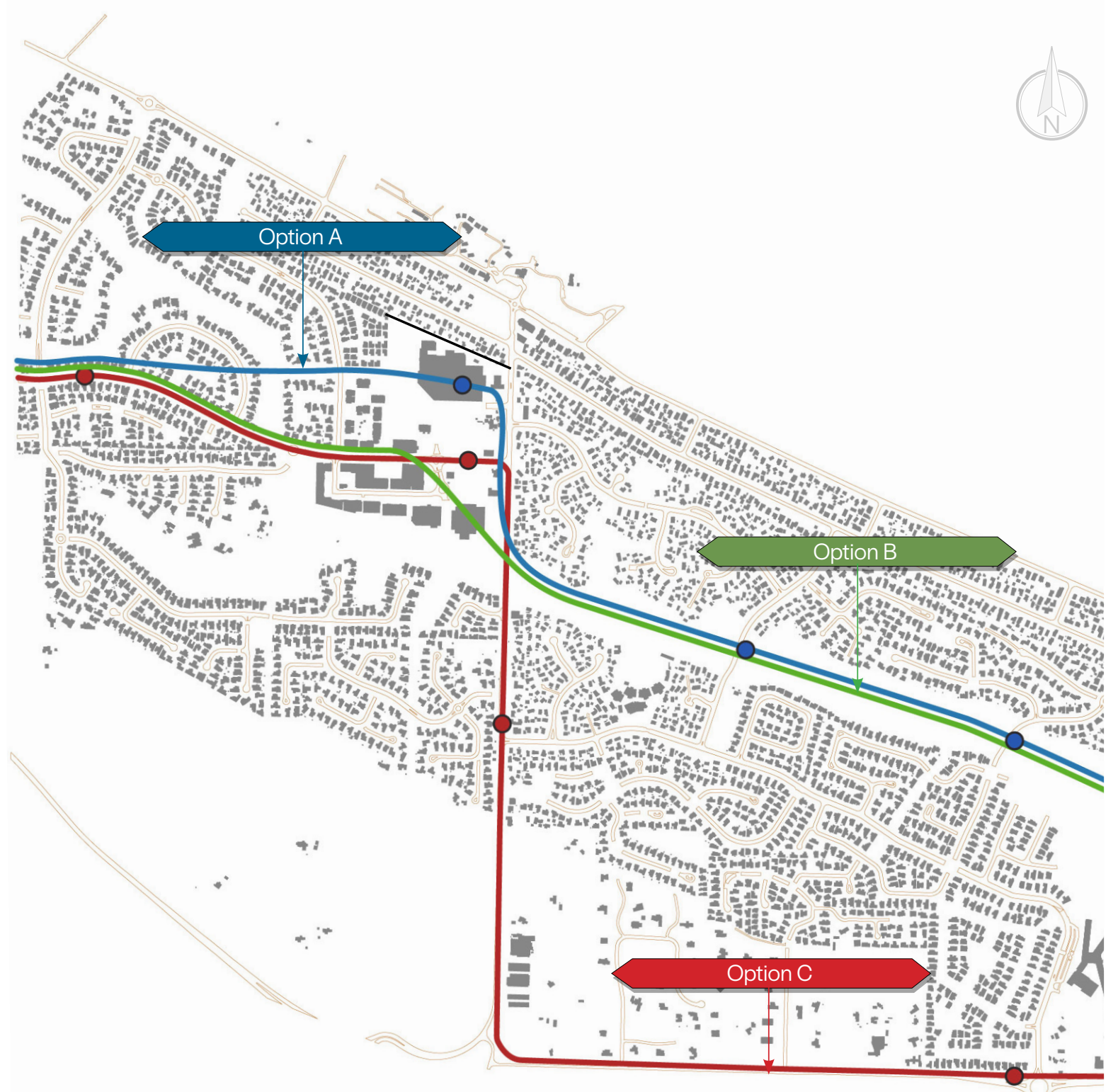

$\wedge$ Figure 38 -Transit Route Evaluation 


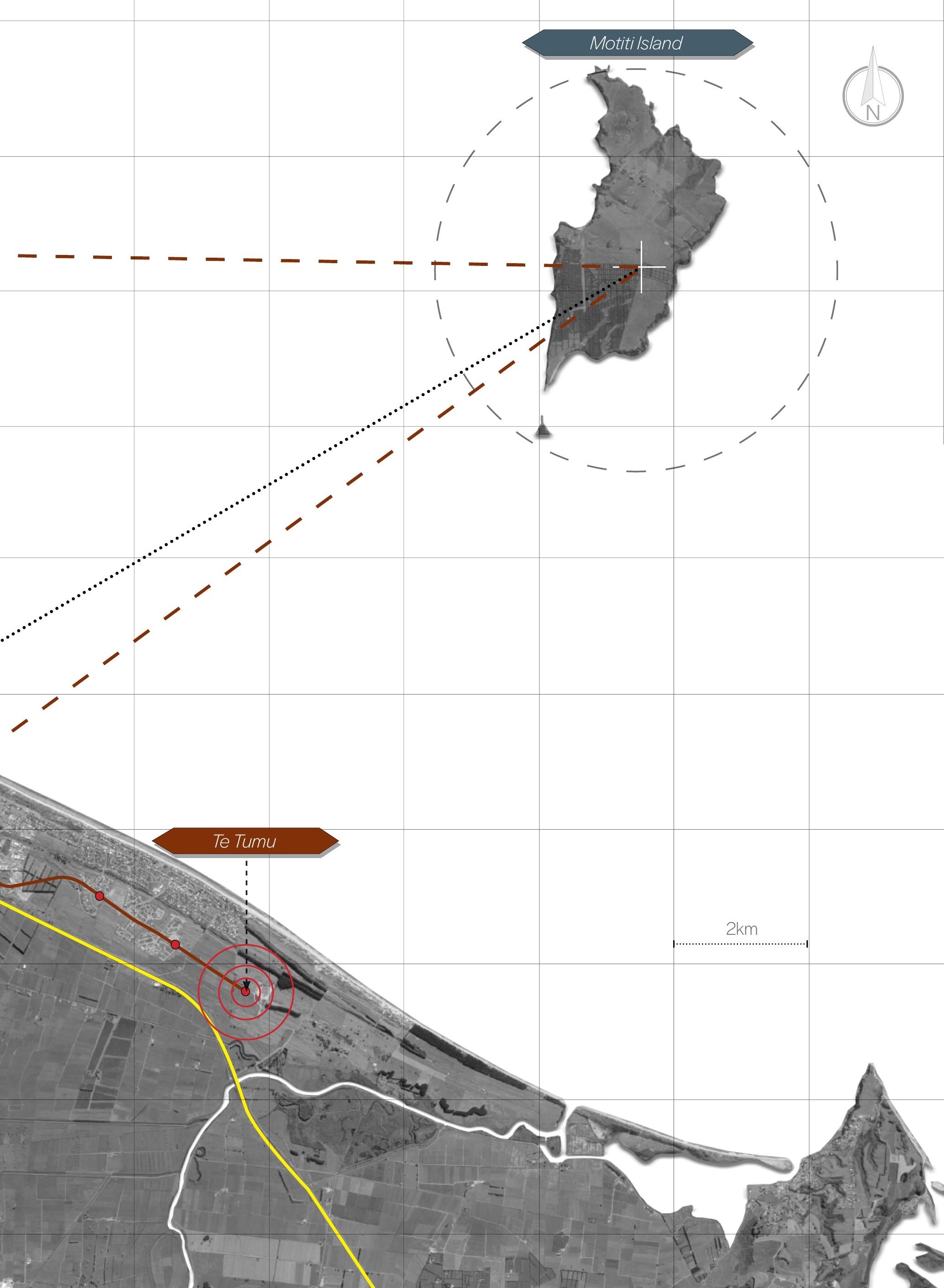


3.1

Preliminary Design 
A key influencing factor in this research was my time spent in Taiwan and Singapore, experiencing how the urban environment and infrastructure is built to cater for the populations there.

This led me to consider how these principles may be applied to the New Zealand context and how they may be used to solve some of the issues that we, as a country, are currently experiencing

The design phase of this research was taken in three separate phases, each tailored toward the development of a specific objective and list of design goals. This success of each phase was assessed at the end and used to inform the development of the next, allowing design learnings to be accumulated throughout the process.

Prior to beginning this phase I began to look at precedents for the Papamoa Plaza site to aid in development ideas. 


\section{Case Study - Oakridge}

\section{Vancouver}

Oakridge is an existing shopping centre in Vancouver, Canada, built in the 1950s. Dominated by over 20 acres of carparking this site bears several similarities with the Papamoa site, both of which are large retail dominated sites situated in primarily suburban residential areas designed around the car (Ebner, 2018).

The owners are currently embarking on a billion-dollar redevelopment as a part of Vancouver's urban densification programme. Designed by Henriquez Partners the proposed centre takes inspiration from the medieval towns, such as San Gimignano, Italy, marketing itself as the geographic centre of Vancouver with goals to become its own micro city (Chan, 2017).

This development represents a global trend of re-purposing shopping centres, following changes in the habits of the consumer. These new centres have a renewed focus on service and experience and have more in common with a town centre than the traditional mall (Ebner, 2018).

This seeks to develop the idea of regional hubs through the inclusion of additional urban elements such as residential, commercial and transport alongside more typical retail destinations to build resident populations and market themselves as vibrant cultural hubs.

Whilst this example strongly favours the retention of the mall it does present some interesting avenues for further exploration. These include the use of public space and pedestrianised connections as a means of linking the different elements of the site and creating a multi-layered experience for the centre, which could be utilised in the development of the Papamoa Plaza site.
This content is unavailable.

Please refer to the caption below or the print version.

This content is unavailable.

Please refer to the caption below or the print version.

This content is unavailable.

Please refer to the caption below or the print version. 
This content is unavailable.

Please refer to the caption below or

the print version.

This content is unavailable.

Please refer to the caption below or the print version.
This content is unavailable.

Please refer to the caption below or the print version.

$\wedge$ Figure 40-Oakridge development Vancouver, Canada. by

< Henriquez Partners Architects. n.d. retrieved from https://

henriquezpartners.com/projects/oakridge/. Copyright

Henriquez Partners Architects 2019. 


\section{Design Phase 1}

'Lifting the Community'

'Lifting the Community' draws off the site's past to ground the design and represent the historical timeline of Papamoa in a way that has not been observed until now.

The primary aim of this phase is to investigate ways that the site can be intensified in order to create a more vibrant and connected centre. This seeks to reintroduce elements of the historical landscape and use them to inform future development, reinforcing the relationship between the site and the community.

Phase one provides an initial framework upon which the design can be extended and improved. 


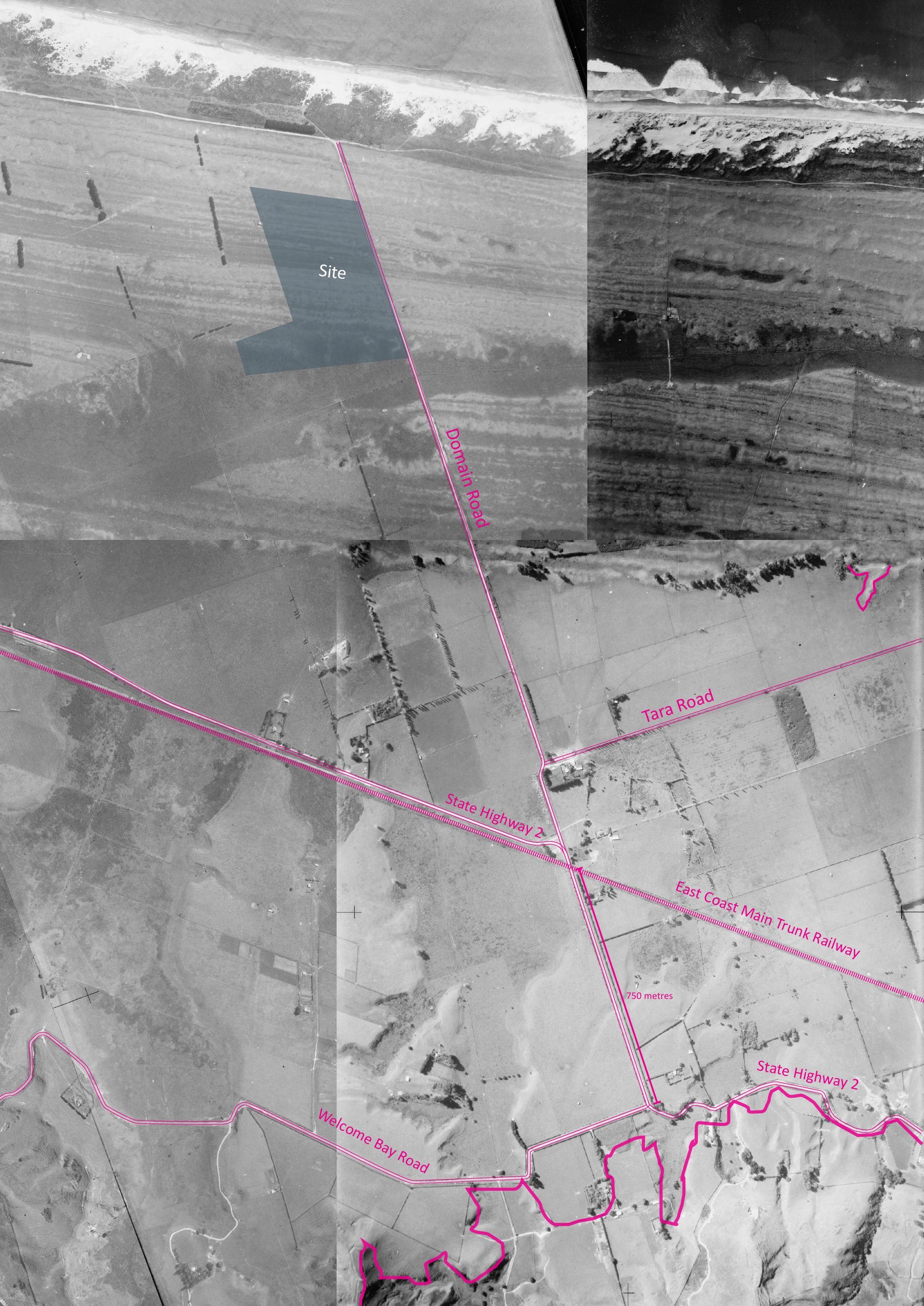




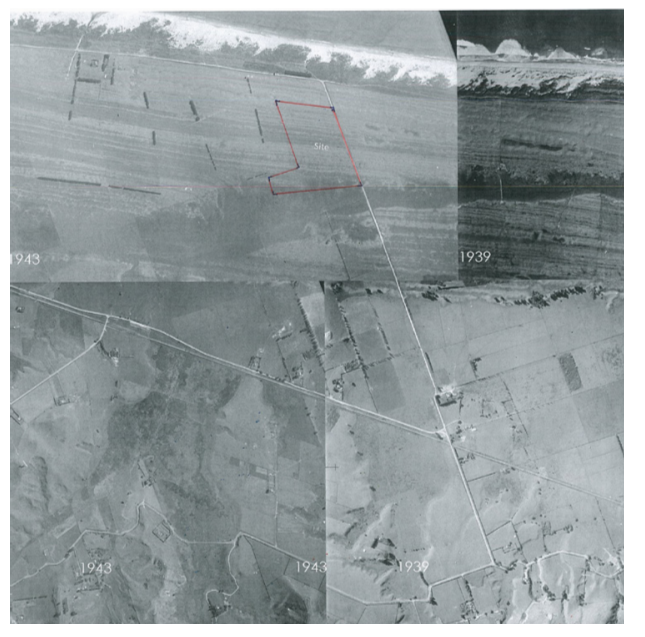

Present day site located on historical map

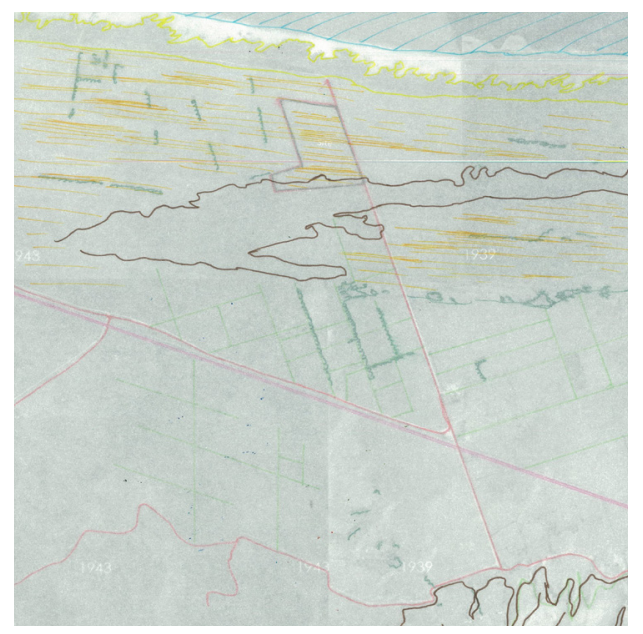

Sediment formations and former wetlands

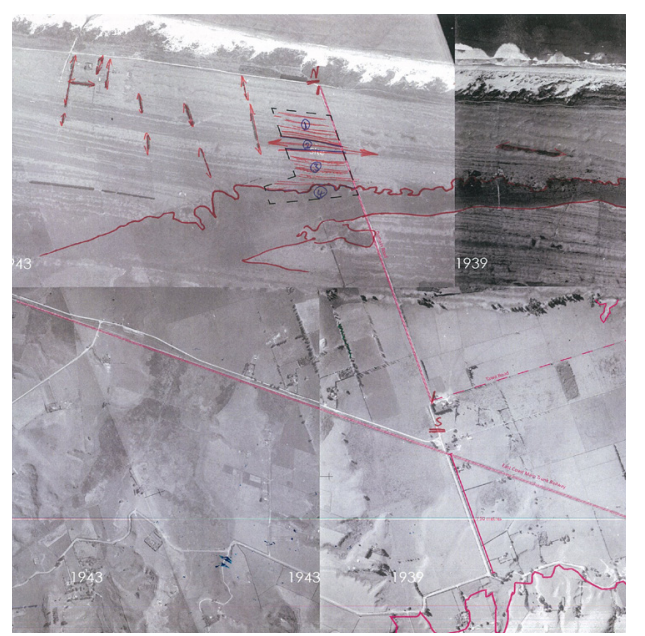

Prominent natural features

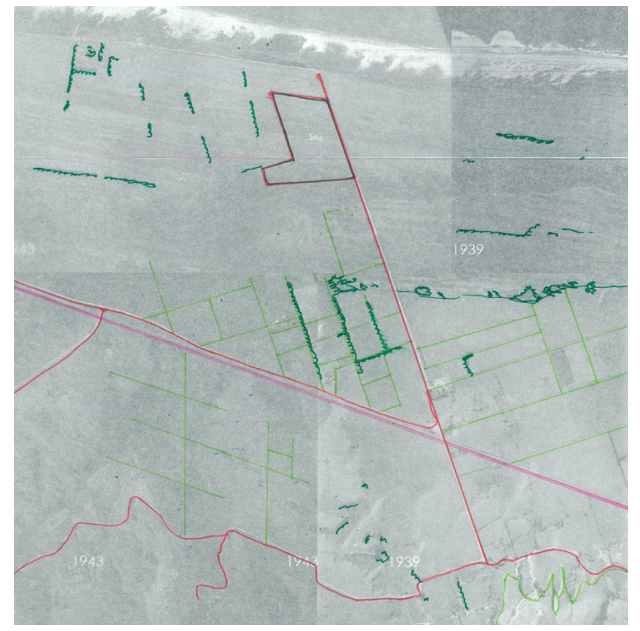

Transport links and greenery

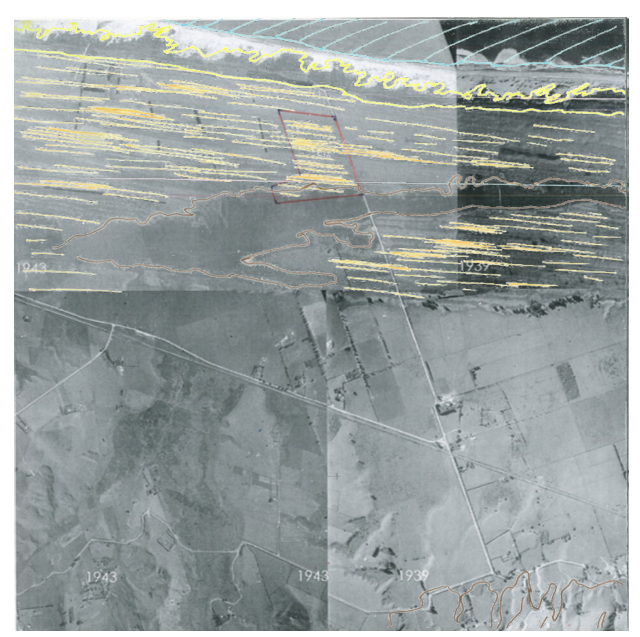

Sediment formations

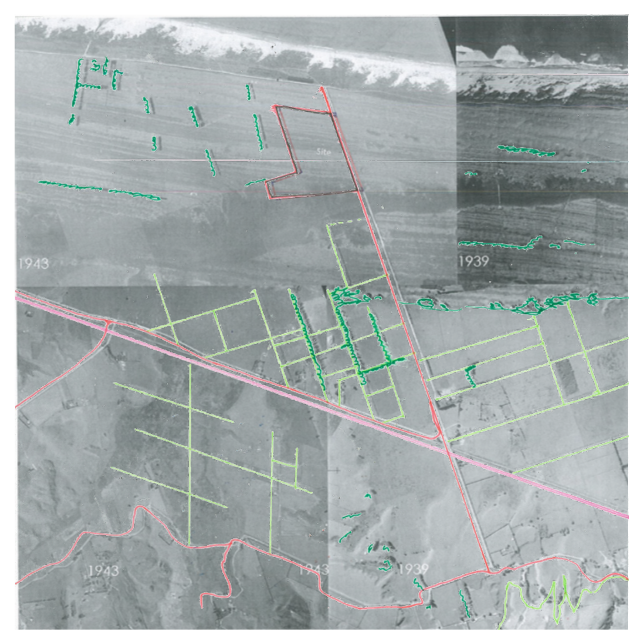

Man-made features
$<$ Figure 47

Analysis of compiled imagery of the Domain Road site ranging from 1939 - 1943. Prominent natural and man-made features have been identified and analysed in order to gain an insight into how development has been informed on the site. 


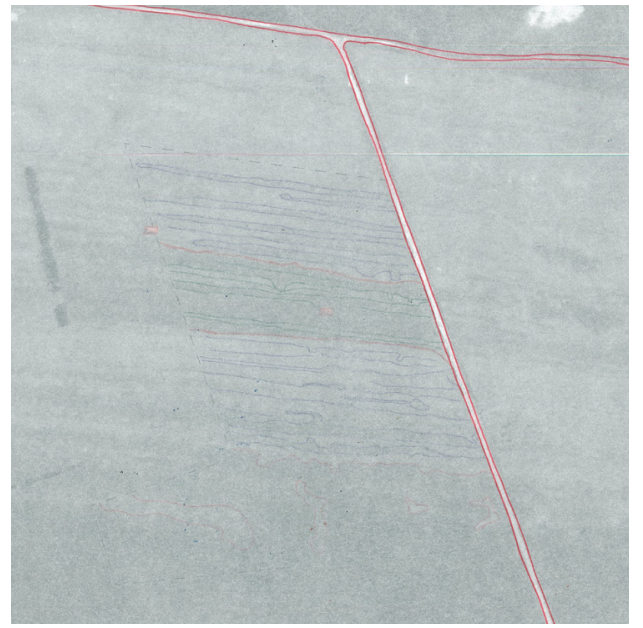

$\wedge \quad$ Figure 48-Arterial roads located in similar location to present day

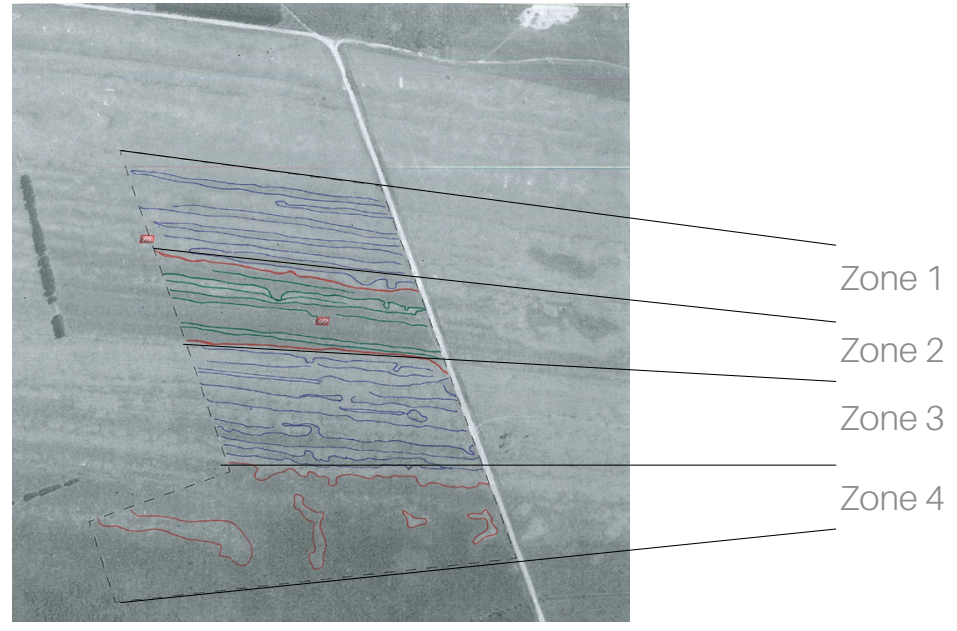

$\wedge$ Figure 49-Sediment and landscape features identified on historical site

Consideration was taken to ensure that historical issues such as flooding were not accidentally reintroduced, and that the established framework is adequately integrated with the new scheme.

Initial analysis began by looking at historical aerial photos of the site in the period of 1939 - 1943, prior to any largescale development in the area. At this stage the land formations of the coastal sand plains and wetlands were still present.

Sedimentary formations in the sand plains were mapped and the locations of historical waterways and wetlands were identified. 
This was then overlaid with the current configuration. This allowed historical features to be located relevant to modern conditions on site, serving to highlight the level of disconnection the current site and suburb suffer from their natural and historical context.

$<$ Figure 50-Historical site overlaid with modern context

Darker areas represent former wetlands and stream beds such as the Wairakei stream which has since been reconstructed as part of the Wairakei flood protection system. 


\section{Design Exploration}

The design exploration looked to solve this disconnect and explore ways that the site could be reoriented and intensified as a part of this process.

As discussed, the site's current configuration alienates the surrounding context, and the surrounding suburbs make it difficult to reconnect the site due to visual and physical obstructions.

A visual connection between the site and its surrounds was established by lifting segments of the site up to create a Podium Level. This provided additional space for intensification and presented the opportunity to establish greater physical and visual connections to the wider region.

Existing site facilities such as the mall, large format shopping areas and parking were accommodated in a newly constructed undercroft space on the ground level. The second level above forms an open pedestrian town centre. This is serviced by rapid light rail and an integrated transit centre including a local bus hub on the lower level.

Gentle ramped landforms connect to the green network and waterways to the south of the site and a generous pedestrian bridge provides access over Papamoa Beach Road to the beach at the north of the site. The second level also includes additional amenities such as apartments, restaurants and civic spaces to cater for the larger population and encourages patronage from the surrounding suburbs.

Various layouts were trialled, taking inspiration from the historical sediment formations which were used to inform the layout of buildings and street access ways. 


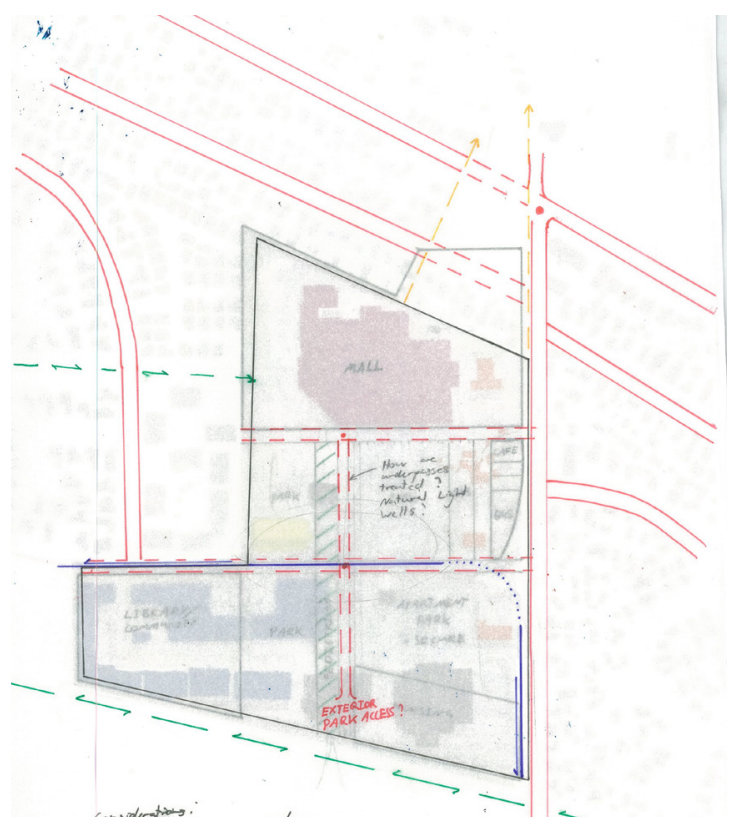

$\wedge$ Figure 51-Ground Level

Mall is enlarged and optimised at the north of the site. Cross site traffic is maintained along Gravatt Road. A new bus hub is created alongside Domain Road and pedestrian access is facilitated down the centre connecting the mall to the Wairakei Stream.

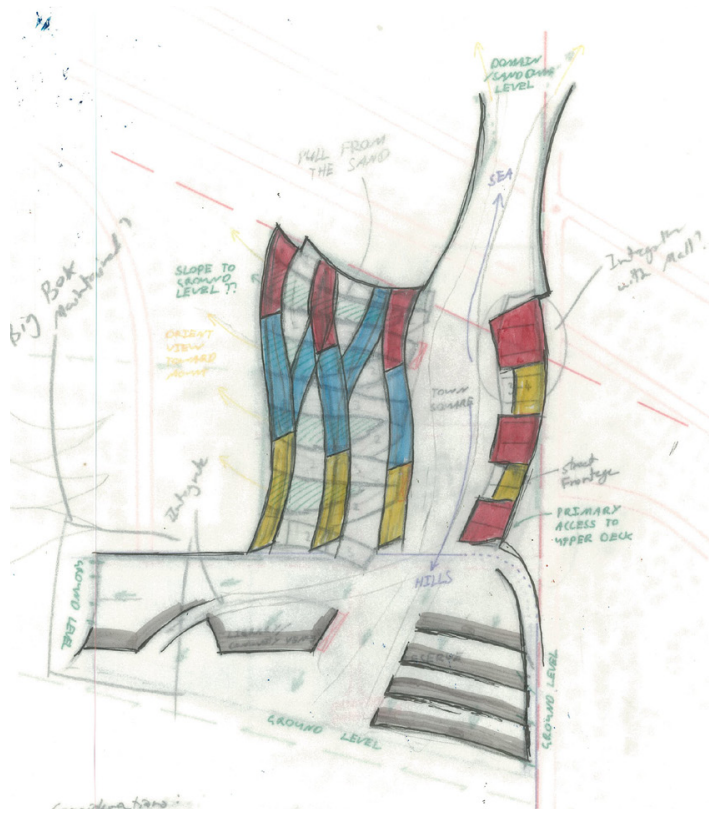

$\wedge$ Figure 53-Scenario A-Podium Level

Commercial and retail facilities are created along the east and new apartment complexes are placed running north-south across the site. A new north-south spine connects the Wairakei stream and beach. Civic amenities and town housing are provided within the Wairakei stream precinct to the South of the site.

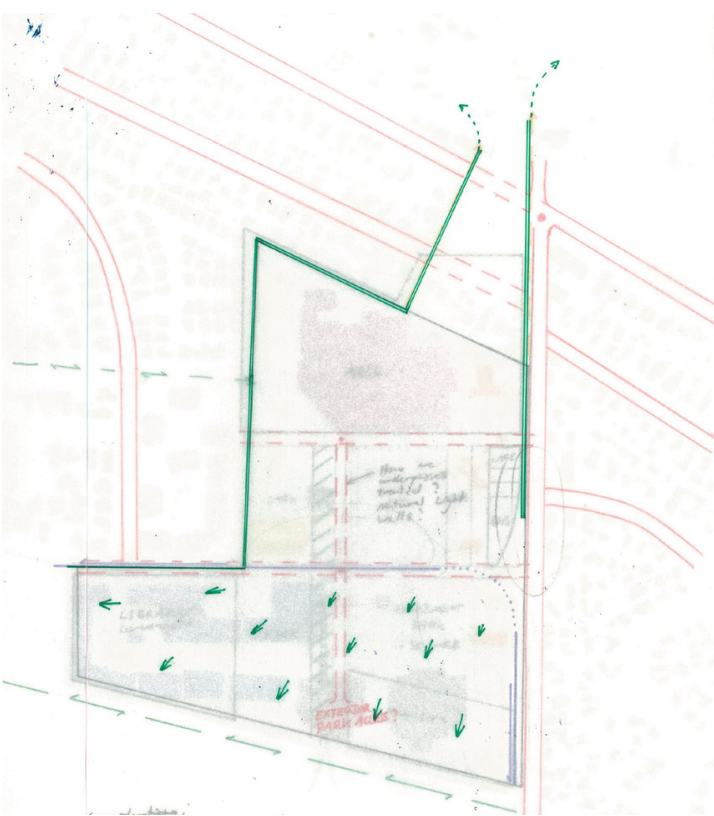

$\wedge$ Figure 52-First Floor Podium

A new podium level at approx. 5-6m of height is created from Gravatt Road to the sites northern extent. The area to the south is formed as a gently sloping park area.

is

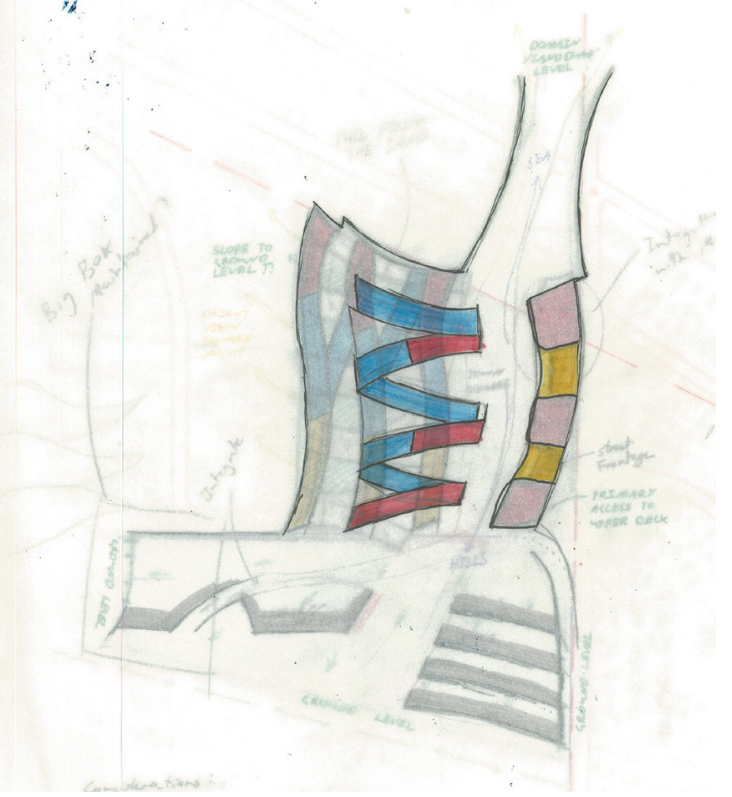

$\wedge$ Figure 54-Scenario B-Podium Level

Similar configuration to scenario A except that apartments have been oriented east/west to reduce bulk and optimise natural light and views. 


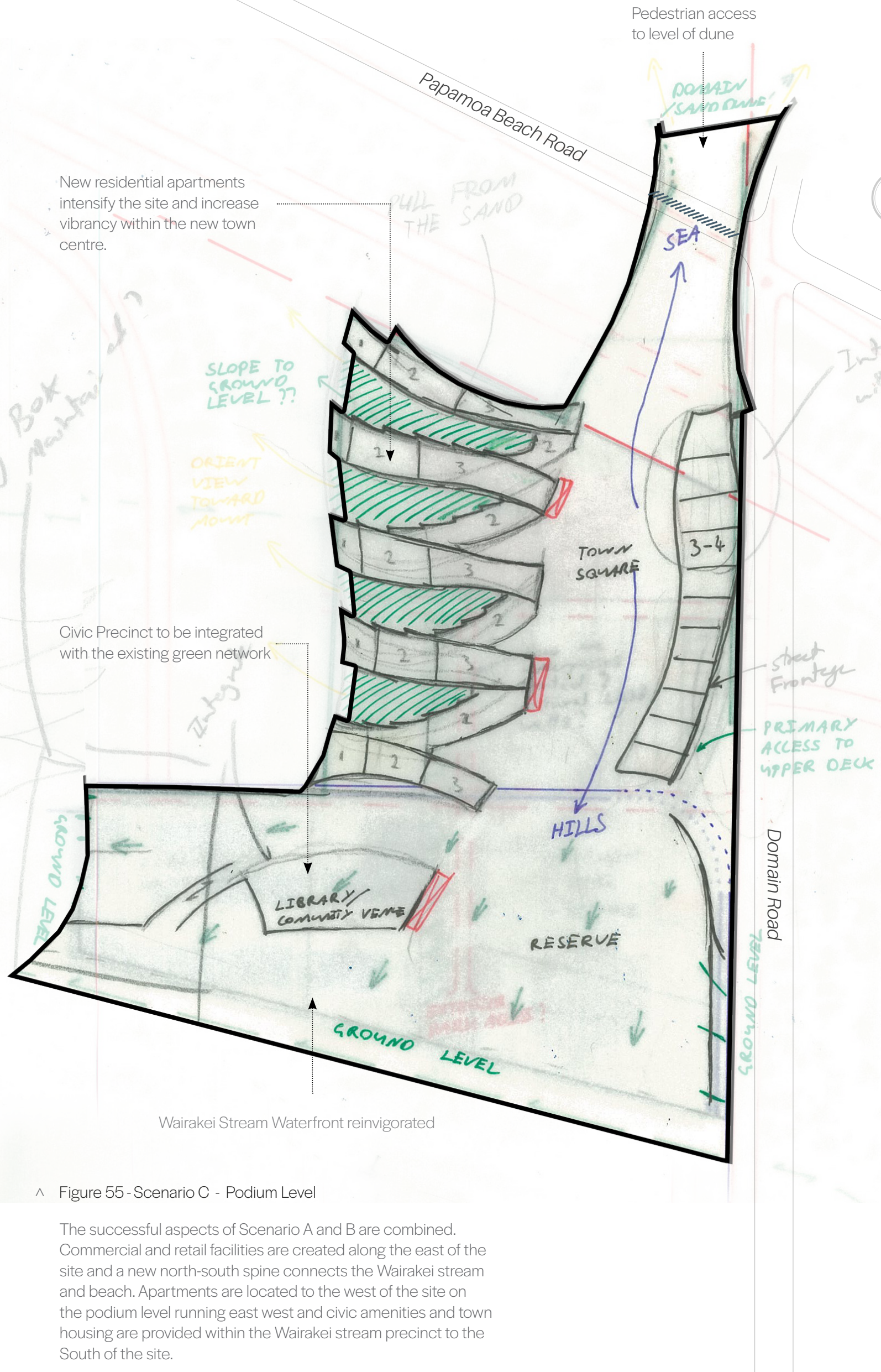




\section{Critical Reflection}

Phase one sought to employ assemblage as means to 'open' up the environment on site and to encourage growth and the cooperation of different sectors to form a balanced and functioning town centre.

Incorporating the site's history into the new town centre helped to ground the scheme and create stronger regional ties that acknowledge the past and use it to inform future development. This was accompanied by an increased on-site population, new eateries, shopping and commercial premises to provide amenity within the town centre and vibrancy with the aim of fostering a true heart and focal point for the suburb.

However, further work to improve integration of the site with the surrounding suburb is required to achieve this. This is primarily due to the separation between the ground and Podium Levels, but also with east-west movement across the site, which is restricted by the current configuration, limiting connectivity throughout the site.

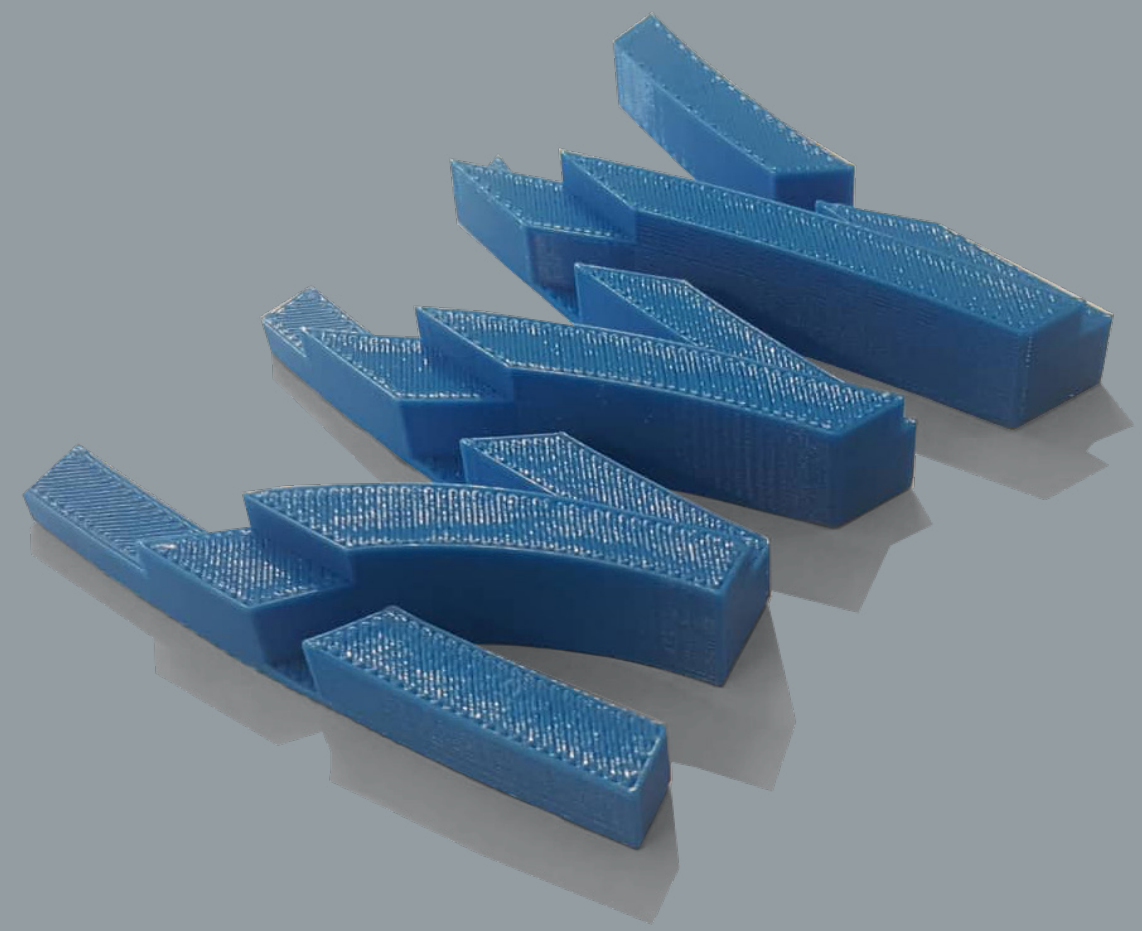

$\wedge \quad$ Figure 56 Staggered level apartment complex trial 


\section{Design Phase 2}

'Coastal Connection'

'Coastal Connection' focuses on reconnecting the site to its surroundings and natural context.

Site assets identified in previous analysis such as the existing green pedestrian links, the Wairakei stream to the south of the site, and the beach to the north, were integrated into the scheme.

This exploration builds upon the previous phase whilst seeking options to improve access for the user to the site's destinations and increase connectivity both within and across the site.

A revised site incorporating the raised podium of Phase 1 and introducing a central axis that serves as the primary circulation on both levels and improves connectivity between the two. 


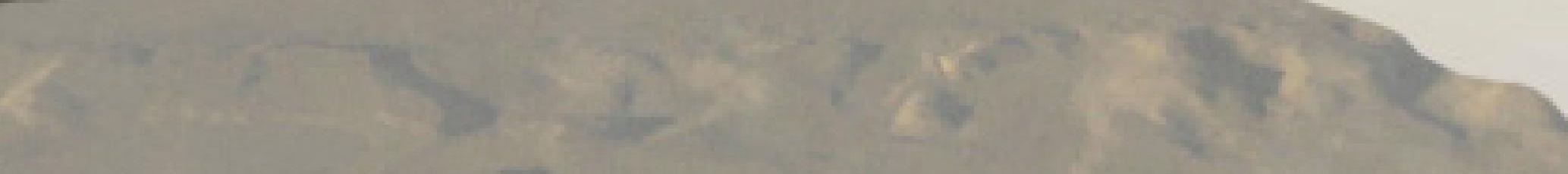

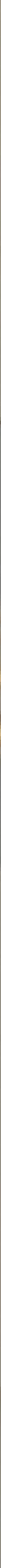




\section{Reconnecting the Wairakei Stream}

Connectivity across the site was approached holistically to integrate both the Ground Level and the proposed Podium Level.

A new pedestrianised boulevard space has been cut through the centre of the site following the predictions of the depth map analysis on page 50 . Intended as a circulation and linear public park space, this link will incorporate a new waterway and associated green spaces inspired by the original Wairakei stream.

The proposed waterway will integrate into the wider Wairakei storm-water system connecting to the main lagoon at the south of the site and the secondary channel to the west which represent the site's main connection into the wider green pedestrian network. This adds the ability to mitigate the flood risk on the site by providing a pathway for floodwaters to escape, which is particularly important in its coastal location.
Envisaged as a central cut through the centre of the site, this design move represents a metaphorical reconnection of the stream to the sea through a view shaft which will connect it back to its head waters on the Papamoa Hills (figure 58). The result is an active public space that draws in the surrounding ecology and ties into the existing green network to strengthen connections with the wider area and provide a green heart to the site.

The new Boulevard will provide a visual and physical connection between the levels and form the arterial route across the site. A series of low-grade ramps, stairs, and walkways will provide users with accessible connections between the Ground and Podium Levels.

Integration across the Domain Road frontage is particularly important as this forms one of the most important visual connections between the new centre and its surrounds (figure 62). 


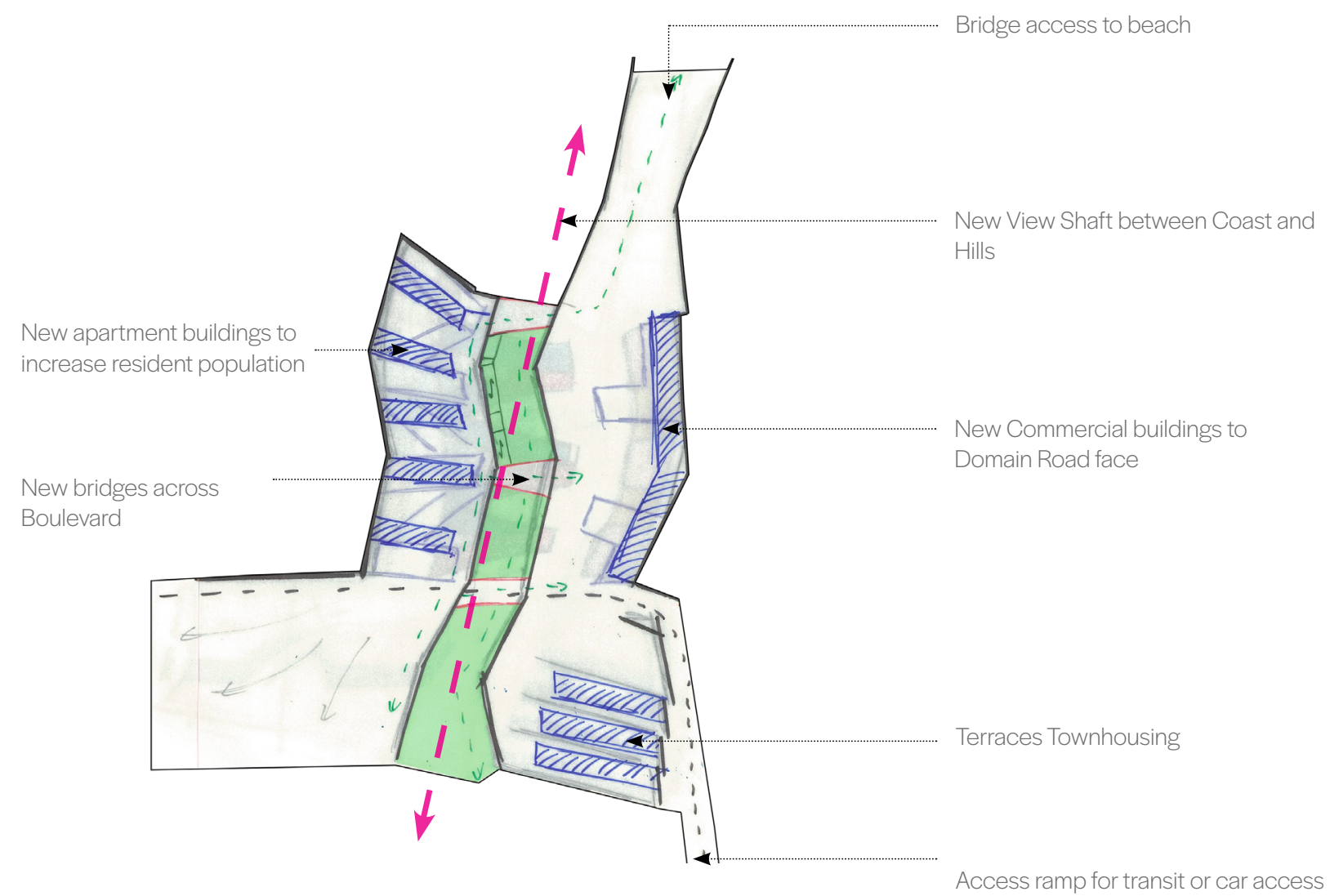

$\wedge$ Figure 58- Proposed Podium Level

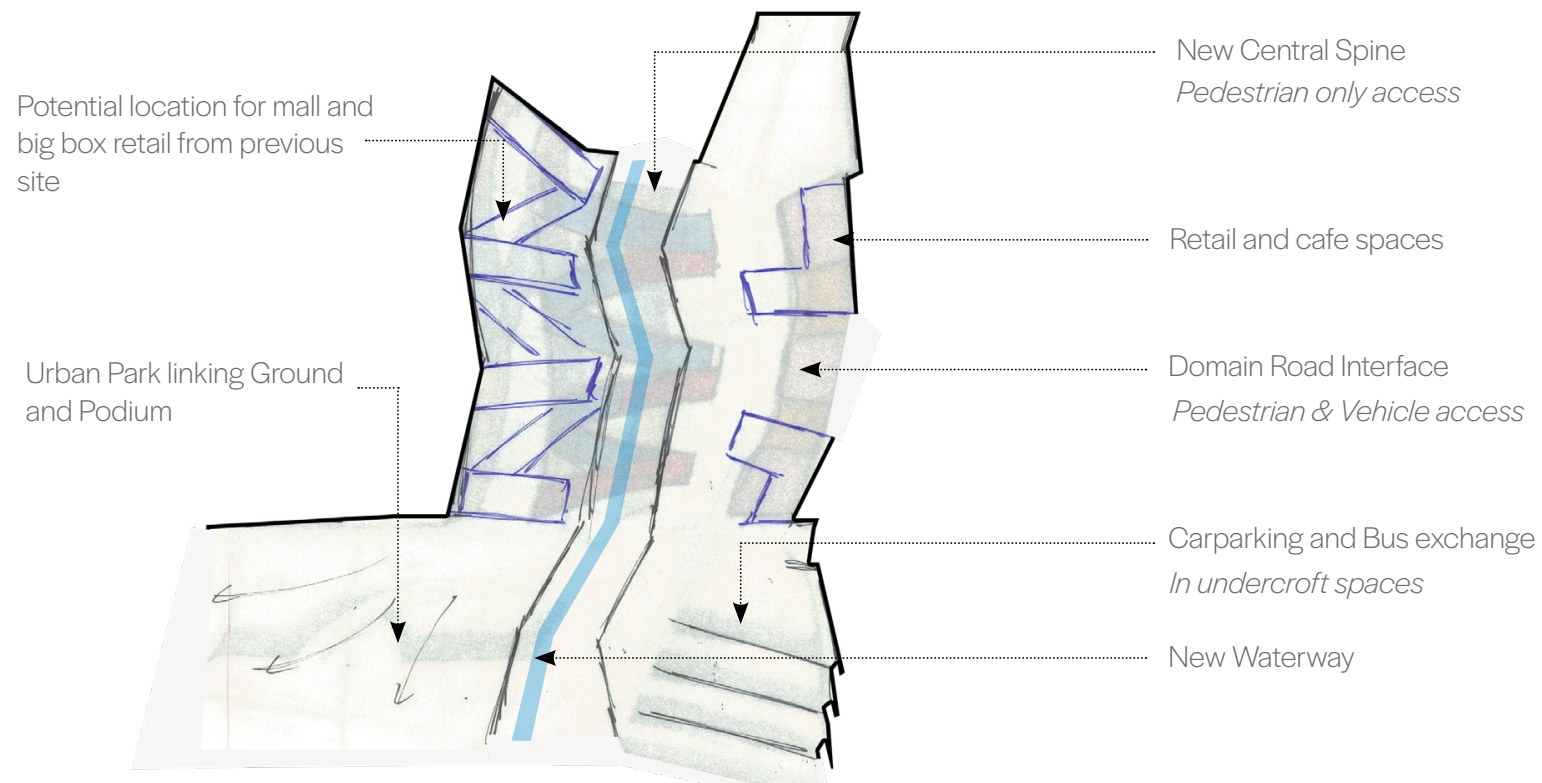

$\wedge$ Figure 59 - Proposed Ground Level 
This will be formed by a new gateway at the intersect of Gravatt and Domain roads anchored by transport, retail and commercial blocks. These provide direct integration with Domain Road on one side and the Ground and Podium Levels on the other with circulation provided between. Visibility will be maintained at key points and access to the central spine encourage through east-west linkages on the Ground Level.

Key aspects of the proposed site circulation network have been designed to link into the existing pedestrian network of the suburb.
Precedents including the New York Highline were analysed to identify ways that urban and green spaces could be incorporated into the Podium Level. Links between this level and the ground are facilitated through parkland to the south of the site. Situated adjacent to the waterway this provides access to both levels of the site and Ground Level links will tie into existing access-ways to ensure the development is sufficiently connected with the wider suburb and accessible to the surrounding population.

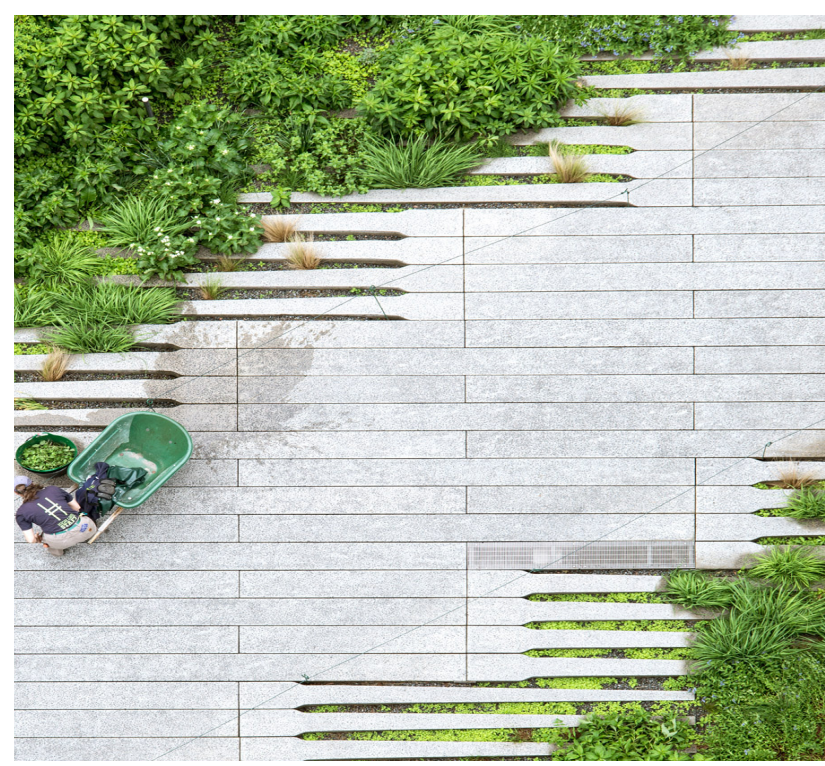

Figure 60 - New York Highline. kindly provided by Timothy Schenck. n.d. retrieved from https://tinyurl.com/yxh6ygrz. Copyright by Timothy Schenck.

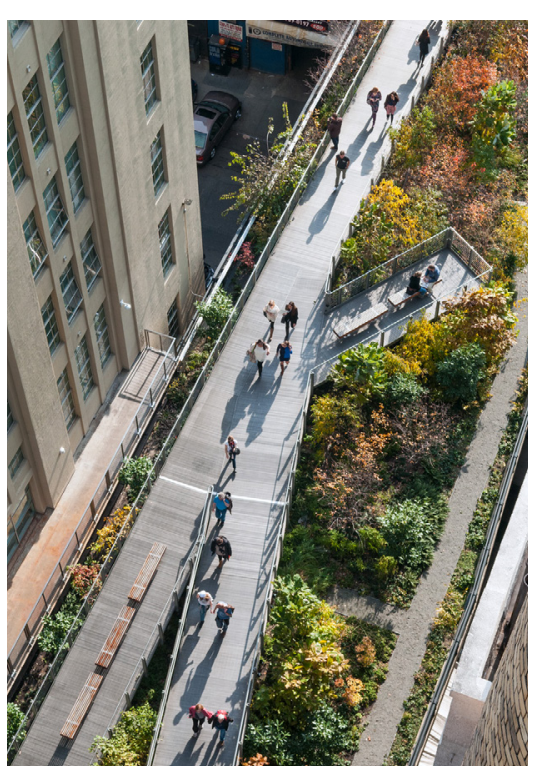

The New York Highline was used as a precedent exploring how urban spaces and greenery can be developed on the podium level. 
Multilevel Integration

추룰르르를
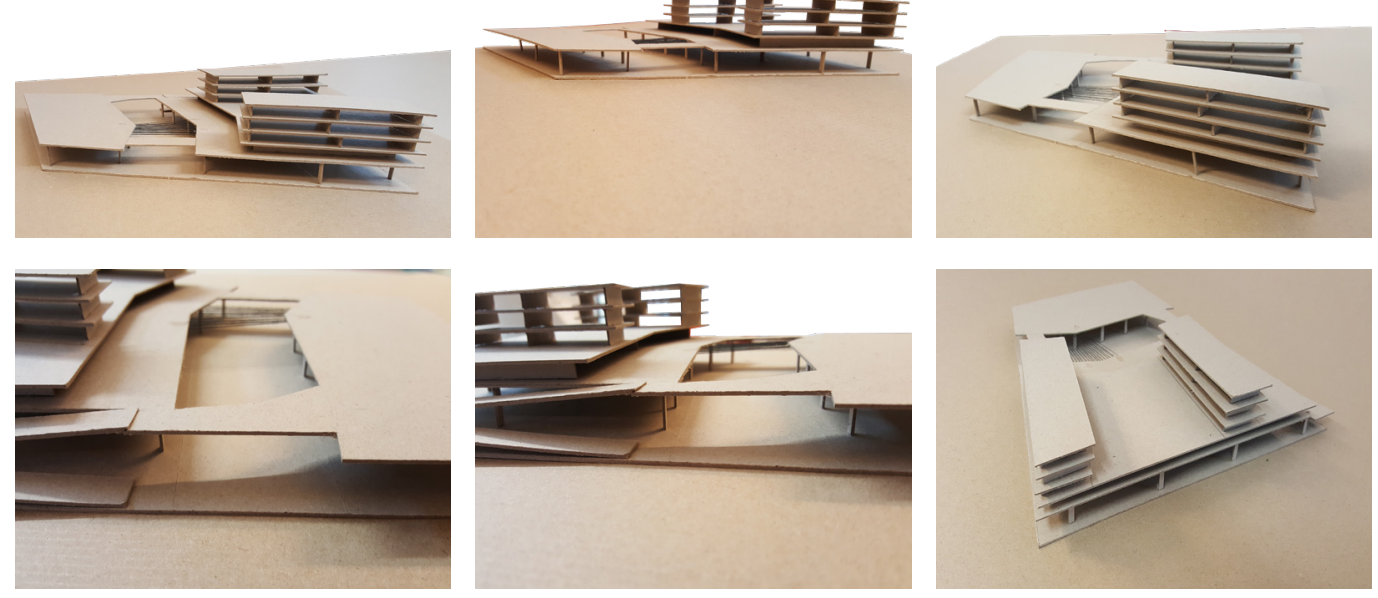

Figure 61-Podium level exploration >
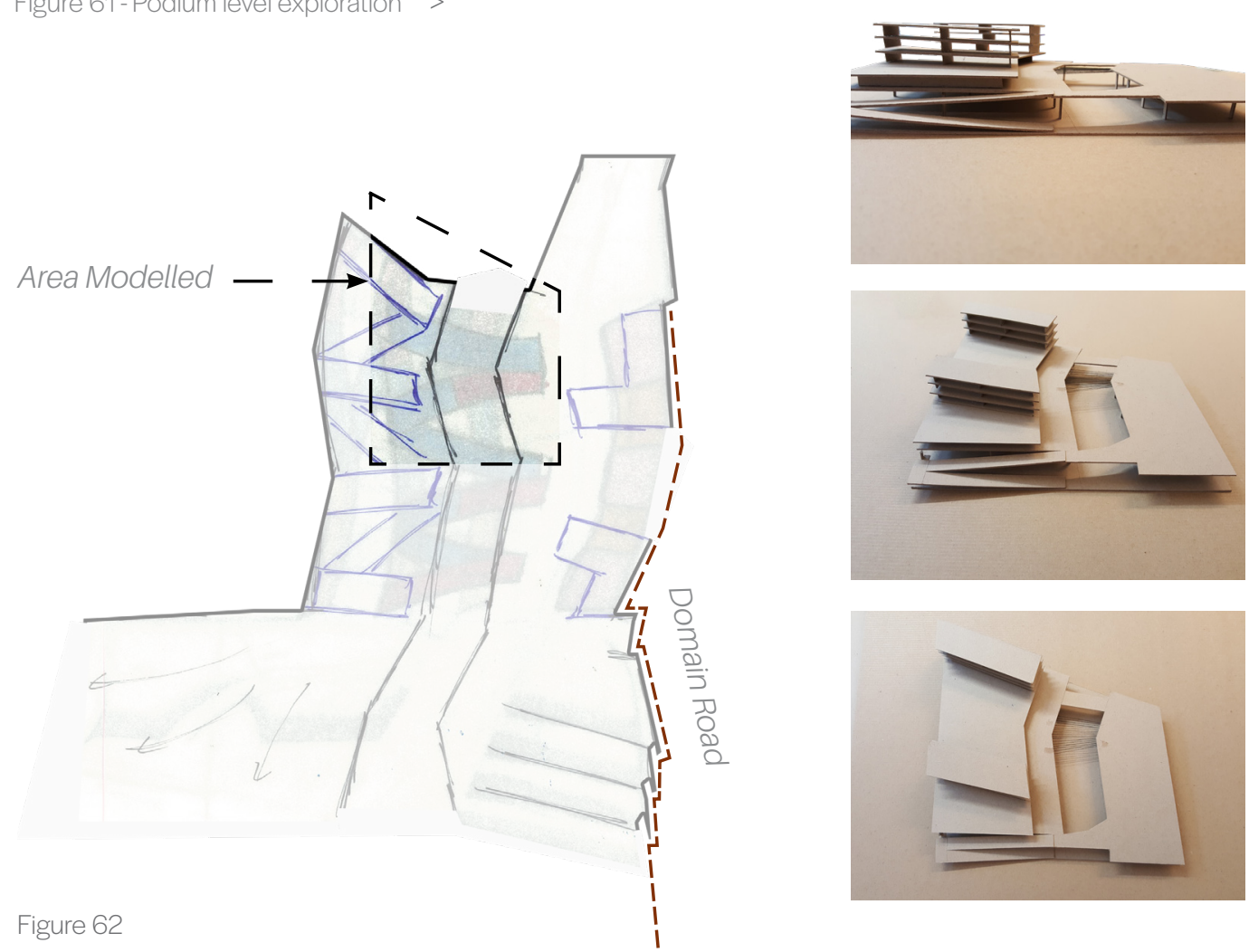

Physical exploration utilised to consider how connectivity between the ground and podium levels will work 


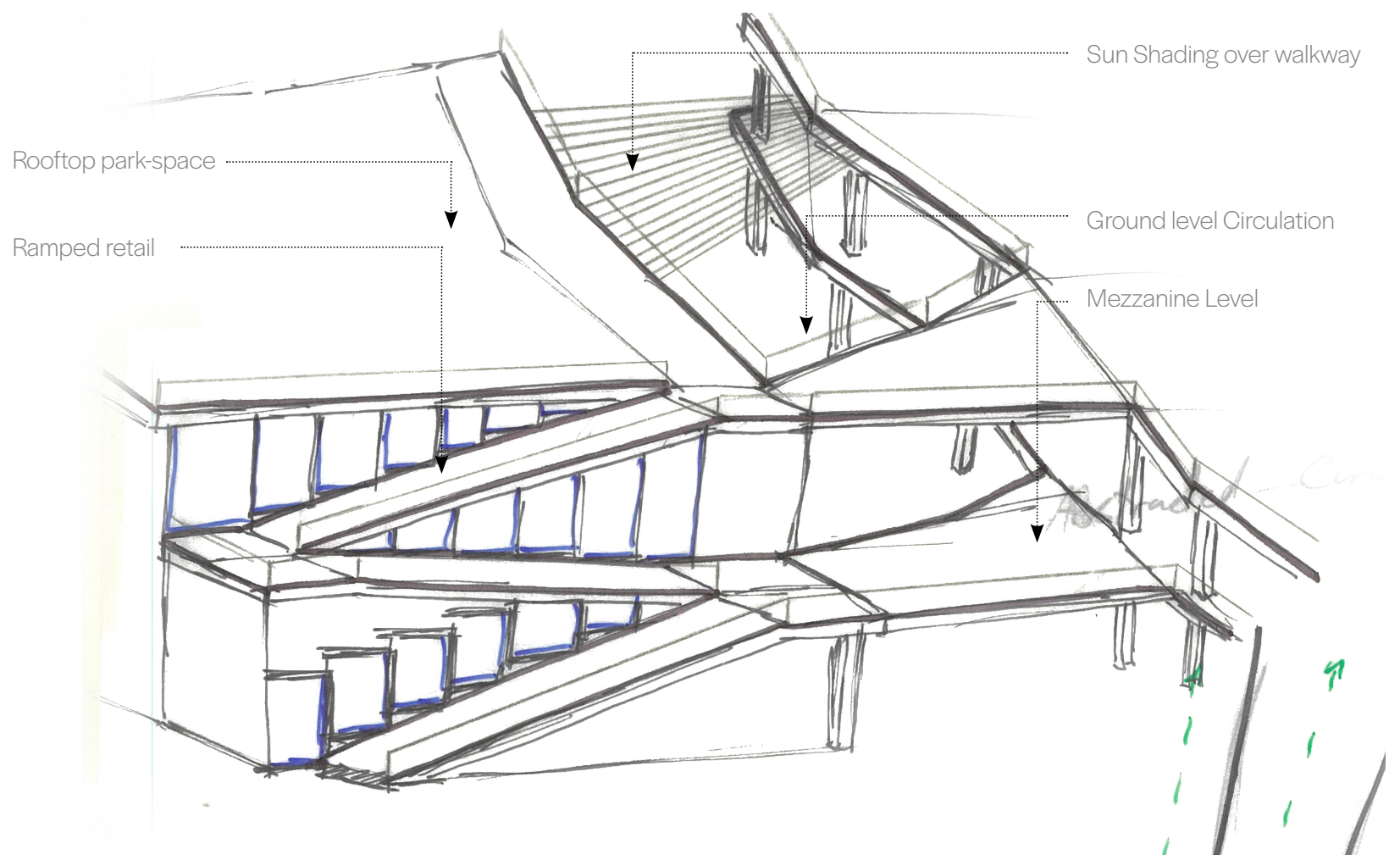

$\wedge$ Figure 63-Podium level circulation exploration

A revised site incorporating the raised podium of Phase 1 and incorporating a central axis that serves as the primary circulation on both levels. This seeks to improve connectivity between the two. 


\section{Critical Reflection}

Phase two began to integrate the Podium and Ground Levels and introduced a central axis to the site which informs the north-south circulation. This established a visual link between the Papamoa Hills and the coast alongside a new pedestrian connection between the town centre and the beach.

This phase introduced more greenery and organised public spaces as well as beginning to explore the issues of vertical circulation.

Issues with the Podium concept remain, however. These primarily evolve from the visual barriers created at ground level and safety concerns associated with enclosed and semi-enclosed public spaces required to remain accessible day and night. This has a detrimental effect on vibrancy within the centre and reduces the usability and vitality of the space due to accessibility and security.

There are also issues with how the undercroft space would be used. The original concept was for enclosed shopping, a transport hub and car parking, however a re-evaluation of the site's transport has suggested a stronger move toward public transit, reducing space requirements.

Moving forward, better integration between the levels is required and greater utilisation of the lower concourse which in turn will forge better connections between the Podium Level and the surrounding suburbs. 



\section{Design Phase 3}

'A Multi-levelled Society'

'A Multi-levelled Society' focuses on the transport elements of the site and develops a means for the different modes to work harmoniously.

This phase focuses on the integration of a multimodal transit system within the site. Previous works have identified regional light rail and local buses as the most suitable modes for the site.

Phase three will look at ways in which the scheme developed can accommodate these systems whilst targeting the issues identified in the previous two phases. 


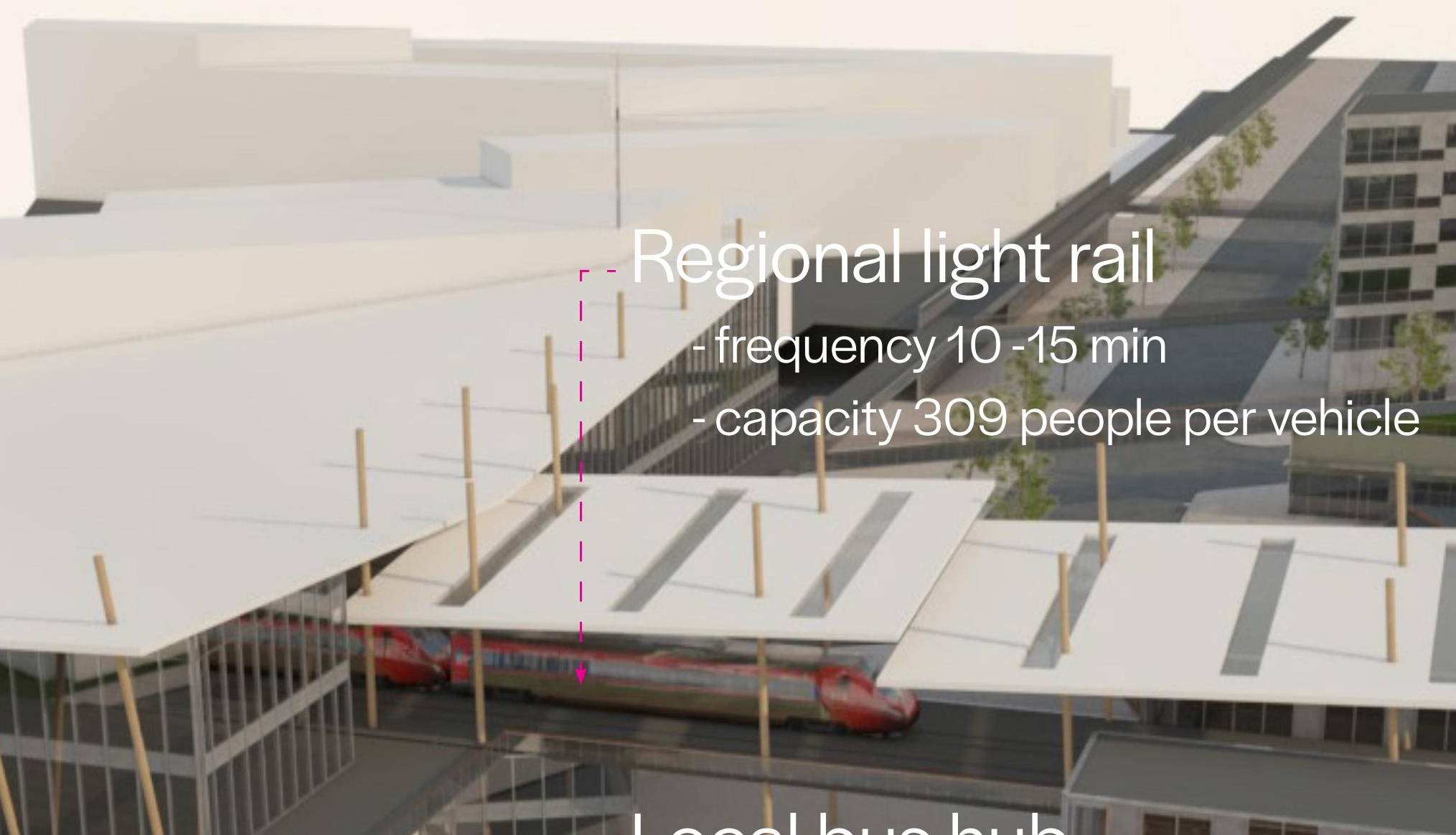
1111

\section{Local bus hub}




\section{Divide and Conquer}

Phase three was approached in two stages. The first looked to resolve the issues identified in phases one and two. The second began to implement the transportation element of the scheme.

This began by reconsidering the role of the Podium. The original concept looked to spread the functions across both levels with the predominant public spaces located on the Podium and functions such as carparking and the mall relegated to the ground level underneath. However, this contributed to range of issues, predominately a disconnect between the two levels. Initially this was hoped to be resolved by situating anchor destinations on the Podium level to draw people up, however, after reflecting on the research objectives, it became clear that this was not a satisfactory solution. This was further compounded by a reduction in parking and a need to make the undercroft space more inhabitable. The proposed space lacked access to natural light and it remained dubious as to how this area will function as a public space especially during the night.

In order to resolve this a reassessment of the proposed scheme was carried out. This looked to remove the Podium level to the east of the boulevard by creating a new ground level plaza area. The Podium area to the west is maintained and the mall and carpark facilities are located underneath this. This facilitates direct ground-level integration to the Domain Road side of the site, and to the southern green link, with additional connectivity maintained by the central boulevard which still serves as the main axis of the site. 


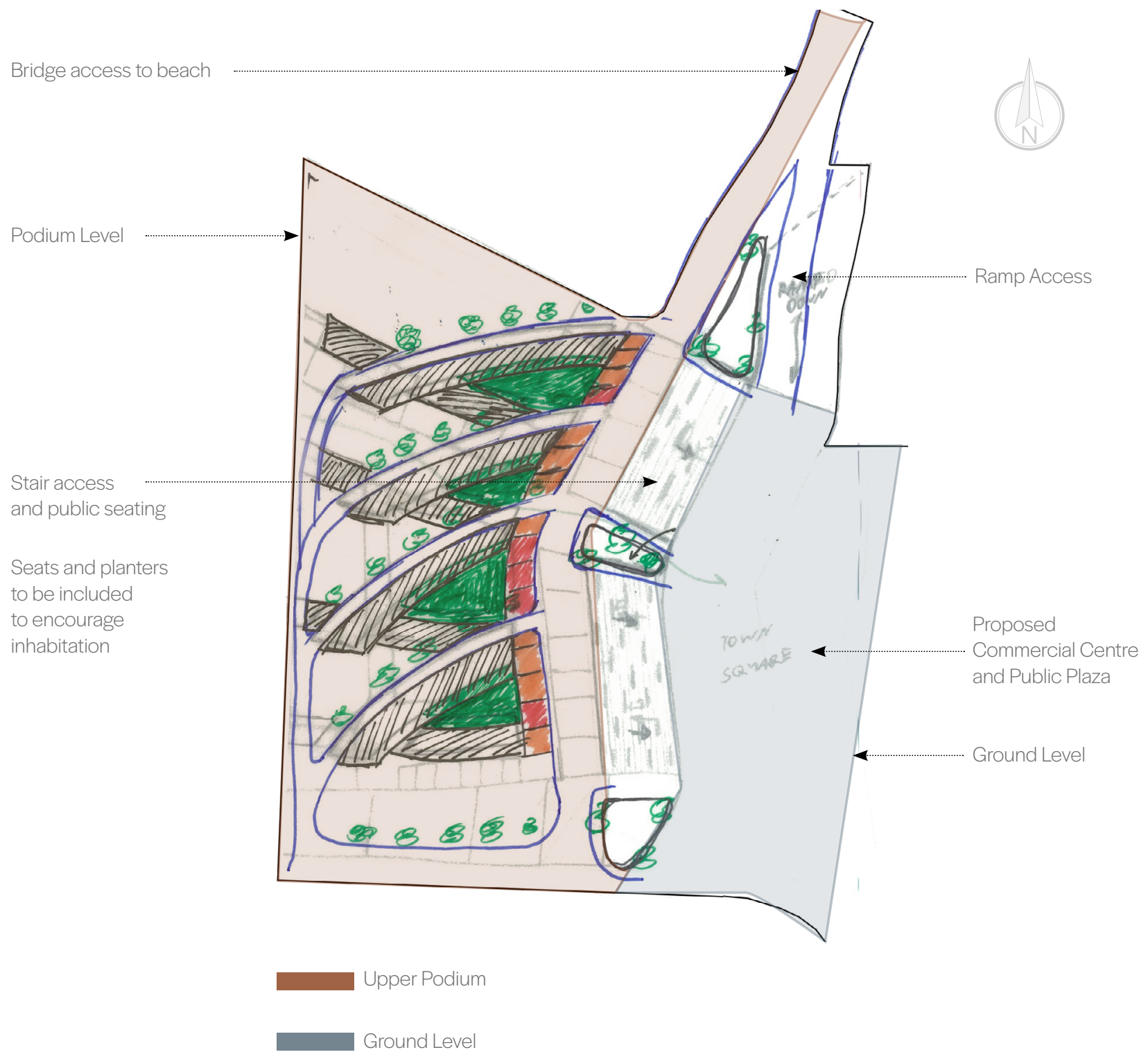

$\wedge$ Figure 66

A revised site revisiting the raised podium concept of Phase 1 and introducing a central axis that serves as the primary circulation on both levels and improves connectivity between the two. 


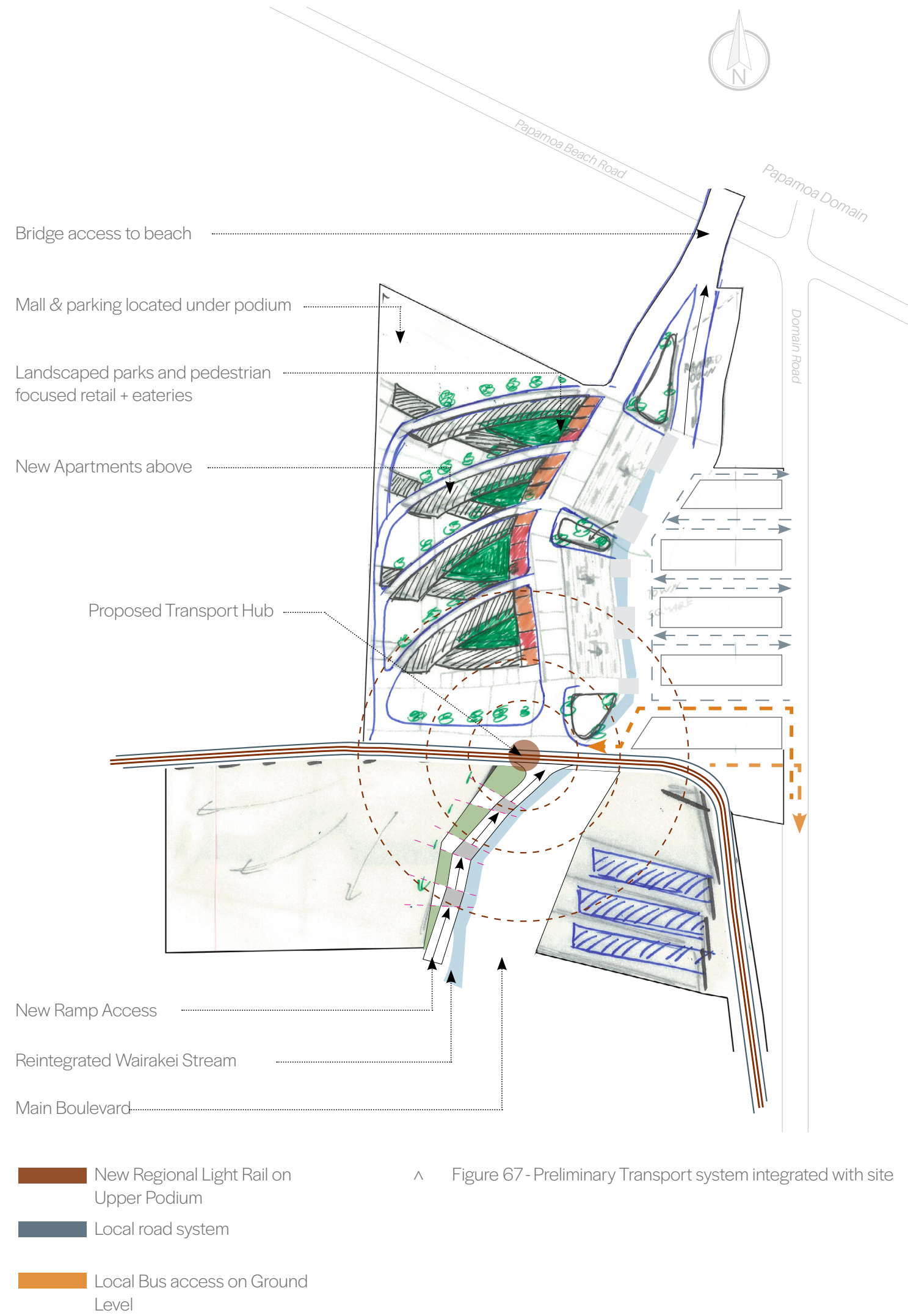




\section{Transport}

The second stage focused on the implementation of a multimodal transit system. Previous investigations have identified regional light rail and local bus as the preferred anchor systems however integration of other modes is essential to the success of this scheme. Consideration was taken into the separation of modes and it was concluded that the light rail link would be placed on the Podium level in order to free the pedestrian boulevard below. This acts as an anchor for the Podium providing a constant flow of people across the upper level and is a catalyst for increased activity. Below this the local bus hub will integrate into the same facility allowing direct connections for those transferring and easy access for locals.

Facilities for ride sharing, taxi, bike and scooter hire will also be developed at this location. This is supplemented by a pedestrian prioritised local roading system, which will provide access into the centre off Domain road for the few who do want to use their cars, as well as service and freight vehicles.

A new bridge running the length of the site adjacent to the boulevard provides grade separated access across Papamoa Beach Road to the beach connecting at the Domain. Links between the ground level and Podium are then facilitated along its length by a series of new ramps and stairways that double as seating and congregation spaces, encouraging inhabitation by users.

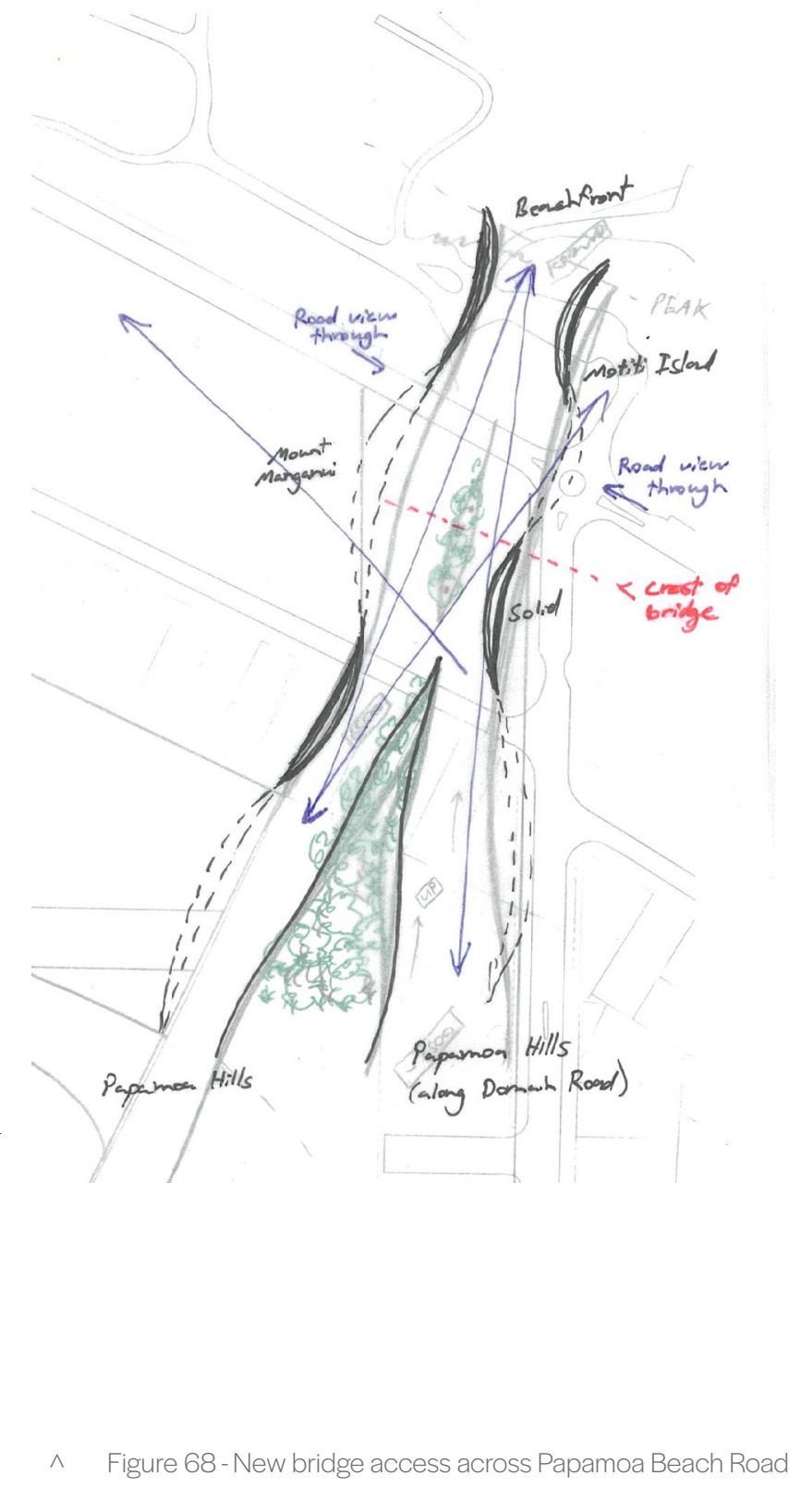



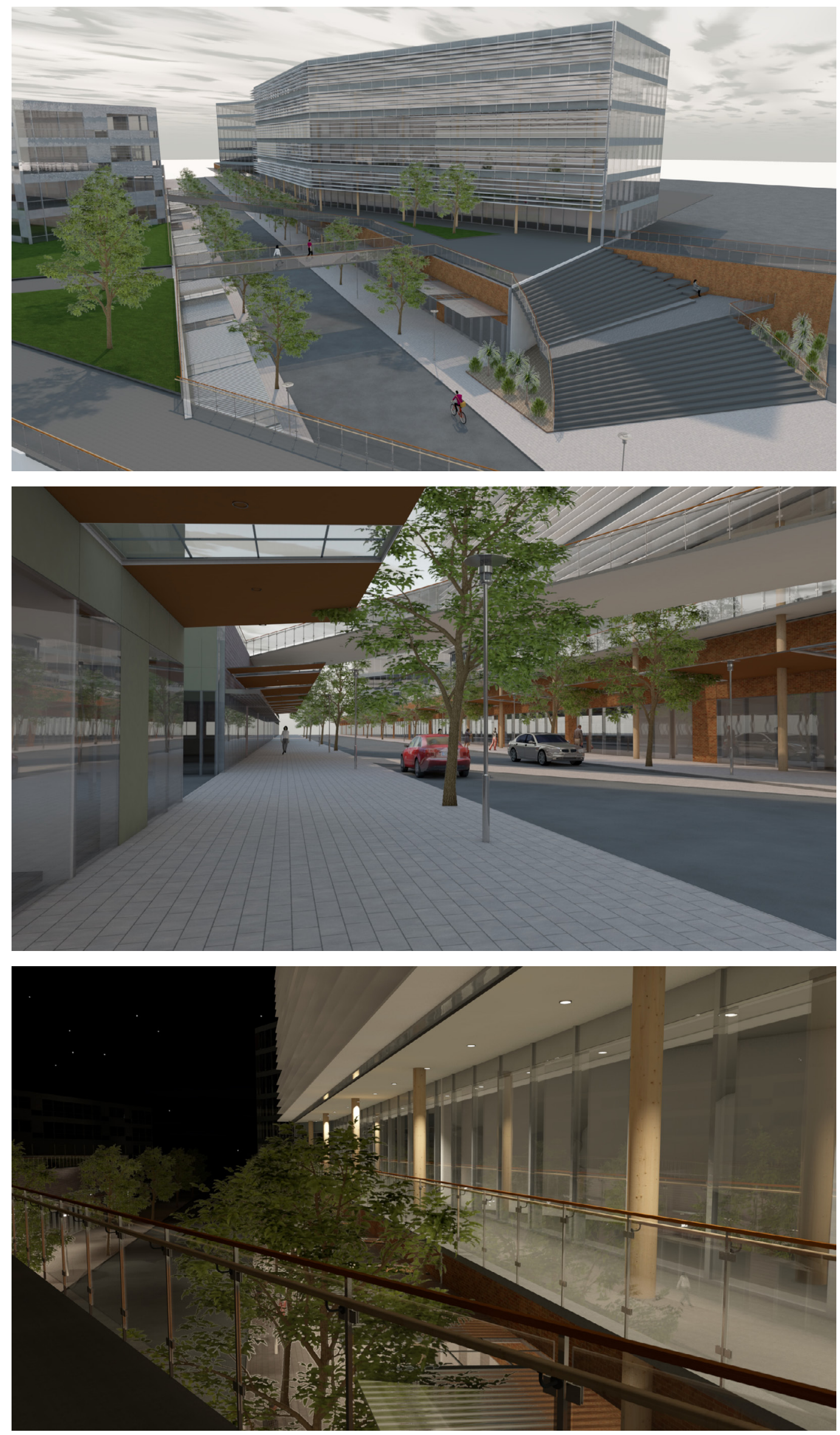


\section{Critical Reflection}

Phase three provided a good basis for the integration of transport infrastructure across the site and highlighted the advantages of grade separation. This exploration also began to resolve some of the issues highlighted previously and activated the lower concourse through increased circulation and new links between the Ground and Podium Levels.

However, several issues remained. These were primarily due to the placement of the transport hub which required several road crossings of the pedestrianised boulevard, including the main bus access. This created conflict points between the free moving pedestrianised areas and vehicle movements, limiting free flowing movement on-site.

With regards to the master planning there needs to be more of a focus on the human experience and identifying how users of the city will experience the different spaces and journeys created. 
Following feedback from reviews this chapter shifts scale, pursuing a need to understand and better design for the human experience of the city.

The feedback identified a lack of connection to the human scale and how the user will experience the spaces that are being designed. This has led me to break the masterplan down into a series of smaller projects. These were developed concurrently to allow a consistent design flow whilst also providing the necessary depth that had previously been missing from my studies.

Master planning began initially through the establishment of principles and theories that aligned with the research objectives. This combines the key learnings of the previous design phases and aligns them more thoroughly with theoretical and international precedents in order to develop key features of the scheme. 



\section{Pedestrian Oriented Environments}

People will generally look to live close to where they work because it is convenient, but these decisions can be swayed by the type of housing available, price, amenities and infrastructure and character of place.

By taking focus away from the car and creating flexible civic spaces whilst increasing density, amenity and shared spaces can be created, calming traffic and giving the street back to the pedestrian.

However, the limitations of walking must also be considered. Walking, especially for elderly populations and parents with small children, can be physically demanding and the issue of access and acceptable distance must be addressed if walking is to be the primary means of moving around the centre. This is discussed in Jan Gehl's "Life between buildings" in which a limit of 400-500 meters is suggested as the longest distance an average person will comfortably walk (Gehl, 2011).

\section{"Life takes place on foot"}

(Gehl, 2011, p. 72)
This can be mitigated partly by the perception of the journey. If the full length of the path is to be 500 meters in a straight line this can be viewed as long and arduous, however Gehl suggests that if it is broken up into a series of smaller journeys it will be perceived as a much shorter and more enjoyable experience (Gehl, 2011). This can be further improved through interplay between the path and the quality of the journey, enhanced by soft edges and other measures. These include a $500 \mathrm{~m}$ maximum distance from the central plaza to anywhere else on the site and a walkable $200 \mathrm{~m}$ diameter central district which will house the Transport Hub, the Mall and the Civic Precinct. 


\section{Walkability}

The principle of walkability is an interesting issue. Andres Sevtsuk, Assistant Professor of Urban Planning at the Harvard Graduate School of Design, makes the observation that walkability does not necessarily come only from the street grid but can also arise from conscious planning of pedestrianoriented destinations or public transit serving the urban core, which is in keeping with the objectives of this research (Harvard Gazette, 2017).

Paul Stangl notes the benefits "A well connected street network provides a range of benefits to the public. Connectivity is related to pedestrian activity levels, as environments with greater connectivity provide more direct routes and therefore shorter distances to destinations". He notes that Manhattan is one of the most walkable environments in the world due to the phenomenal amount of destinations in a relatively small walking radius (Stangl, 2015).

This is a principle replicated most commonly in the layout of the mall which is designed to stimulate the user. People may spend several hours walking, but they travel a much shorter perceived distance as they are that much more engaged in their environments. This suggests that people are willing to walk if the environment is conducive, highlighting the need not only for destinations at each end of the route, but stimulation along the journey, which is particularly important when designing public spaces such as parks and squares.

Figure 71b-Acknowledgements

Architects: LEA Invent

Location: Fatih Vatan Street, Istanbul, Turkey Design Team: LEA Invent (Emir Drahsan, Alexandre Schrepfer, Lorenzo Sangiorgi) \& Burcak Pekin architect Client: Istanbul City Structure: Grohmann \& Bollinger Collaborators: Erkan Goray, Ugur Seymen (Yapi Akademisi), Charlotte Cote

Materials: Steel structure, green facade, wood Images: Courtesy of LEA Invent
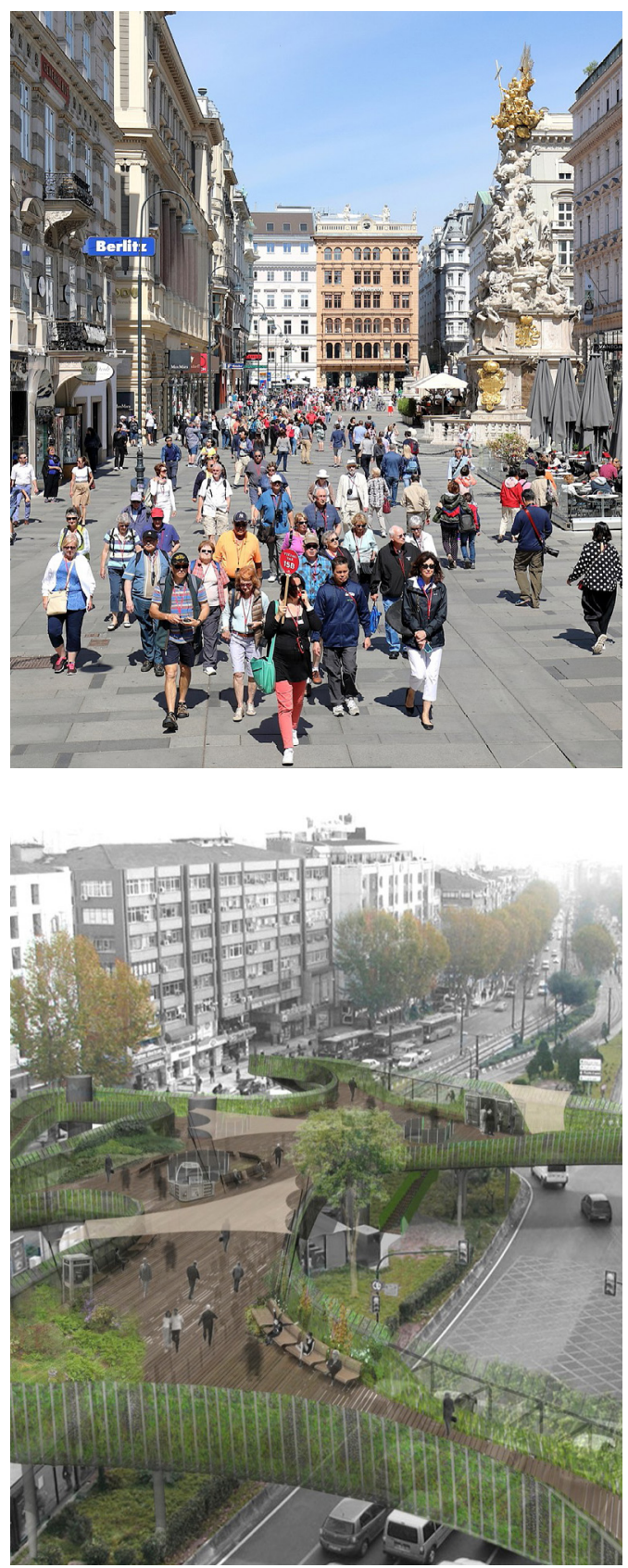

$\wedge$ Figure 71a - Vienna's first pedestrian zone on the Graben. by Bwag. 2018. retrieved from https://commons. wikimedia.org/w/index.php?curid=69437375. Copyright creative commons share alike 4.0 International.

^ Figure 71b - Footbridge project in Istanbul (Starfish). kindly provided by LEA Invent \& Burcak Pekin. 2011. retrieved from https://tinyurl.com/y6lsd23c. Copyright by Alexandre Schrepfer Architects. 
The block forms an important aspect of the journey and defines the walking radius. The nature of walking as a form of physical exercise naturally causes pedestrians to be conscious of the distance that they are travelling. As a result, people tend to prefer direct routes and shortcuts and will generally avoid large detours or level changes (Gehl, 2011).

This suggests that larger arterial pathways are the solution, however a side effect of these are people are less likely to engage with their environments compared to more roundabout routes. A compromise needs to be found between engagement of the user and efficient route planning.

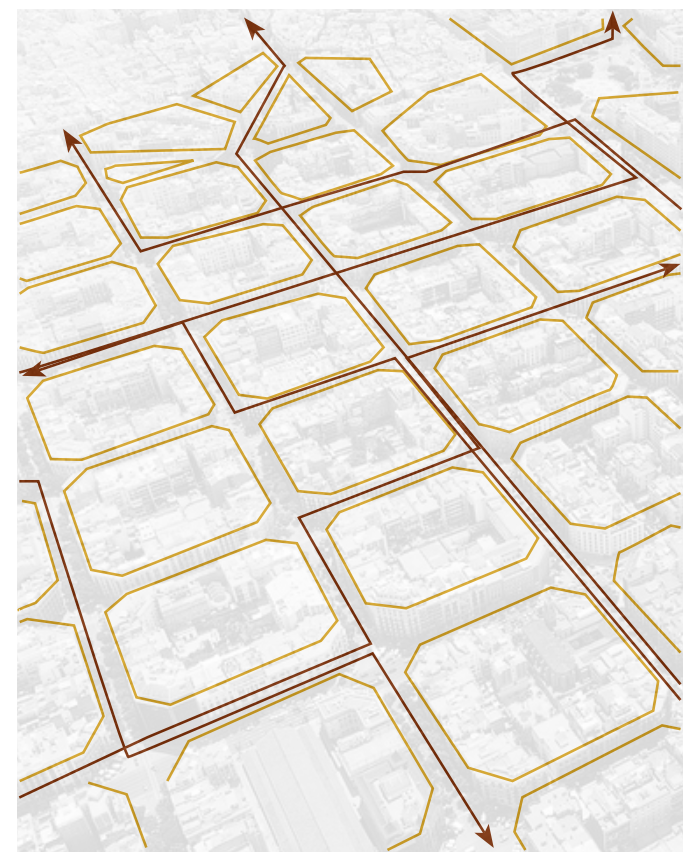

^ Figure 72-Barcelona City Blocks
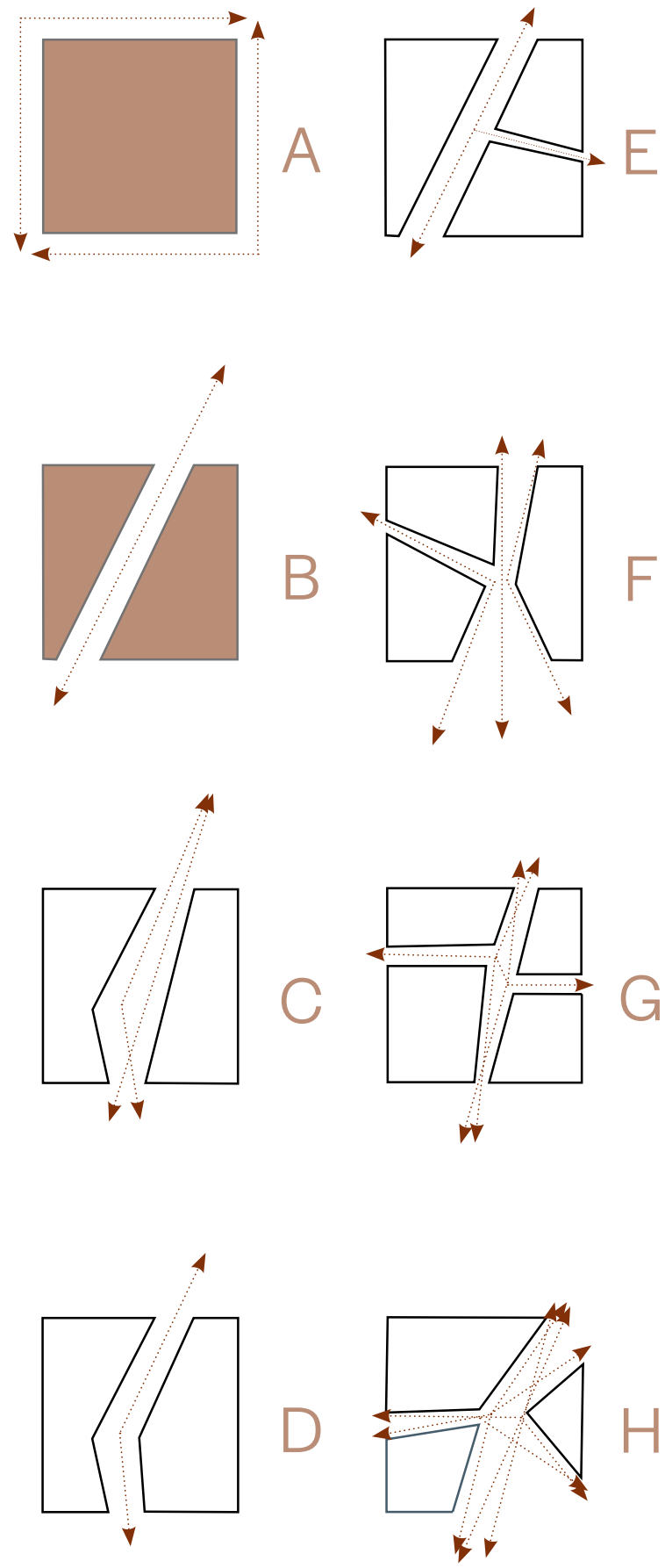

$\wedge$ Figure 73

The above modules explore means by which the standard block module of the city grid could be broken or modified 


\section{Block Size}

Conventional wisdom suggests that smaller block sizes allow for better connectivity. This has been repeatedly backed by urban theorists such as Jane Jacobs and Leon Krier who have both advocated smaller block sizes noting the increase of interaction and encounters experienced by pedestrians using smaller grids (Harvard Gazette, 2017).

However, a balance that must be struck between size and walkability. Sevtsuk notes the non-linear relationship of the block. This relates to blocks remaining walkable whilst not unnecessarily impeding the pedestrian through additional road crossings. Sevtsuk uses the examples of Adelaide, Australia whose blocks would become significantly more pedestrian friendly if they were half their current size, and Portland, Oregon, which currently has a relatively small block size that would benefit by doubling the current length (Harvard Gazette, 2017).
A compromise of this is to consider the street and pedestrian grids as separate elements. Currently vehicular and pedestrian movements tend to follow the same routes, however this is generally not the most efficient for either mode. By introducing a network of smaller access ways, such as laneways that overlay the larger road network, with a smaller more intricate and intimate network of pedestrian orientated access ways, each system can then be optimised and sized accordingly.

\section{Block Measurement}

This brings us to the issue of measuring block size. Standard techniques utilise methods such as perimeter or area to calculate the level of obstruction and influence that a block can have on the urban reality. However, when put into practice, these techniques can produce misleading results.

Stangl employs the research of Jacobs and others to formulate a new system of measurement for street connectivity. This revised assessment moves away from perimeter and square meter assessment processes, instead using a diagonal corner to corner measurement which recognises the maximum obstruction presented by a block in any direction (Jacobs, 1993), (Stangl, 2015).

This was employed as a means of informing and justifying block sizing and access patterns across the scheme. 
Perimeter Method
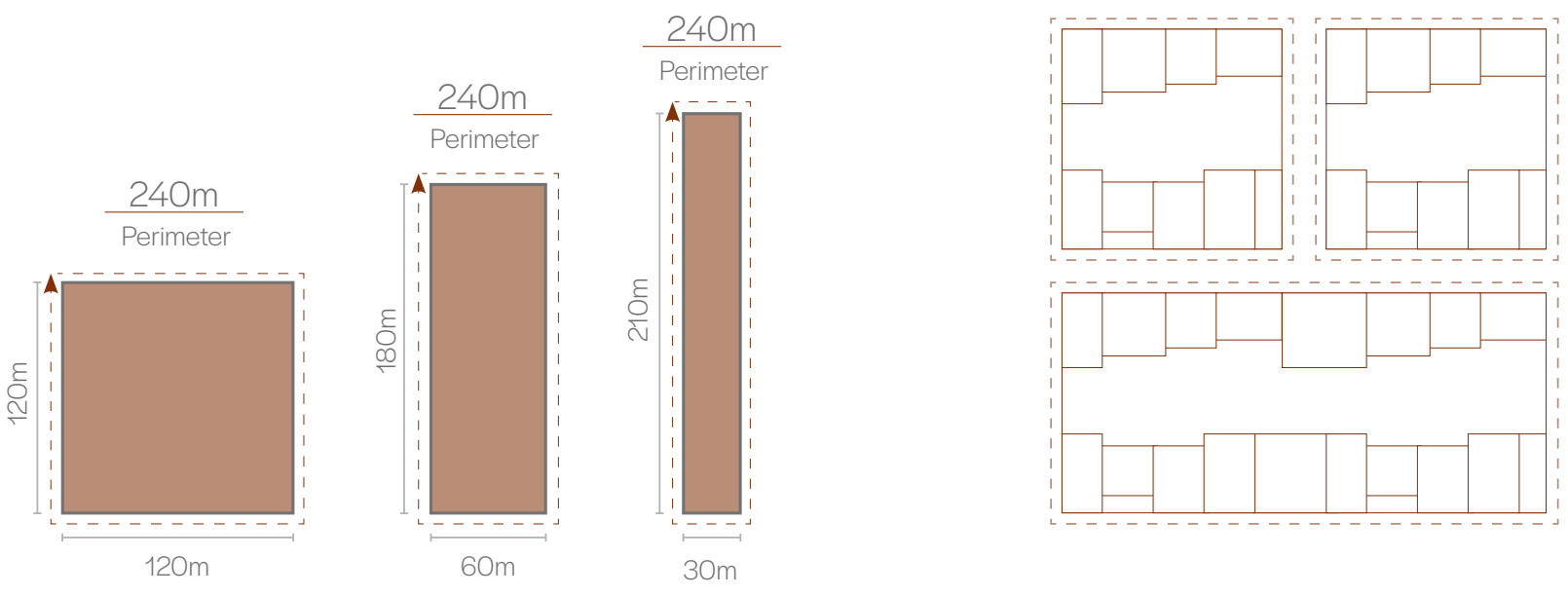

Total Area
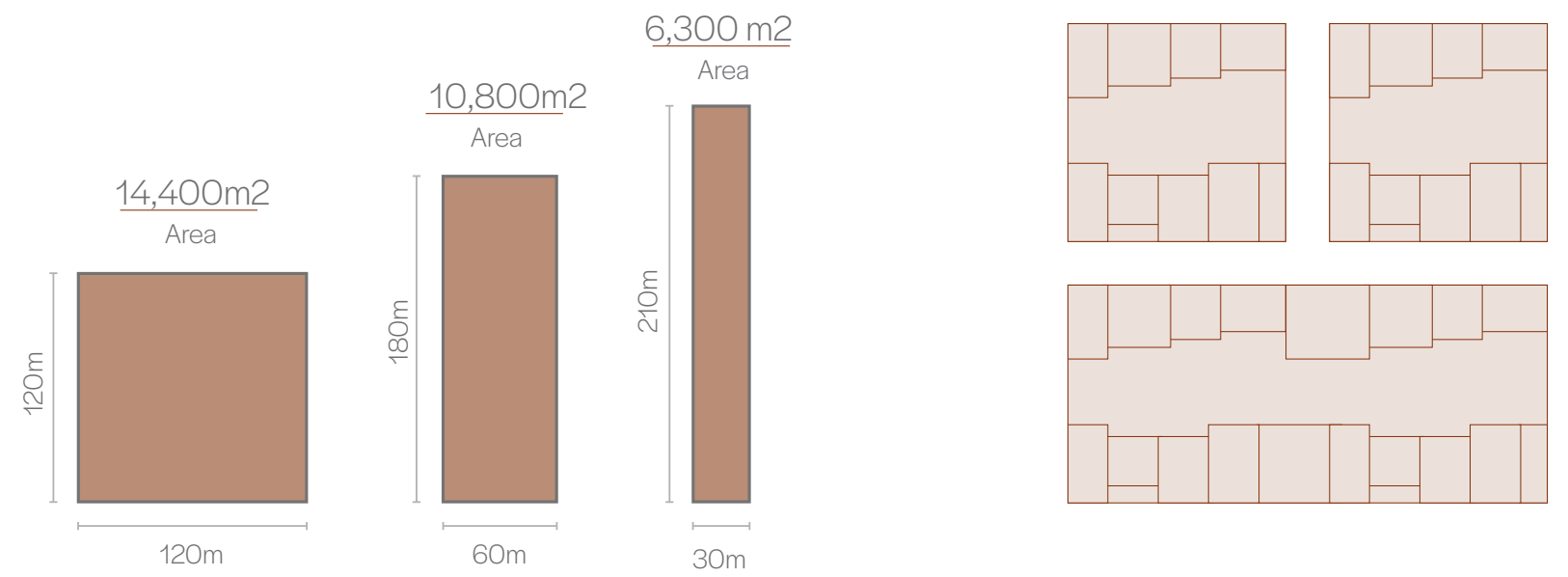

Block Section
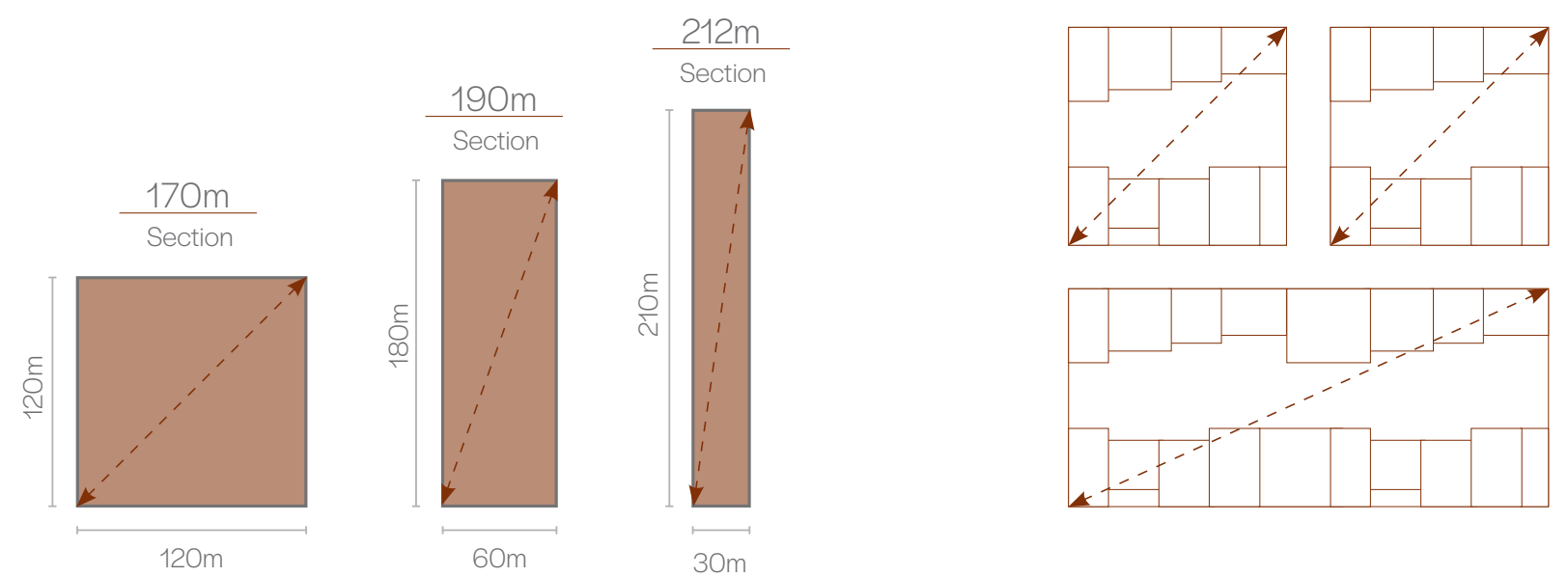


\section{Overlaying Connectivity}

This exercise explored the idea of breaking up the block, taking the geometry of gridded systems and cutting pathways through to encourage different interactions and experiences. This used Kevin Lynch's theory of journey through place and focused on creating identity through interaction rather than relying on the same repetitive and alienating structure of the grid. The goal of this was to identify different ways that connectivity could be introduced into the urban plane and how different modes of travel could be incorporated in both overlapping and separated circumstance.

This utilises Stangl's measurement method to maximise connectivity and identify the impact of varying block configurations. In this exercise the primary block is informed by roads, avenues and vehicular transport links which are situated using a standard grid. This is overlaid by a smaller secondary network of pedestrianised laneways which shrink the blocks, providing a network of alternative pathways and links across the block, increasing connectivity, and strengthening the overall street network. 

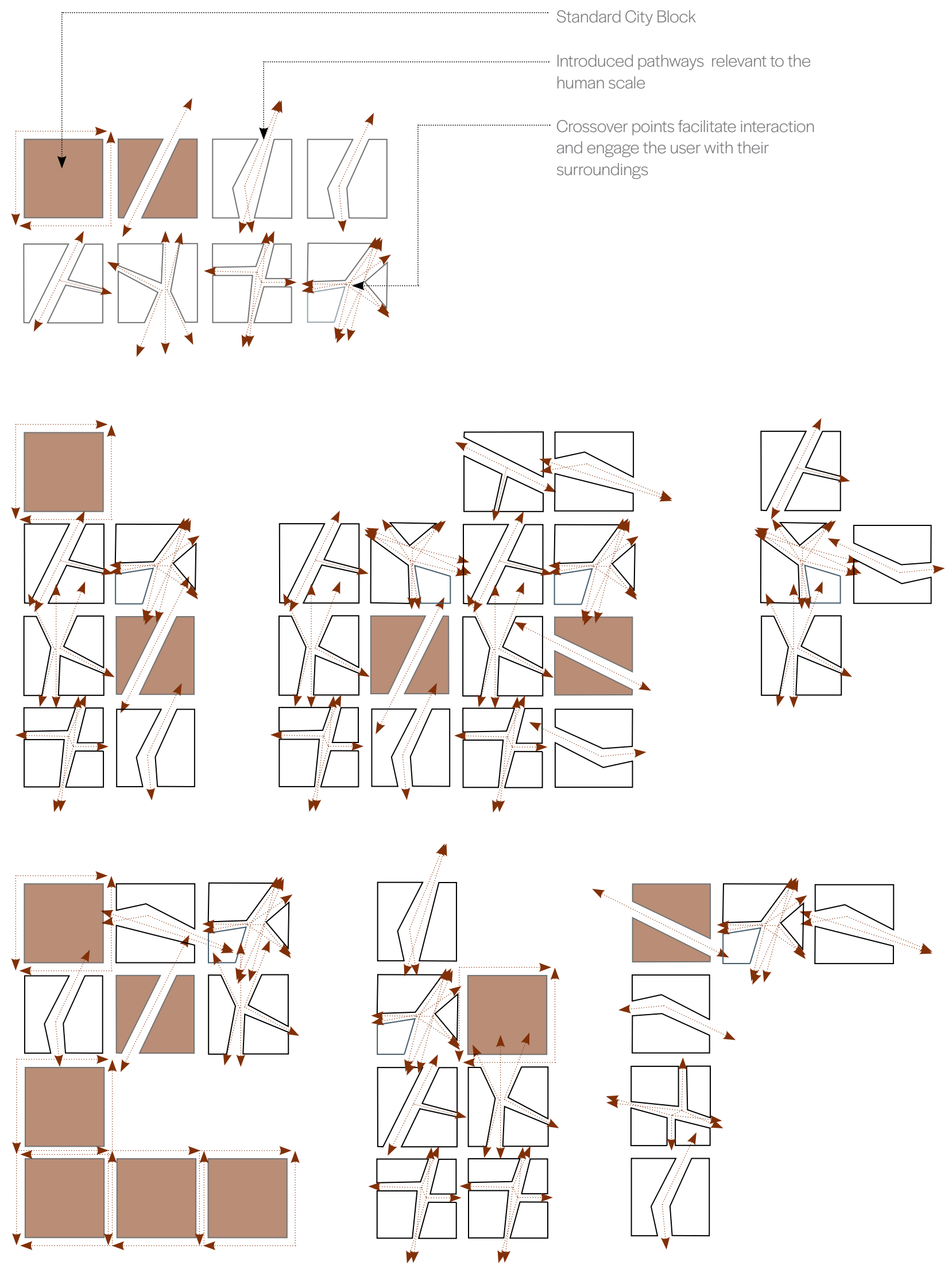
An Integrated Response

This exercise looked at the intertwining of functions and ways of establishing an integrated living response to the needs of Papamoa. This used a module-based system and was explored through physical massing to test design ideas and evaluate how various schemes would function.

The housing modules were developed using average house sizes from the Auckland City Council Housing Guide ("Apartment space - Auckland Design Manual," n.d.).

20 metres

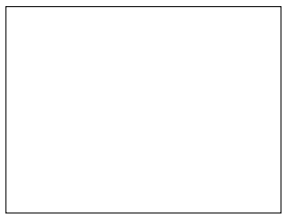

Block A -

Retail/Commercial
15 metres

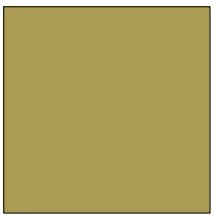

Block B -

Retail/Commercial

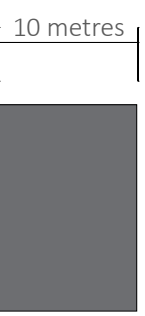

Block C -

Townhousing

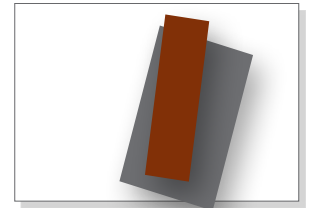



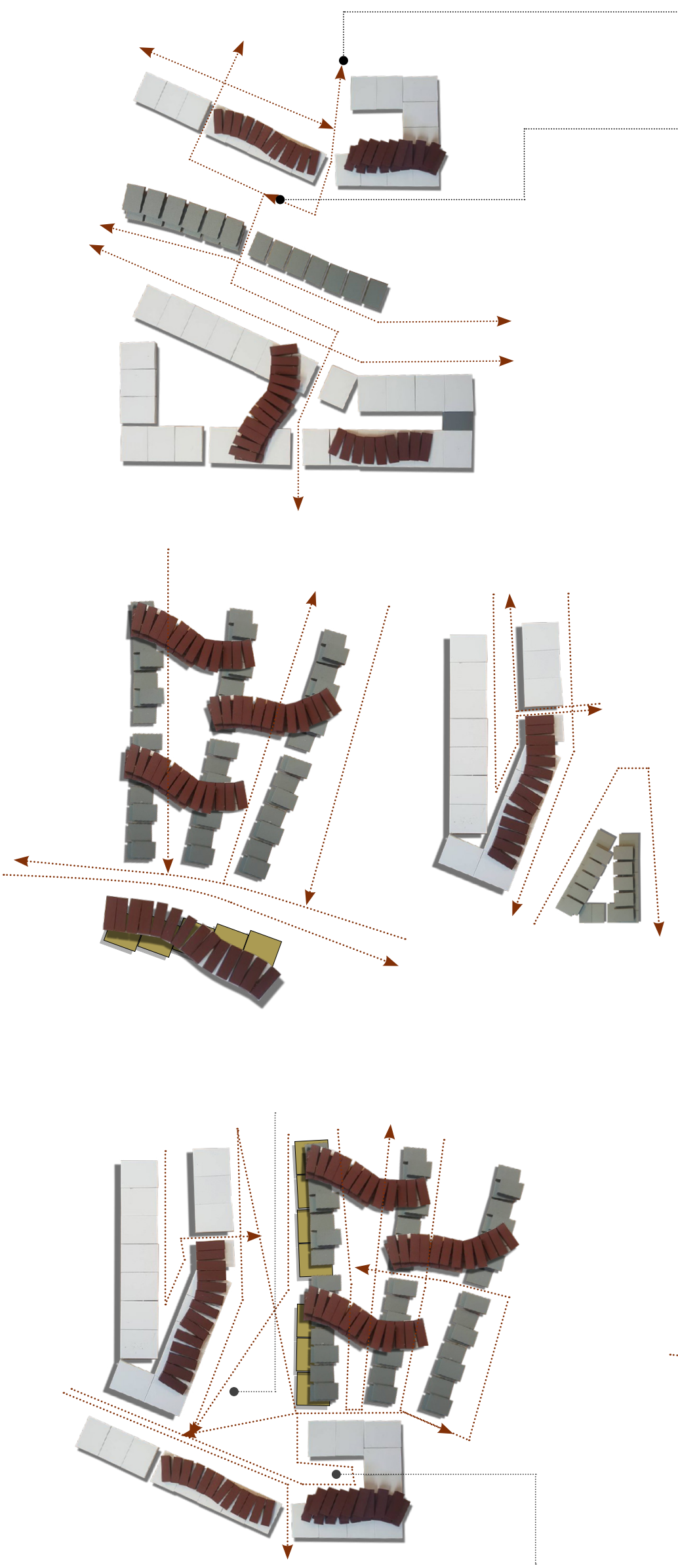

Dead spaces to be avoided
Introduced pathways relevant to the human scale

Crossover points facilitate interaction and engage the user with their surroundings
Mid-block Spaces to be activated through laneways

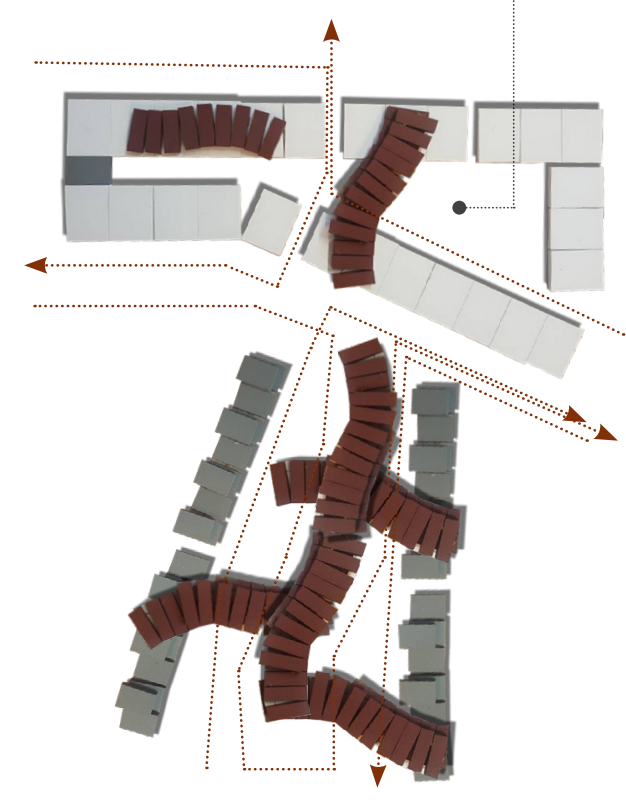

Areas of increasing intersection provide opportunities for public space

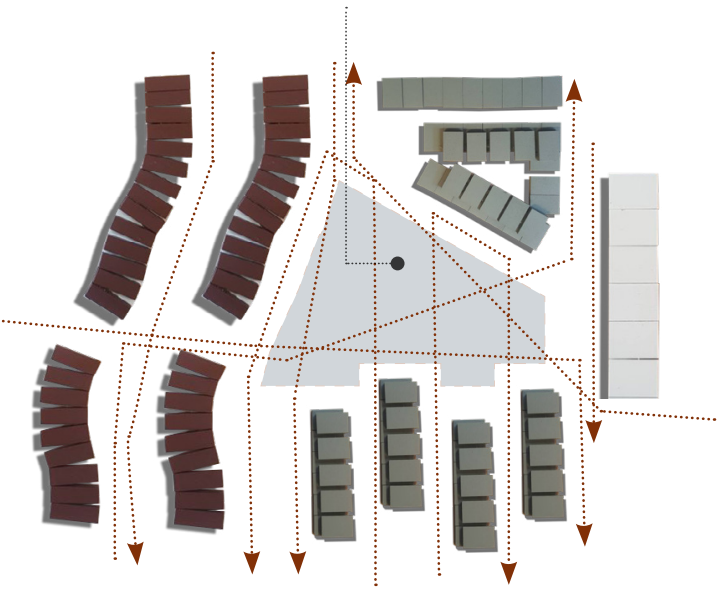




\section{Case Study - Tonsley Innovation District}

Adelaide

Formed out of a disused Mitsubishi factory, Tonsley is a new suburb and innovation precinct being developed in Adelaide, Australia. This development integrates industry, start-ups, education and residential precincts to form a cohesive urban hub (Landezine, 2018).

This is Australia's first 'innovation district' and seeks provide a supporting case for green infrastructure within future planning of our urban centres. The project moves away from the idea of a rigid masterplan and towards an aptly named "development palette", allowing the development to grow organically over time (Landezine, 2018).

The public realm has been a key part of the scheme, facilitating connections between the different urban functions. This emphasis on the importance of public space has been rewarded through establishment of industry partnerships helping to attract business, education providers and students to the district. As a result, resident populations have increased, instilling vibrancy through inhabitation.

The heart of this development is the Town Square, a space designed for people. It features cafés, retail and a full range of services and facilities capable of meeting the demands of the resident population. This area is designed with the same focus on the public realm, incorporating communal facilities such as urban forests, parks, and breakout spaces within the heart of the scheme. By providing spaces for people to interact, gather and inhabit, the Town Square is invigorated with activity.
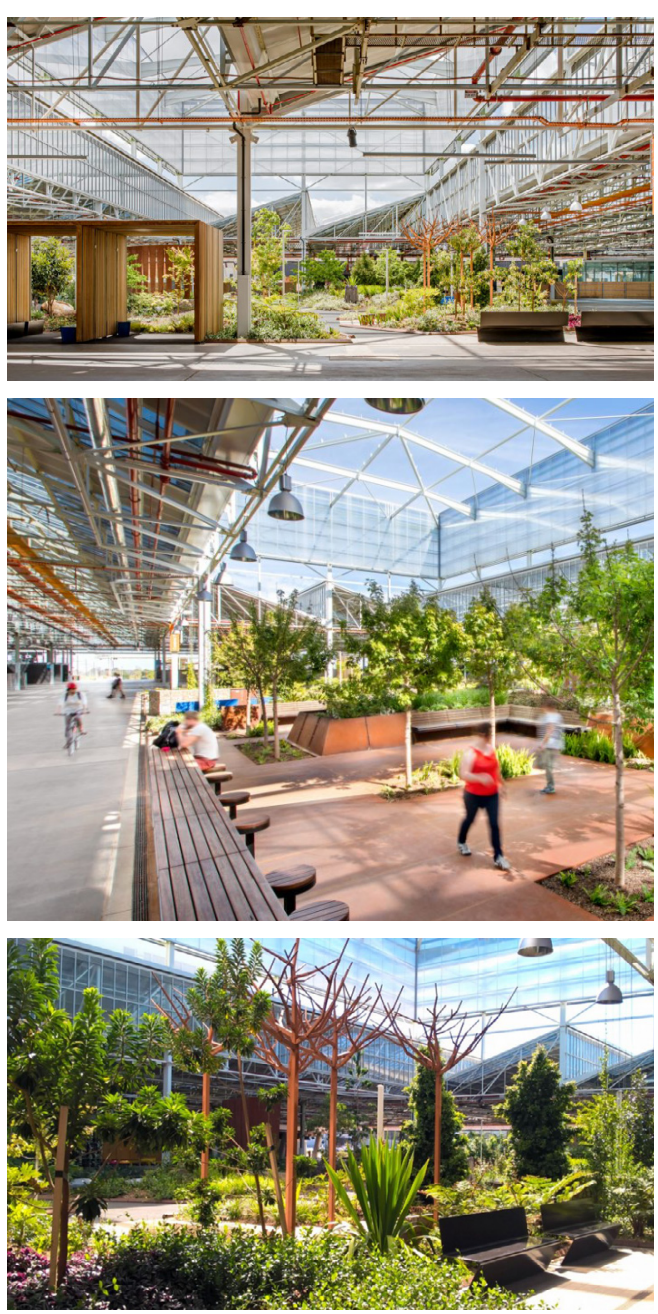

Figure 78 - Tonsley heart. by the Government of South Australia. n.d. retrieved from https://tonsley.com.au/news/ update-tonsley-innovation-district/. Copyright Tonsley 2019.

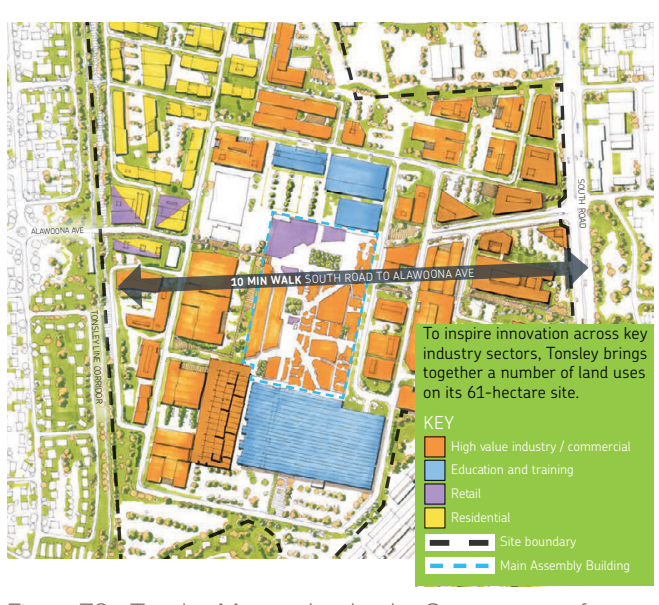

Figure 79 - Tonsley Masterplan. by the Government of South Australia. n.d. retrieved from https://tinyurl.com/ y4nysec3. Copyright Tonsley 2019. 
While considering the grid layout and block size it was important to consider the stakeholders and destinations of the proposed centre. The Tauranga region is growing rapidly, resulting in significant interest from a range of different sources. The first, and most important, are of those of the residents. Next is the Tauranga City Council which has a vested interest in how the area grows and develops for the good of the region, and then there are organisations such as Universities and businesses. Two examples of this are Waikato University, which is opening a new campus in central Tauranga, and the Te Puke Economic Development Group have begun to move forward with the new Rangiuru Business Park near Te Puke (Cousins, 2017), (Hunter, 2018a).

In 2018 Tauranga processed over half a billion dollars' worth of commercial building consents, which is expected to rise, indicating a high confidence from developers and businesses within the region (Hall, 2018). Considering case studies such as Tonsley, it is important to look at how this investment could impact and shape the city.

While space syntax is an excellent tool for identifying potential connectivity within urban spaces, it is still the responsibility of the designer to ensure that the spaces and places created utilise this effectively.
For a scheme to work, places need to be desirable, and there need to be clear distinctions between different types of spaces. An example of this is the usage of streets and laneways where people will interact briefly to enter, look and then exit a shop or stall, as opposed to public spaces such as squares and parks which will actively engage the user to encourage inhabitation and vibrancy in order to function. The connectivity potential needs to be aligned with a range of destinations within the urban realm.

Gehl identifies that if activities and people are assembled it is possible for events to stimulate and reinforce one another rather than acting in isolation (Gehl, 2011). This presents an opportunity for the connectivity identified through space syntax to be aligned with strategic destinations, building vibrancy into the fabric of the city.

This research employs the principles of assemblage in order to develop an integrated response to Papamoa's growth issues. This will be done by introducing clear congregation and flow points throughout the street grid, creating a blend of formal and informal spaces for the hosting of events, allowing them merge into one another. 
Grade separation of the different transportation modes is important. Not only does it allow each system to function independently of the other, it increases capacity, efficiency and the reliability of the wider system. It also reduces conflict with the pedestrian realm allowing better pedestrian-oriented facilities to be developed and each system to function unencumbered.

As discussed previously, successful transport systems must use different modes to function effectively. In this case rapid transit light rail will serve as the primary spine of the network, providing frequent transport in both directions up and down the coast and to the Tauranga CBD. This will be aided by a secondary system of local bus networks that will serve the areas around each of the primary nodes. Space will also be allocated for pedestrian, cycling and private car access. These will be facilitated by a fully integrated Transport Hub that will allow for ease of access and painless transfers between systems.

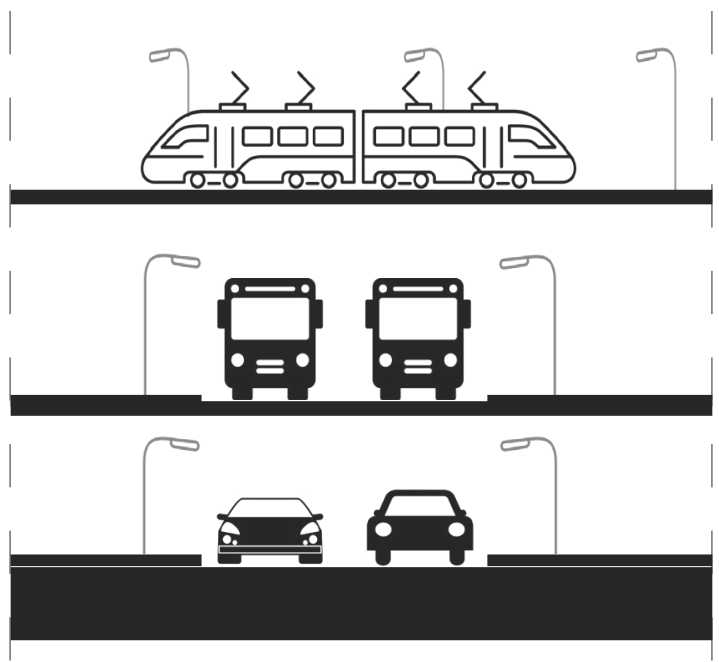

$\wedge \quad$ Figure 82 - Grade separated transport systems

\section{Multiple Modes}
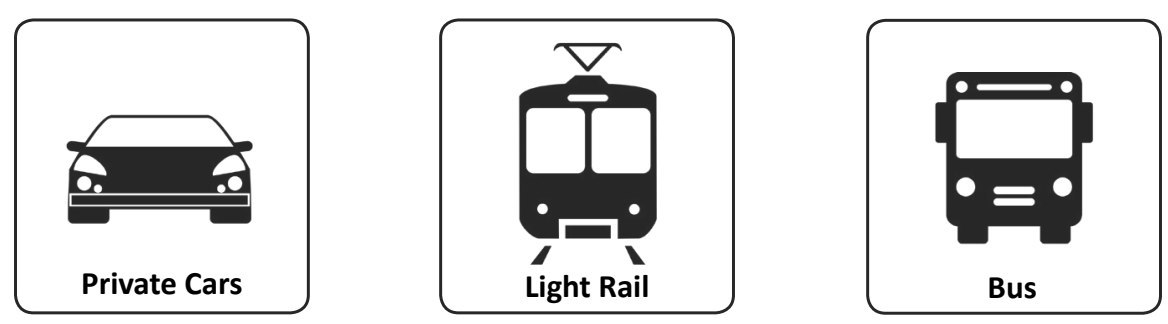


\section{Case Study - Salesforce Transit Hub}

San Francisco

The Salesforce Transit centre is a multimodal transit centre located in downtown San Francisco in the United States. Built as a replacement to the old Transbay Transit centre, this facility caters to 11 transit operators and an array of transport services including a gondola to the roof and a yet to be built train link as part of San Francisco's proposed downtown train extension (Pelli Clarke Pelli Architects, 2018).

When fully operational this transit hub will host city, regional and national connections all in one complex serving up to 45 million people per year (Metro, 2010).

A key element of the design is the 5.4 acre rooftop park complete with cafés, playgrounds and quiet areas separate from the hustle and bustle of the rest of the city. This is complimented by retail and restaurants on the ground level creating a destination that exceeds expectation (Pelli Clarke Pelli Architects, 2018).

This integration of public amenity through dining, retail and even public park spaces is particularly noteworthy as an example of how transport, public spaces and destination type facilities can be intertwined. Activity and vibrancy are woven throughout the design, which seamlessly integrates multiple modes of transportation into one facility, providing free and easy movement across all modes. Aspects of this will be brought forward in this research through a similar integration of grade separation and intermingling of urban functions.
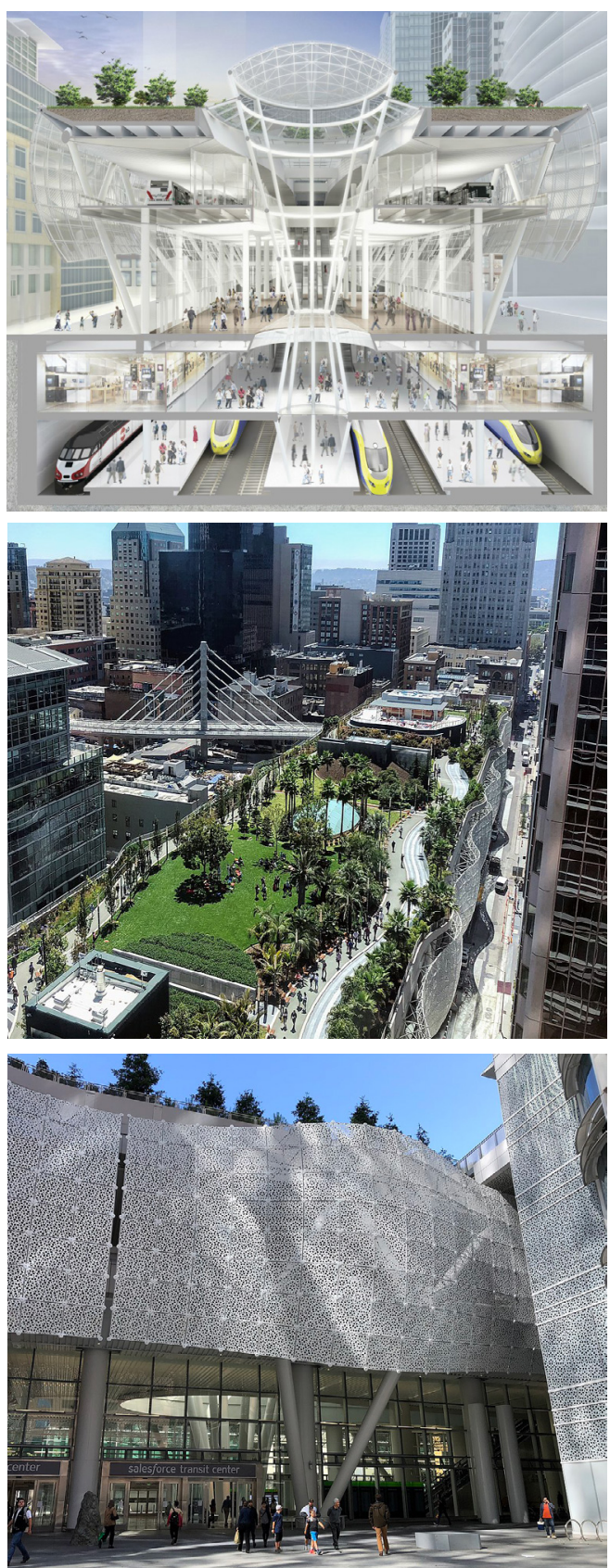

Figure 83 - Salesforce Transit Hub section. by WSP. n.d. retrieved from https://www.wsp.com/en-CA/projects/ transbay-transit-center. Copyright WSP 2019.

$\wedge \quad$ Figure 84 - Salesforce Transit Hub overview. by Fullmetal2887. 2018. retrieved from https://commons. wikimedia.org/w/index.php?curid=71705542. Copyright creative commons share alike 4.0 International.

Figure 85 - Salesforce Transit Hub entrance. by Fullmetal2887. 2018. retrieved from https://commons. wikimedia.org/w/index.php?curid=71708702. Copyright creative commons share alike 4.0 International. 


\section{An Abridged Network}

The wider Podium concept of the initial design phase is based on this concept of grade separation. This is not a new concept and has been present in cities since the early 20 th century.

An infamous example is the London Pedways system, which was esteemed as a solution to growing conflicts between the pedestrian and the motorcar in the 1950's and failed in spectacular fashion due to issues in design and uptake leading to its eventual removal from the London district plan.

However, elsewhere many of these systems have flourished. Minneapolis and St Paul's in North America have extensive skyway systems, and Montreal, Canada, has turned the concept into a well frequented subterranean pedestrian network (Yoos, 2016).

Hong Kong is regarded as one of the most successful cities to have adopted this form of three-dimensional urban planning (Yoos, 2016). The city has large threedimensional routes connecting transit hubs, offices, parks and homes, building a popular system that continues to expand.

The nature of activities is directly influenced by the quality of the outdoor spaces and how precisely optional recreational and social functions are accommodated (Gehl, 2011). Elevated pedestrian ways have often been considered a delamination of the urban environment causing spatial disconnects between levels. Accordingly, increased connectivity and improved urban design can provide resolution. Gehl suggested that activities taking place on the same level have an engagement radius up to 100 metres, however once extra levels are introduced this is reduced significantly (Gehl, 2011).

In order to overcome these issues an emphasis on integration has been engaged. This seeks to create a network of destinations across both levels serviced by a series of unique accesses across each individual level. In the case where parallel pathways are created, they will be linked in together as one unified accessway.

Past observation has also highlighted the organic nature of similar systems, where networks grow naturally as cities expand (Yoos, 2016). In the case of Papamoa this concept provides an alternative approach to increasing density, while providing the opportunity to integrate and link different urban functions within the city environment.

\section{Victoria on River}

A redevelopment of the Hamilton riverside by 'Edwards White Architects' has established a new precinct connecting the central city to the Waikato River. This intervention uses the vertical connection between the river and city to create a series of banked seating and gardens allowing people to both move through and inhabit the space. 

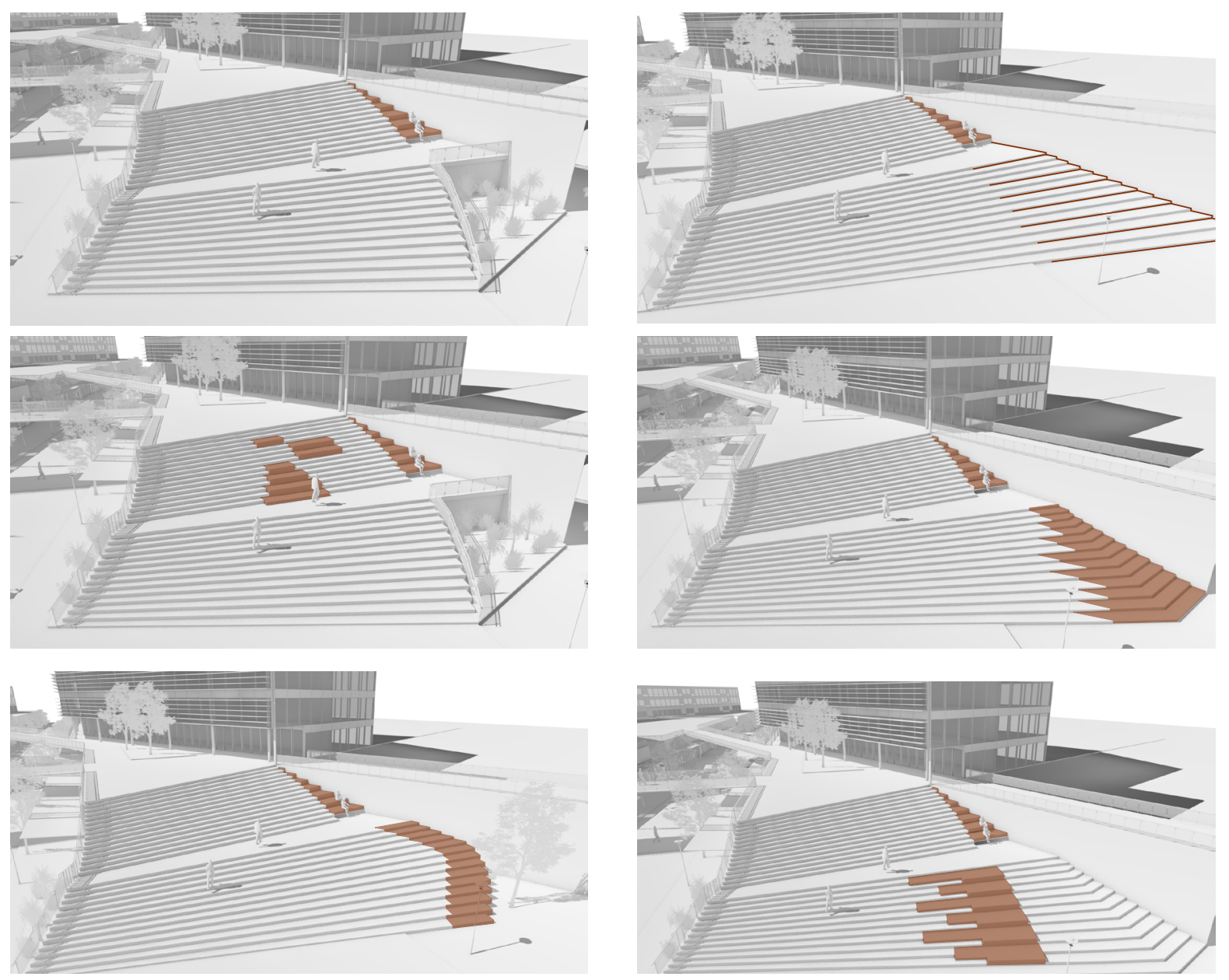

$\wedge \quad$ Figure 86 - Inhabited stair development

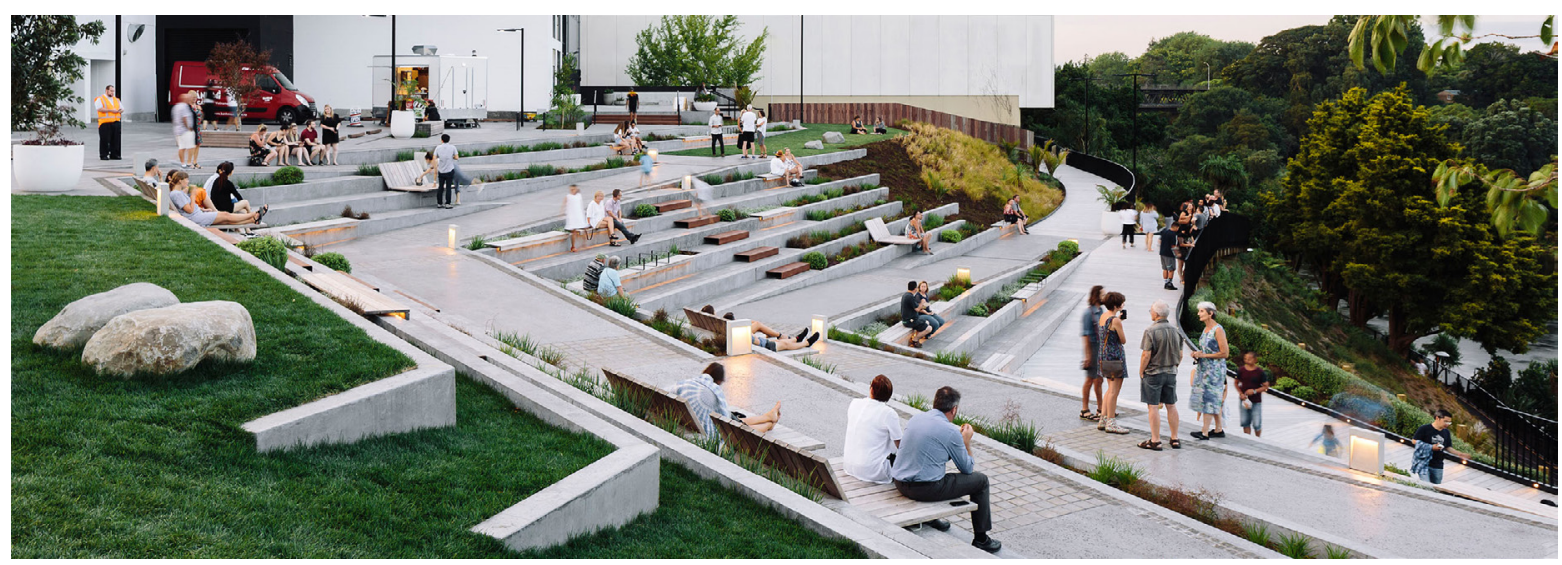

$\wedge$ Figure 87 - Victoria on river, Hamilton. by S. Wilson. 2018. Copyright by Simon Wilson. 


\section{The Podium}

The Podium concept will focus on creating two distinct environments merged through circulation.

This seeks to create a pedestrian haven at the Podium Level composed of a network of green park spaces that accompany the commercial offices, cafés and eateries, and the residential levels above.

The lower levels will become a higher speed environment. In Wellington, New Zealand, an example of this is the difference between the environments of Lambton Quay and Cuba Street. Both are well known for their high levels of pedestrian traffic, but the way in which people inhabit them are markedly different. Lambton Quay is populated with people moving from place to place, while Cuba Street provides opportunities for pause at various points along its length.

The lower level will primarily use the methodology of moving transit for both people and vehicular traffic. Interspacing of parks and plazas will break up these routes and serve as moments of respite within the wider network.

The podium level will focus more on inhabitation of space, by creating environments in which the user engages, pauses and relaxes. These will include hospitality venues such as cafés, restaurants and bars. Commercial premises will be inter-spaced on this level, and the level above, to ensure a buzzing workday population. Apartments above these and the surrounding suburban development will attract a vibrant resident population during nights and weekends and ensure passive surveillance for user safety.

\section{Integrated Living}

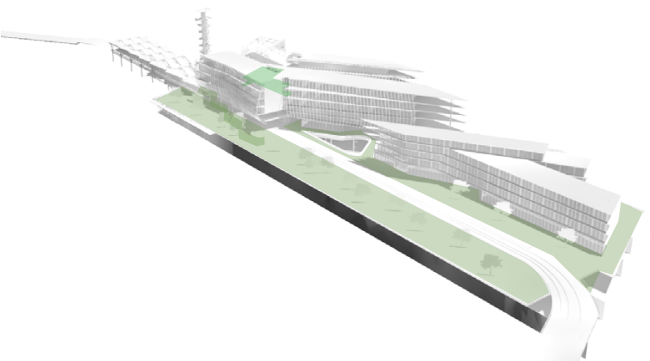

Figure 88- Sky decks + Roof terraces $\wedge$ -

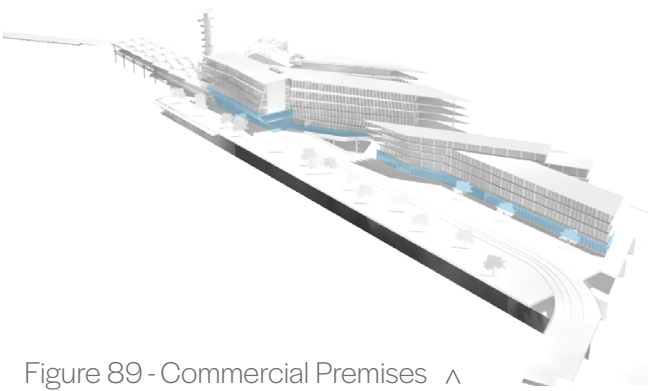

Figure 90 - Mixed typology apartments $\wedge$ -

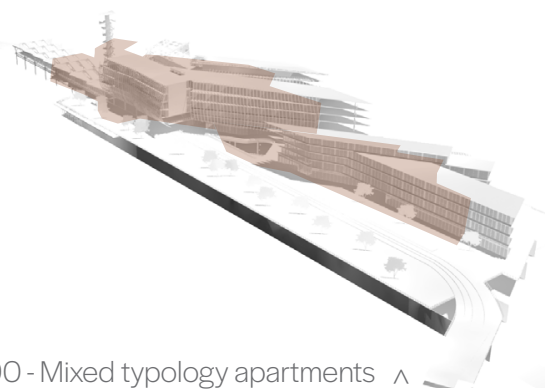

Marina One

Designed by Ingenhoven Architects, Marina One is a mixed-use tower development located within the Marina Bay precinct of Singapore. This integrates commercial, retail and residential typologies together.

These are linked by the building's green heart which takes the form of a lush public park in the centre of the complex. Accessible over multiple levels this public forum provides a good example of how the assemblage of different functions can be used to aid in urban connectivity. 
Podium Development

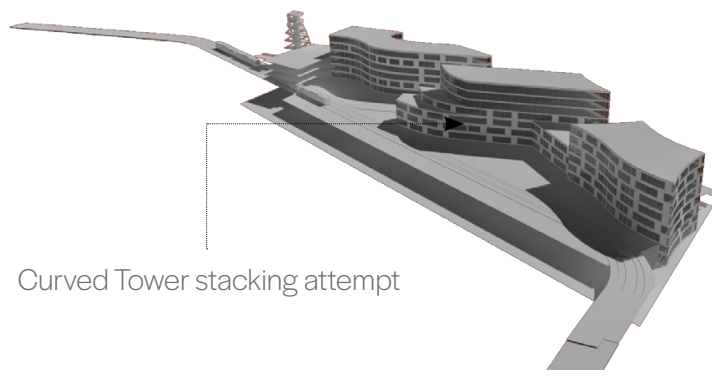

Light well and external atrium space
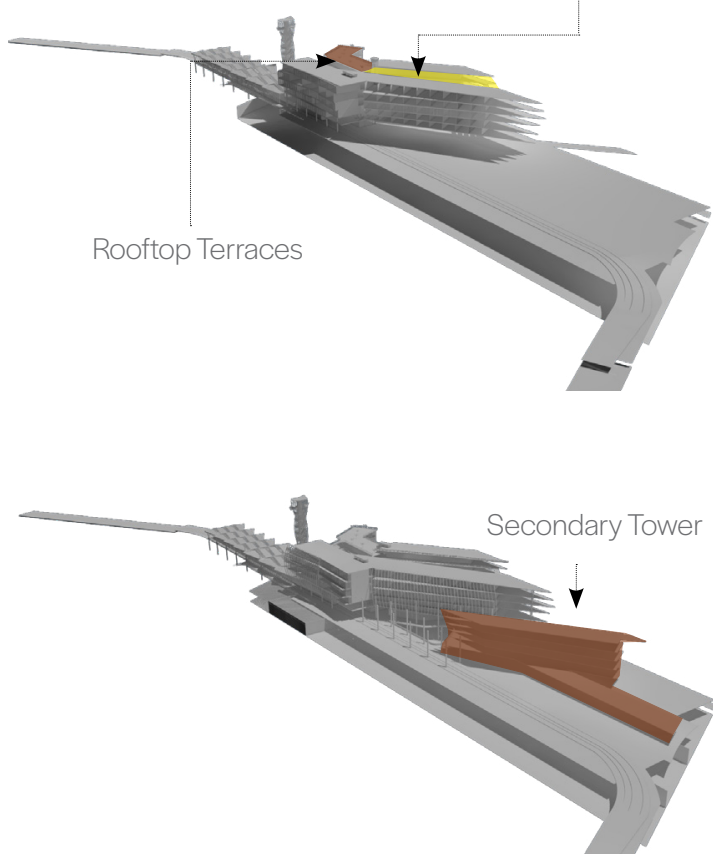

Curved concept amended to suit

dynamics of wider site

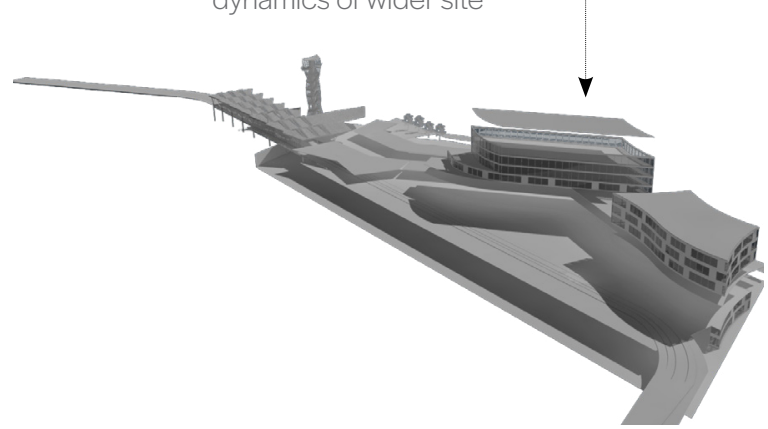

Louvre installation for privacy and shading

Figure 91 - Podium Development ^
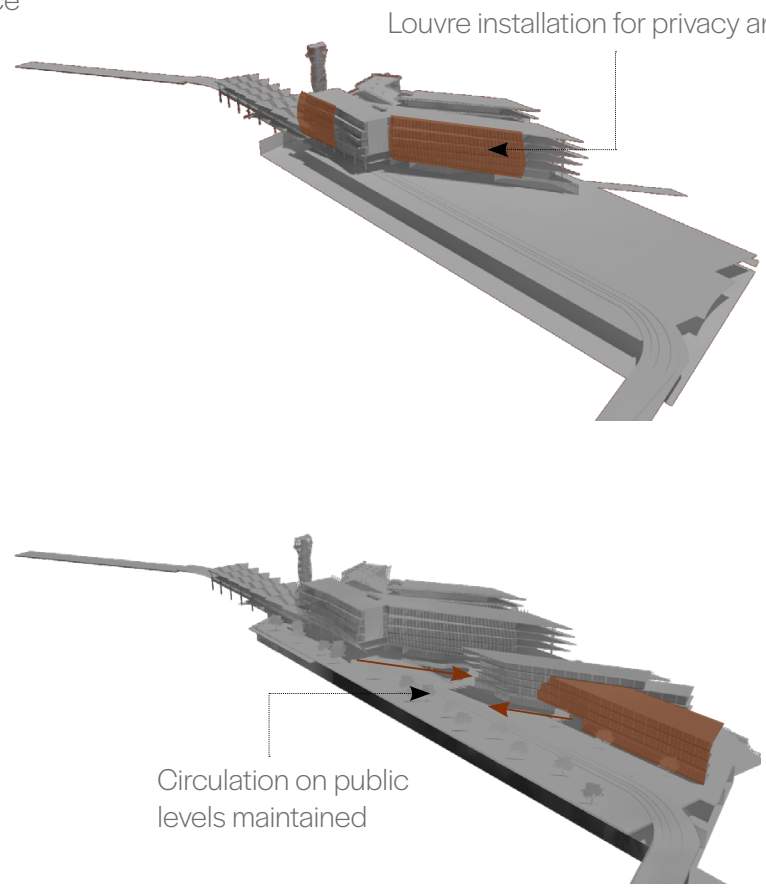

Circulation on public

levels maintained
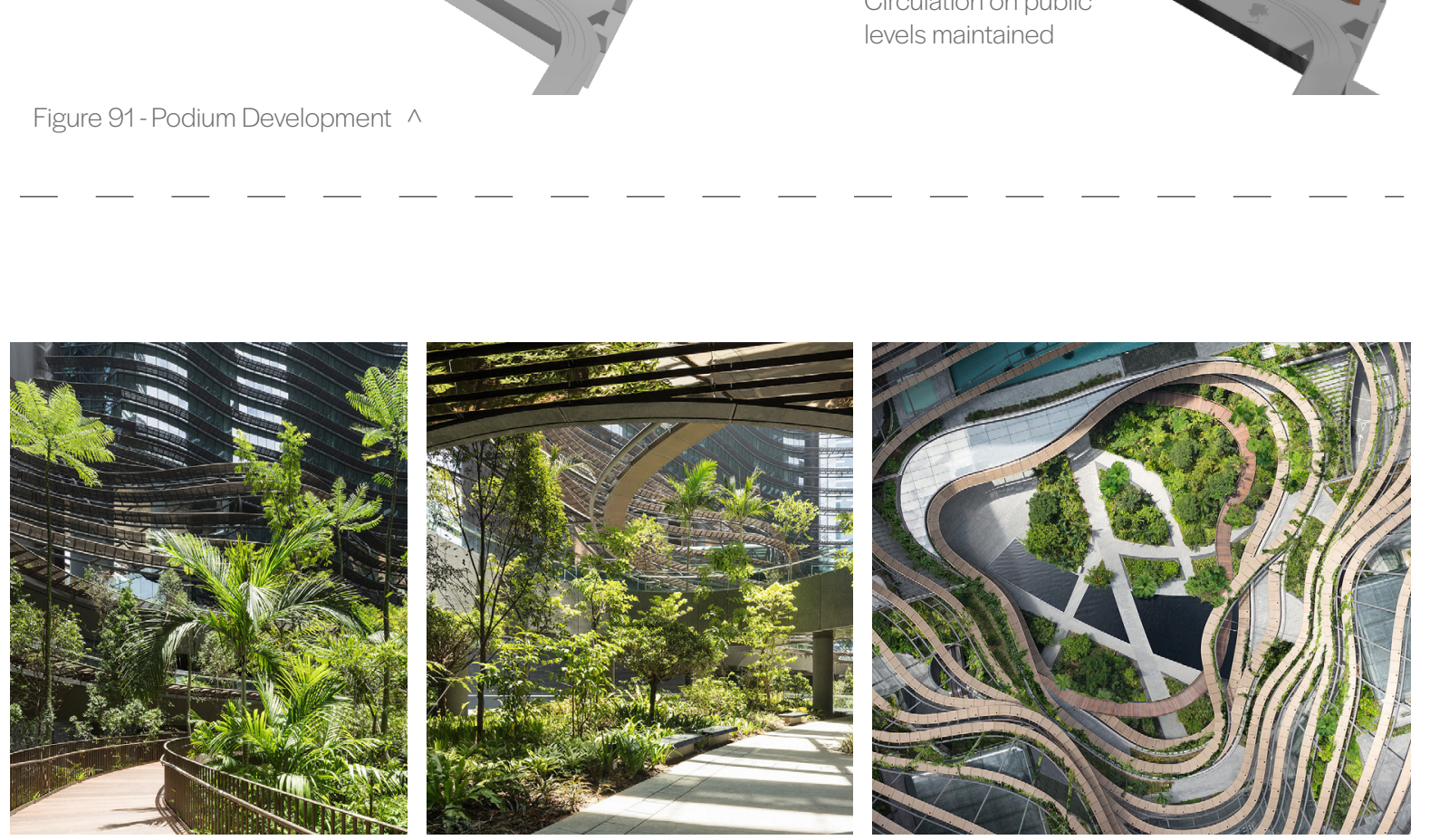

$\wedge$ Figure 92- Marina One heart. kindly provided by HGEsch photographers. 2017. retrieved from https://tinyurl.com/y2du2yu7. Copyright by HGEsch photographers. 
4.1 The Approach 


\section{Critical Reflection}

Assemblage theory treated the urban system as an array of interlinked components and principles. The previous section explored these components individually allowing for a greater depth of investigation and better understanding of how different elements of urban space function in different roles. Specifically, this focused on the human scale and integration of pedestrianised spaces as linkages between urban structures.

Key learnings included discussion around destination-based planning, the integration of different transport modes, and exploration into resolving issues surrounding grade separation. These learnings were used to inform the development of the wider scheme.

However, whilst the ability to explore the intricacies of each component has been helpful, it has also created an element of disconnect within some of the design process. This has made it difficult to ensure that all elements of the design are resolved to the same level and that the needs of the end user are met.

The following section looks to bring the previous exploration together and resolve any disconnects through the integration of each aspect as part of one cohesive system. 
Vehicle access

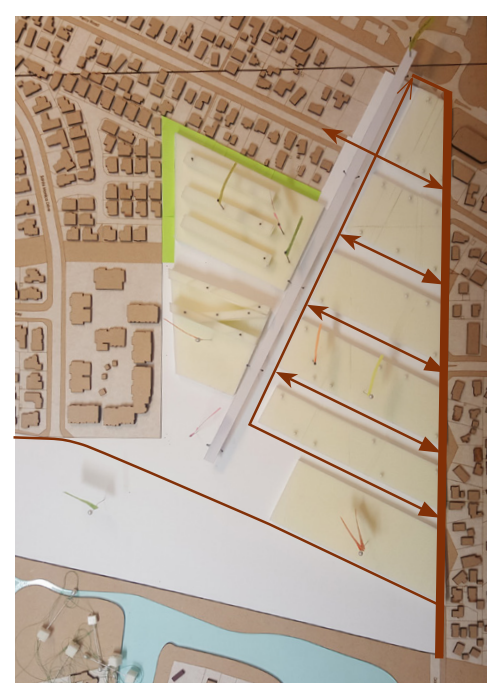

Public Transit

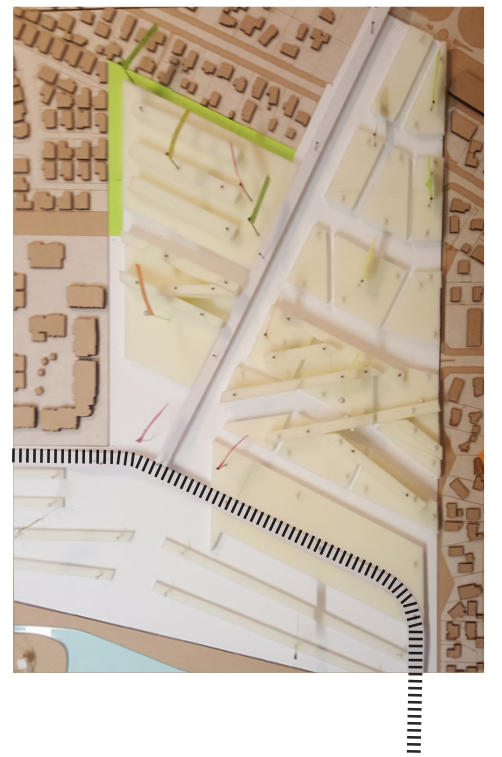

$\wedge$ Figure 95-Masterplan development
Pedestrianised Laneways

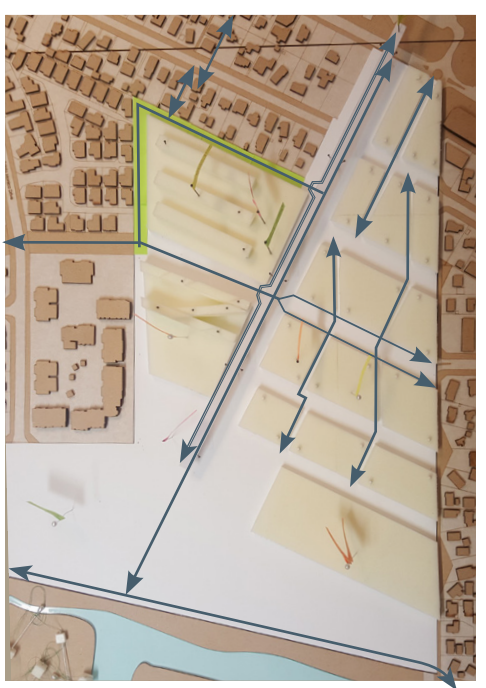

Podium Circulation

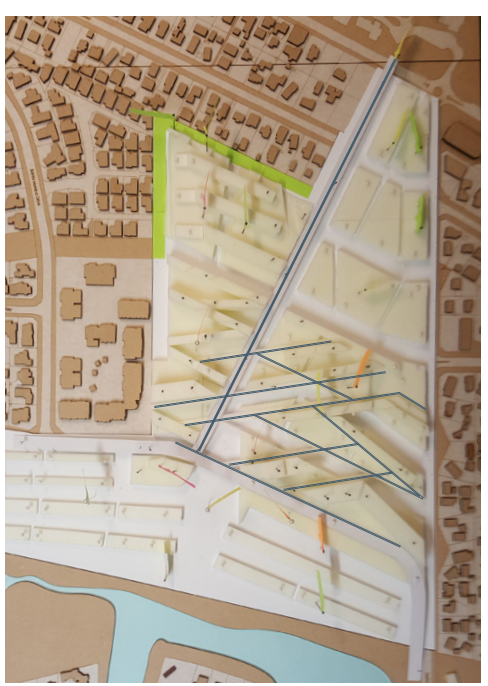

Plaza

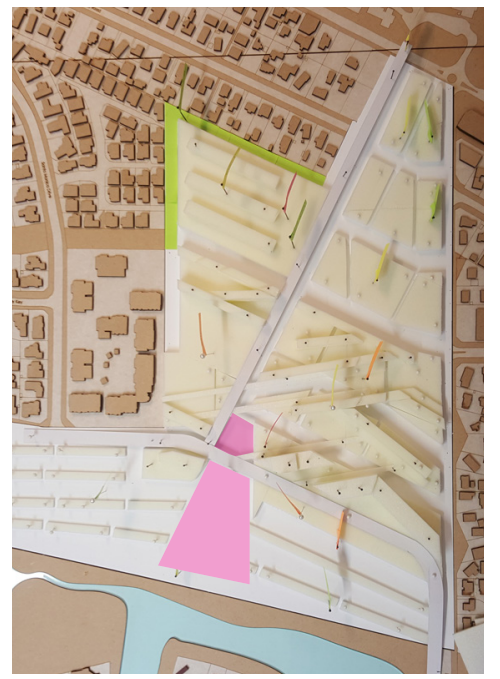


Townhousing

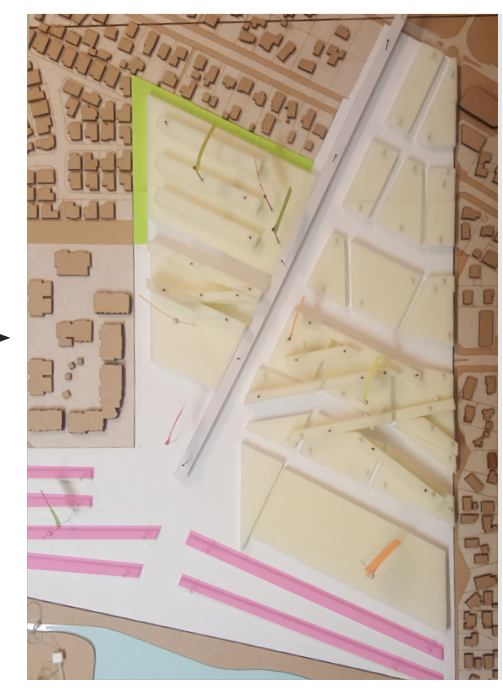

\section{Districts}

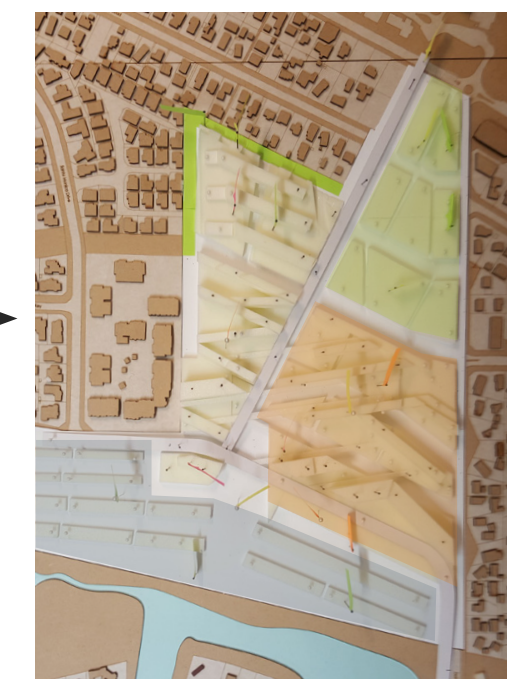

The grid began as a very rigid and structured approach, however the integration of the pedestrian laneway network has allowed it to develop more organically and the overall connectivity across the site has increased substantially.

The pedestrian network within the site integrates completely with the suburb's existing green network to provide an accessible and coherent system throughout. This fosters stronger connections between destinations and increases the porosity of the block and employs Kevin Lynch's 5 Principles surrounding the city as a journey. This allows each journey to be customised to the needs of the user and enables increased flexibility on the route chosen, instilling a greater sense of individuality and home (Lynch, 1960).

In this scheme the blocks are relatively long due to the shape of the site and layout of connector roads. In order to mediate the impact of this the width of the blocks will be reduced as the length increases. This ensures that the overall perimeter of the block is kept to a minimum. In addition to this the density of laneways will increase as the length of the block does, ensuring that the level of porosity across the scheme is maintained. 


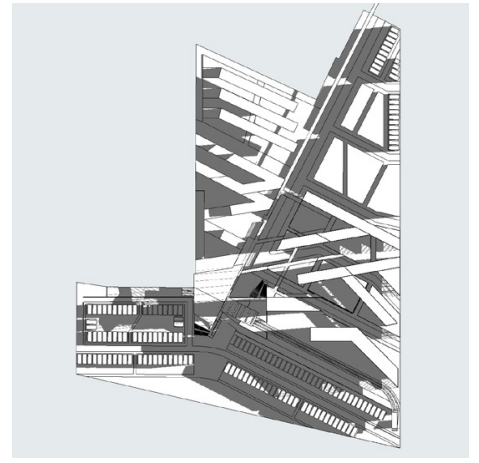

$7 a m$

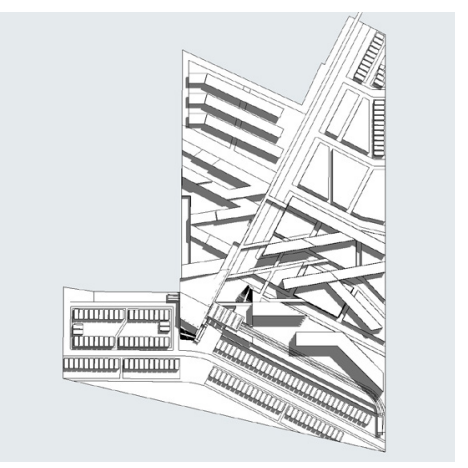

$11 a m$

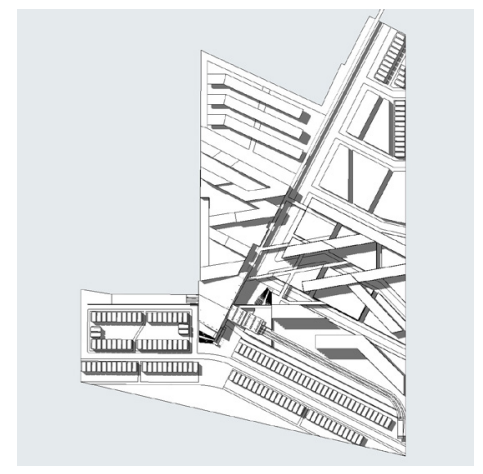

$3 p m$

$\wedge \quad$ Figure 96 - Daylight Analysis

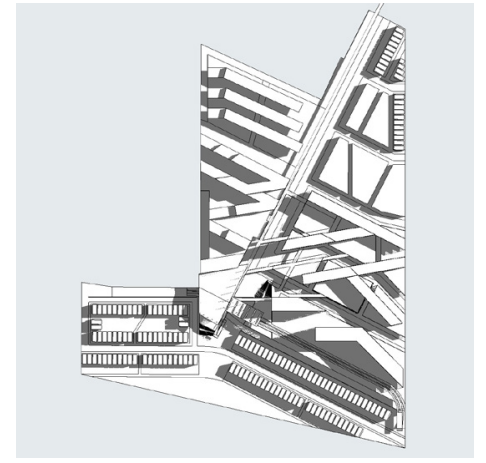

$8 a m$

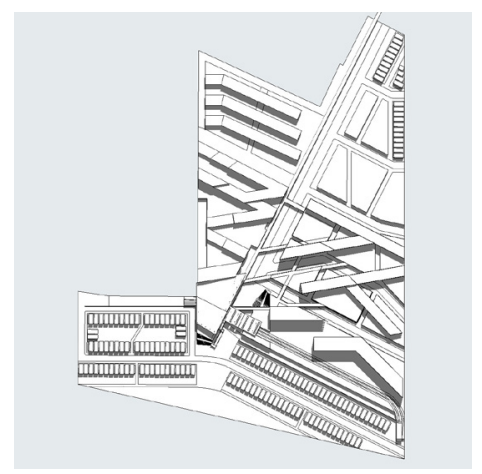

$12 a m$

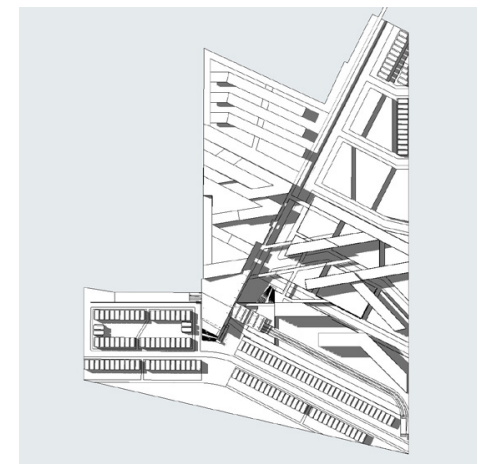

$4 \mathrm{pm}$

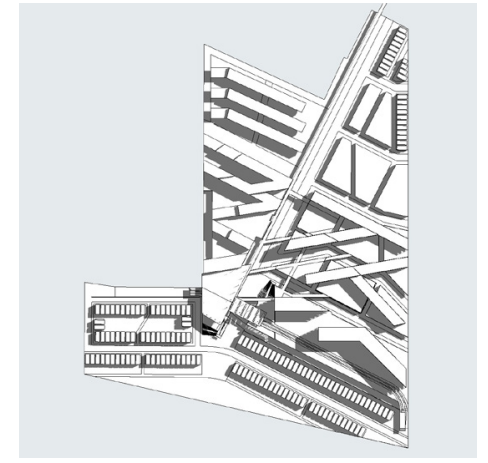

9am

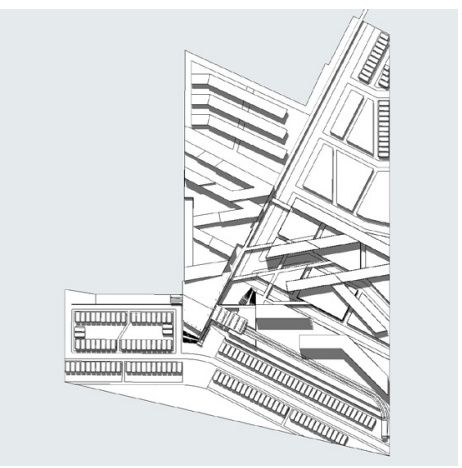

$1 \mathrm{pm}$

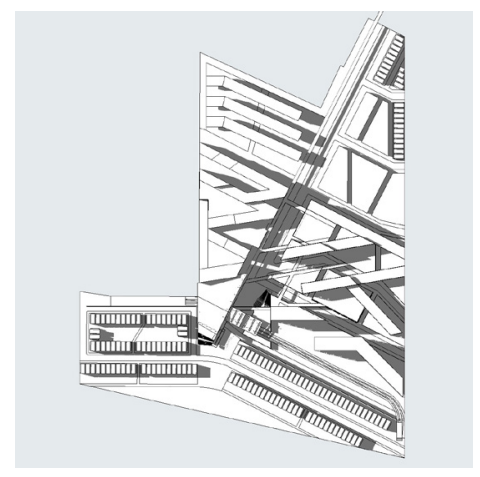

$5 p m$ 


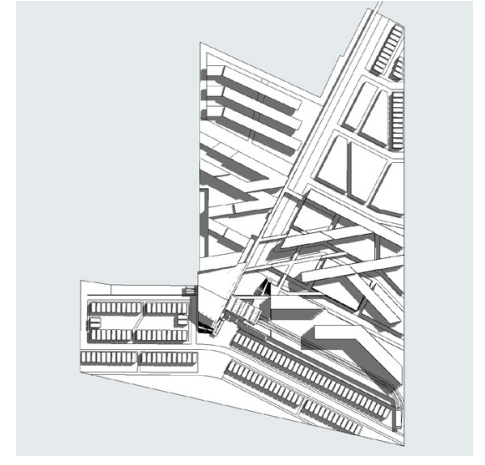

$10 a m$

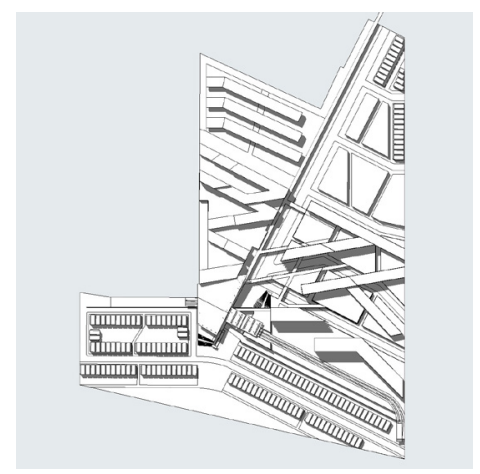

$2 \mathrm{pm}$

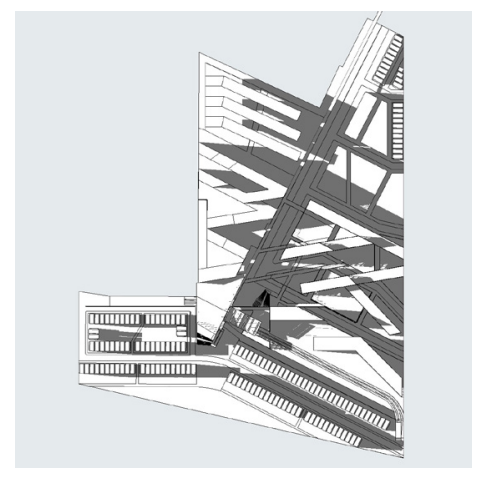

$6 \mathrm{pm}$
The placement of buildings and heights have been designed to maximise access to sun for the apartments and public spaces.

Building alignments have been designed to maintain view shafts and minimise the impact of wind on the site.

Most of the apartments have been faced north east or north west to ensure access to either morning or evening sun and all buildings, apart from the southernmost towers, are composed of single apartments facing toward the coast. This helps to maintain privacy and view shafts.
Building Distance

A building separation of approximately $40 \mathrm{~m}$ was found preferable to ensure access to sunlight throughout the day, at all levels, for a building up to 6 stories tall.

(For Massing Exercise Refer Appendix Page 210 - 211)

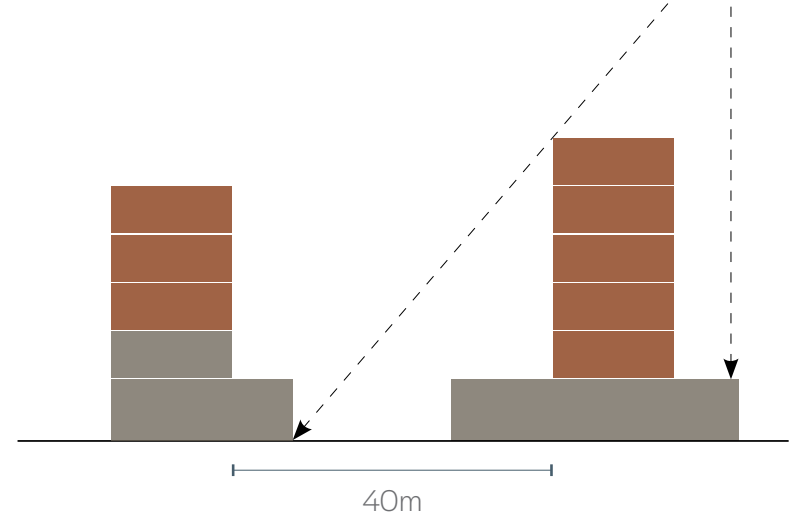

Figure 97-Building height analysis 


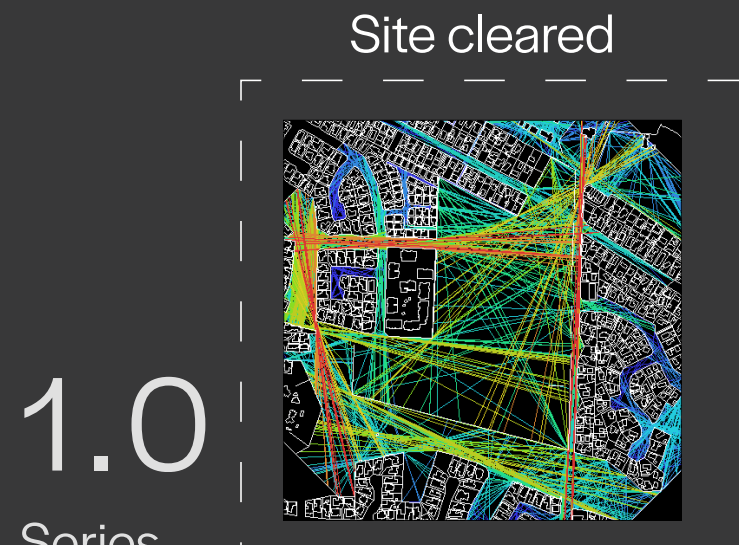

Series
1.1

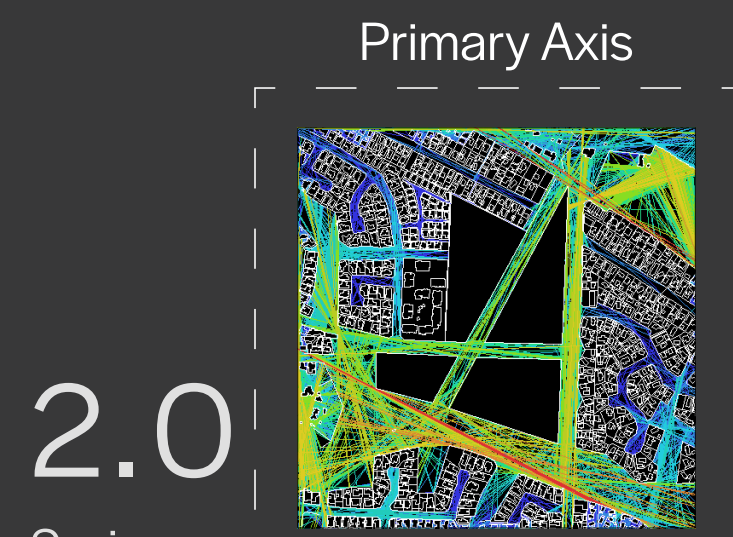

Series

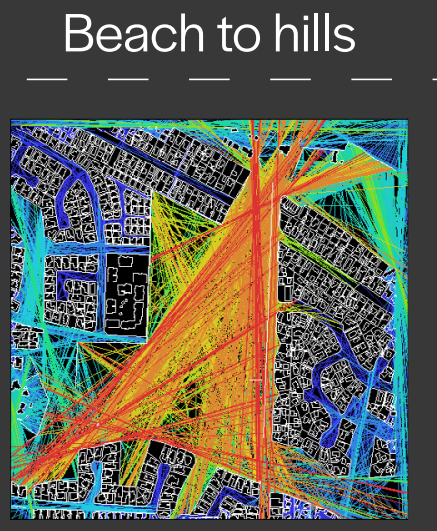

1.2
No boundaries

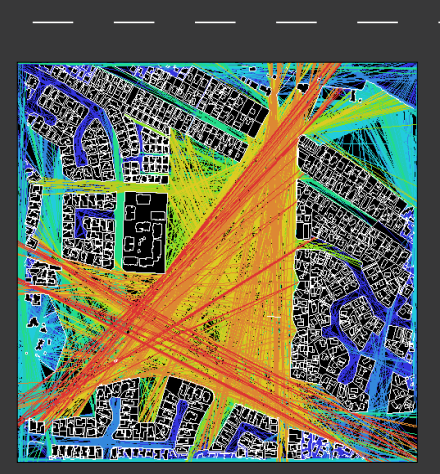

- - - - -

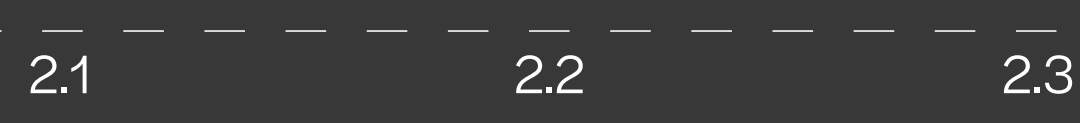

1.3

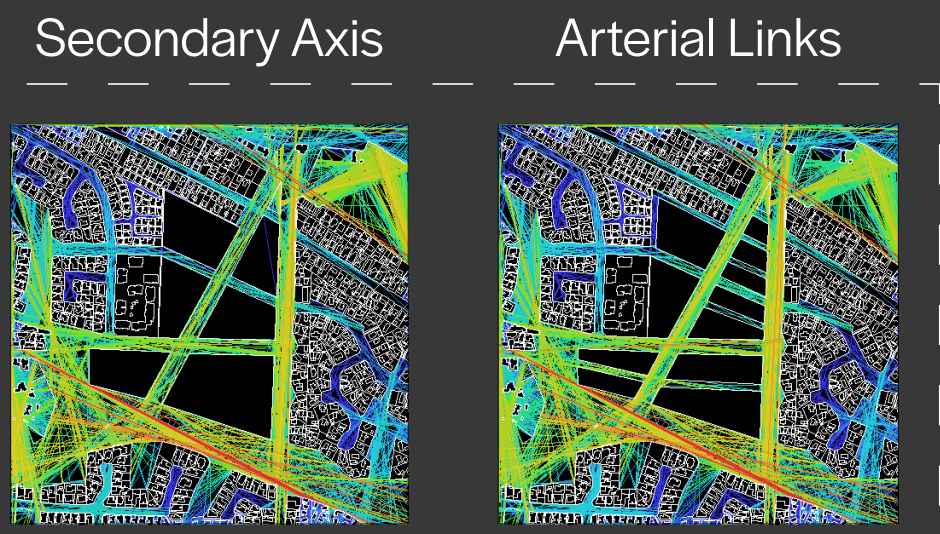

2.3

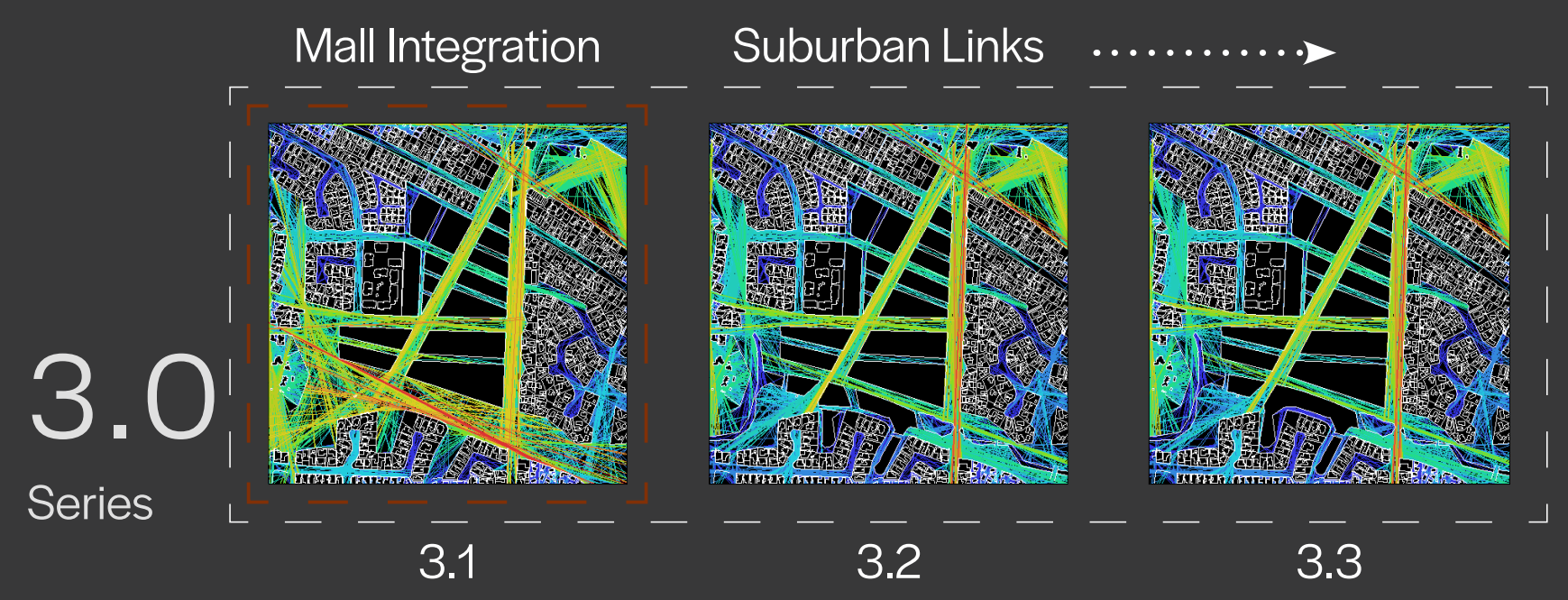

\section{Connectivity Studies}

Existing developmental frameworks and growth trends were analysed. Using this information several schemes were developed. These built upon each other and were evaluated using 'Space Syntax' to establish levels and patterns of connectivity. Key aspects of this development explored both the site as it stands currently and as a cleared site. This provided the ability to identify key features of the site and the potential for development in both scenarios to be assessed based on the connectivity studies. A selection process of the most viable schemes were explored in detail. These were then broken into key sections which were progressively iterated upon to generate a range of different options. 

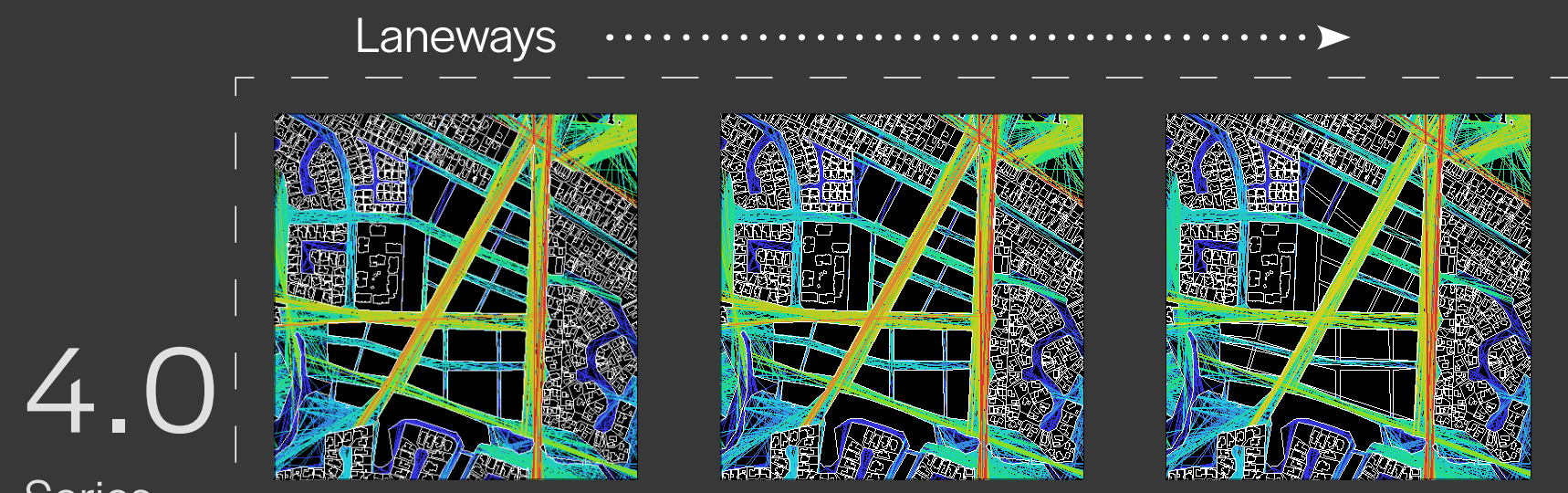

Series

$$
\overline{4.1}--
$$$$
\overline{4.2}-
$$

Transport Hub

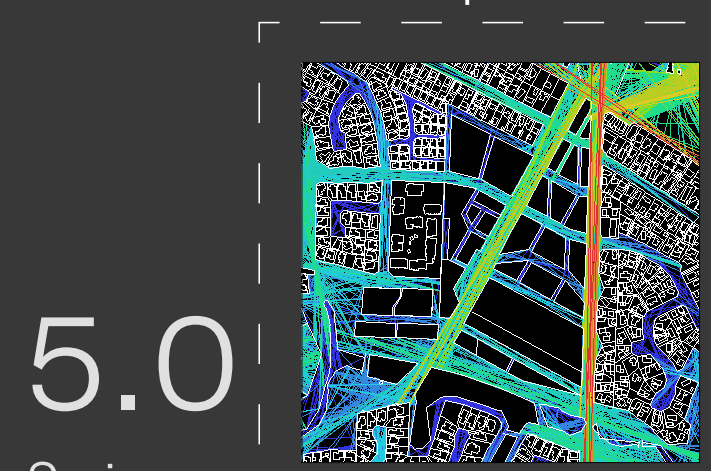

Series

\section{1}

Gravatt Road Link

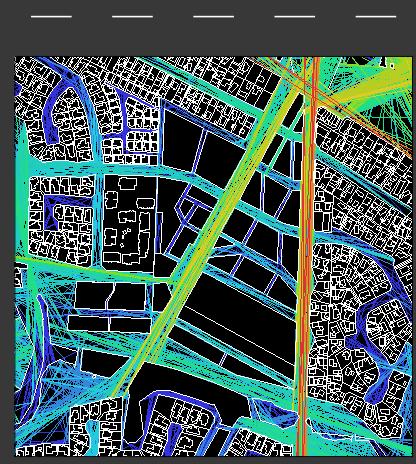

5.2
Transport H. Shifted

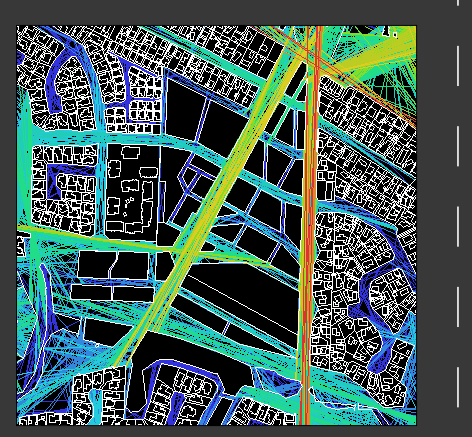

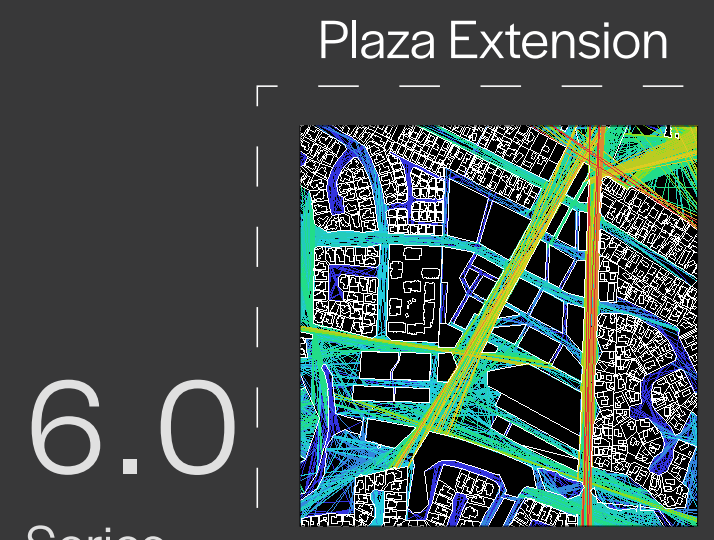

Series
6.1

6.2

Figure 98 - Masterplan connectivity analysis $\wedge$

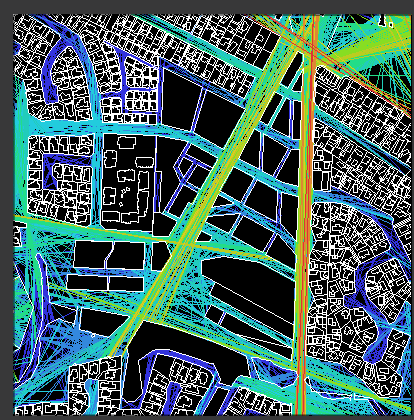

Initial Findings

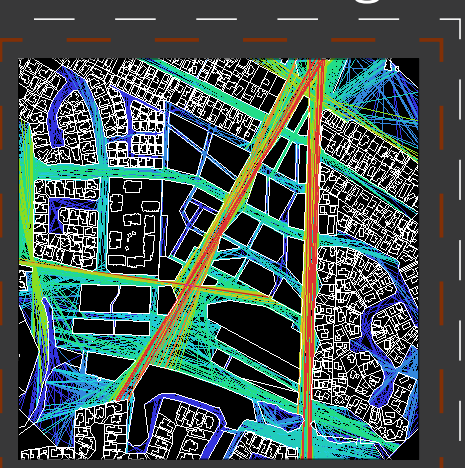

\section{3}

Working Model

\section{Connectivity}

High

Low 


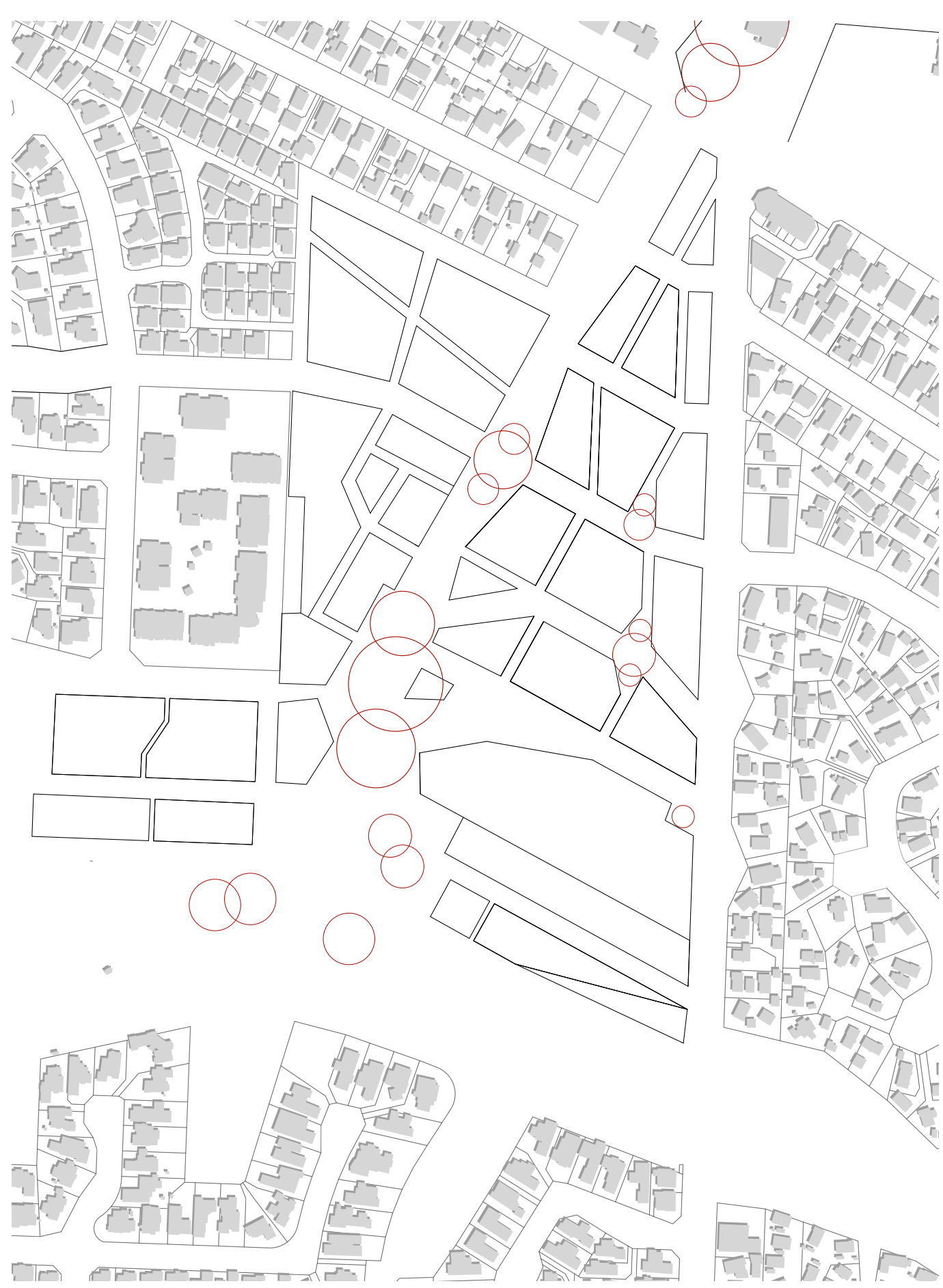

Moments in time

Expansive and compressive spaces were used to create a series of moments along the key arterials, via expansion and compression points which were used to establish hierarchy. This sets a precedent for what these spaces are used for, taking advantage of areas predicted to have high levels of connectivity and installing parks and soft edges that encourage inhabitation rather than simple arterial routes. This encourages people to use the space and increases vibrancy throughout the site (Gehl, 2011). 


\section{Initial Findings}

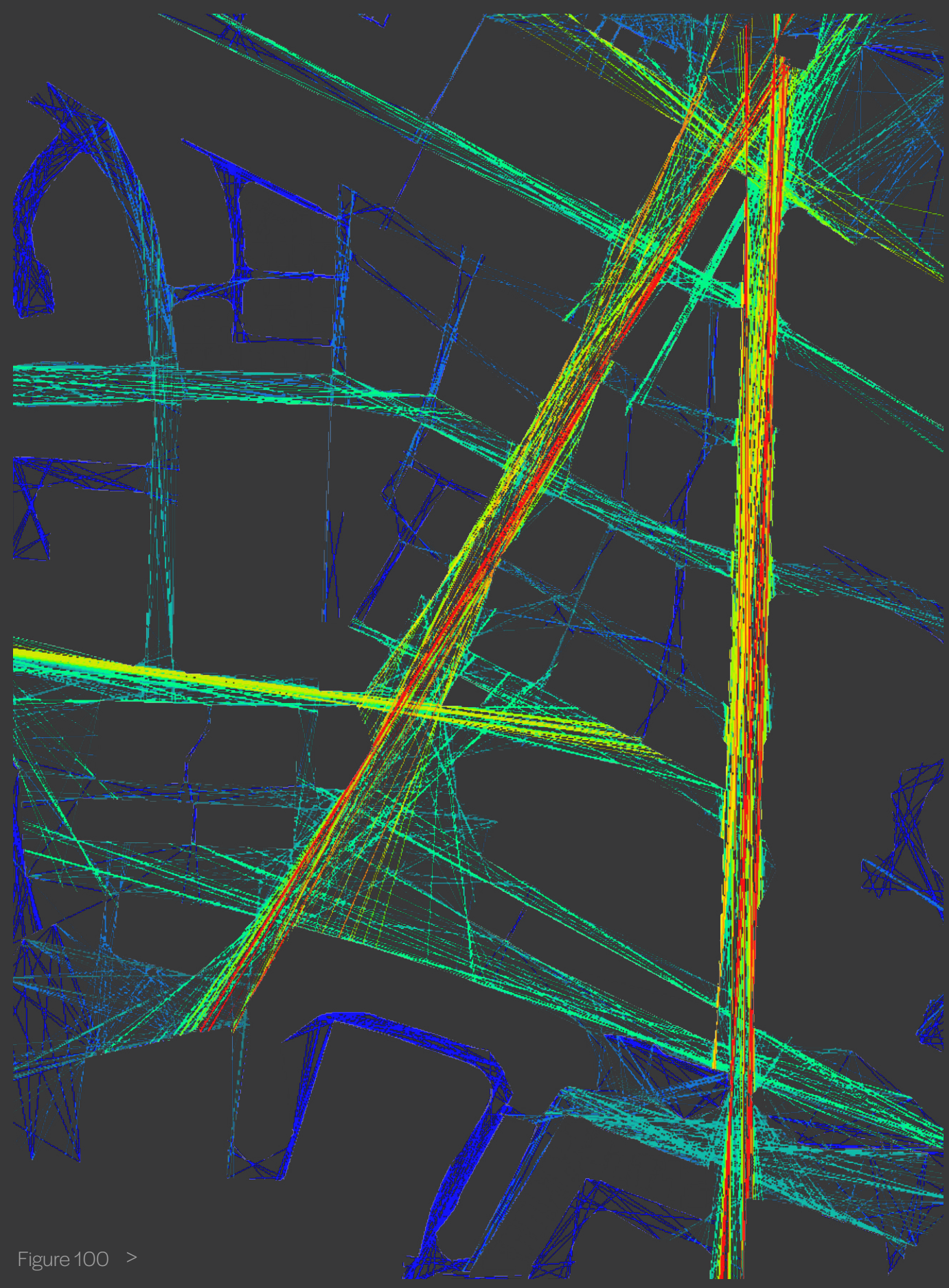

6.3

Paths of enhanced connectivity are shown down Domain Road and the Central Boulevard. Lower, but still significant, connections across

Series link roads suggest the site is beginning to work as intended. 

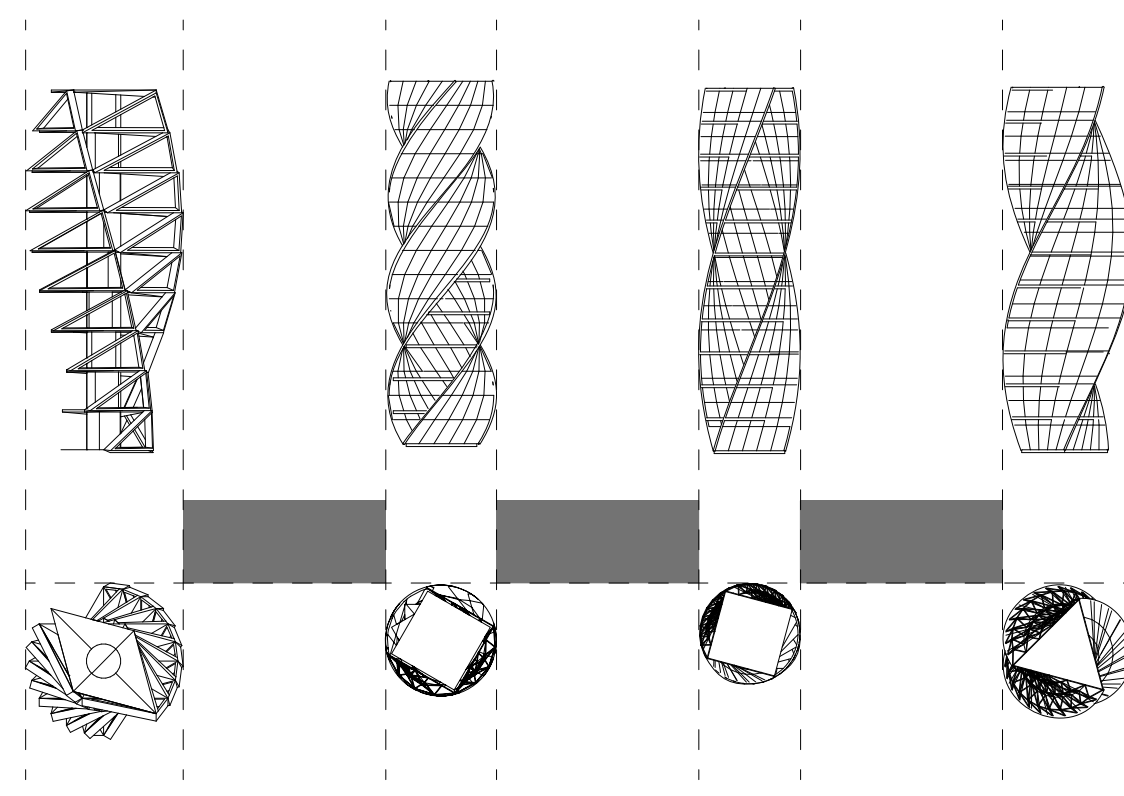

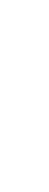

\section{|}
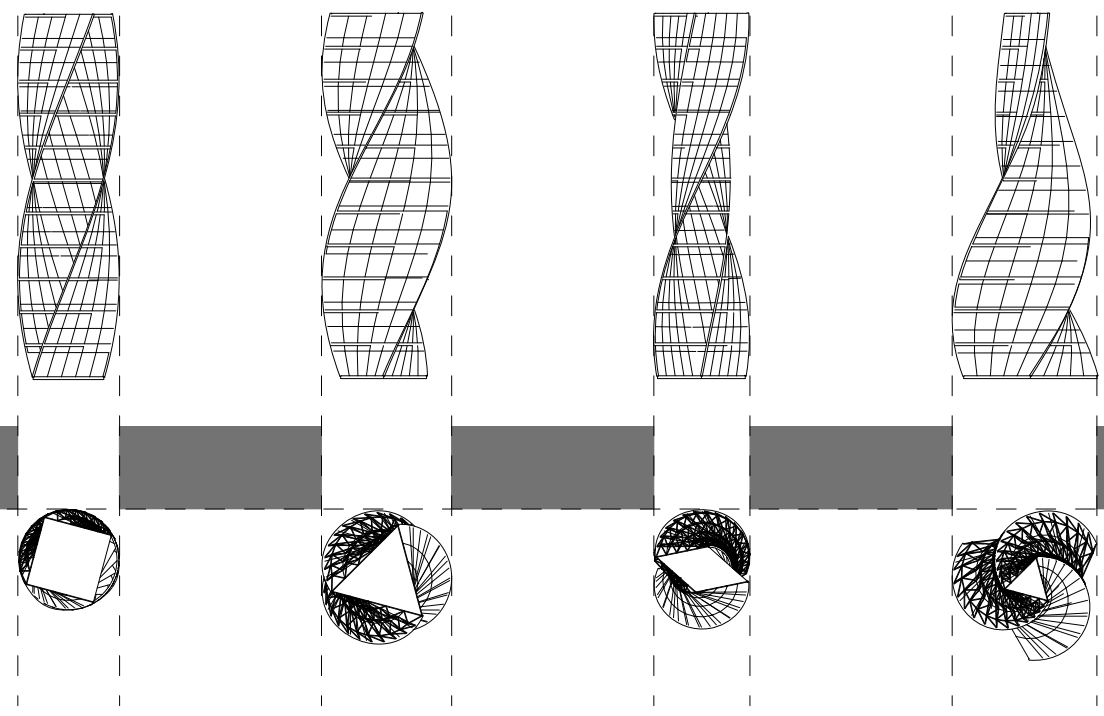

2

3

\section{Local Landmarks}

Navigation is an important part of the urban experience. Using Kevin Lynch's 5th Principle of the Landmark, the site will develop a local lookout tower. This will serve as a local landmark for the site and a reference point for the transport hub at the heart of the centre.

This allows the user to orientate themselves accordingly and provides a visual connection between the transport hub and the outlying areas of the town centre, and wider suburbs, helping to increase the visual connectivity and integration of the site.

The Lookout Tower itself employs the principle of orientation of view seeking to highlight strategic points about the region. 

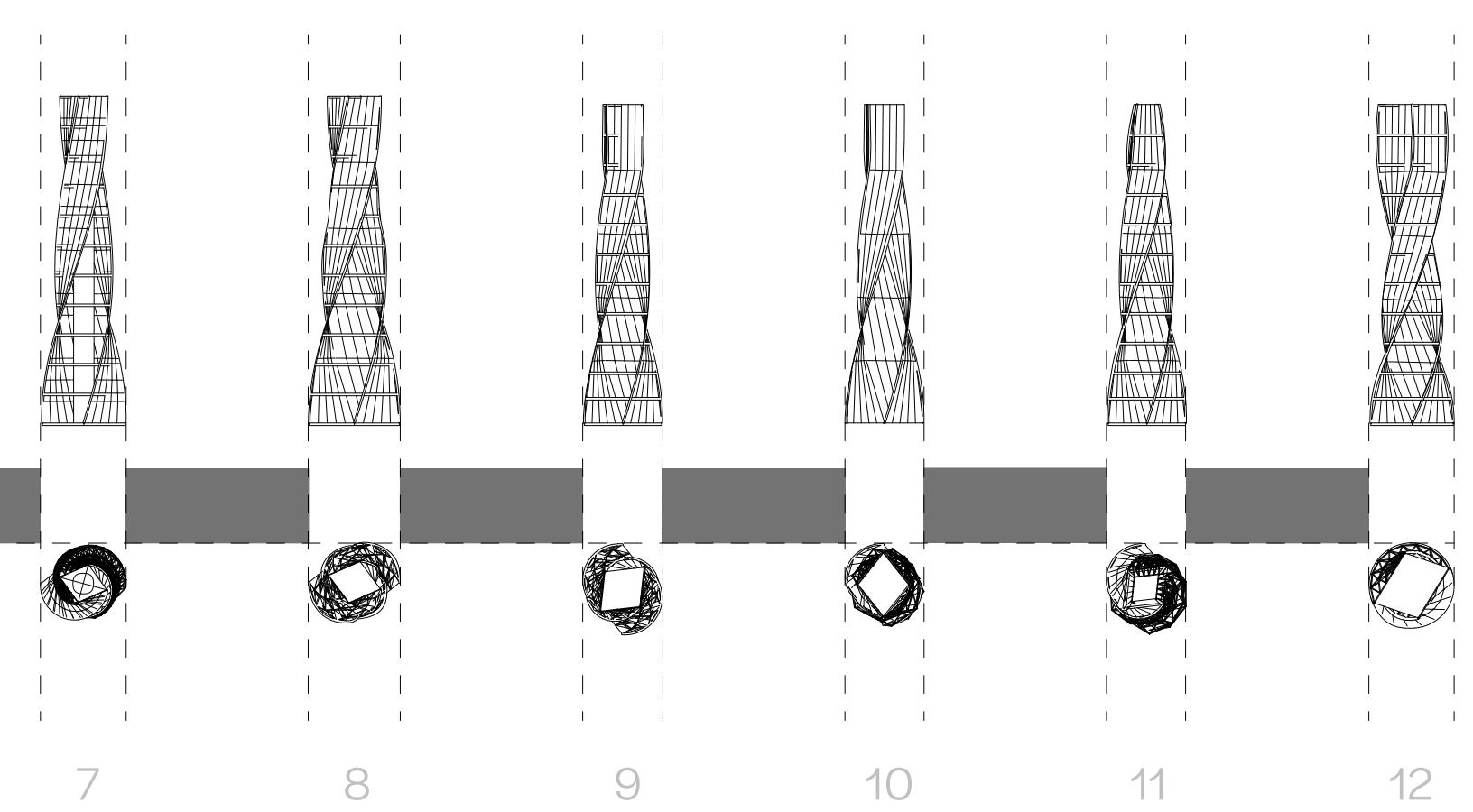

8

9

10

11

12 


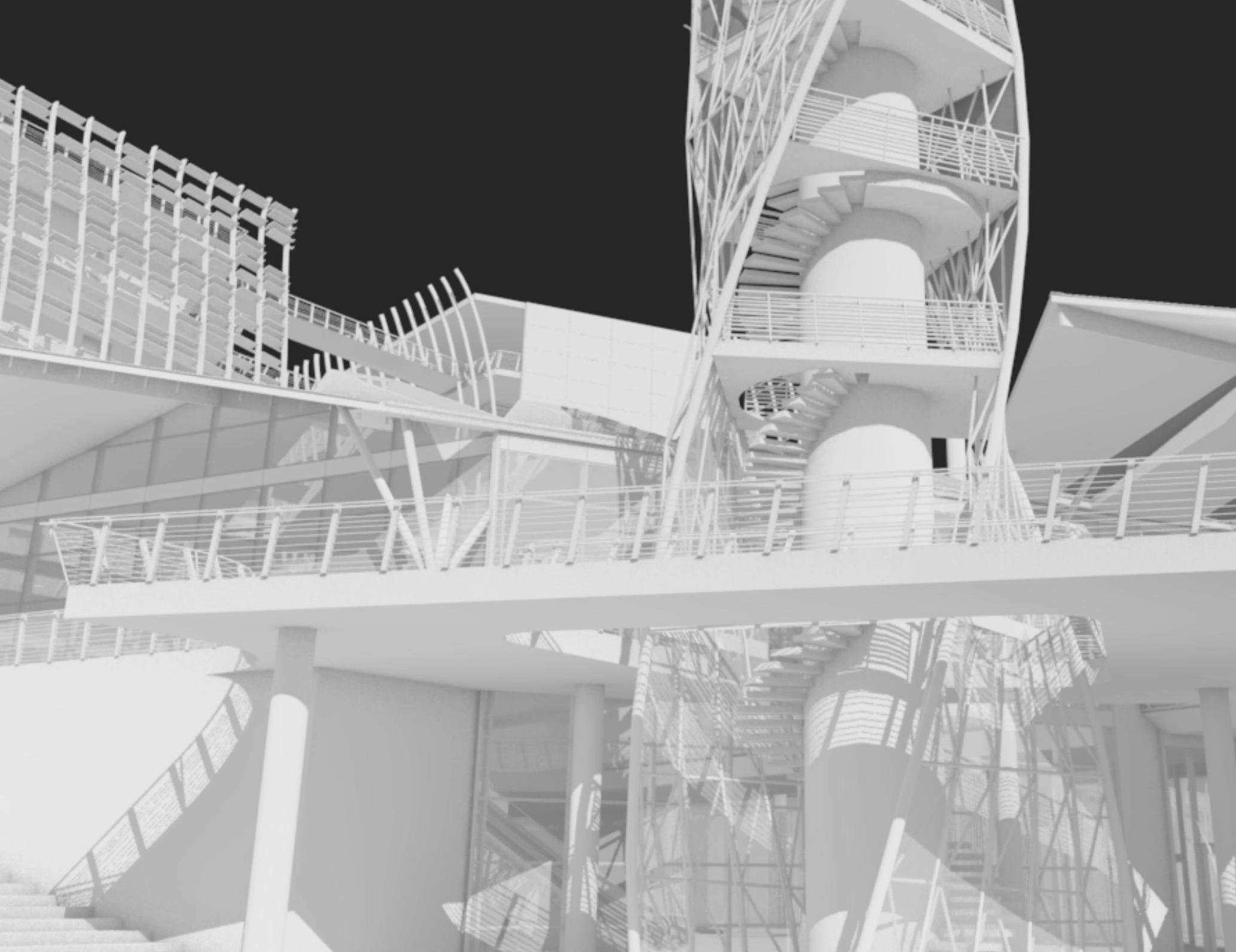


Visibility Analysis

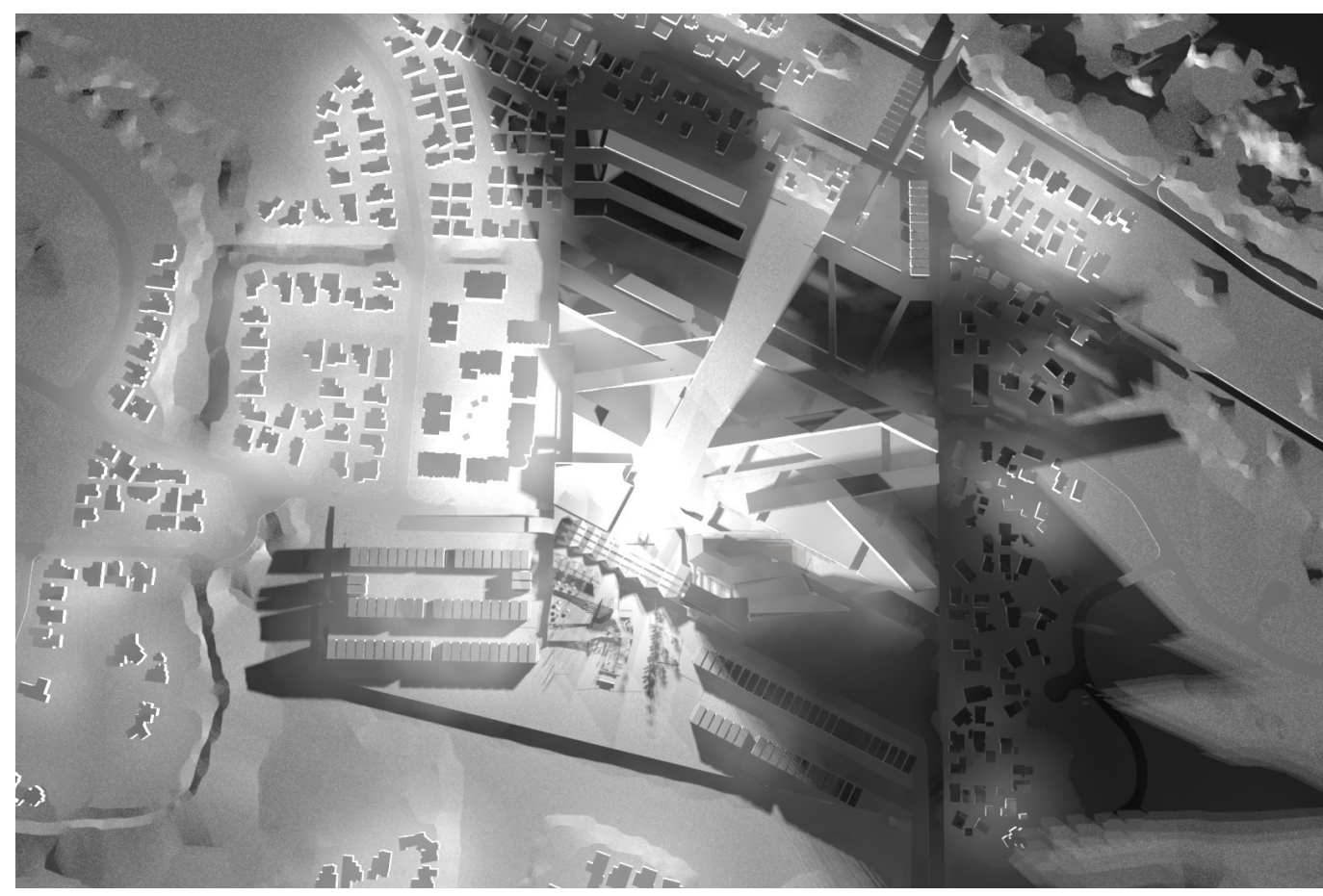

$\wedge \quad$ Figure 103 - Lookout Tower visibility lighting analysis.

Lights were placed on top of the tower within the computer model and cast downwards. This enabled the effectiveness of the tower as a way-finding landmark to be evaluated and adapted to suit.

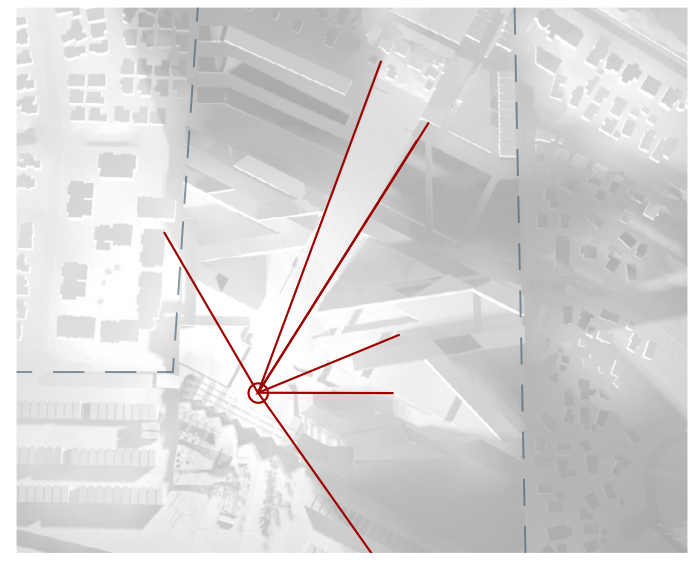

Existing visibility identified

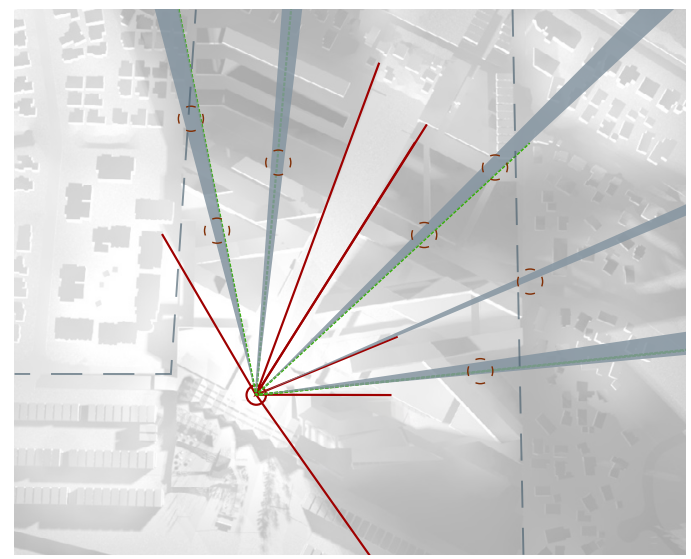

Revised view shafts following analysis

$\wedge \quad$ Figure 104-Lookout Tower visibility analysis

$<$ Figure 102-Lookout Tower base integration

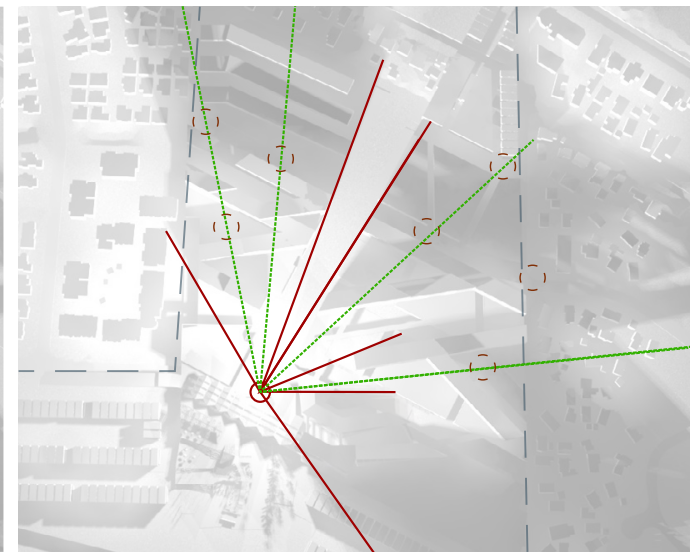

Proposed new visibility locations identified

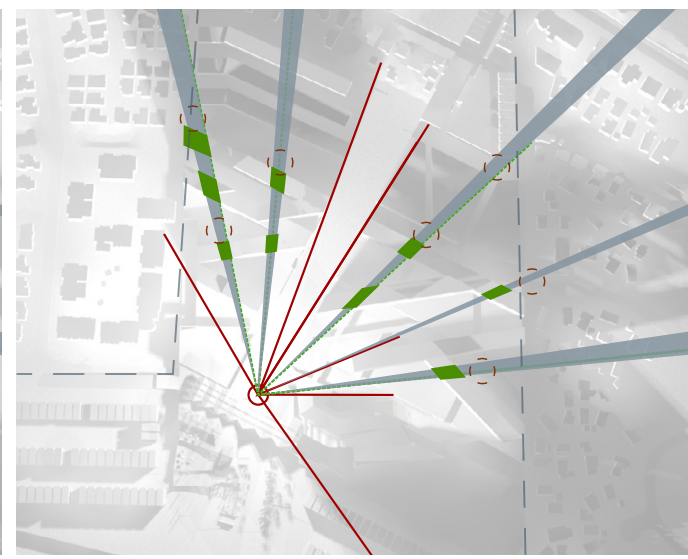

Revised building form to enable visibility at strategic locations 
4.2 The Plan 


\section{Critical Reflection}

"The Approach' brought the key learnings of the initial design phases and master planning into one coherent scheme. This provided the first insight into what the design could look like and how it would work.

The connectivity analysis conducted using 'Depth Map' allowed real time testing, facilitating a rapid transgression of ideas, to testing, to working model, proving itself an excellent asset throughout the master planning process.

Returning to the research objectives set at the beginning, the next phase begins to detail the different functions and aspects of the site bringing the scheme from working model to functioning town centre. 
A multimodal approach

The multimodal transport system facilitates strong links within the region and seamlessly integrates the community with the surrounding suburb.

Transport options are provided for all distances, from regional light rail, to buses, to bikes and scooter hire.

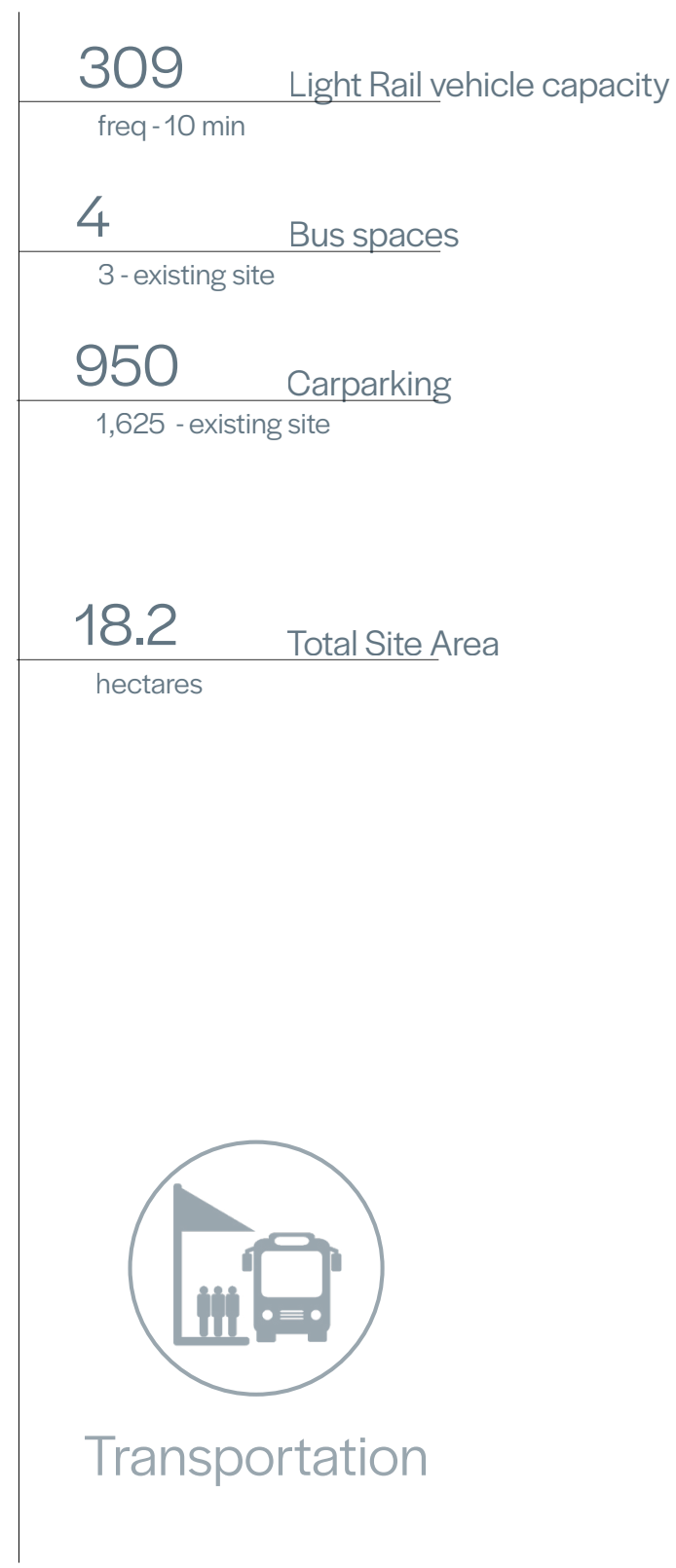




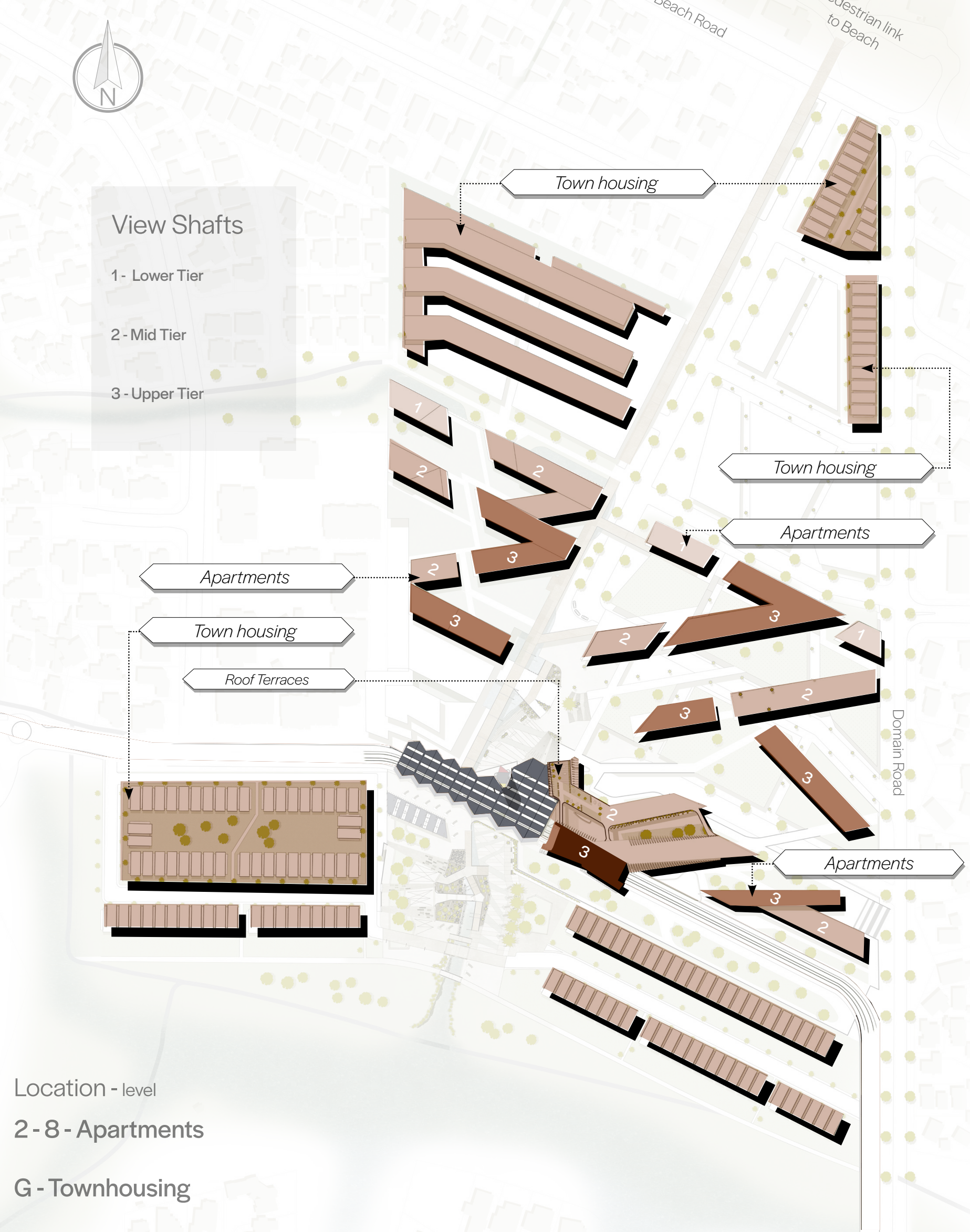




\section{A choice in living}

A range of living typologies are introduced providing options of high and medium density living in addition to Papamoa's current offering of suburban detached housing.

Building heights are carefully designed to maintain view shafts across the region and ensure access to natural ventilation and light.

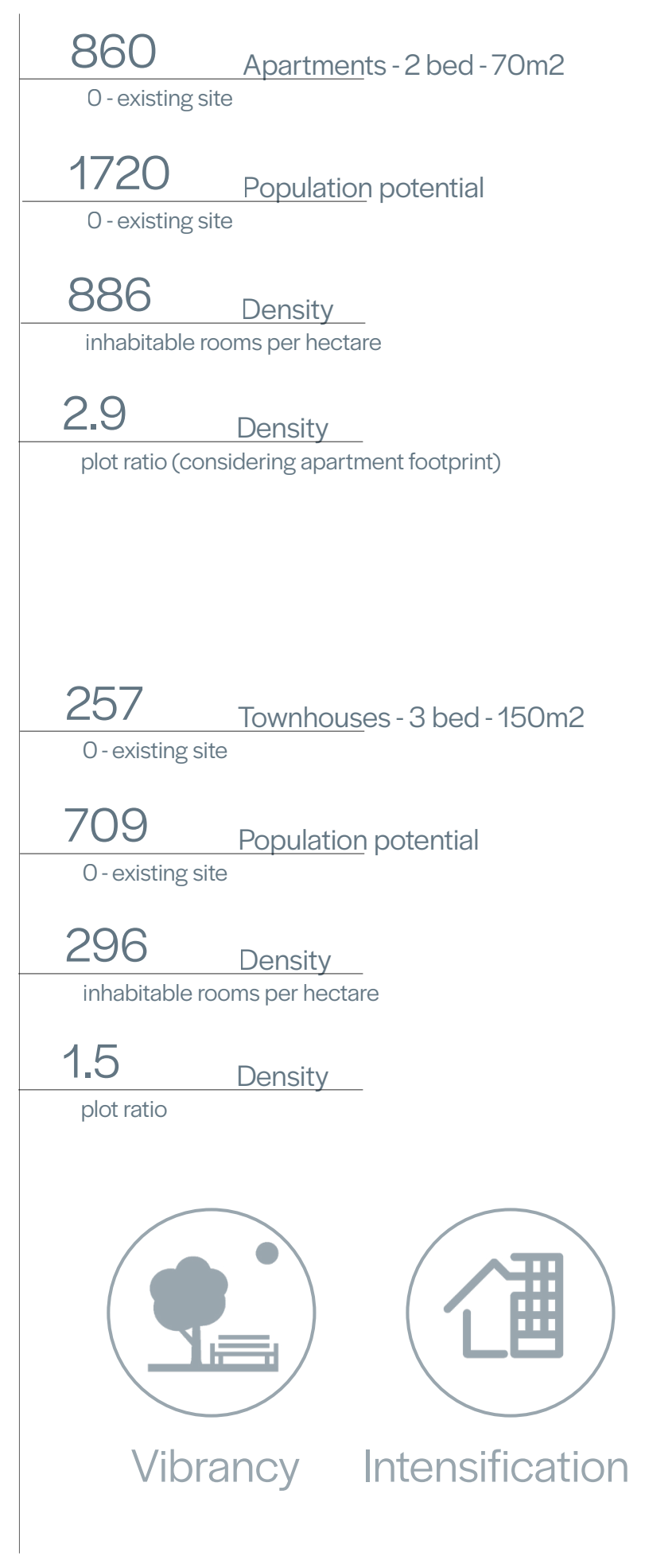



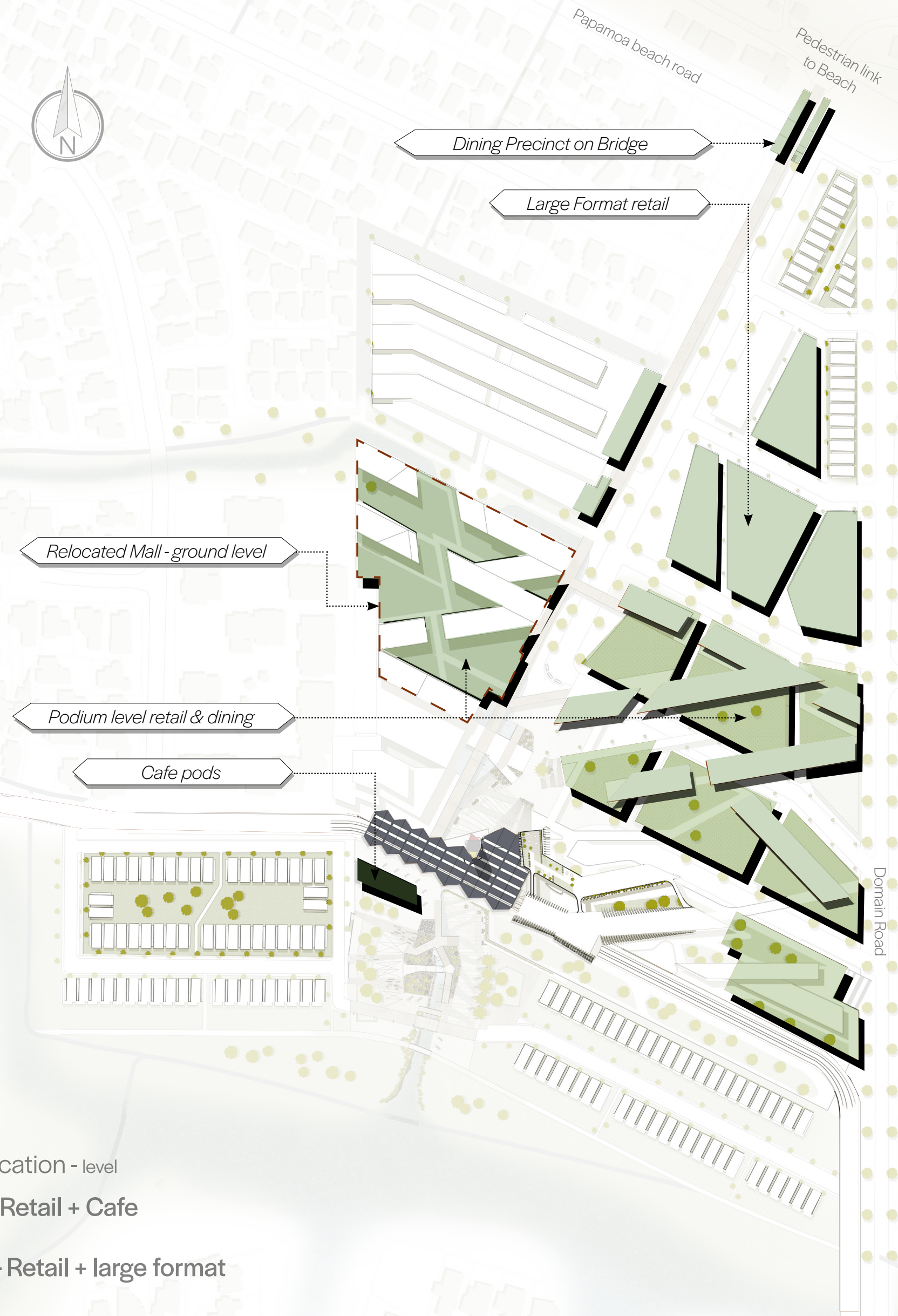

Location - level

1- Retail + Cafe

G - Retail + large format 
Shops a plenty

The total retail area is increased in order to accommodate the larger population.

This includes retail precincts across the ground level and a range of boutique cafés and services, such as gyms and day-care facilities across the Podium Levels.

Additional space is provided on both levels to accommodate future growth. For example the current carpark building in the north-west corner is earmarked for expansion of the mall or large format shopping as people become less reliant on their cars.
66,776 Retail m2

53,600 - existing site

18.2

hectares
Total Site Area

rata

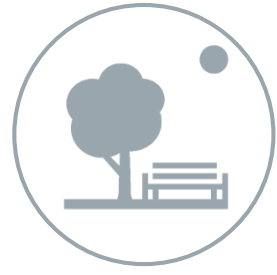

Vibrancy

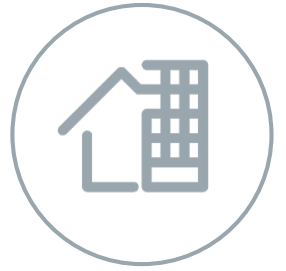

Intensification 

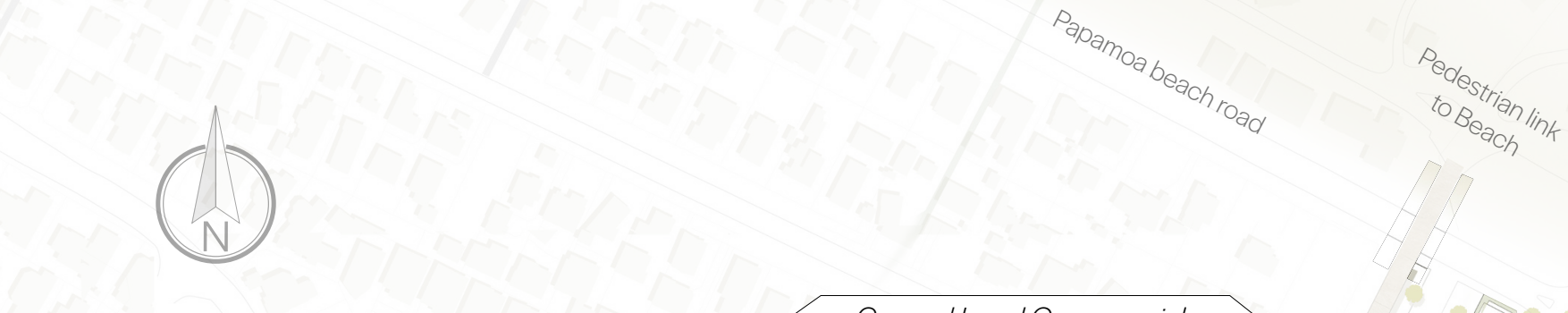

Ground Level Commercial

Commercial Office Space

Business \& Innovation Hub

Location - level

2-3 - Additional Commercial Office

1- Business \& Innovation Hub

G - Commercial - Small Business 
Jobs for all

Commercial spaces have been created on the Podium Levels to encourage growth and allow people to live within walking distance of their workplace. A preliminary $25,694 \mathrm{~m} 2$ has been allocated with additional space available for development as required.

Cafés, and other facilities including gyms and day-care facilities compliment the workforce and reinforce the centre as a destination for businesses.
25,694 commercial m2

0 - existing site

18.2 Total Site Area

hectares ratal Aite

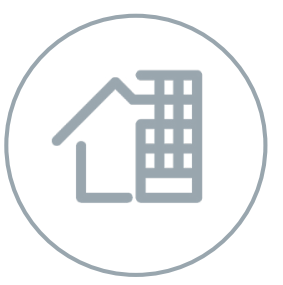

Intensification 


\section{0}

The previous chapter has provided the foundational planning of the masterplan and with it a solid base from which to develop. However past criticism remains true and the previous works have not yet fully considered how people will experience the site and how the different elements will function.

The following chapter changes scale once more, breaking the scheme down into key design areas that can then be explored in a greater level of detail. These focus on key areas such as transport, way-finding, connectivity and amenity, which consider how different aspects of the scheme come together and how primary elements integrate with the wider context. 
Development Area 1

The Transport Hub

The Transport Hub is situated at the heart of the Town Centre providing links between the centre and the wider region. Rapid transit light rail serves as the primary spine of the network, providing frequent transport in both directions up and down the coast and to the Tauranga CBD. This is aided by a secondary local bus network that serves the immediate suburb and areas south. Additional facilities include ride sharing, bike and scooter parking and hire facilities providing a choice of modes, depending on distance and destination.

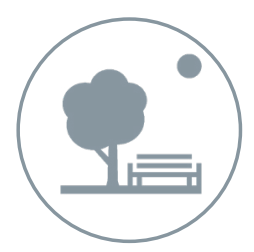

Vibrancy

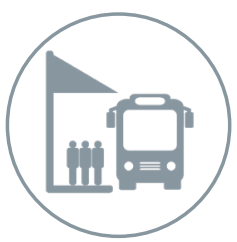

Transportation

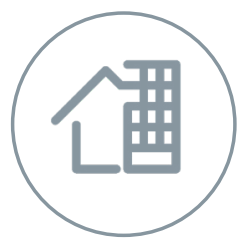

Intensification 


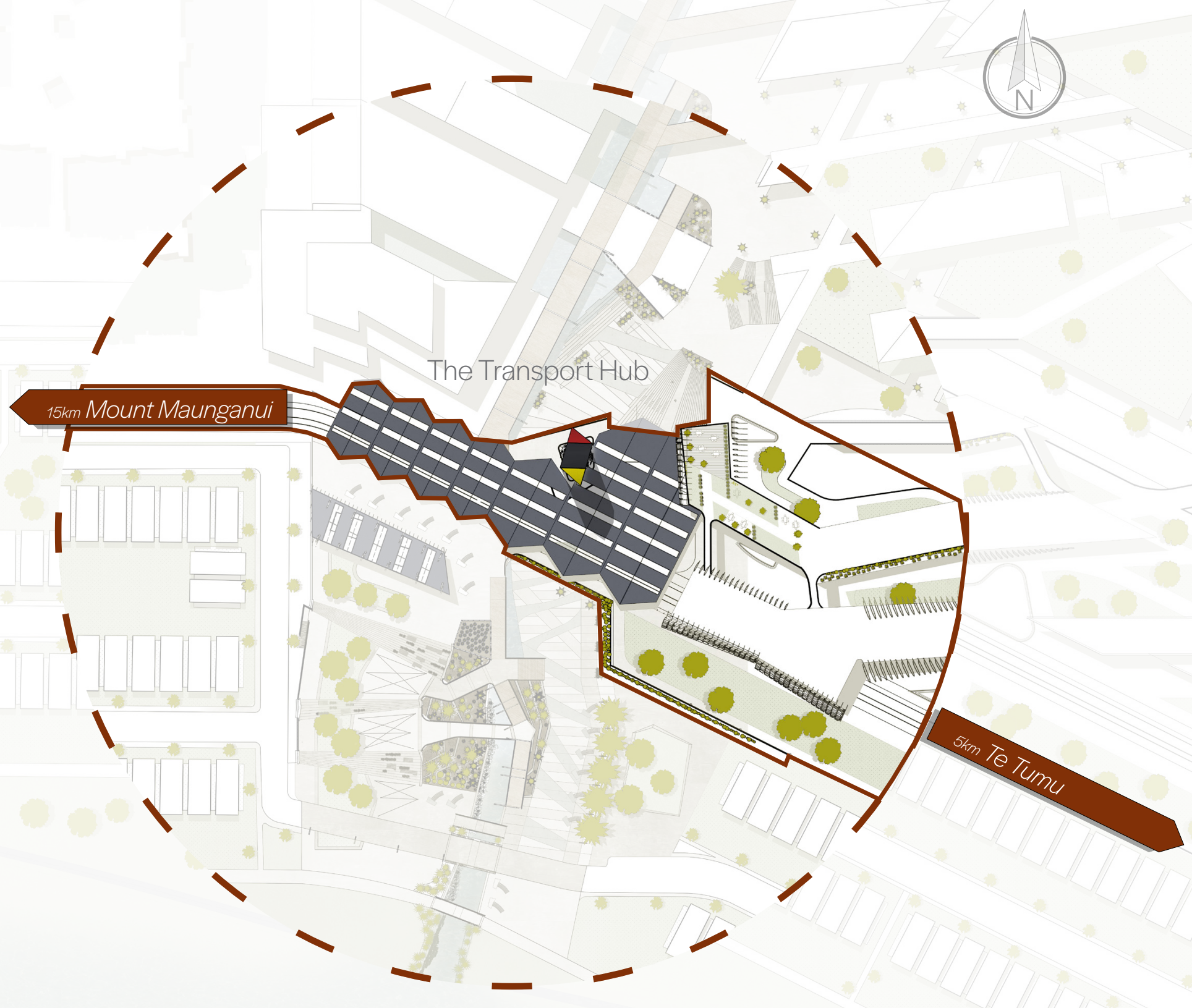




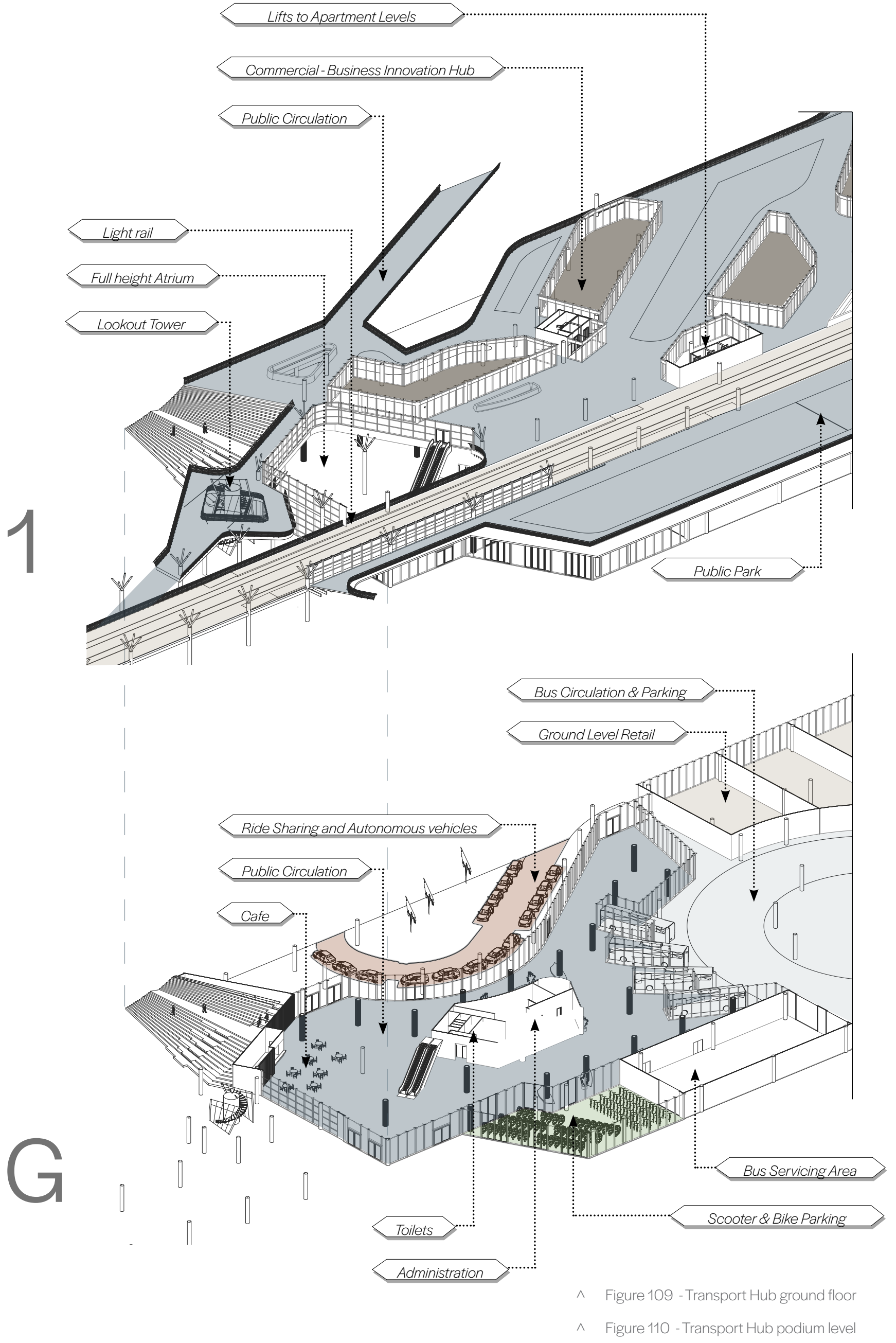




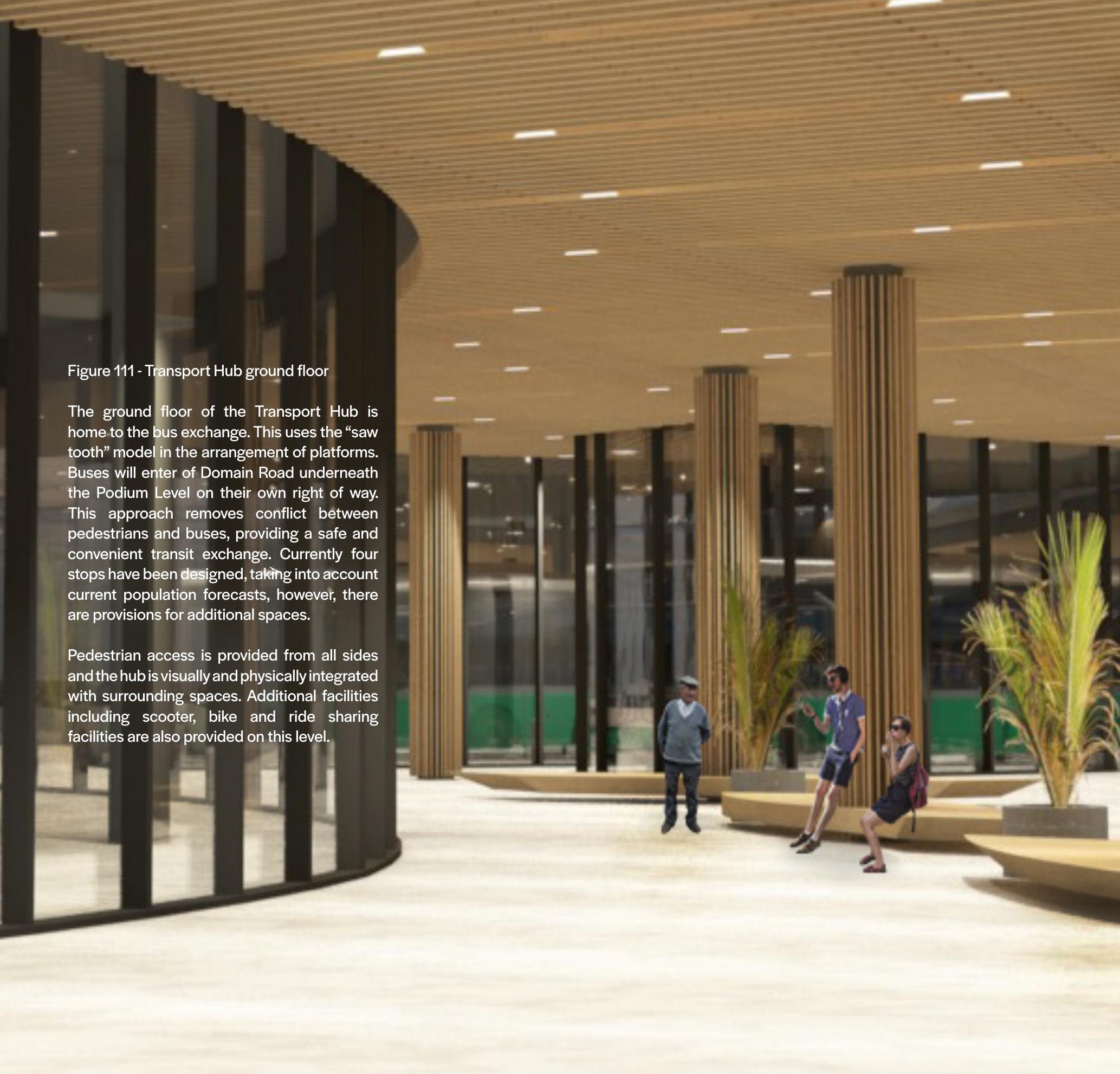





\section{Sightlines}

Reinforcing the connection down the spine of the site linking the hills to the sea, the canopy of the Transport Hub frames the Papamoa Hills behind enticing the user to look through and beyond. The canopy itself is designed to mimic the hills with larger sections to the east gradually reducing in size as the hills diminish from view.

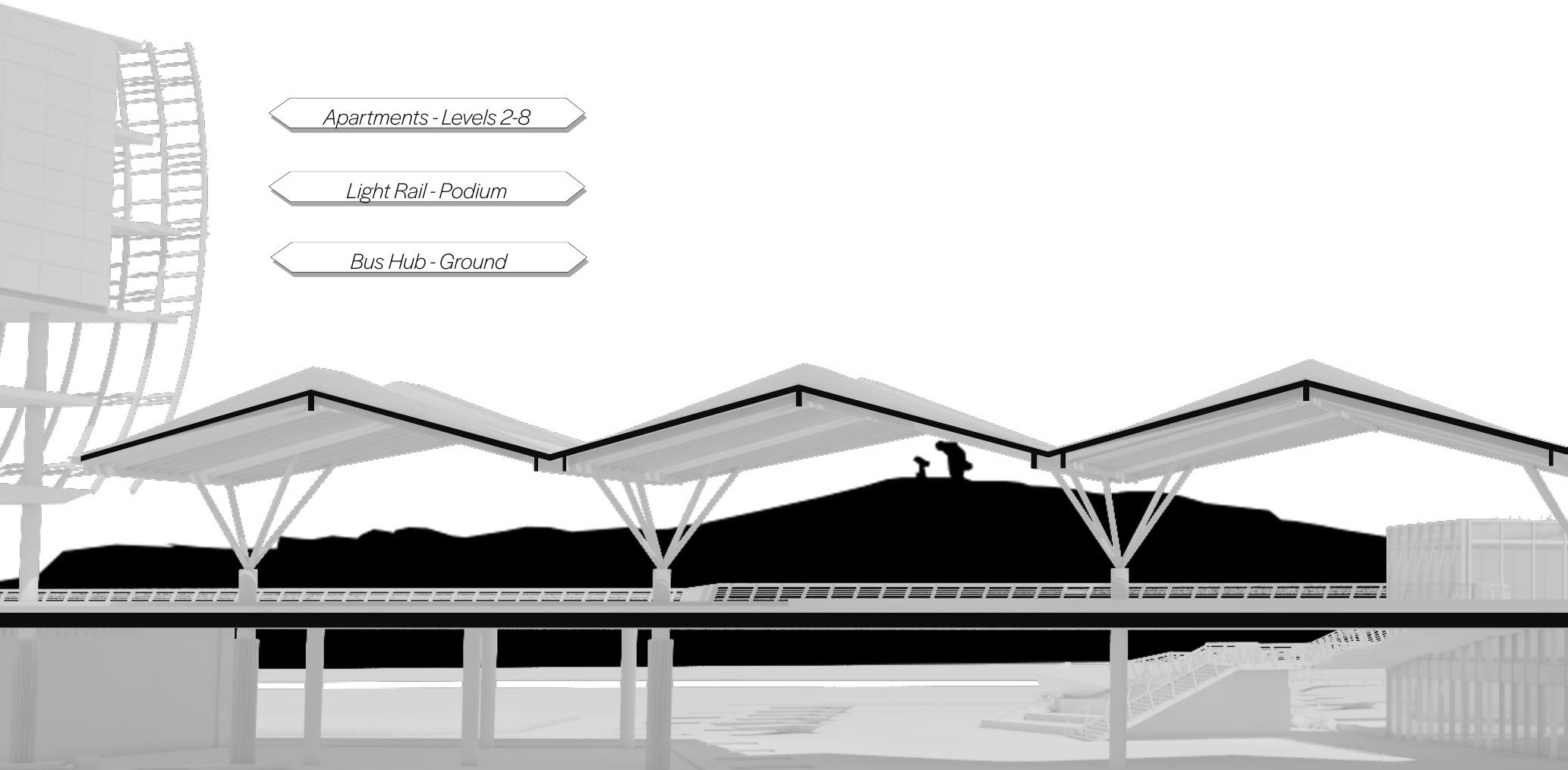

$\wedge$ Figure 113 -Transport Hub section looking south to Papamoa Hills 
Papamoa Beach

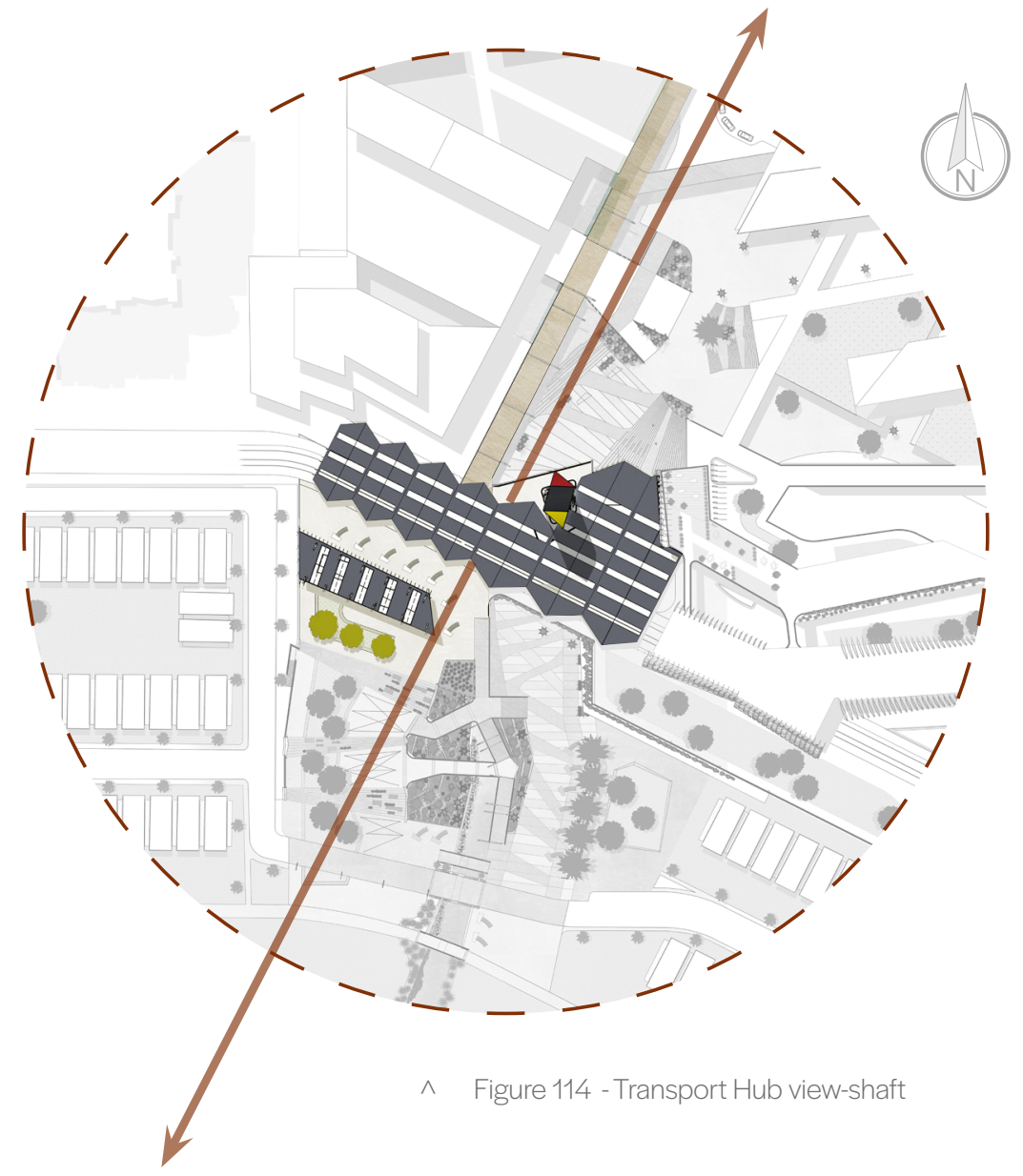

Papamoa Hills
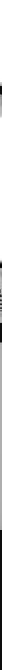
Figure 115 - Transport Hub ground level external

The ground level of the Transport Hub seamlessly engages with external spaces. Visual connectivity is maintained through transparent boundaries allowing the user to look in and through the internal spaces.

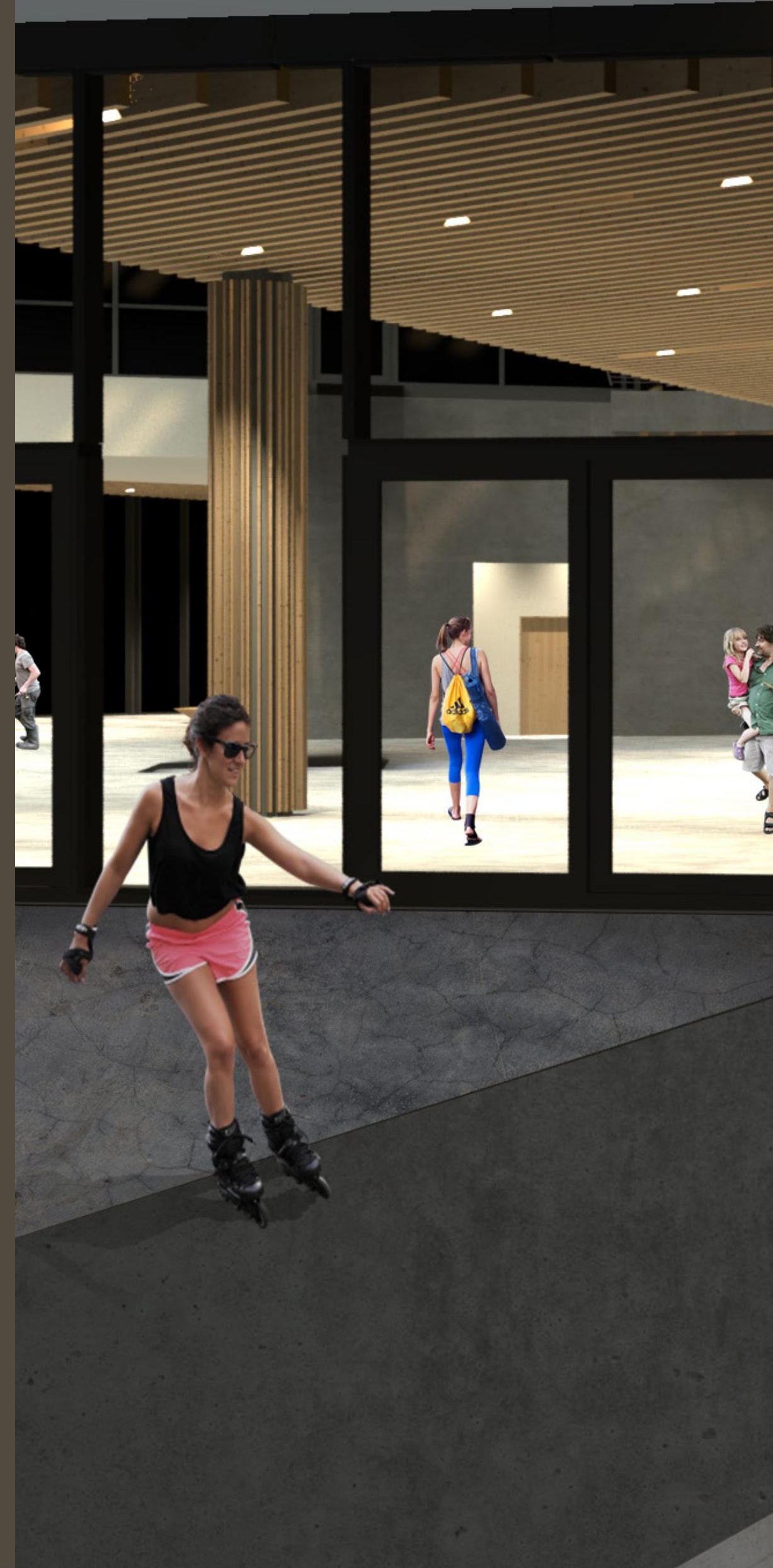




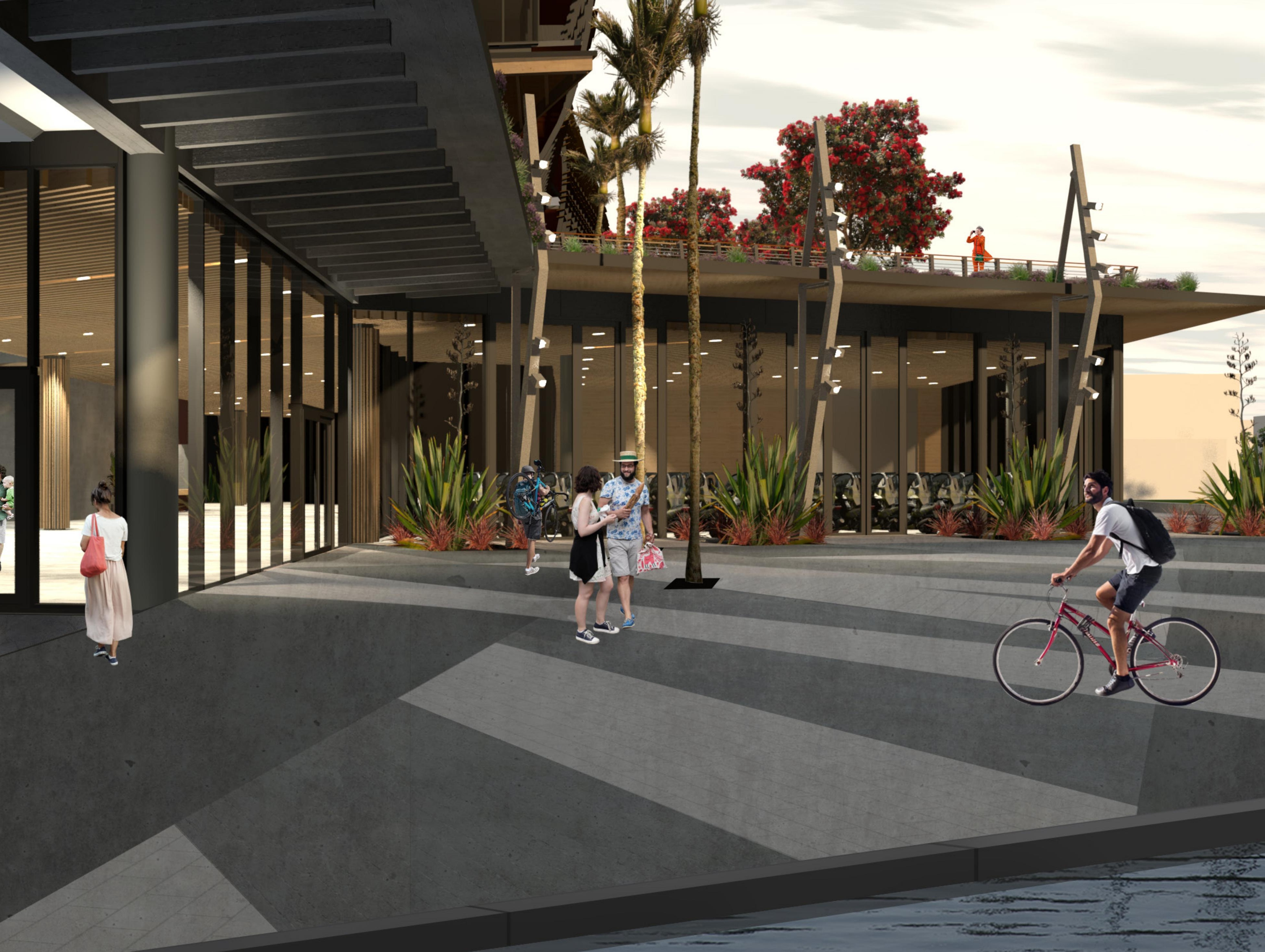


.

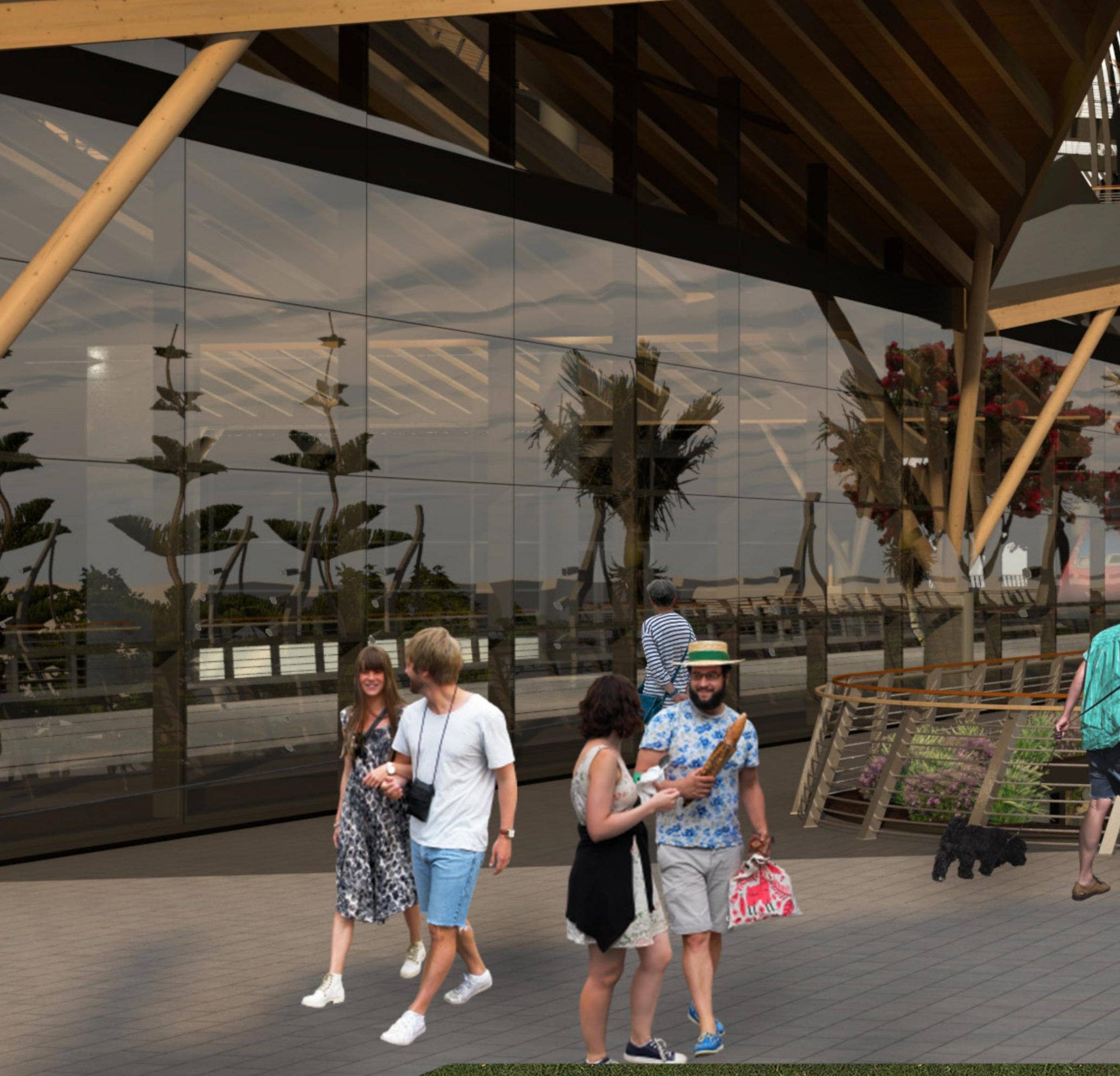

Figure 116 - Transport Hub podium level external (south)

The podium level of the Transport Hub integrates with the surrounding

parks and public spaces. 


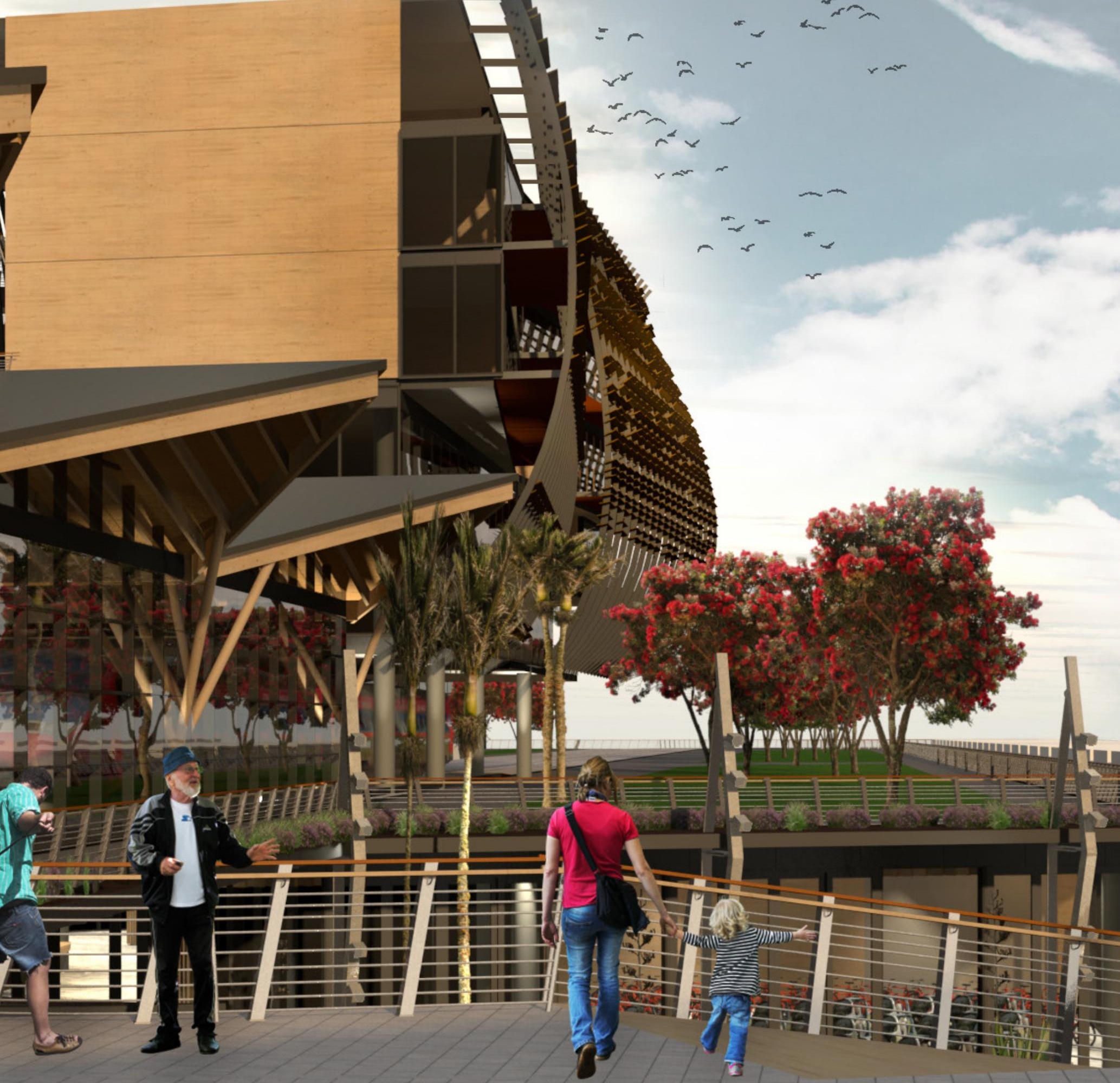


Development Area 2

The Plaza

The Public Plaza is the heart of the town. Designed as the primary public space the Plaza marks the convergence of several arterial routes, the entrance to the repositioned mall, and direct connections to the new Lookout Tower and Transport Hub. The space is a place of meeting and gathering.

Vertical circulation between the Ground and Podium Levels encourages inhabitation and the amphitheatre seating of the transport hub stairs doubles as a place for people to sit during events such as markets and festivals. On the Ground Level circulation is dotted with inhabitable areas and interactive elements such as the stream which enables interaction through tiered steps leading into the water. Interactive installations also encourage active engagement by the public.

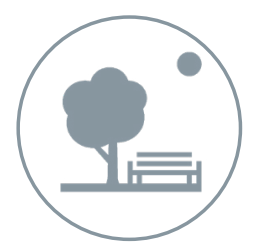

Vibrancy

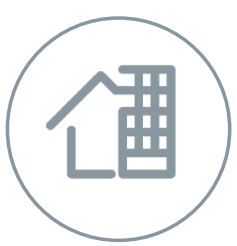

Intensification 


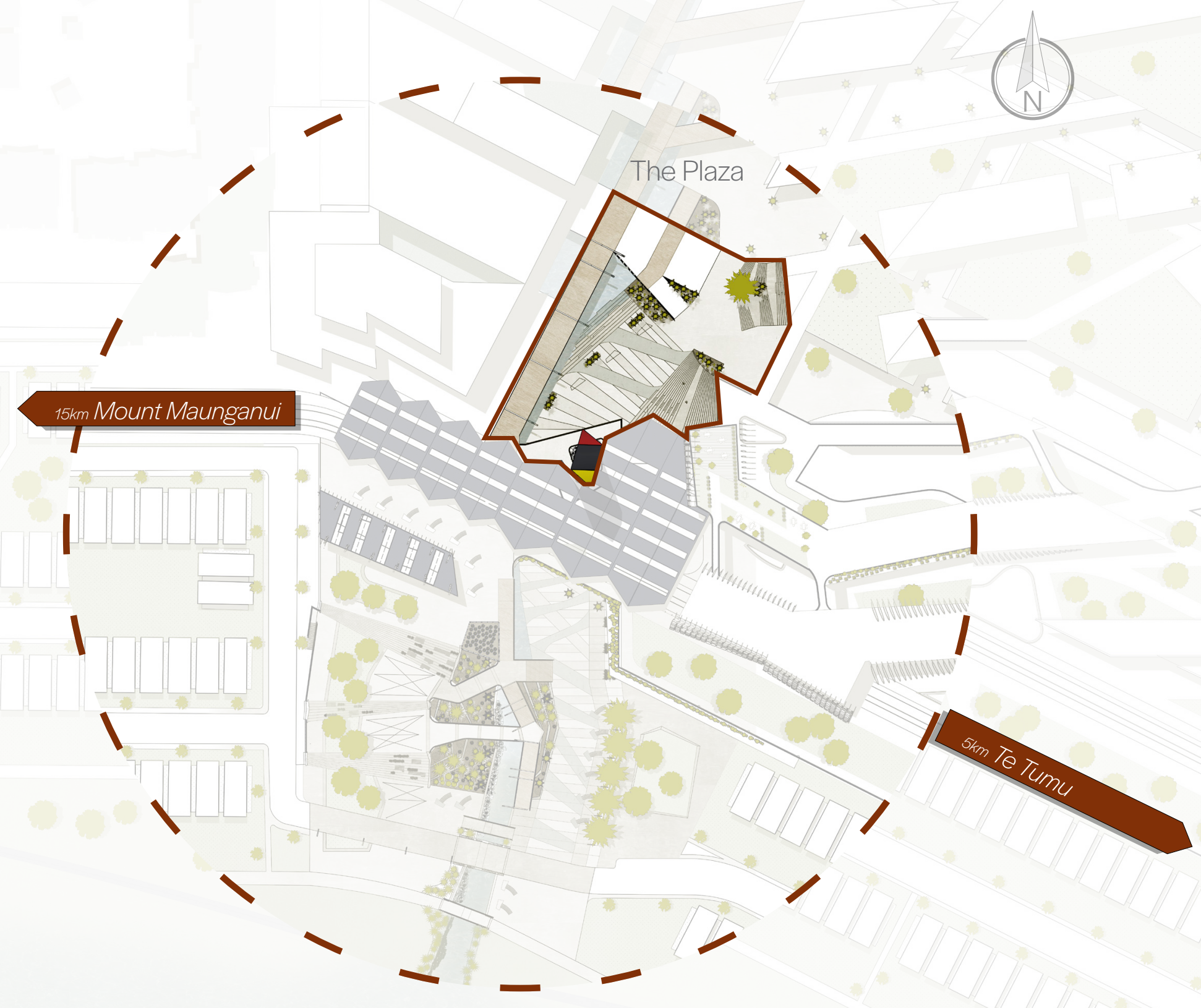




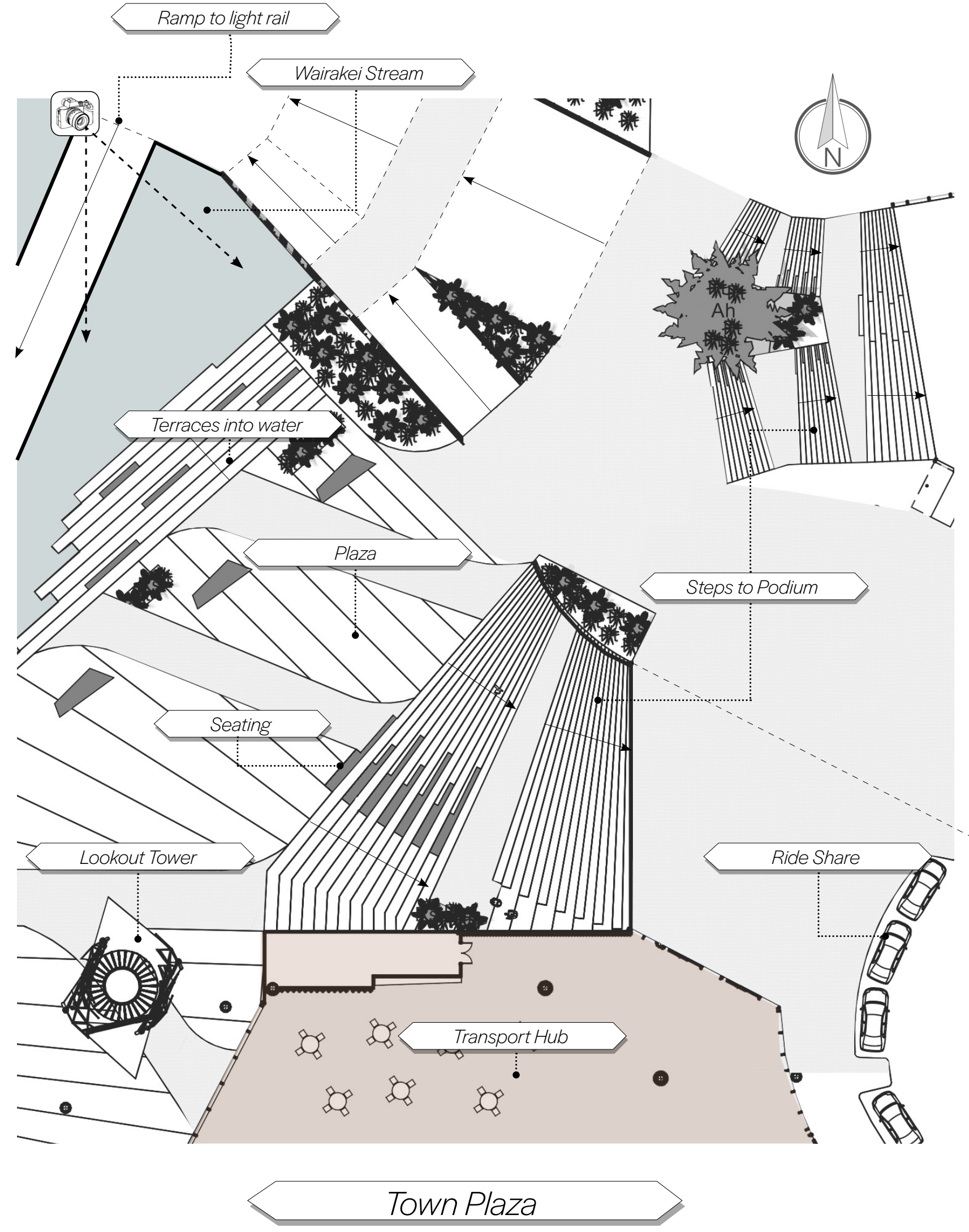



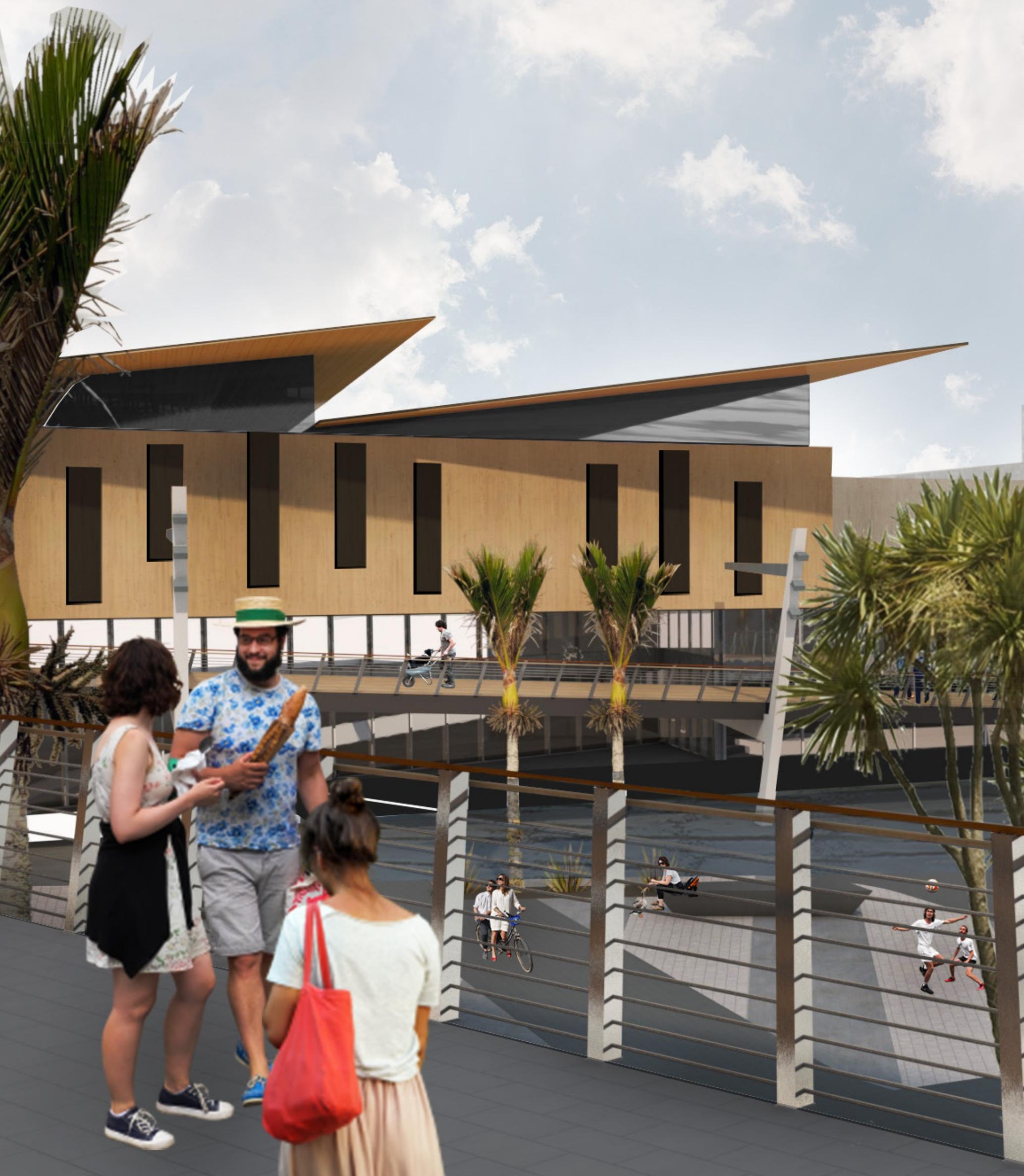

Figure 121 - Public Plaza viewed the podium level of the Transport Hub 


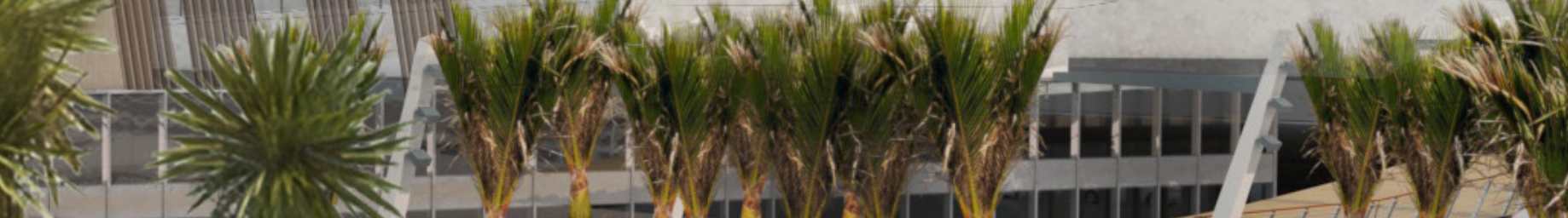

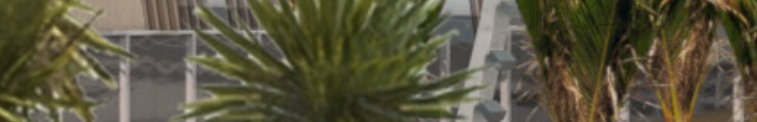

\section{-}

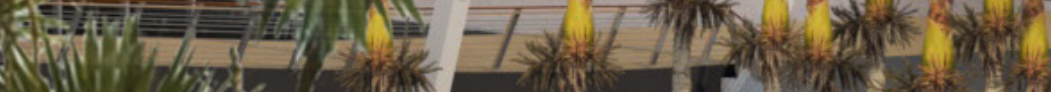

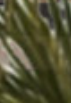

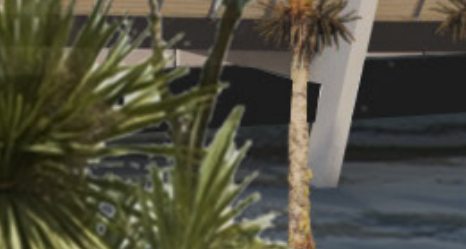

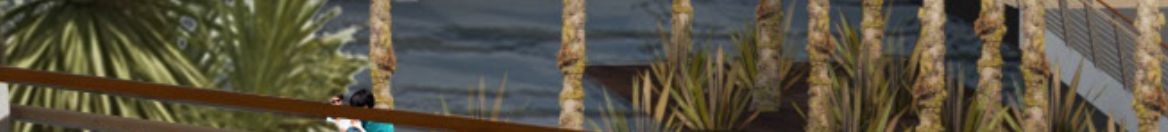

Milit

$\frac{1}{16}$ iil

$\frac{11}{11}$

indill?

$\frac{1}{1}$

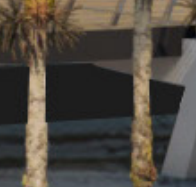




\section{Development Area 3}

The Terraces

The Terraces are an urban park conceived as a link from the light rail to the lower concourse. This primarily acts as a linking mechanism between the two levels of the centre, but also forms an important urban moment for people transitioning between different living modes. The creation of an urban forest facilitates this change from home to work and provides a space that integrates and celebrates the natural features of the site, orientating the view back toward the south, linking in with the Papamoa hills and inner green network of Papamoa.

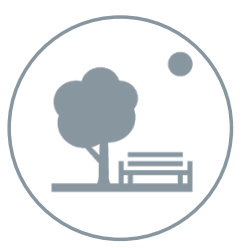

Vibrancy

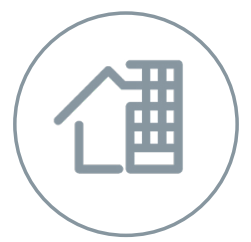

Intensification 


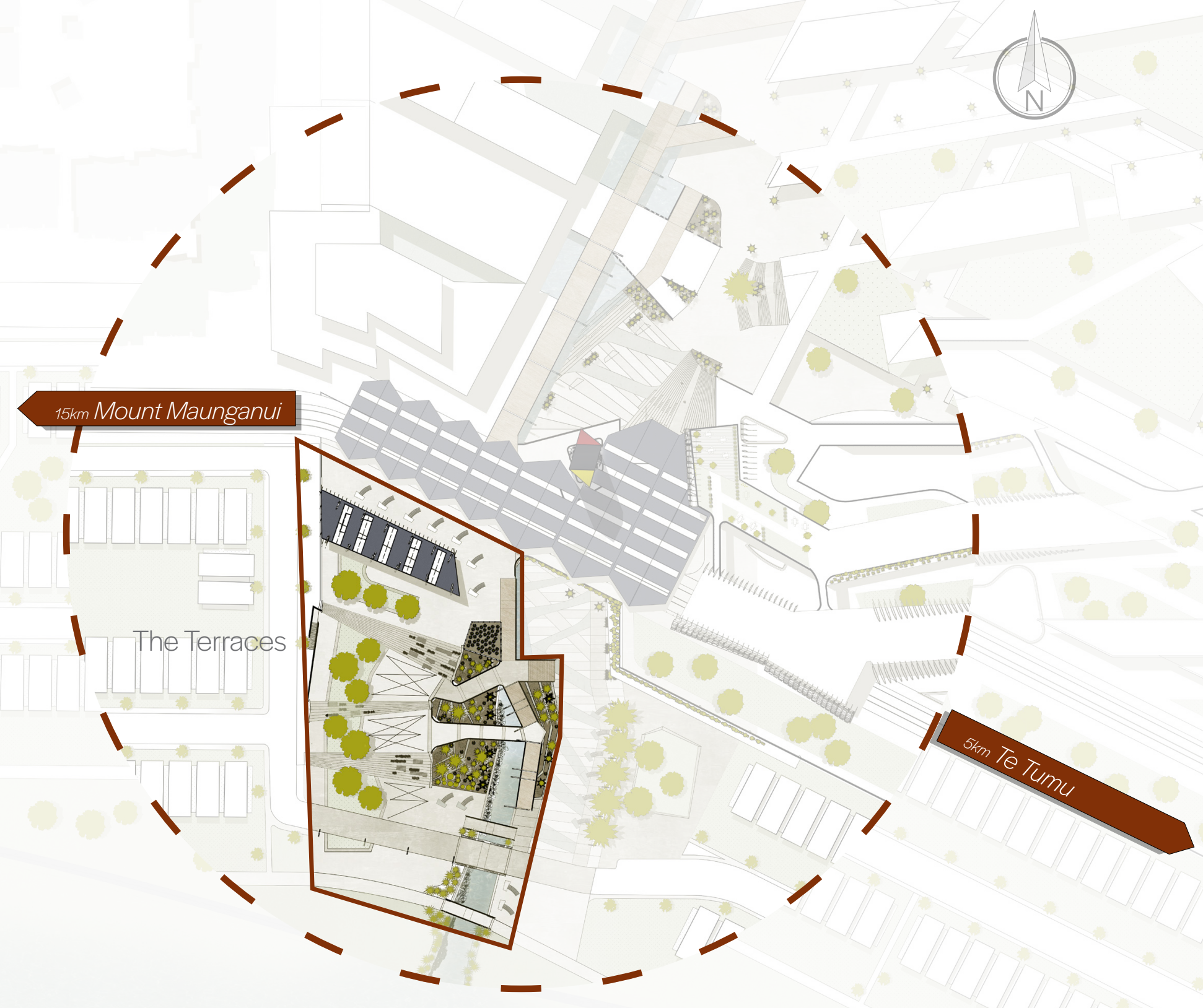




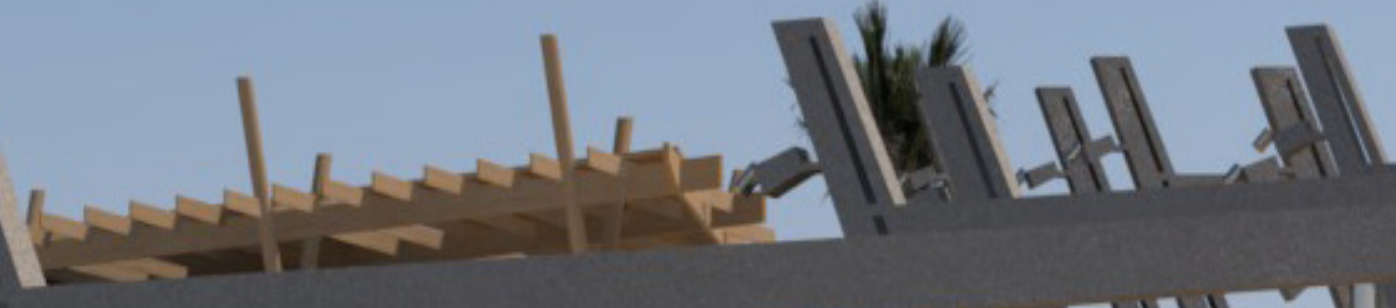

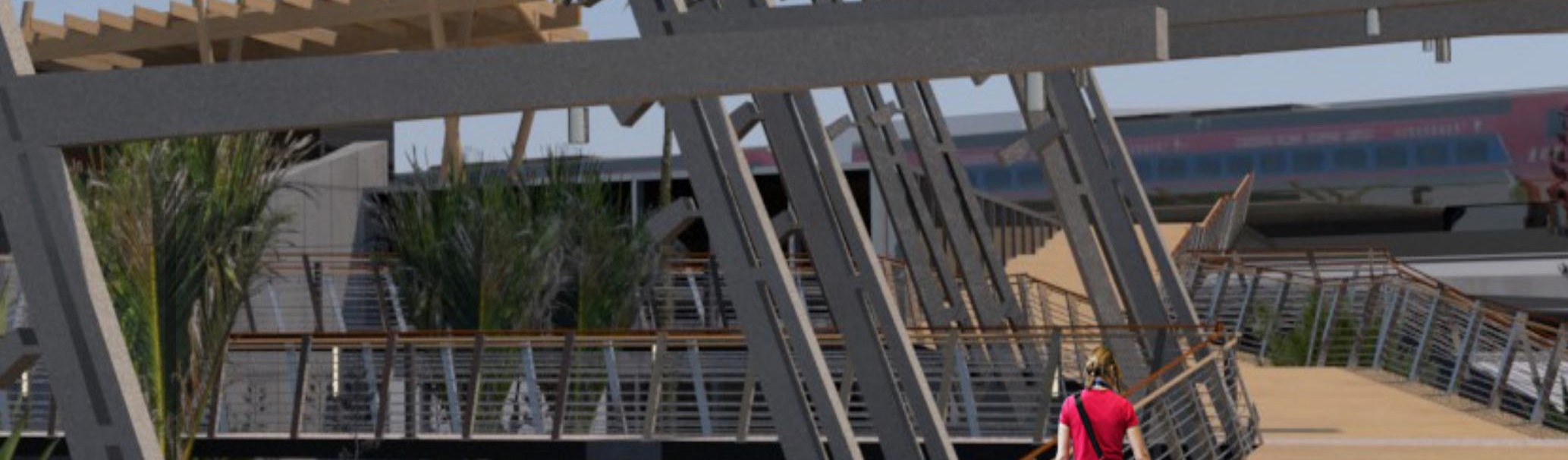




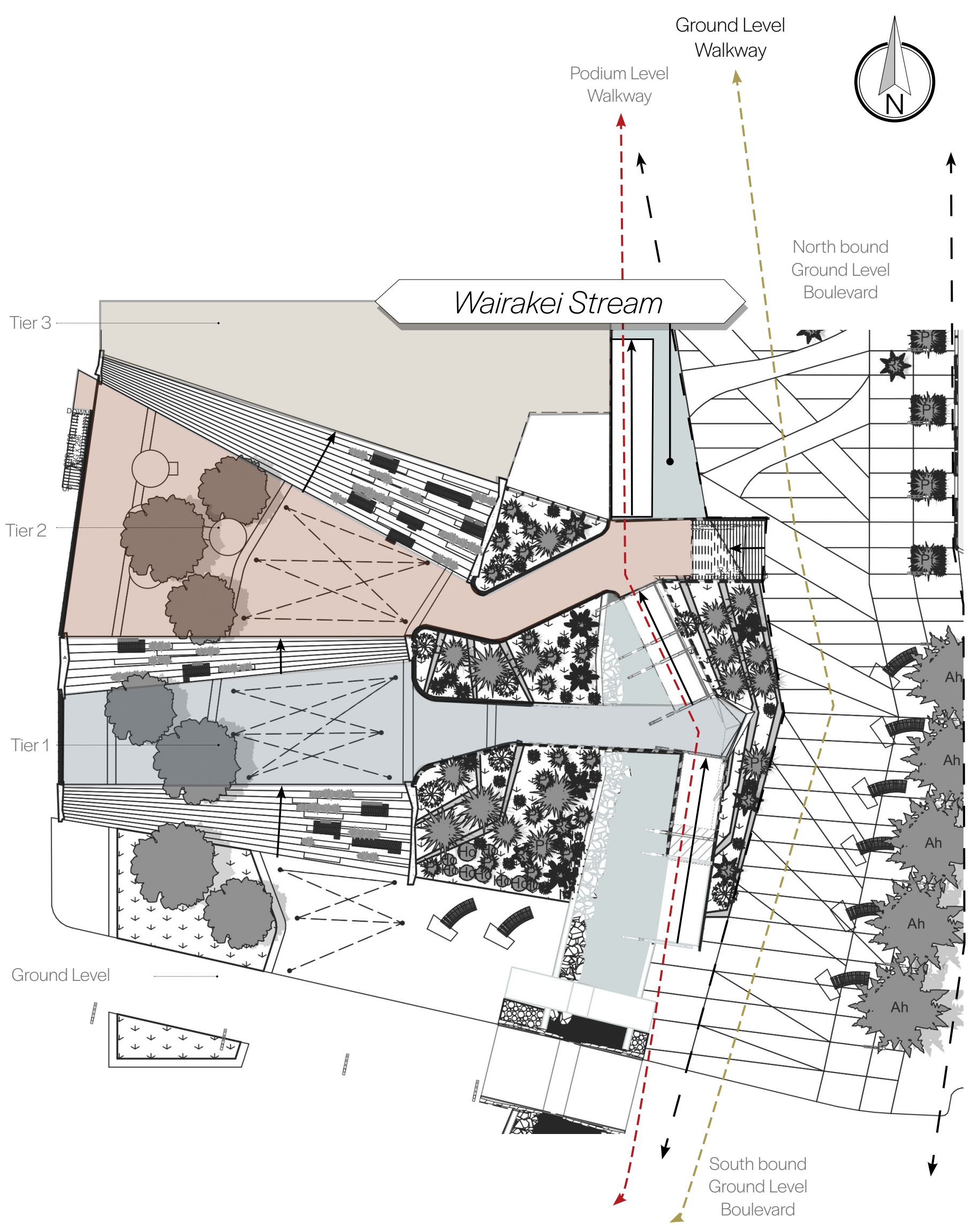

Elevate Park 


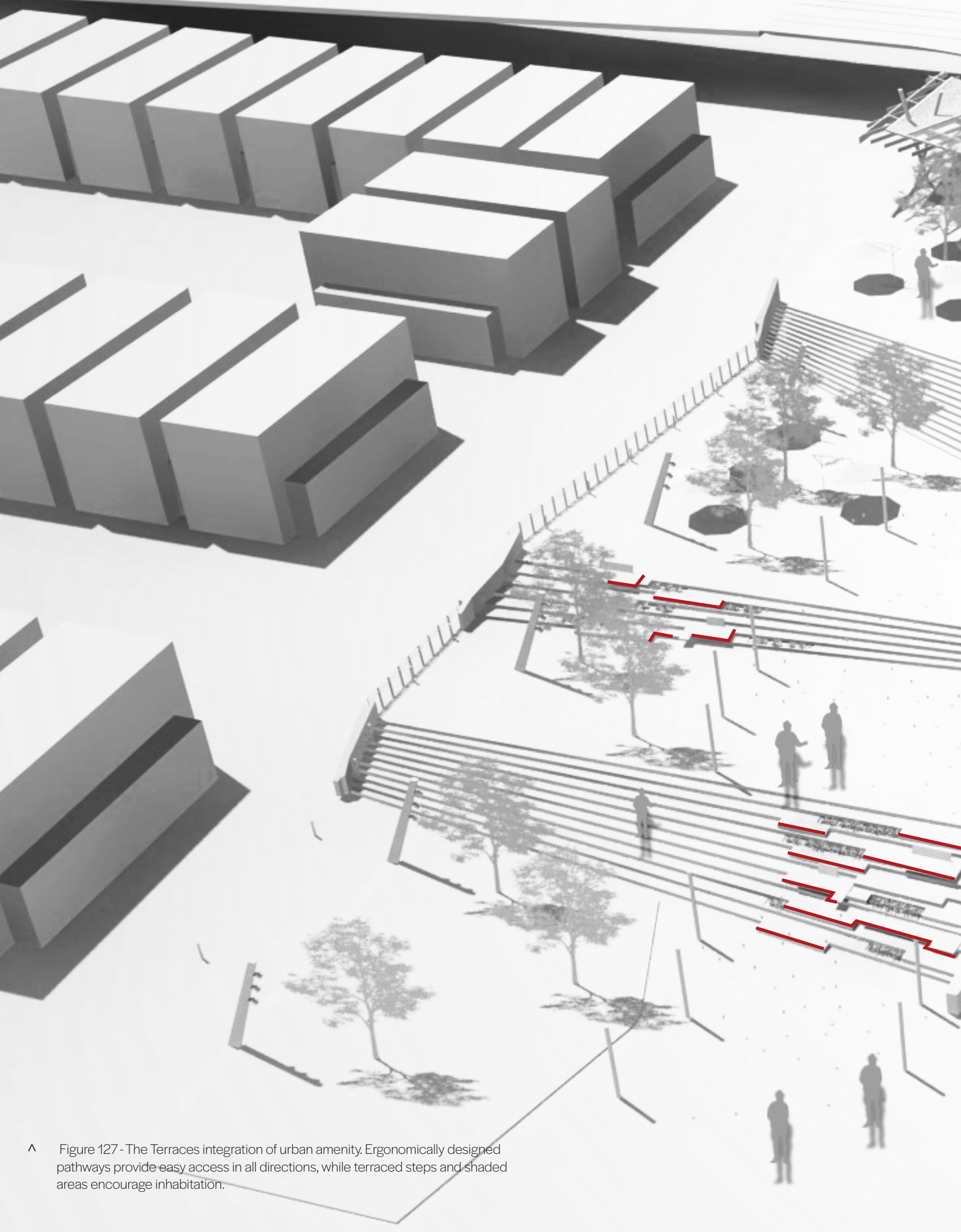




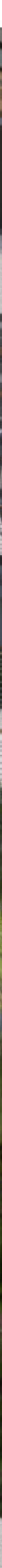


atias

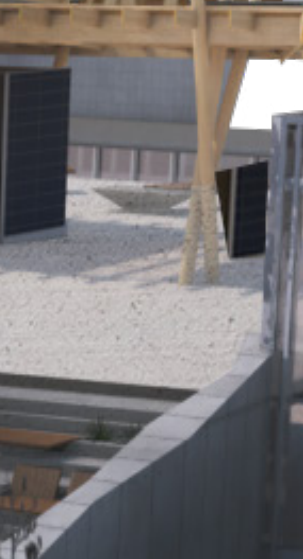

(x)

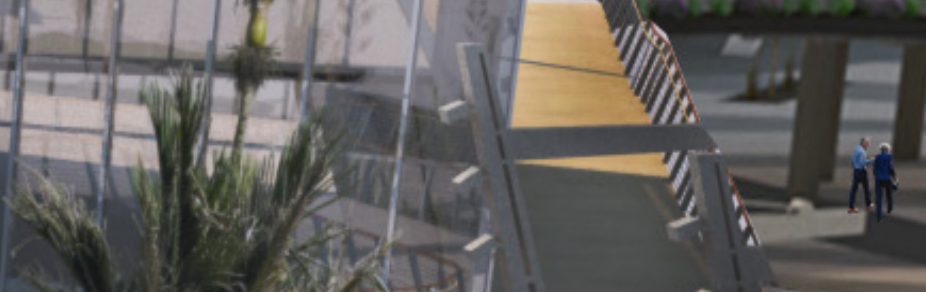

$x=9$
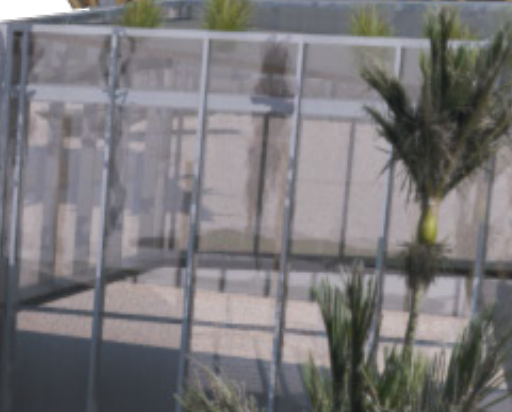

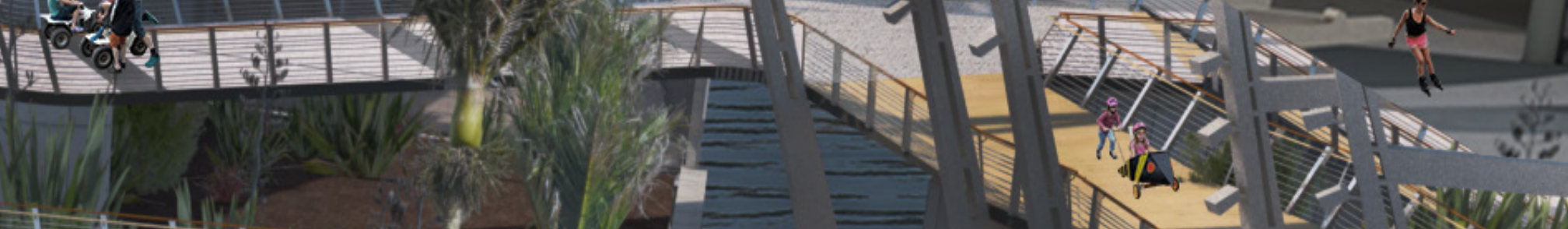

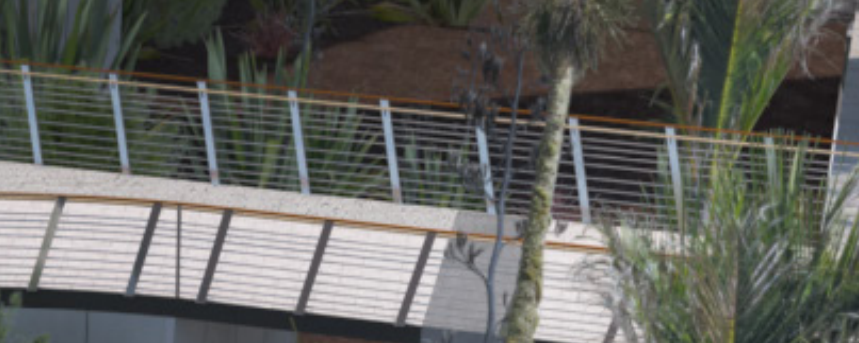
4

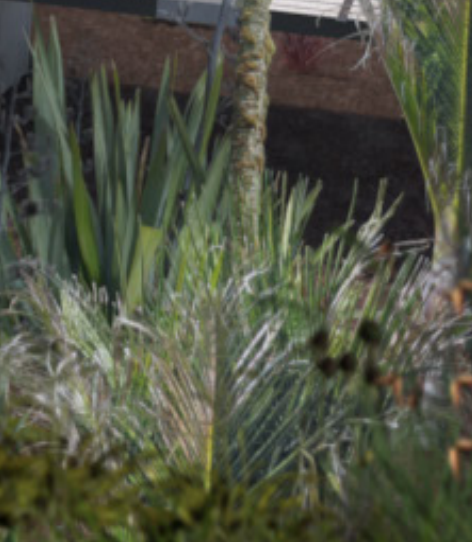

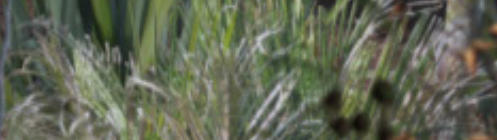

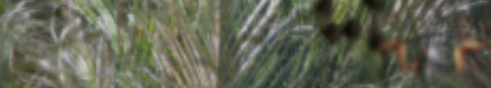
(4) $\sqrt{2}+2$

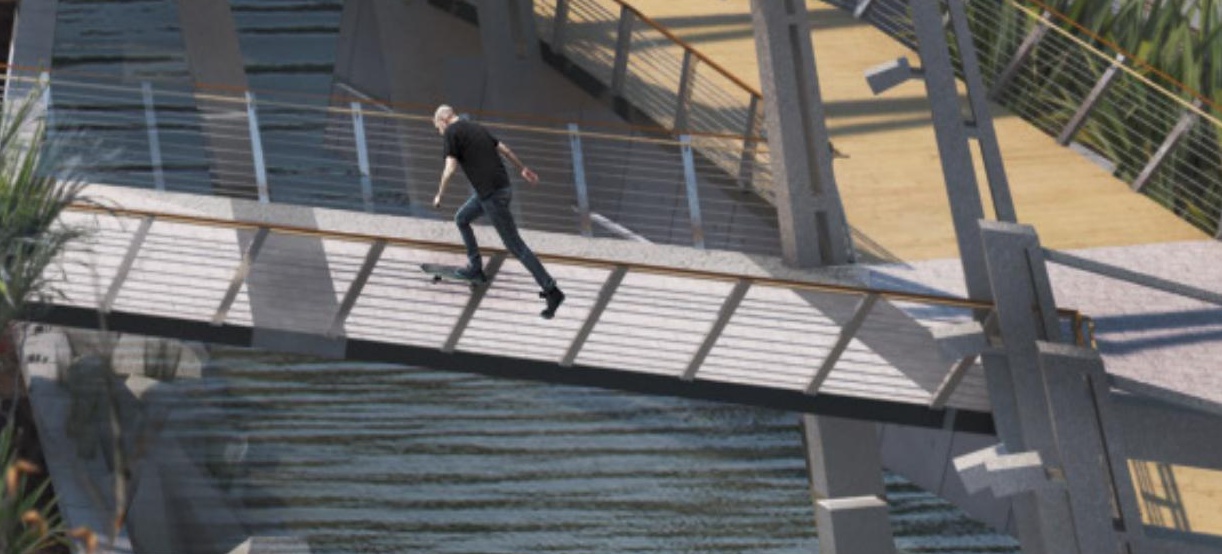

1

(

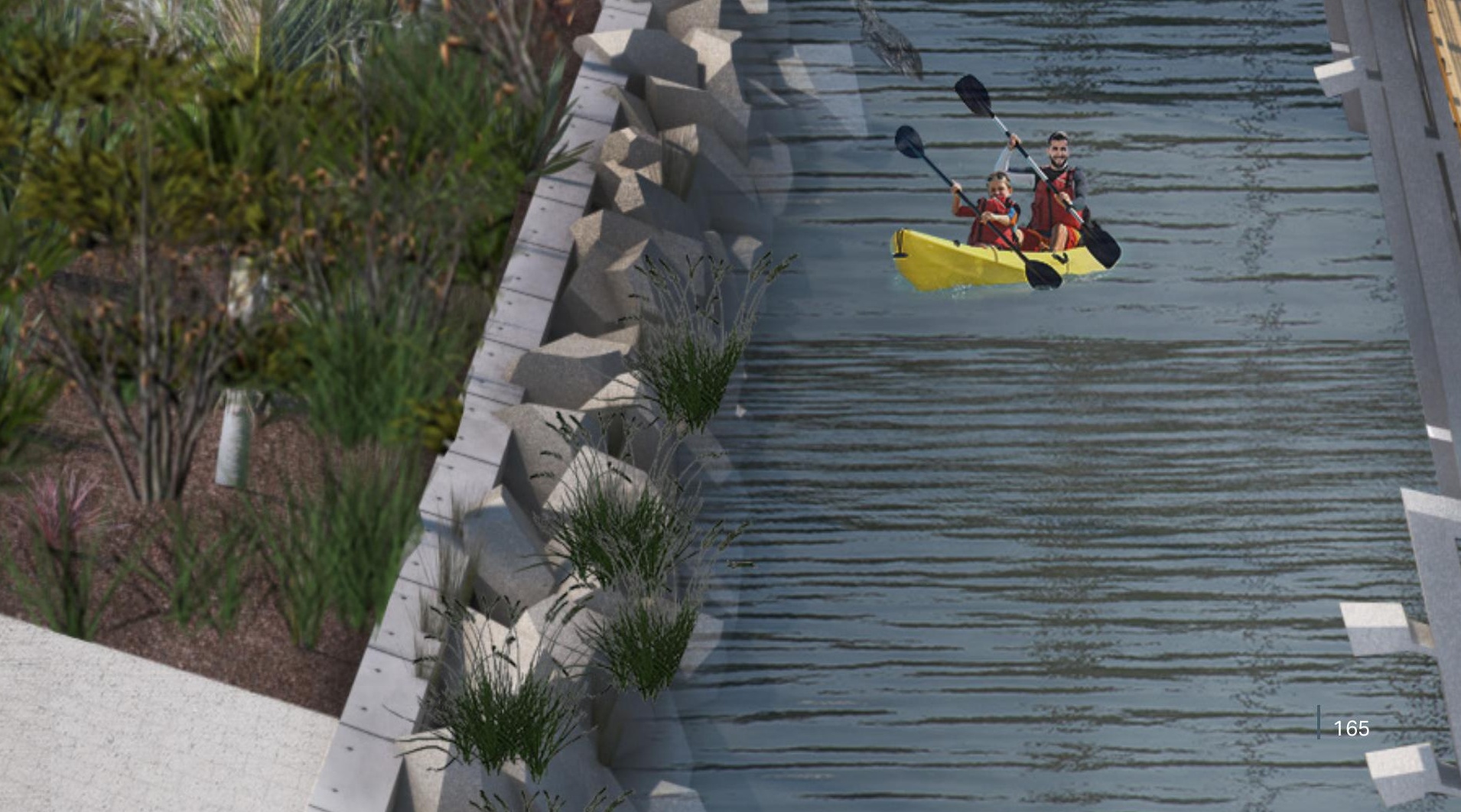




\section{A coastal ecology}

Michael Sorkin - 'Local code'

Sorkin has developed a system of rules and guidelines of what a good city should have. Two key elements are his definition of blue and green spaces which loosely apply to the inclusion of natural elements within the built form through waterways, urban forests and other ecologies. In this research a strong emphasis was put on the reconnection of the former Wairakei stream and the inclusion of the coastal ecology as a part of the site development (Sorkin, 1993).

\section{The Terraces}

Re-established wetlands 


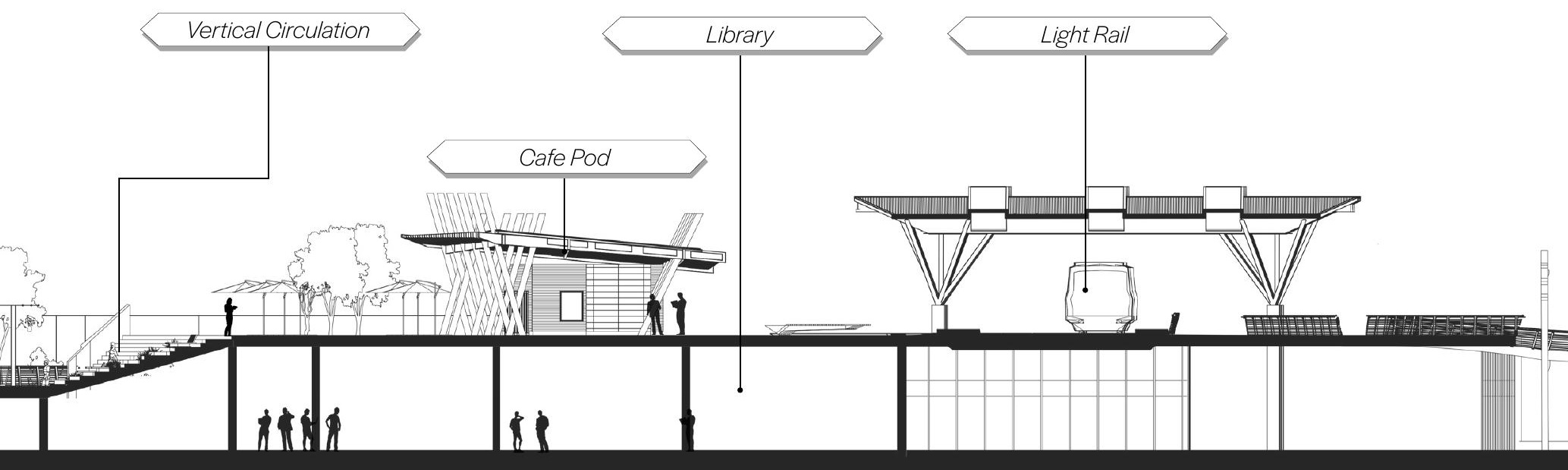

$$
\text { B-B }-\cdots \rightarrow \text { North }
$$




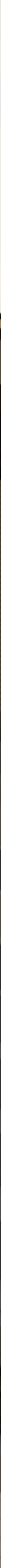




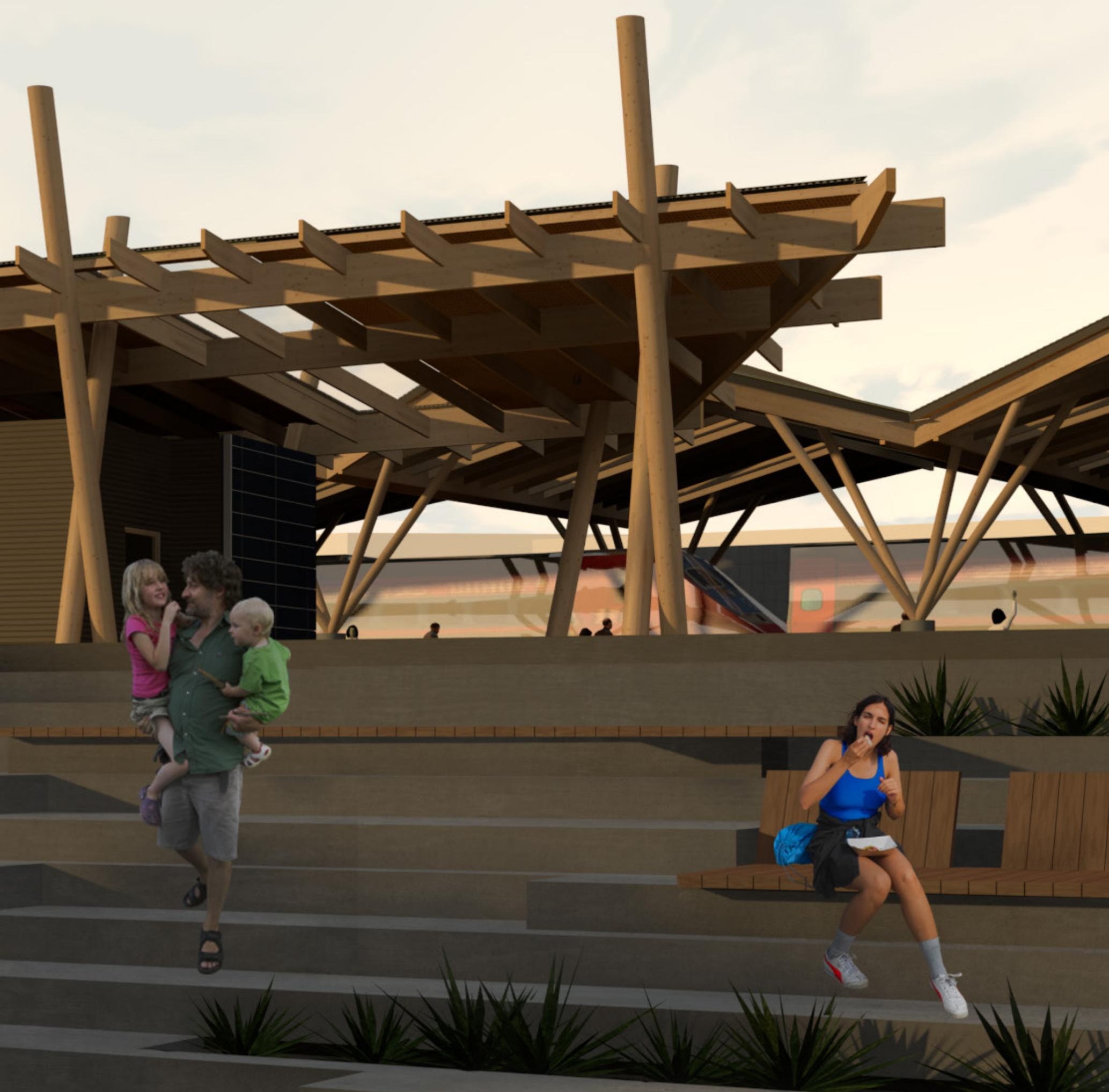

anlys whown 


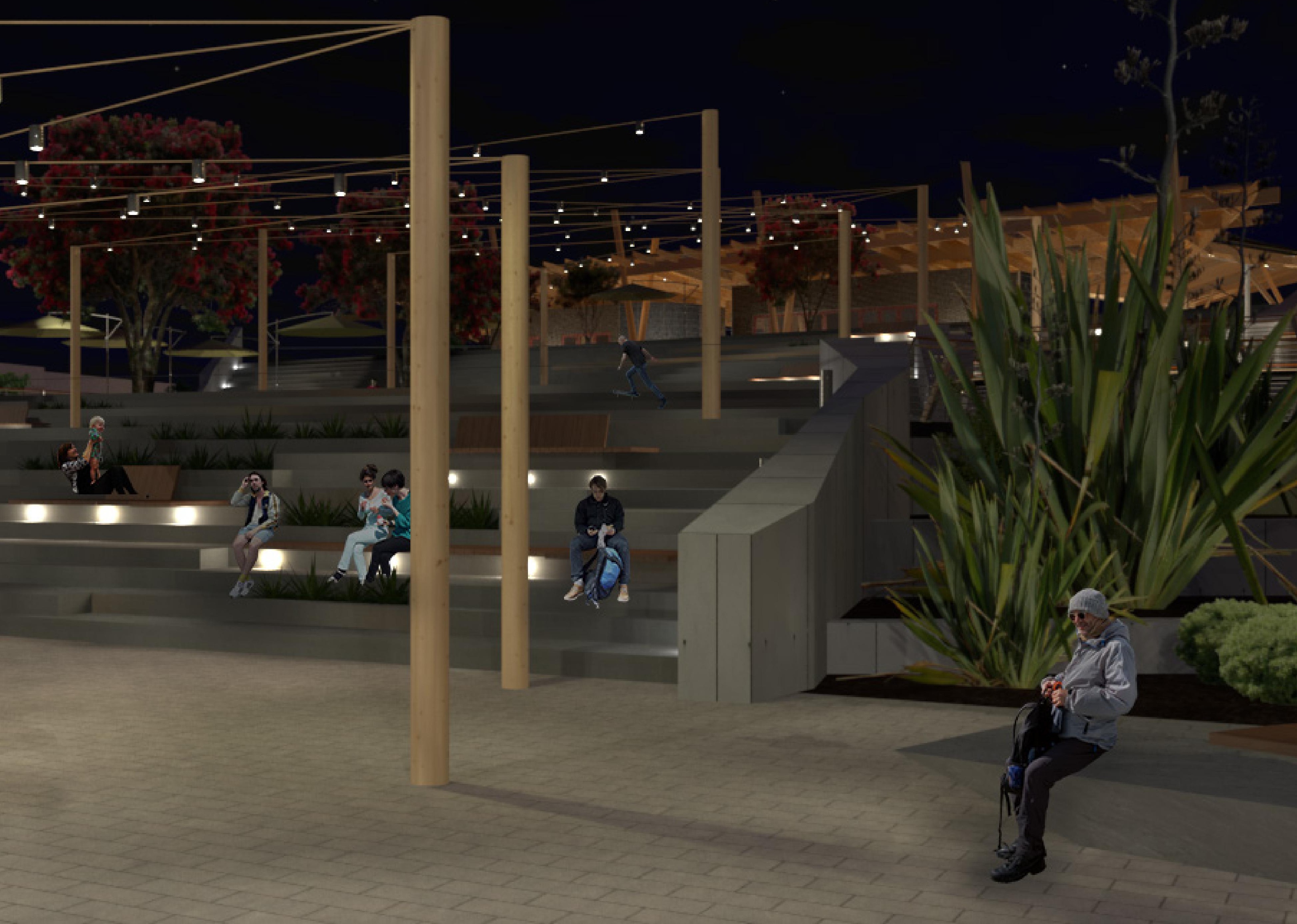




\section{Development Area 4}

The Tower

The Lookout Tower serves as a local and regional landmark from which people can identify the suburb. Its location denotes the position of the new Transport Hub and Public Plaza at the heart of the town centre, helping to guide people through the centre. Building height and street intersections have been designed to ensure visibility of the structure at strategic locations shown in the exercise previously on page 127. This helps the user to orientate themselves accordingly and provides a visual connection between the town centre and outlying areas.

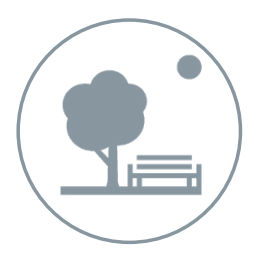

Vibrancy 


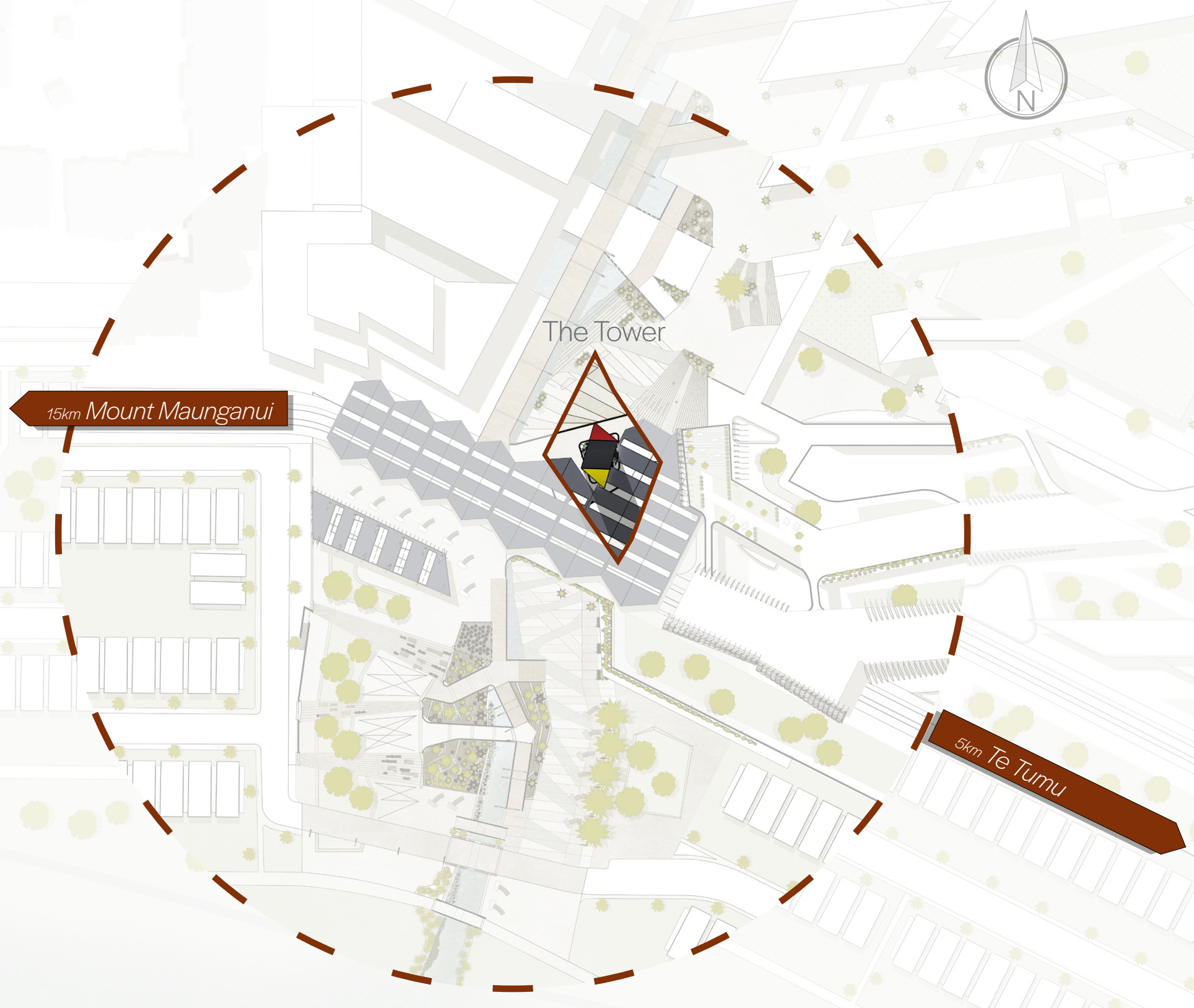




\section{A Local Landmark}

Inspired by Santiago Calatrava's Turning Torsos the tower explores the idea of an evolving view.

This uses the twisting motion of the tower and its spiral stair to orientate the user toward different aspects of the region as they journey upwards.

The floor plate is that of a diamond twisting 15 degrees with each level until it reaches a north south orientation at the top, reinforcing the connection between the hills to sea through the site.

The tower draws off its coastal location referencing the yellow and red of the lifeguard tower serving as a lookout for the region. 


\section{Grounding the Tower}

The tower is linked into the fabric of the city through direct integration with the Plaza and Transport Hub. At the top of the tower is an experience like no other, a zipline runs the full length of the central boulevard providing the rider with a stunning coastal vista as they fly toward the beach.

\section{Town Plaza}

\section{Coastal Connection Bridge}

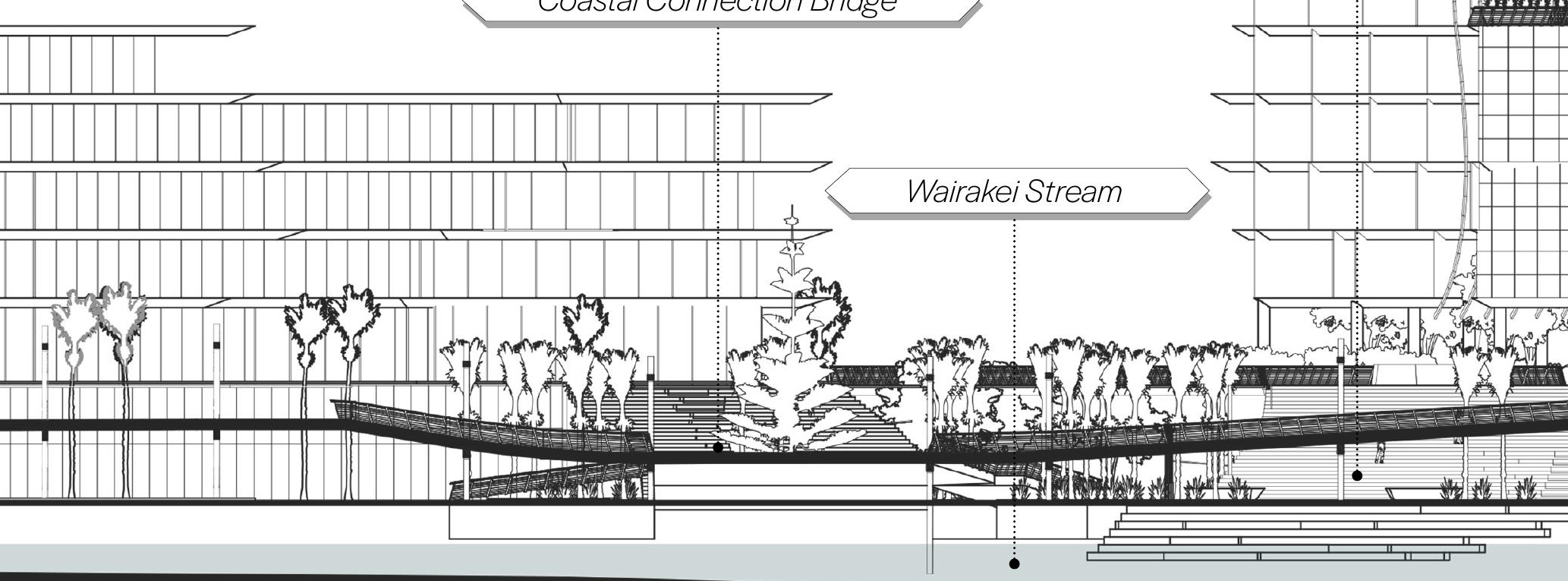




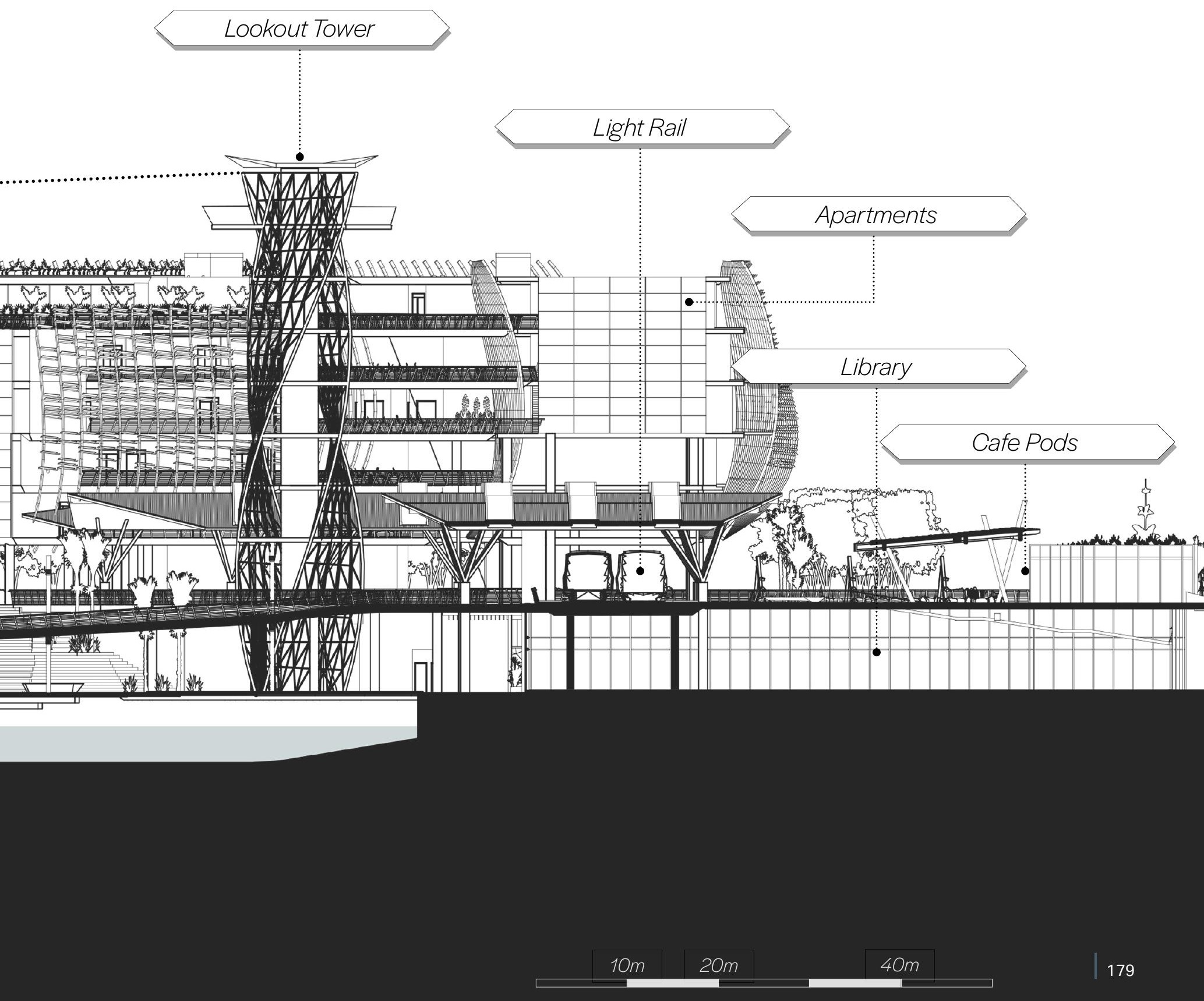






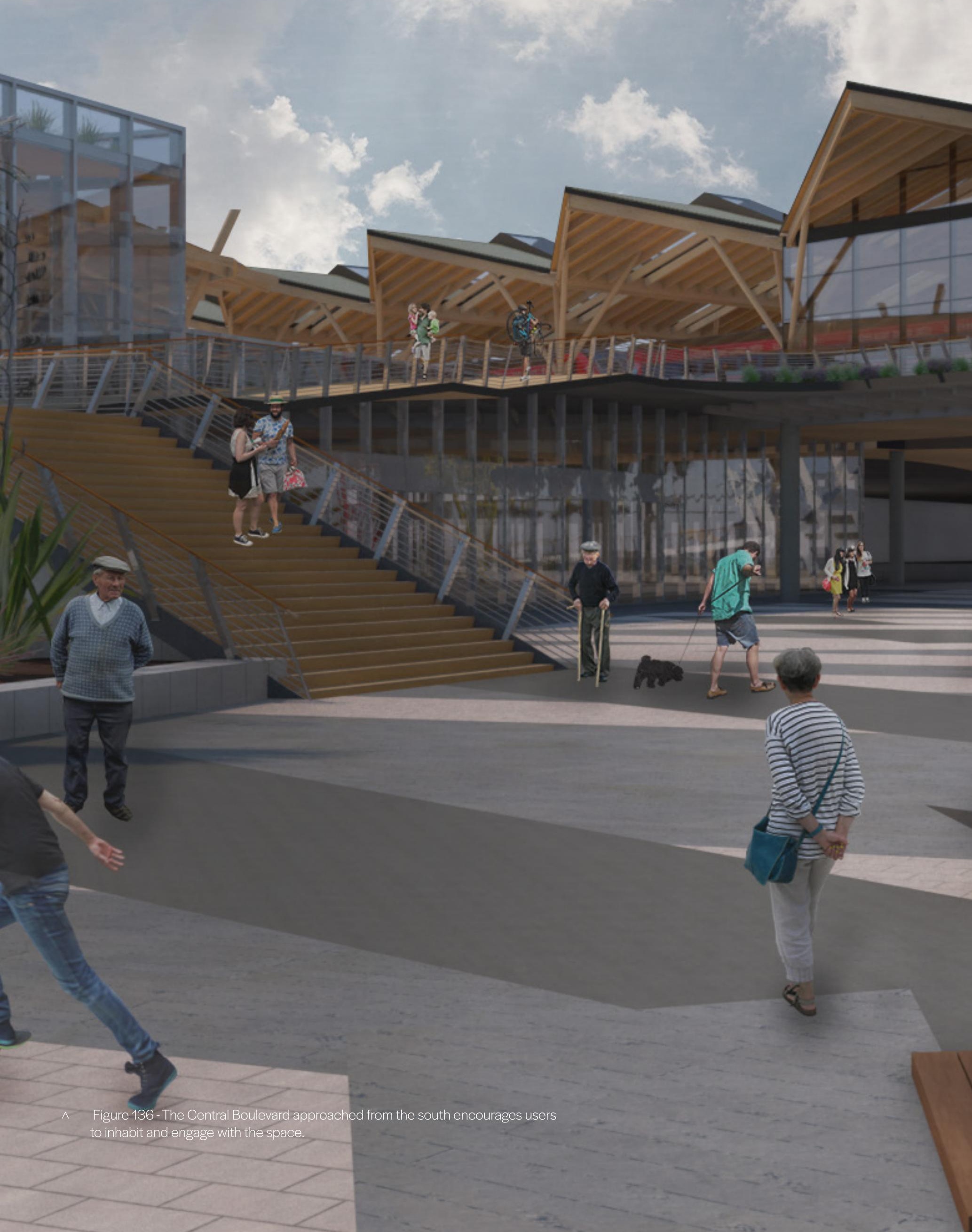




\section{Wher}

\section{$P=1 \times 1 \%$}

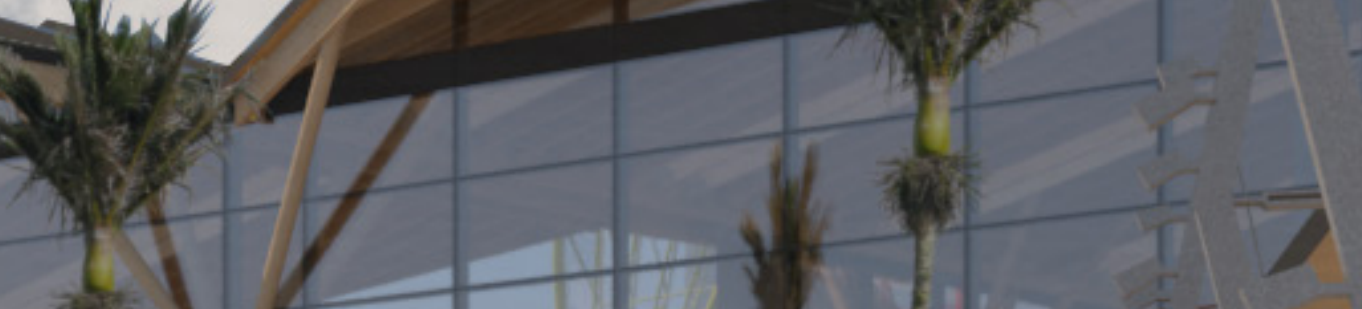

$3-2-1, \frac{1}{4}$

No

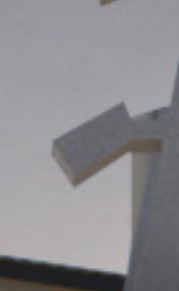

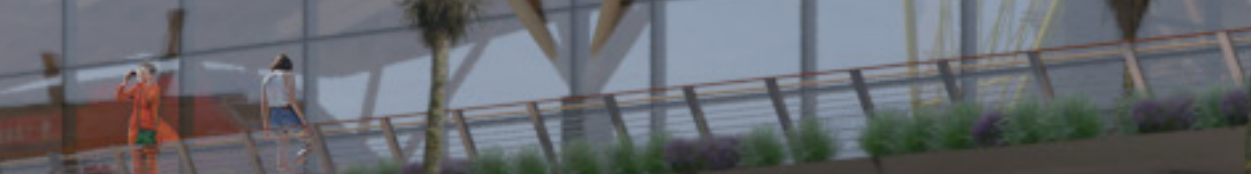

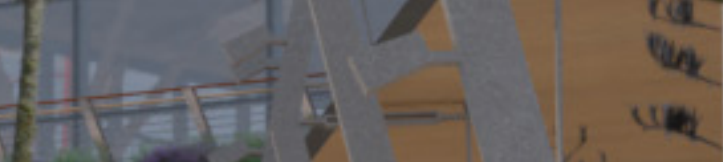
Le. 1.)

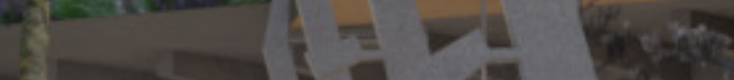


5.1 The Assemblage 


\section{Design Reflection}

'The Parts' provided an opportunity to retrospectively expand upon and dissect the design decisions of the previous stages. Splitting the project into design areas allowed this to occur at a higher level of detail than previous investigations. This stage focused primarily on the quality of spaces and the connectivity between the different urban functions of the site, which has culminated in a city environment designed around connected spaces and the pedestrian.

Ultimately this design is a means in which to explore the underlying principles of 'Assemblage' and 'Connectivity'. It could be argued that certain outcomes would have occurred as part of the natural design process. However, the ability to actively analyse and assess the effectiveness of the scheme through 'Space Syntax's' depth map has greatly sped up this process and improved its effectiveness by accurately identifying connectivity across the site, rather than being left to designer assumption.

This process highlights the importance of public space as a linking mechanism between urban connectivity and vibrancy in our town centres.

By understanding the links between urban structures in assemblage, this research identifies the place of public space as the all-important lynch-pin which binds the site together into one coherent system. 
'A Coastal Co North South Section of Site 
nnection' 


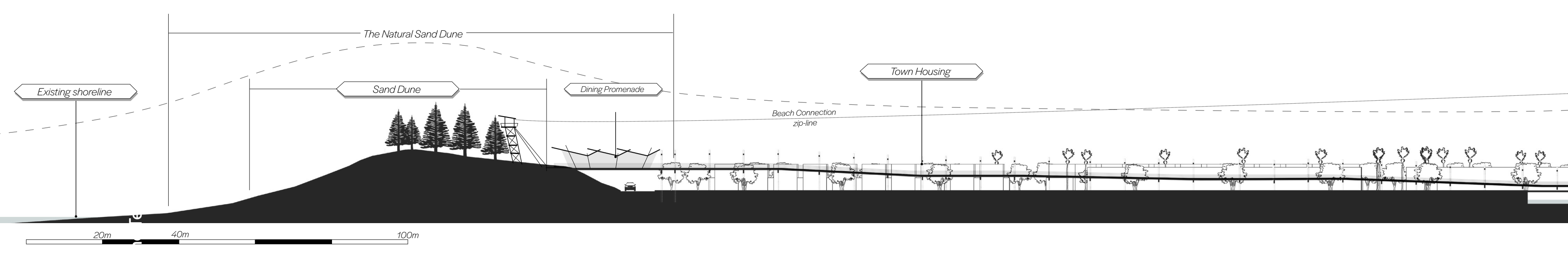

$$
\text { North -.-Section }
$$

Figure 137- The central boardwalk forms the spine of the network and serves as the connector between 
Masterplan - A Connected System

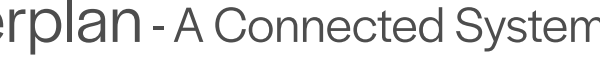

Dining Promenade

Public Space-Podium Level

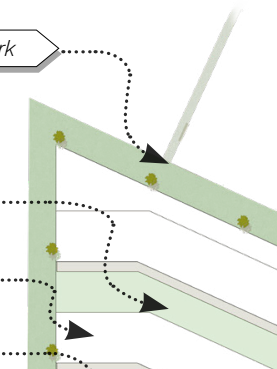

Beach Connection
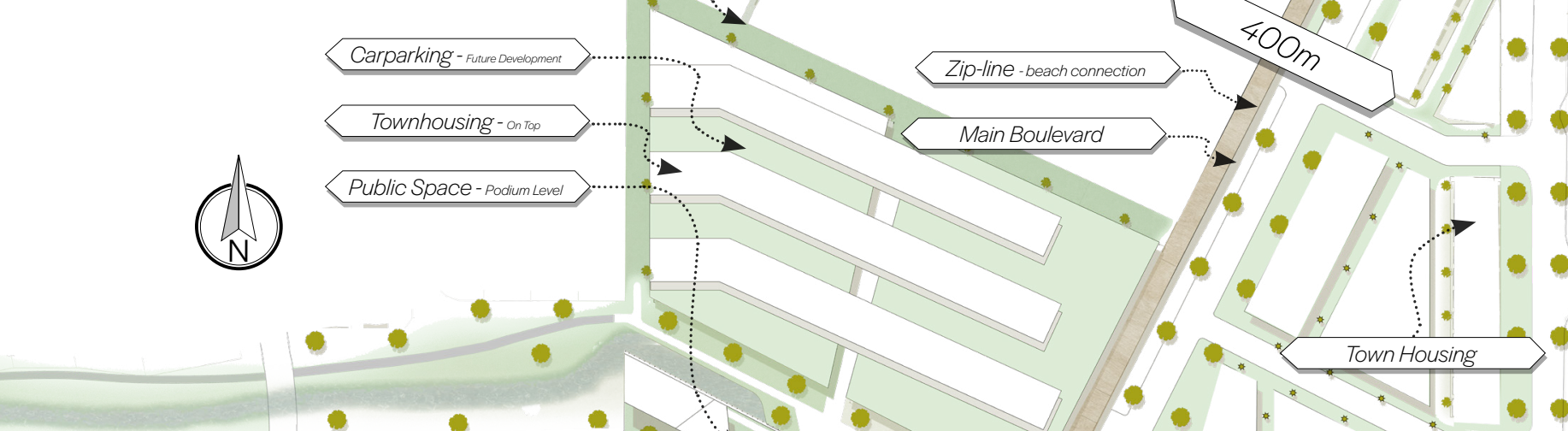

$15 \mathrm{~km}$ Mount Maunganui

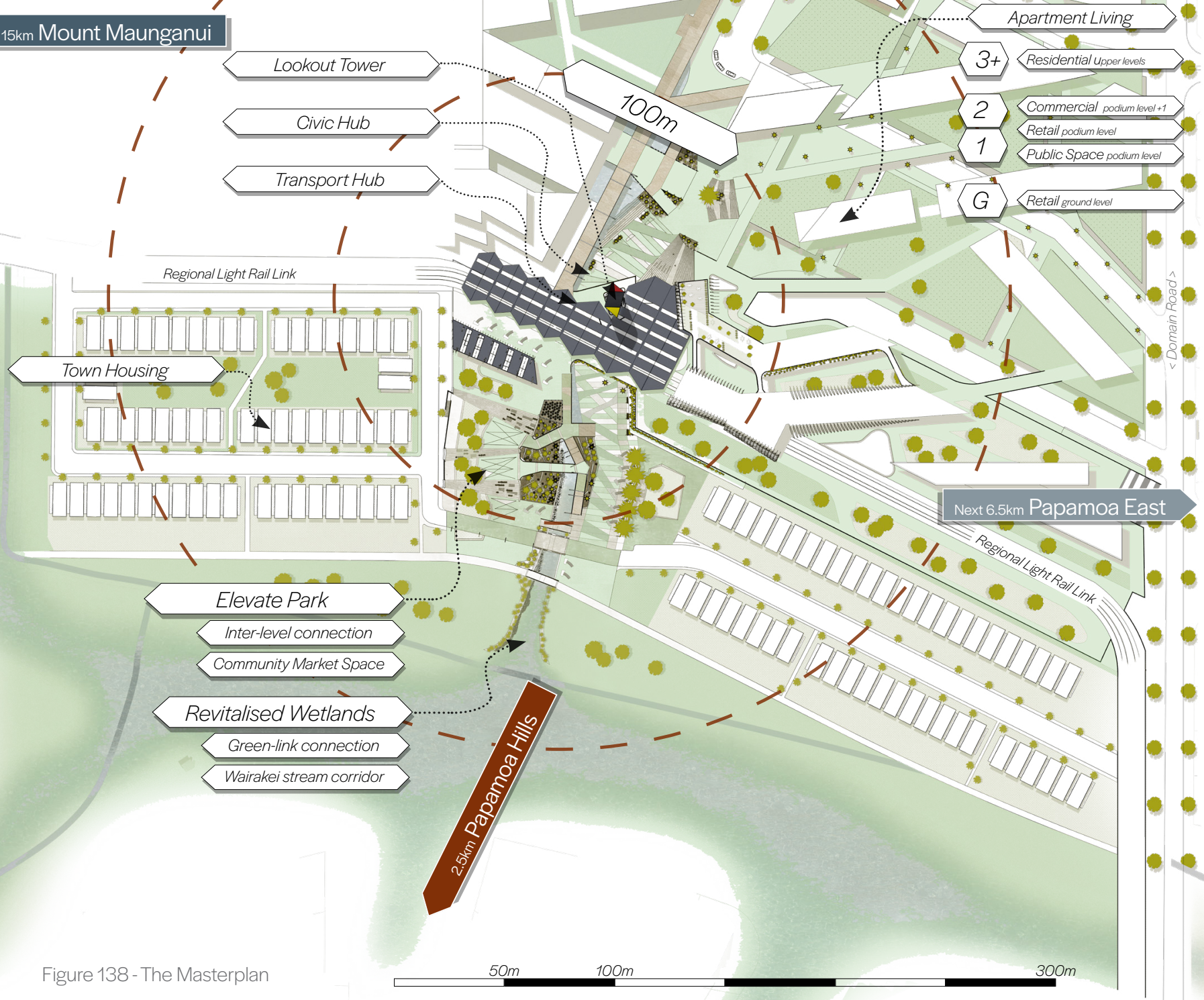



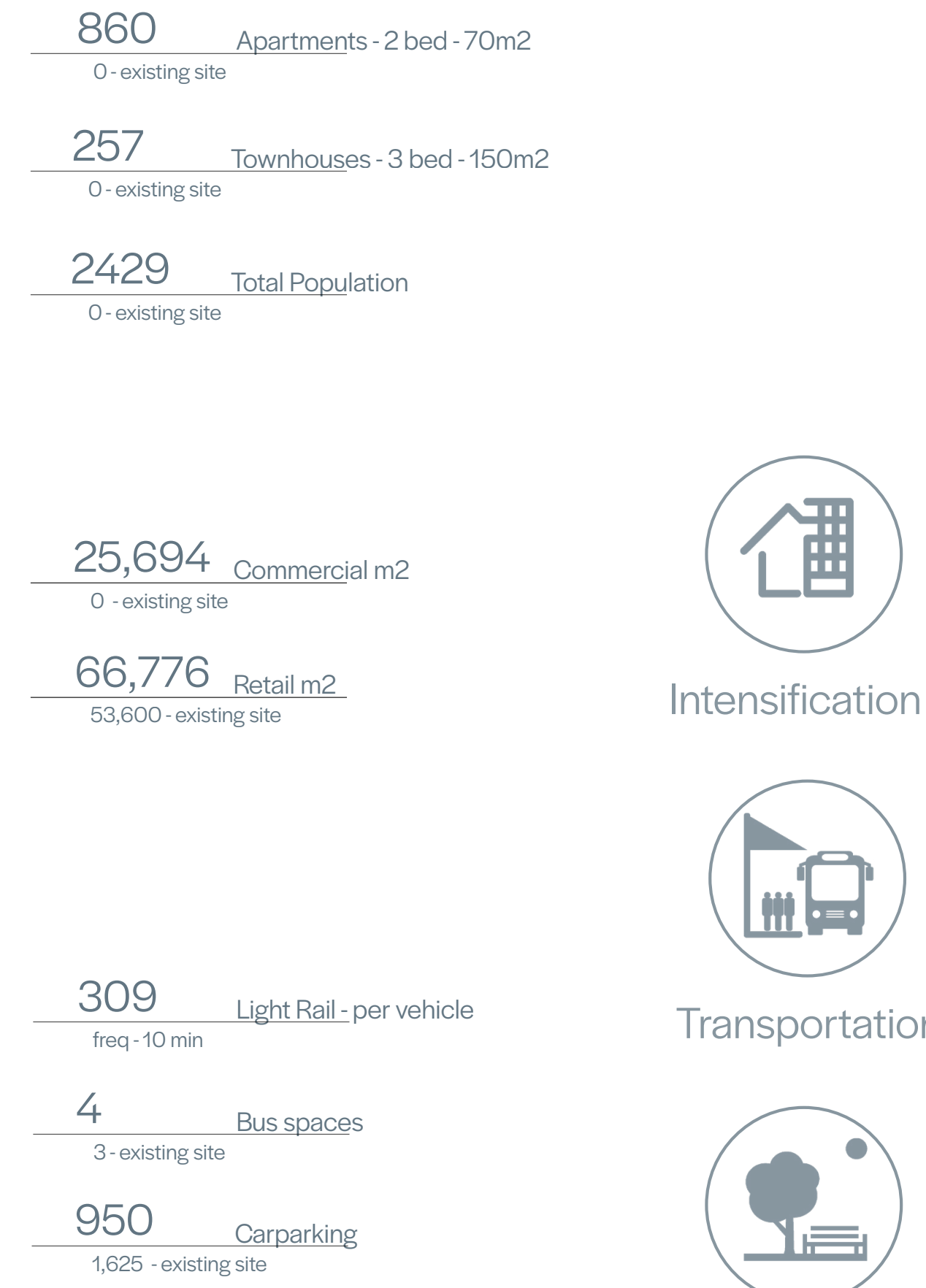

Transportation

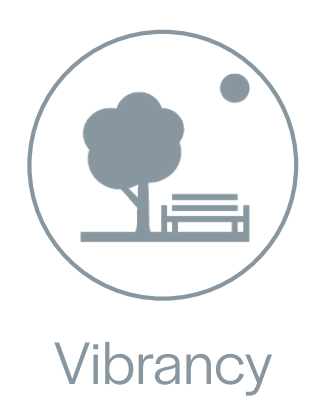
\begin{tabular}{c}
18.2 Total Site Area \\
\hline hectares
\end{tabular}
$\frac{61 \text { Overall Density }}{\text { dwellings per hectare }}$


6.0

$\frac{c}{0}$

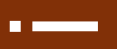

( )

5

0

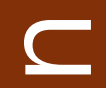

0

0 

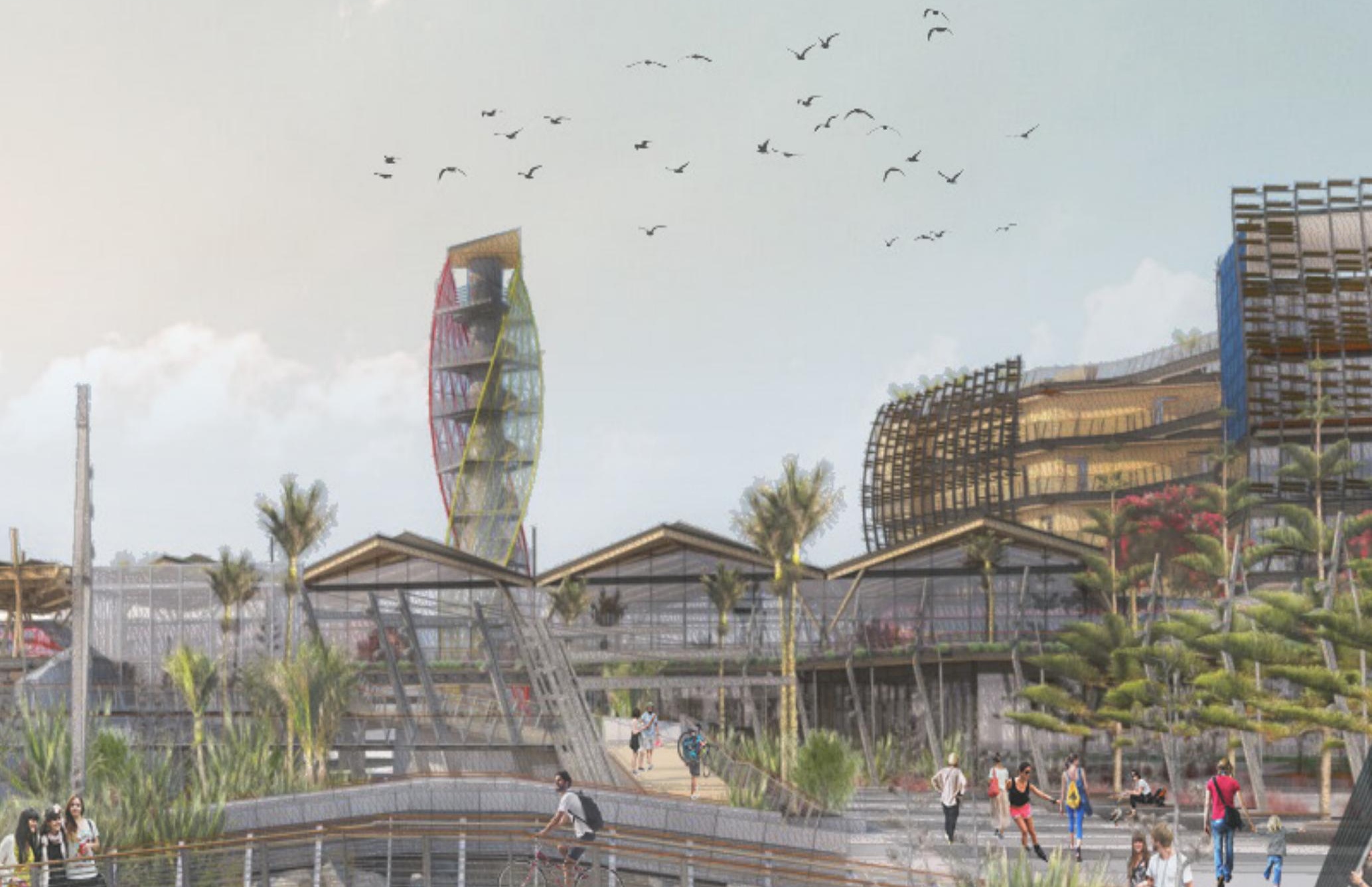

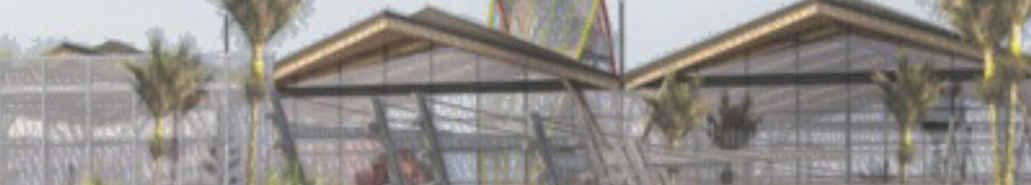

?

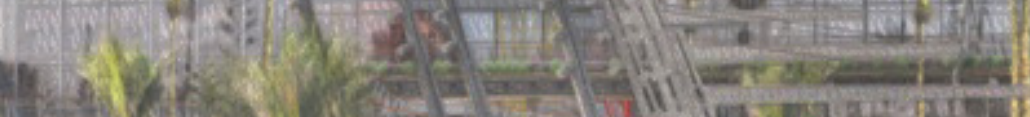

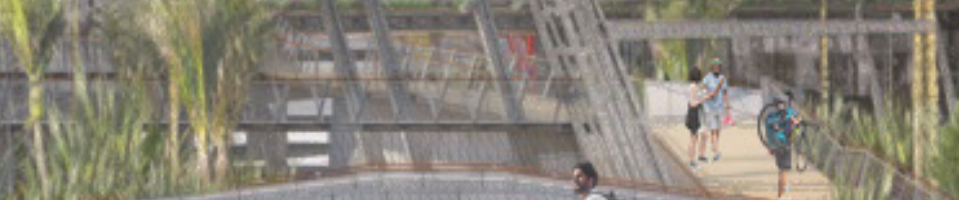




\section{Conclusion}

Interlinked presents a new conceptual urban framework for the suburb of Papamoa. The research explores an alternative approach to the rapid growth currently experienced by the region. This proposes a new medium to high density town centre on the site of the existing Papamoa Plaza and Fashion Island shopping centres.

The proposed centre is an assemblage of interconnected urban structures aimed at creating a cohesive, vibrant and connected heart for Papamoa. These explore the historical and ecological aspects of the site in order to incorporate and inform development, so as to ground the site and form quality links with the surrounding context

The structure of the thesis was important as it allowed aspects of the design to be explored at varying scales. These built upon the principles of 'Assemblage Theory', treating each aspect as a separate component of the wider system. This put an emphasis on the importance of linkages between urban structures and ensuring that the correct systems and principles were employed.

Transport was used as a catalyst for this development employing the principles of 'Transit Oriented Development' to implement a fast and convenient multimodal transit system within the site. This facilitates increased development and intensification around key transport connections regionally and allows for higher density development and intensification of key sites such as Papamoa Plaza.
Furthermore, by providing quality transport options and a multimodal system, the reliance of the population on the private car is reduced. This allows the attention of the urban designer to move from the car to the pedestrian.

In this scheme the pedestrian was made central to the scale and accessibility of the design, which utilised the existing green networks of the suburb to integrate the scheme with the wider region. Pedestrian focused design methodologies and increased opportunities including jobs, public spaces and other amenities were incorporated to create an inclusive centre and a destination for the wider region. This put an emphasis on connectivity, putting walking as the primary mode of transport.

'Space Syntax' was employed as an evaluation process using the 'Depth Map' software to analyse and identify connectivity within the design and ensure the scheme was working as intended. This methodology identified the need to offset the limitations of 'Space Syntax' with additional theory and metrics in order to understand the full picture. This also identified the role of the designer in realising the potential for connectivity in spaces identified by the 'Depth Map' analysis.

Through this pursuit of connectivity and amenity, 'Interlinked' provides an alternative framework forming a cohesive, connected, and vibrant heart for the suburb. 


\section{Limitations}

While considering what this research has achieved it is important to consider its limitations and future directions it could take. Urban design is a multifaceted, constantly evolving discipline and each new project brings a wealth of new knowledge and experience. However, as is the case with any project, there are limitations on what can be done in a given time frame. In the case of this research it was necessary to explore a larger scheme in order to properly explore the key ideas and objectives. This did, however, limit the level of detail that I was able to go into. Future stages of this research would include greater depth of detail and exploration of issues such as community engagement. This would also include greater cultural integration and discussion with local iwi. These stages would look to developing implementation plans, detailed design and explore in more depth the different components of the scheme, focusing on key points such as the residential typologies and the linkages between the public and private areas of the site.

Limitations also exist in the analysis process of the 'Depth Map' software. This analyses data from a two-dimensional plan, however this created issues when attempting to analyse the connectivity between different levels. During this research this was mitigated by additional studies and remodelling of floor plans to best simulate the interactions between levels. Further research could expand the scope to explore additional modelling and analysis software to overcome this issue. This could also look at additional methods outside of axial analysis to generate a greater understanding of the design involved.

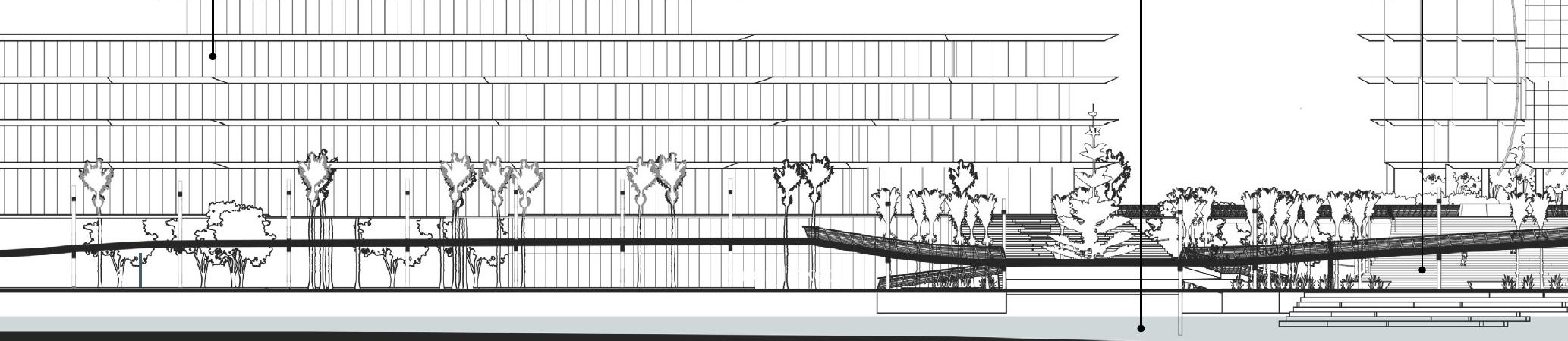




\section{Future Research}

The nature of this research is very site specific and responsive, however the methodologies and underlying principles are more universally applicable. While it was never the intention to create a universal solution, it would be interesting to explore the principles of this research in a different context to test the outcomes, identifying the potential for these theories and concepts to be applied universally as a part of the design process and tailored to individual circumstance.

The research focus on planning and the community targets many of the growing issues facing Papamoa and presents opportunities for new future development methodologies. The concept of an 'Assemblage of Urban Structures' can be used in a variety of urban frameworks to suit the needs of the community, and the ability for assemblage theory to cater to the changing needs as time moves on makes it particularly useful in urban design.

This research is by no means a resolved or complete solution to the issues faced by Papamoa. However, it does identify several key issues in the way we are expanding, namely the unsustainable consumption of land, poor infrastructure planning and a lack of human scale thinking within our urban planning. This highlights the potential for improvement through connected design principles and a more holistic and consistent approach to urban planning by councils and urban authorities.

Looking to the future, this suggests a rethink of our urban development policies and the direction that development is taking, with a renewed focus on connectivity as a guiding principle and people centred design.

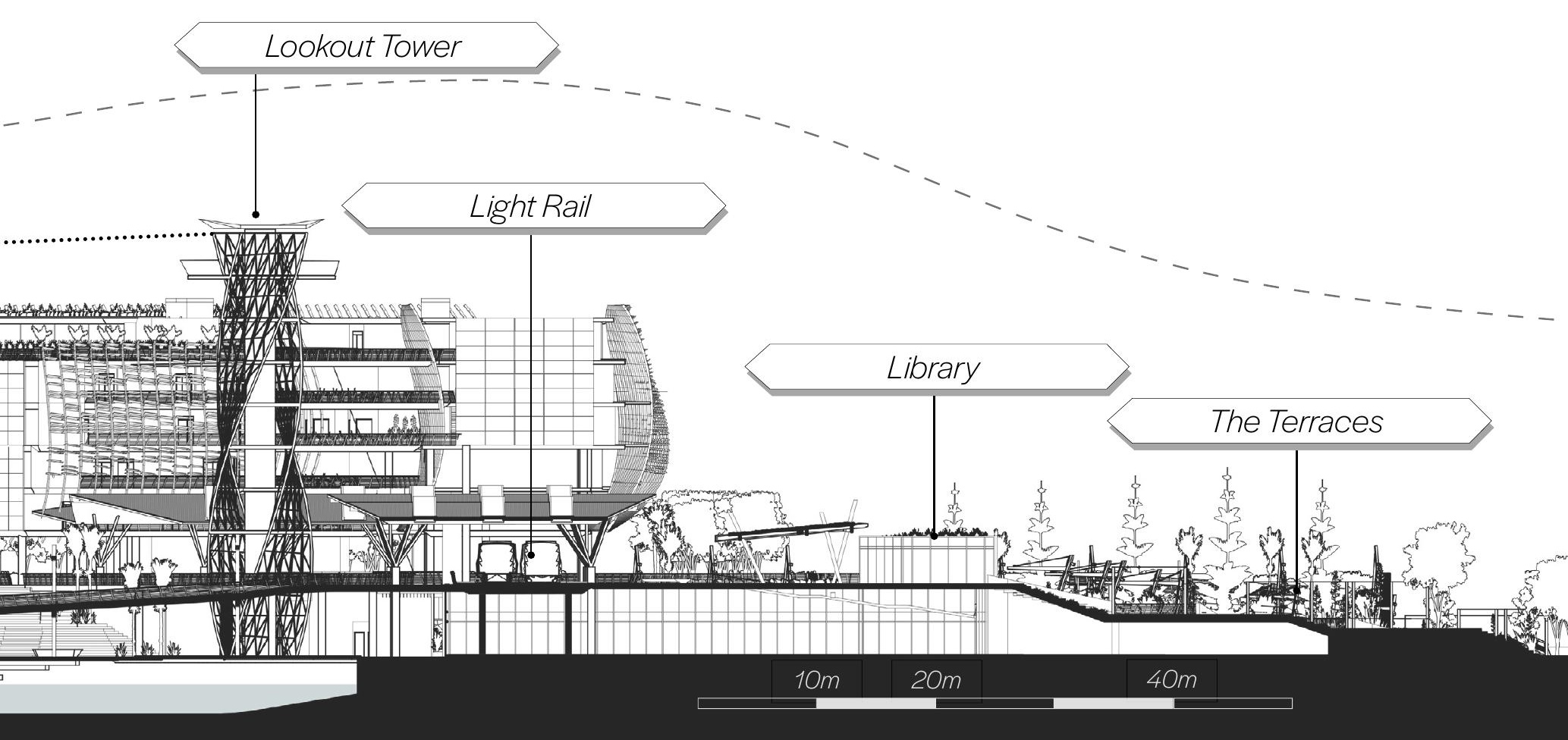




\section{Papamoa Hills F}

View from Papamoa Hills - phot 


\section{Regional Park Sunrise}

ographed by author 


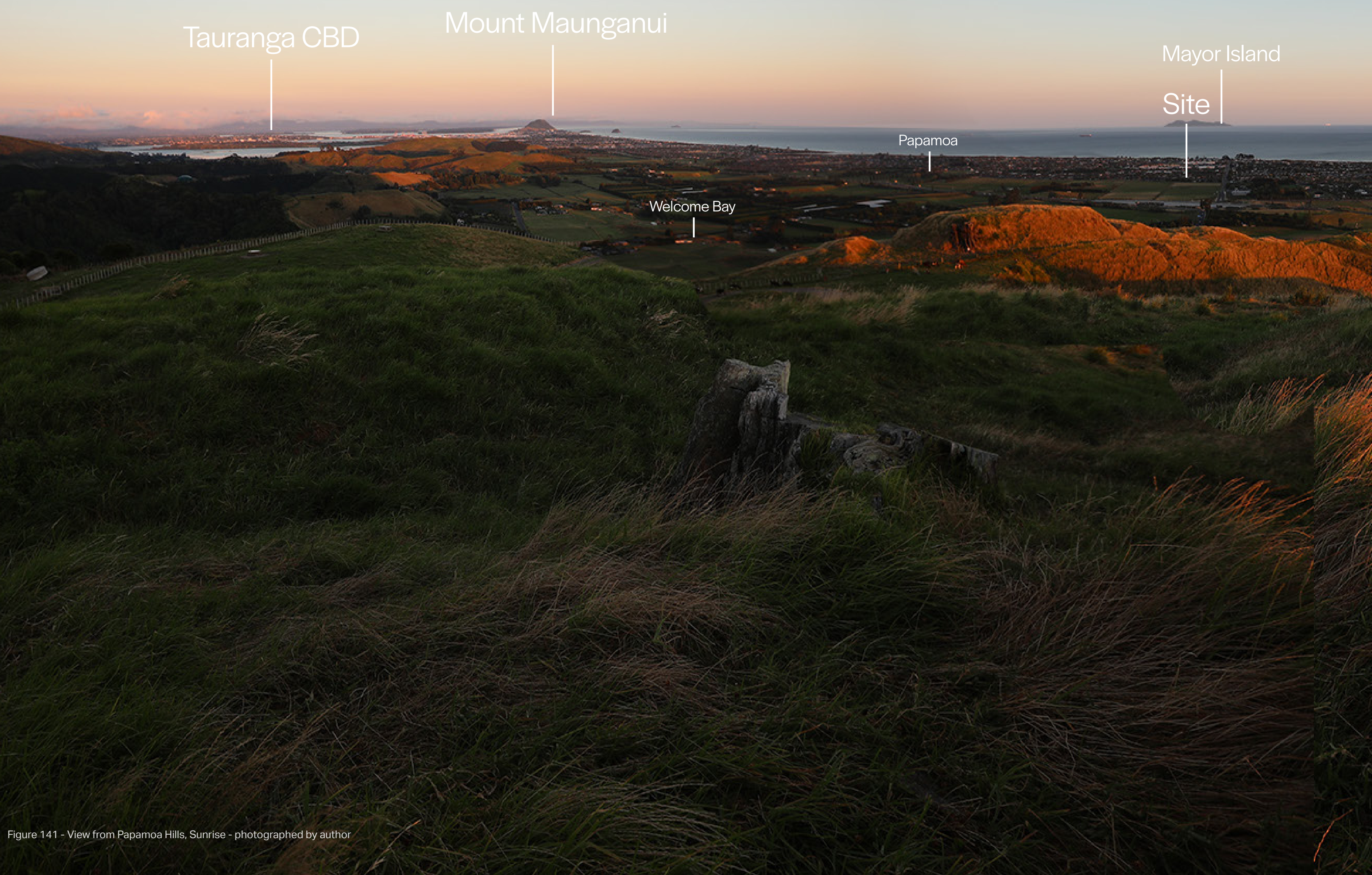




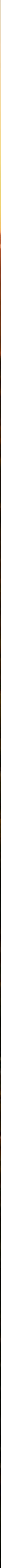


Apartment space - Auckland Design Manual. (n.d.). Retrieved January 15, 2019, from http://www. aucklanddesignmanual.co.nz/sites-and-buildings/apartments/guidance/the-building/ apartment-layout/apartment-space

Axial line Space Syntax_Online Training Platform. (n.d.). Retrieved January 27, 2019, from http:// otp.spacesyntax.net/term/axial-line/

BPT. (2016, September 18). Te Tumu development crucial for Tauranga's growth, say project managers. Bay of Plenty Times. Retrieved from https://www.nzherald.co.nz/bay-of-plentytimes/news/article.cfm?c_id=1503343\&objectid=11708972

Chan, K. (2017, April 12). Major new 9-acre public park to be built on rooftop of Oakridge Centre redevelopment. Retrieved March 30, 2019, from Daily Hive website: https://dailyhive.com/ vancouver/oakridge-centre-oarkidge-park-design-concepts-december-2017

Clty of Gold Coast, E. \& T. | C. T. | W. S. (2018). G:link light rail [Text]. Retrieved March 30, 2019, from http://www.goldcoast.qld.gov.au/rapid-transit-6004.html

Convex space Space Syntax_Online Training Platform. (n.d.). Retrieved January 27, 2019, from http://otp.spacesyntax.net/term/convex-space/

Corner, J. (1999). Chapter 10: The Agency of Mapping: Speculation, Critique, and Invention. In D. Cosgrove (Ed.), Mappings (pp. 213-252). London: Reaktion Books.

Cousins, J. (2017, May 26). Massive industrial park promises thousands of jobs. Retrieved from https://www.nzherald.co.nz/bay-of-plenty-times/news/article.cfm?c_ id=1503343\&objectid $=11864073$

Cox, W., \& Pavletich, H. (n.d.). 15th Annual Demographia International Housing Affordability Survey: 2019 (No. 15). Retrieved from http://www.demographia.com/dhi.pdf

Deleuze, G., Parnet, C., Habberjam, B., \& Tomlinson, H. (2007). Dialogues II. Retrieved from https:// books.google.co.nz/books?id=iqKGldo7A2gC

Dovey, K., \& Ristic, M. (2017). Mapping urban assemblages: the production of spatial knowledge. Journal of Urbanism: International Research on Placemaking and Urban Sustainability, 10(1), 15-28. https://doi.org/10.1080/17549175.2015.1112298

Ebner, D. (2018, February 2). Vancouver's Oakridge mall gets a makeover - and a new lease on life - The Globe and Mail. Retrieved March 30, 2019, from https://www.theglobeandmail.com/ news/british-columbia/vancouvers-oakridge-mall-gets-a-makeover-and-a-new-lease-onlife/ article37845571/

Gehl, J. (2011). Life between buildings: using public space / Jan Gehl. Washington, DC: Washington, DC : Island Press. 
G:link. (2018). G:link Frequency | Arrival and Departure Times of the Gold Coast Light Rail. Retrieved March 30, 2019, from G:link website: https://ridetheg.com.au/\%ef\%bf\%bcridingthe-g/time-table/

Goldlinq. (n.d.). volume-7-technical-report-lrt-operations-assessment-4cd897db.pdf. Retrieved February 5, 2018, from http://www.goldlinq.com.au/resources/volume-7-technical-reportIrt-operations-assessment-4cd897db.pdf

Hall, C. (2018, July 2). "Cooking with gas": Half a billion dollars in commercial consents for Tauranga. Retrieved from https://www.nzherald.co.nz/business/news/article.cfm?c_ id=3\&objectid $=12069997$

Harvard Gazette. (2017, January 9). Why city blocks work. Retrieved March 20, 2019, from Harvard Gazette website: https://news.harvard.edu/gazette/story/2017/01/why-city-blocks-work/

Hillier, B. (2003). The architectures of seeing and going:or, are cities shaped by bodies or minds? And is there a syntax ofspatial cognition? In: (Proceedings) 4th International Space Syntax Symposium. : London.

Hillier, B. (2007). Space is the machine: a configurational theory of architecture. Space Syntax.

Hillier, B., \& Penn, A. (2004). Rejoinder to Carlo Ratti. ENVIRONMENT AND PLANNING B-PLANNING \& DESIGN.

Hunter, Z. (2018a, September 12). Tauranga residents concerned over proposed four-storey student accommodation. Retrieved from https://www.nzherald.co.nz/nz/news/article. cfm?c_id=1\&objectid=12120951

Hunter, Z. (2018b, December 4). Stuck in traffic? Congestion worsens in Tauranga, new data shows. Retrieved from https://www.nzherald.co.nz/bay-of-plenty-times/news/article.cfm?c_ id=1503343\&objectid $=12170831$

Incorporated, P. B. (2012). Track Design Handbook for Light Rail Transit, Second Edition. https:// doi.org/10.17226/22800

Isovist Space Syntax_Online Training Platform. (n.d.). Retrieved January 27, 2019, from http://otp. spacesyntax.net/term/isovist/

Jacobs, J. (1993). The death and life of great American cities / Jane Jacobs (Modern Library ed..). New York: New York: Modern Library.

L, M. (2015, November 11). Light Rail lessons from the Gold Coast. Retrieved March 30, 2019, from Greater Auckland website: https://www.greaterauckland.org.nz/2015/11/12/light-raillessons-from-the-gold-coast/

Landezine. (2018). Tonsley Innovation District « Landezine International Landscape Award LILA. Retrieved March 30, 2019, from https://landezine-award.com/tonsley-innovation-district/ 
Level, B. S. V. P. for S., Impacts, C., \& Central, C. (n.d.). Before the Flood - Sea Level Rise. Retrieved March 24, 2019, from Before the Flood website: https://www.beforetheflood.com/explore/ the-crisis/sea-level-rise/

Lynch, K. (1960). The image of the city. Cambridge [Mass.: Cambridge Mass. Massachusetts Institute of Technology Press.

McFarlane, C. (2011a). Assemblage and critical urbanism. City, 15(2), 204-224. https://doi.org/10. 1080/13604813.2011.568715

McFarlane, C. (2011b). The City as Assemblage: Dwelling and Urban Space. Environment and Planning D: Society and Space, 29(4), 649-671. https://doi.org/10.1068/d4710

Metro. (2010, December 8). San Francisco breaks ground on \$4.2B Transbay Transit Center. Retrieved March 30, 2019, from https://www.metro-magazine.com/rail/news/285334/sanfrancisco-breaks-ground-on-4-2b-transbay-transit-center

Motion, S. (2019, September 23). Census 2018: Bay of Plenty New Zealand's second-fastestgrowing region. Bay of Plenty Times.

Nunns, P. (2016, February 16). Tauranga: Sunshine, sprawl, and high house prices. Retrieved August 5, 2018, from Greater Auckland website: https://www.greaterauckland.org. nz/2016/02/16/tauranga-sunshine-sprawl-and-high-house-prices/

NZ Herald. (2016, October 11). Traffic squeeze worsens in Tauranga. Retrieved from https://www. nzherald.co.nz/nz/news/article.cfm?c_id=1\&objectid=11723994

NZTA. (2018). Auckland light rail | NZ Transport Agency. Retrieved February 16, 2019, from https:// www.nzta.govt.nz/roads-and-rail/rapid-transit/auckland-light-rail/

NZTA. (n.d.). auckland-light-rail-tender-brochure.pdf. Retrieved from https://www.nzta.govt.nz/ assets/Roads-and-Rail/docs/auckland-light-rail-tender-brochure.pdf

Overview Space Syntax_Online Training Platform. (n.d.). Retrieved January 26, 2019, from http:// otp.spacesyntax.net/overview-2/

Pafka, E., Dovey, K., \& Aschwanden, G. D. (2018). Limits of space syntax for urban design: Axiality, scale and sinuosity. Environment and Planning B: Urban Analytics and City Science, 2399808318786512. https://doi.org/10.1177/2399808318786512

Pelli Clarke Pelli Architects. (2018, August 29). Salesforce Transit Center / Pelli Clarke Pelli Architects | ArchDaily. Retrieved August 29, 2018, from https://www.archdaily.com/900117/ salesforce-transit-center-pelli-clarke-pelli-architects

Qiu, F., Li, W., \& Haghani, A. (2015). A methodology for choosing between fixed囚route and flex区 route policies for transit services. Journal of Advanced Transportation, 49(3), 496-509. https://doi.org/10.1002/atr.1289 
Ratti, C. (2004). Space Syntax: Some Inconsistencies. Environment and Planning B: Planning and Design, 31(4), 487-499. https://doi.org/10.1068/b3019

Segment Space Syntax_Online Training Platform. (n.d.). Retrieved January 27, 2019, from http:// otp.spacesyntax.net/term/segment/

Stangl, P. (2015). Block size-based measures of street connectivity: A critical assessment and new approach. URBAN DESIGN International, 20(1), 44-55. https://doi.org/10.1057/udi.2013.36

Taonga, N. Z. M. for C. and H. T. M. (2018). 5. - Bay of Plenty places - Te Ara Encyclopedia of New Zealand [Web page]. Retrieved March 24, 2019, from https://teara.govt.nz/en/14823

TCC. (2018c). Tauranga Statistical Information Report May 2018.pdf. Retrieved from TCC website: http://www.tauranga.govt.nz/Portals/0/data/council/reports/statistical_information_report_ may2018.pdf

TCC. (n.d.-a). 14 Residential Zones.pdf (No. 14). Retrieved from http://econtent.tauranga.govt.nz/ data/city_plan/ch/14/14_residential_zones.pdf

TCC. (n.d.-b). Proposed Tauranga Urban Stratagey 2050. Retrieved from https://www.tauranga. govt.nz/Portals/0/data/future/strategic_planning/strategic_focus/files/tga_urban_intro.pdf

TeAra. (2018). Tauranga Moana. Retrieved from https://teara.govt.nz/en/tauranga-moana/print

Wainwright, O. (2017, April 30). Street fighter: how Jane Jacobs saved New York from Bulldozer Bob. The Guardian. Retrieved from https://www.theguardian.com/artanddesign/2017/ apr/30/citizen-jane-jacobs-the-woman-who-saved-manhattan-from-the-bulldozerdocumentary

Yoos, J. (2016). Parallel cities: the multilevel metropolis / Jennifer Yoos, Vincent James (First edition..). Minneapolis: Walker Art Center. 


\section{Figure List}

Note : All images unless noted otherwise are by the author

Figure 2 - Stewart, R. (2017). Mount Maunganui Summit Sunrise [Photograph]. Bay of Plenty, Tauranga. Reproduced with permission from the owner.

Figure 4 - Papamoa Aerial View [Photograph found in Retrolens]. (n.d.). Retrieved April 28, 2018, from http://retrolens.nz/map/\#/1872588.4868622671/5811523.780667712/1893723.325 18309/5828817.658317209/2193/8 (Originally photographed 1937, April 12). Copyright creative commons 3.0 New Zealand.

Figure 5 - Dovey, K., \& Ristic, M. (2017). Mapping urban assemblages: the production of spatial knowledge. Journal of Urbanism: International Research on Placemaking and Urban Sustainability, 10(1), 15-28. https://doi.org/10.1080/17549175.2015.1112298.

Figure 7 - Dovey, K., \& Ristic, M. (2017). Mapping urban assemblages: the production of spatial knowledge. Journal of Urbanism: International Research on Placemaking and Urban Sustainability, 10(1), 15-28. https://doi.org/10.1080/17549175.2015.1112298.

Figure 8 - Dovey, K., \& Ristic, M. (2017). Mapping urban assemblages: the production of spatial knowledge. Journal of Urbanism: International Research on Placemaking and Urban Sustainability, 10(1), 15-28. https://doi.org/10.1080/17549175.2015.1112298.

Figure 9 - Pafka, E., Dovey, K., \& Aschwanden, G. D. (2018). Limits of space syntax for urban design: Axiality, scale and sinuosity. Environment and Planning B: Urban Analytics and City Science, 2399808318786512. https://doi.org/10.1177/2399808318786512.

Figure 10 - Hillier, B. (2003). The architectures of seeing and going:or, are cities shaped by bodies or minds? And is there a syntax ofspatial cognition? In: (Proceedings) 4th International Space Syntax Symposium. : London.

Figure 13 - TCC. (2018). Tauranga Statistical Information Report May 2018.pdf. Retrieved from TCC website: http://www.tauranga.govt.nz/Portals/0/data/council/reports/statistical_ information_report_may2018.pdf.

Figure 14 - TCC. (2018). Tauranga Statistical Information Report May 2018.pdf. Retrieved from TCC website: http://www.tauranga.govt.nz/Portals/0/data/council/reports/statistical_ information_report_may2018.pdf.

Figure 15 - TCC. (2018). Tauranga Statistical Information Report May 2018.pdf. Retrieved from TCC website: http://www.tauranga.govt.nz/Portals/0/data/council/reports/statistical_ information_report_may2018.pdf.

Figure 16 - Google Maps: Mount Maunganui. (2018). Retrieved from Google earth. Copyright Google 2018.

Figure 17 - Google Maps: Tauranga. (2018). Retrieved from Google earth. Copyright Google 2018. 
Figure 24 - Papamoa Aerial View [Photograph found in Retrolens]. (n.d.). Retrieved from http:// retrolens.nz. Copyright creative commons 3.0 New Zealand.

Figure 26 - Tauranga City Council and LINZ. (2018). Papamoa Mapi viewer. Retrieved October 1, 2018, from https://mapi.tauranga.govt.nz/Html5/index.html?viewer=Mapi. Copyright creative commons 3.0 New Zealand.

Figure 32 - Department of Transport and main roads, Queensland. (n.d.). Tram 1 [digital image]. Retrieved September 27, 2018, from retrieved from https://ridetheg.com.au.

Figure 33 - Department of Transport and main roads, Queensland. (n.d.). Tram 2 [digital image]. Retrieved September 27, 2018, from retrieved from https://ridetheg.com.au.

Figure 34 -Department of Transport and main roads, Queensland. (n.d.). Future stages [digital image]. Retrieved June 10, 2018, https://tinyurl.com/y4xgghyv.

Figure 35 - Department of Transport and main roads Queensland. (n.d.). Current route \& Stations. [digital image]. Retrieved September 25, 2018, from hhttps://tinyurl.com/y2kyazld.

Figure 36 - Department of Transport and main roads, Queensland. (n.d.) Bridge Crossing. [digital image]. Retrieved September 25, 2018, from https://www.mcconnelldowell.com/projects/ gold-coast-light-rail-australia.

Figure 40 - Henriquez, N . (n.d.) Oakland Aerial View looking West [digital image]. Retrieved June 12, 2018, from https://henriquezpartners.com/projects/oakridge/

Figure 60 - Schenck, T. (n.d). New York Highline [Photograph]. New York, United States. Retrieved from https://tinyurl.com/yxh6ygrz. Reproduced with permission from the owner.

Figure 71a - Bwag. (2018) Vienna's first pedestrian zone on the Graben [digital image]. Retrieved October 22, 2018, from https://commons.wikimedia.org/w/index.php?curid=69437375. Copyright creative commons share alike 4.0 International.

Figure 71b - LEA Invent \& Burcak Pekin. (July 12 2011) Footbridge project in Istanbul (Starfish) [digital image]. Retrieved October 23, 2018, from https://www.archdaily.com/103462/newvisions-for-pedestrian-footbridge-design-competition-winner-lea-invent/vat-pers-2

Figure 78 - Government of South Australia. (n.d.). Tonsley Heart. [digital image]. Retrieved November 1, 2018, from https://tonsley.com.au/news/update-tonsley-innovation-district/

Figure 79 - Government of South Australia. (n.d.). Tonsley Masterplan. [digital image]. Retrieved November 1, 2018, from https://tinyurl.com/y4nysec3

Figure 83 - WSP . (n.d.) Salesforce Transit Hub section [digital image]. Retrieved September 2, 2018, from https://www.wsp.com/en-CA/projects/transbay-transit-center 
Figure 84 - Fullmetal2887. (2018). Salesforce Transit Hub overview. [digital image]. Retrieved September 2, 2018, from https://upload.wikimedia.org/wikipedia/commons/1/19/ Salesforce_Park_and_bus_bridge\%2C_seen_from_Salesforce_Tower.jpg. Copyright creative commons share alike 4.0 International.

Figure 85 - Fullmetal2887. (2018) Salesforce Transit Hub entrance. [digital image]. Retrieved September 2, 2018, from https://commons.wikimedia.org/w/index.php?curid=71708702. Copyright creative commons share alike 4.0 International.

Figure 87 - Wilson, S . (2018) Victoria on River [digital image]. Retrieved August 2, 2018, from http://edwardswhite.co.nz/project/victoriaontheriver. Reproduced with permission from the owner.

Figure 92 - HGEsch photographers . (2017) Marina One heart [digital image]. Retrieved August 6, 2018, from https://www.hgesch.de/commissioned-works/architecture/marina-onesingapore-ingenhoven-architects-duesseldorf-2017/\#928/by-architects/ingenhovenarchitects-duesseldorf/ 
Appendix 
Massing

Block form \& density exploration
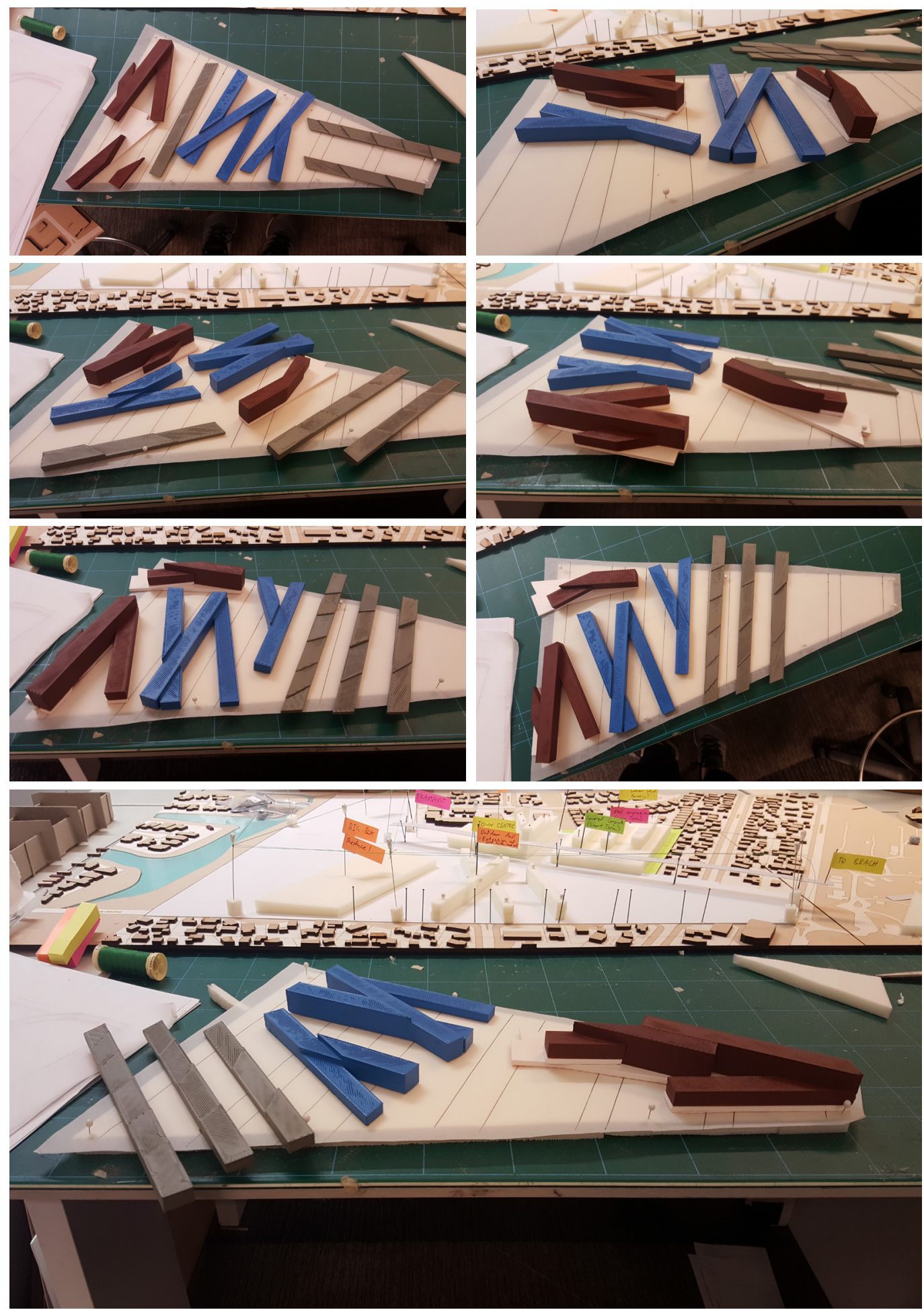

Figure 142 -Exploration of spatial form using modular components to inform an impromptu street grid 

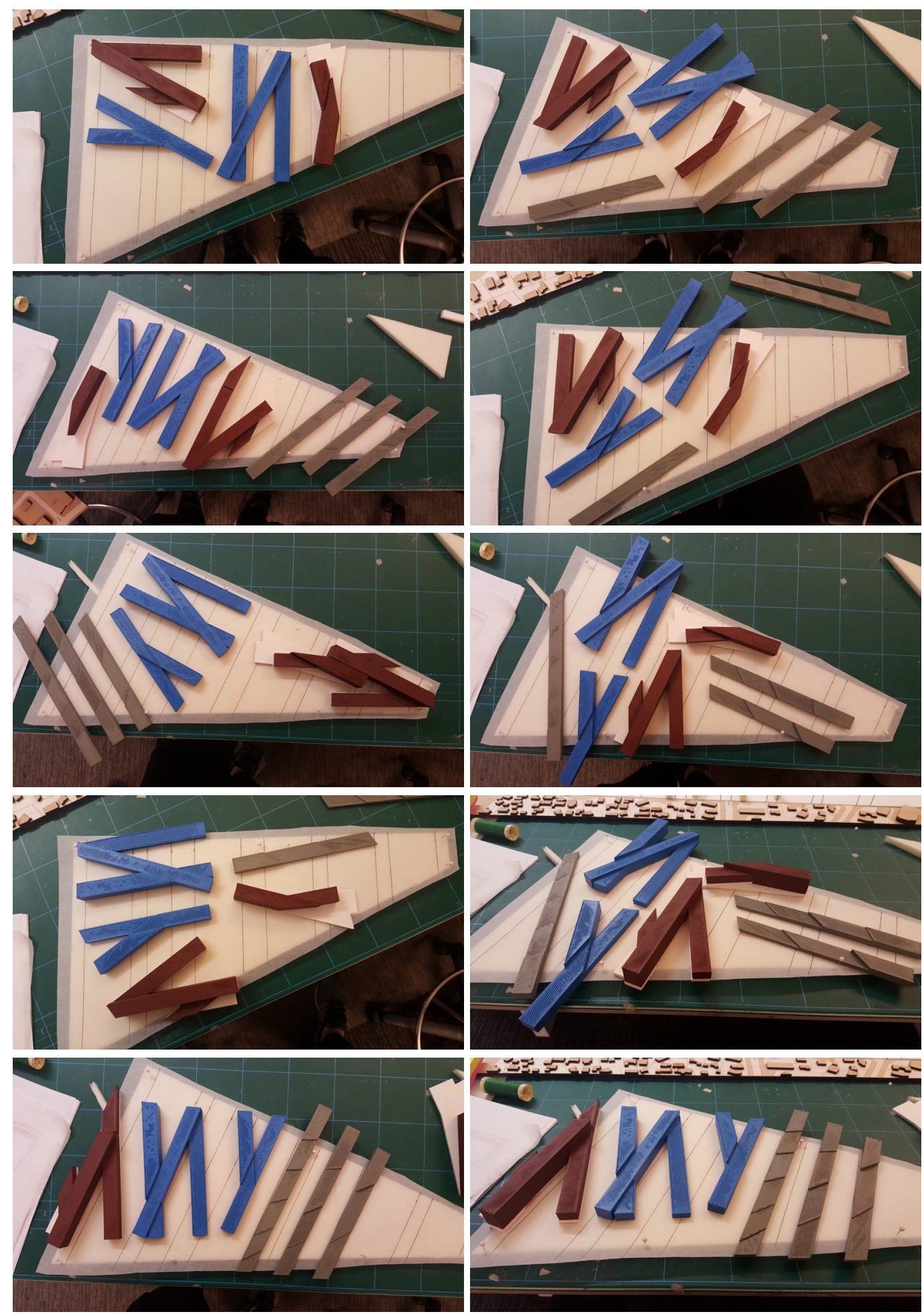


\section{Building Form Massing}

Fragmenting the floor plate
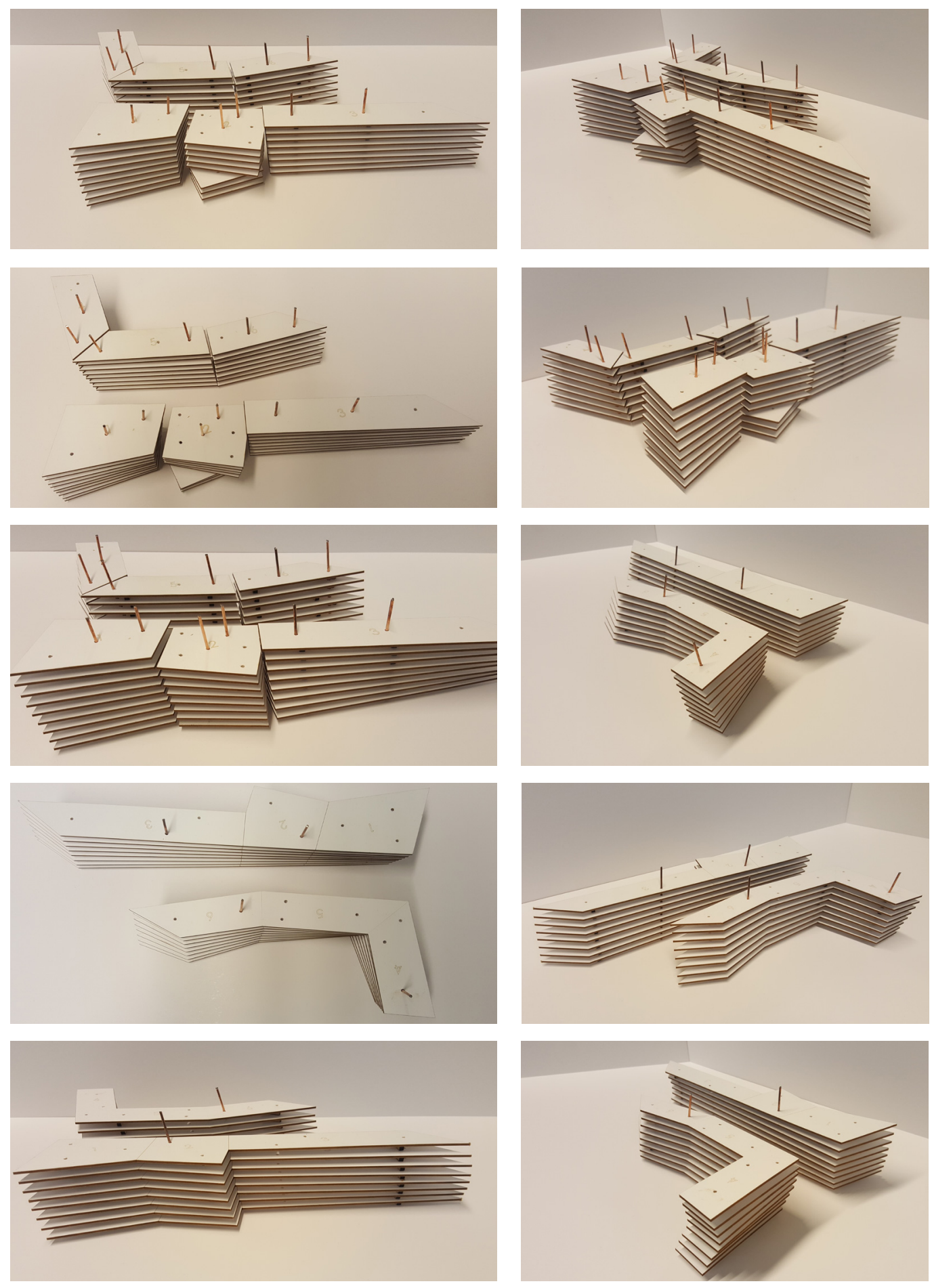

\section{Figure 143}

This exercise looked at ways to break up the mass of high rise buildings on the site. Points of rotation at various points in the floor-plate were trialled and assessed based on visual effects on the surrounding public spaces and functional impacts on the buildings design. Through this technique buildings were able to be customised based on location to maximise views and allow sunshine into even the lowest levels through strategic angling of the structure.

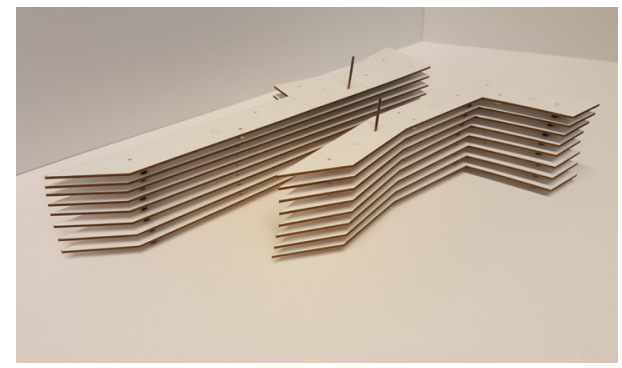



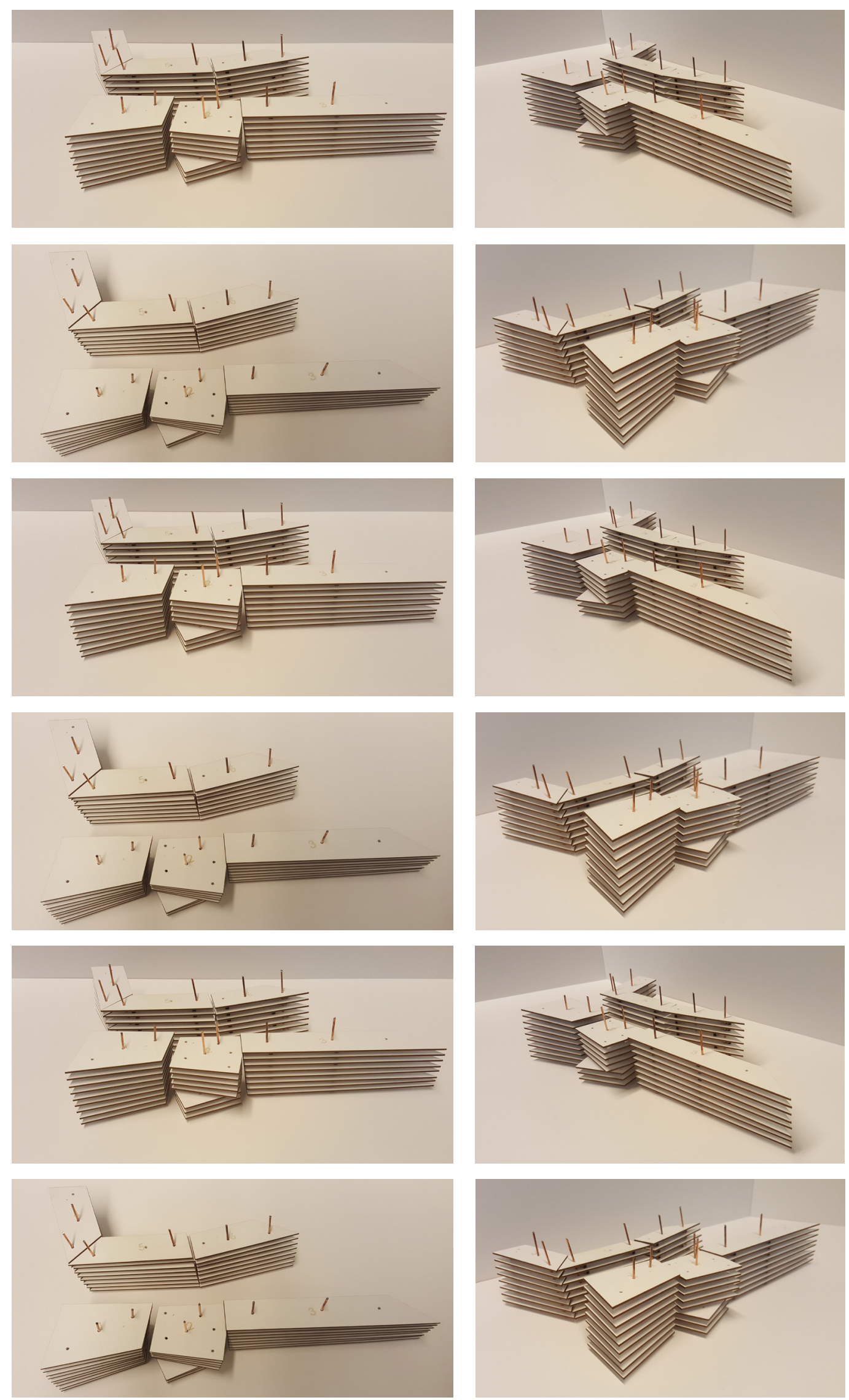
Apartment Facade

Shading \& Privacy
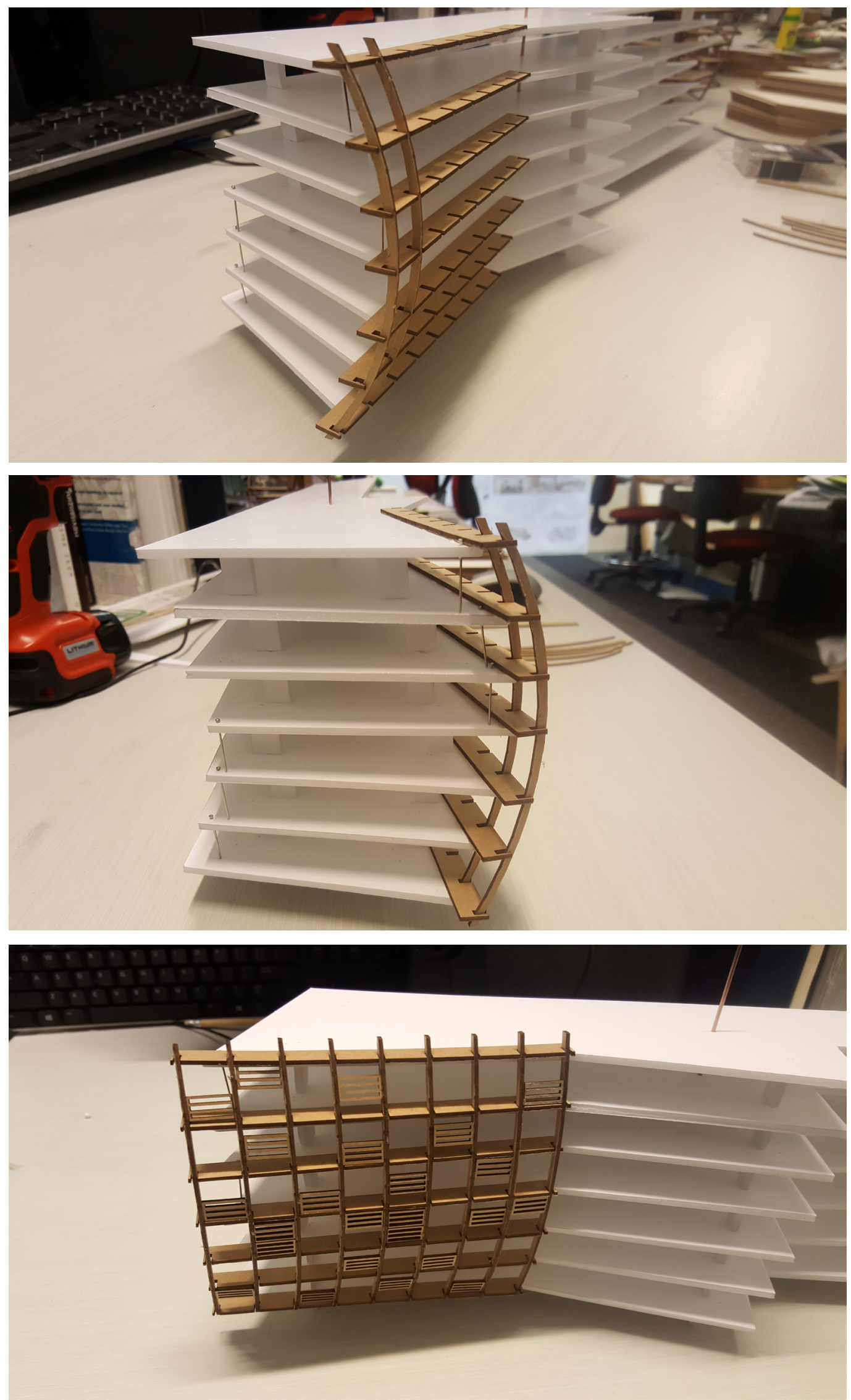

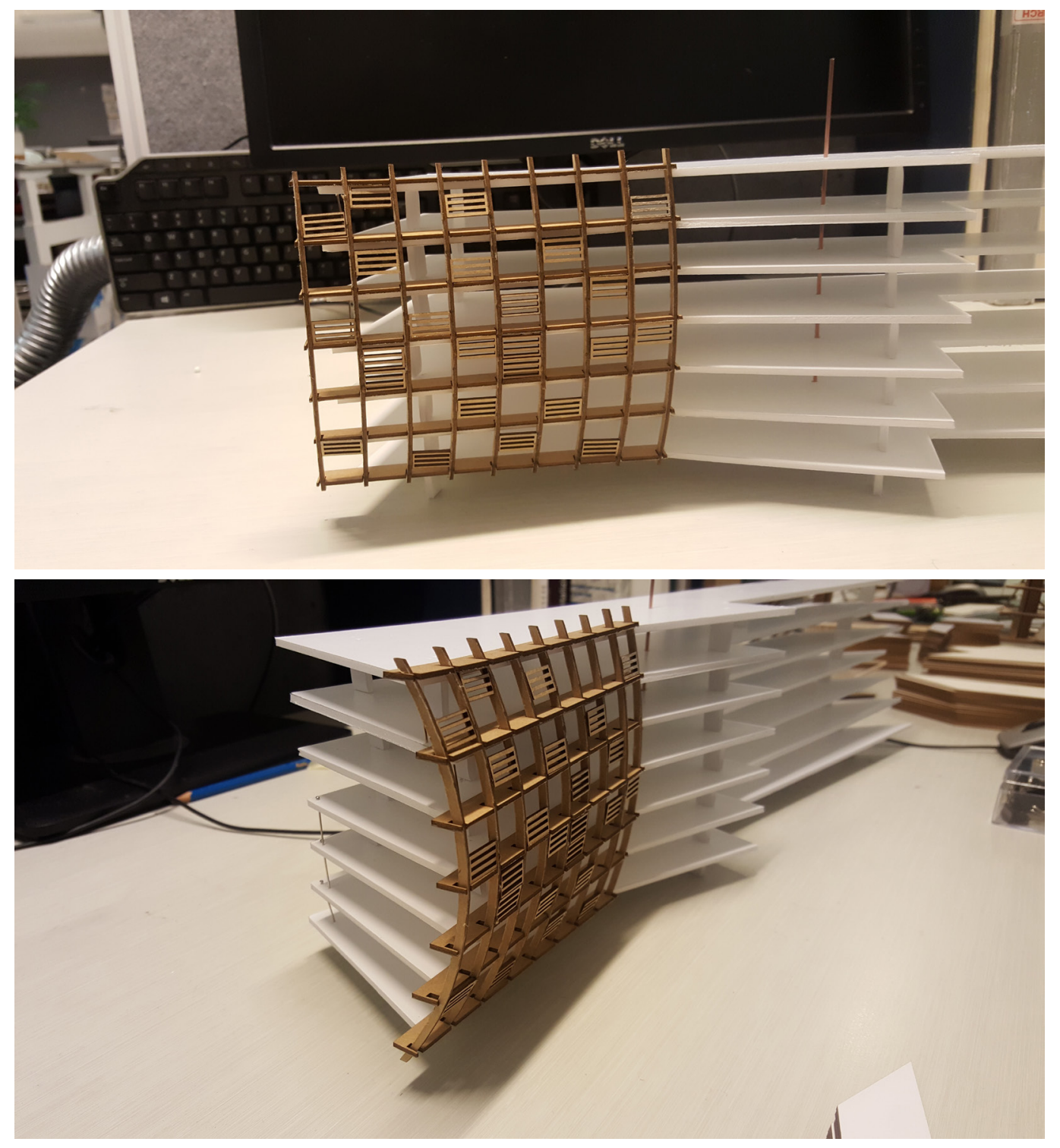

Figure 144- Apartment block facade development considering shading and privacy of the occupant. $\quad \wedge$ 


\section{Homes For Living}

Apartment typology development - Supplementary to main primary design
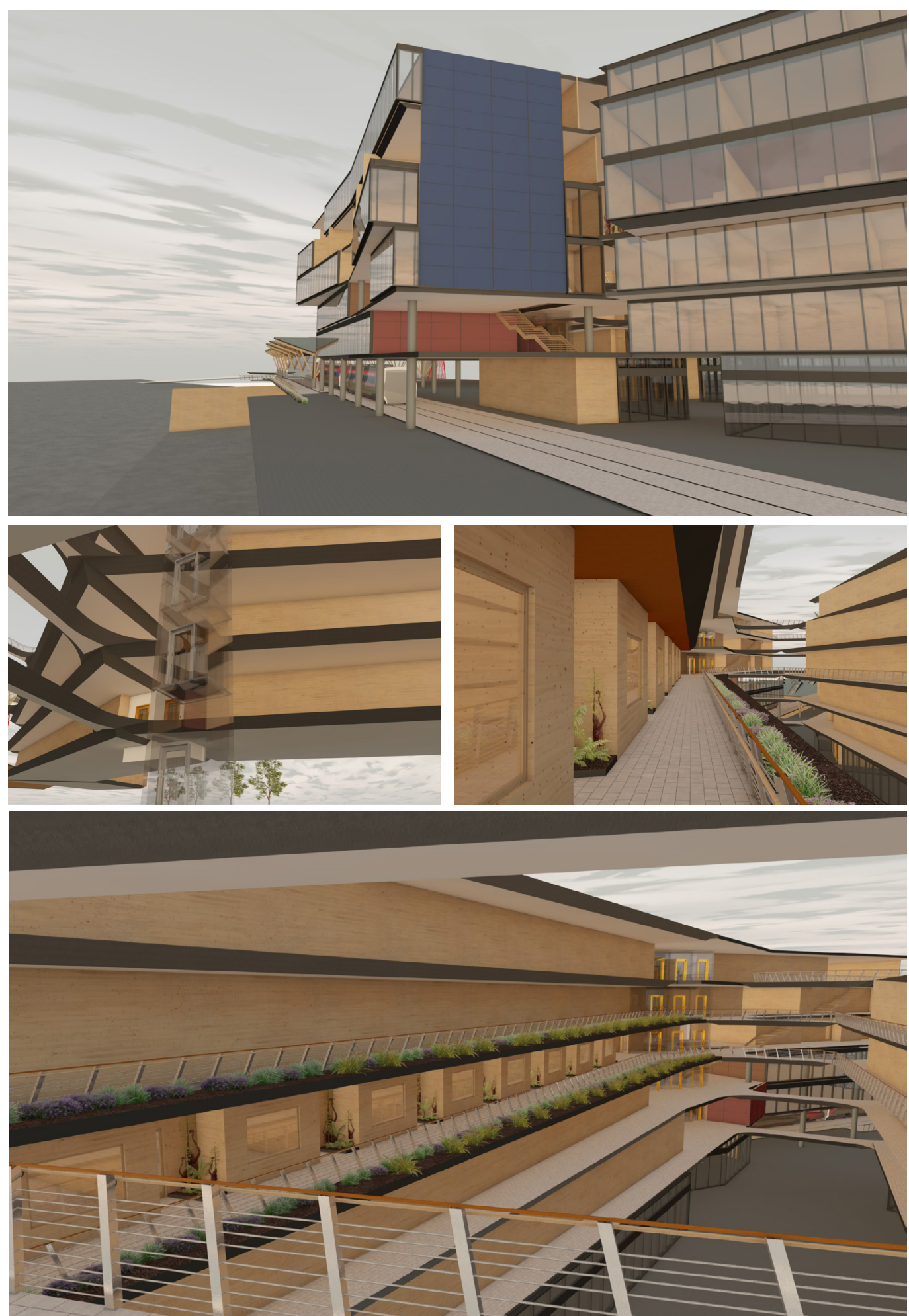

Figure 145 - Conceptual apartment design bridged by communal gardens and terraces. This followed exploration into building amenity and space into the apartment, taking what people like about suburban living and incorporating into apartment design. 

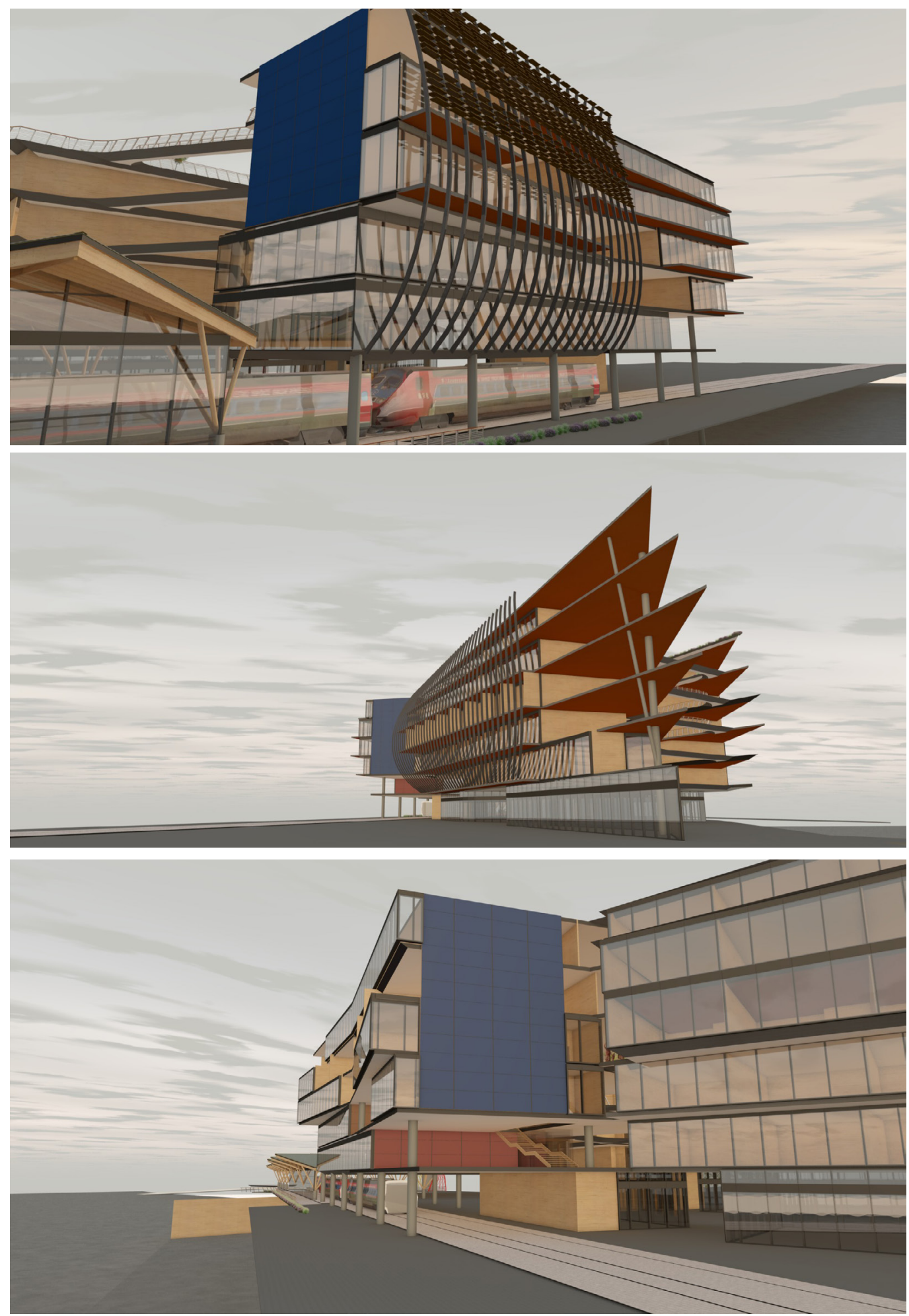

$\wedge$ Figure 146 - Exterior cladding exploration following floor plate fragmentation exercise. 


\section{Transport Hub}

Integration \& Accessibility

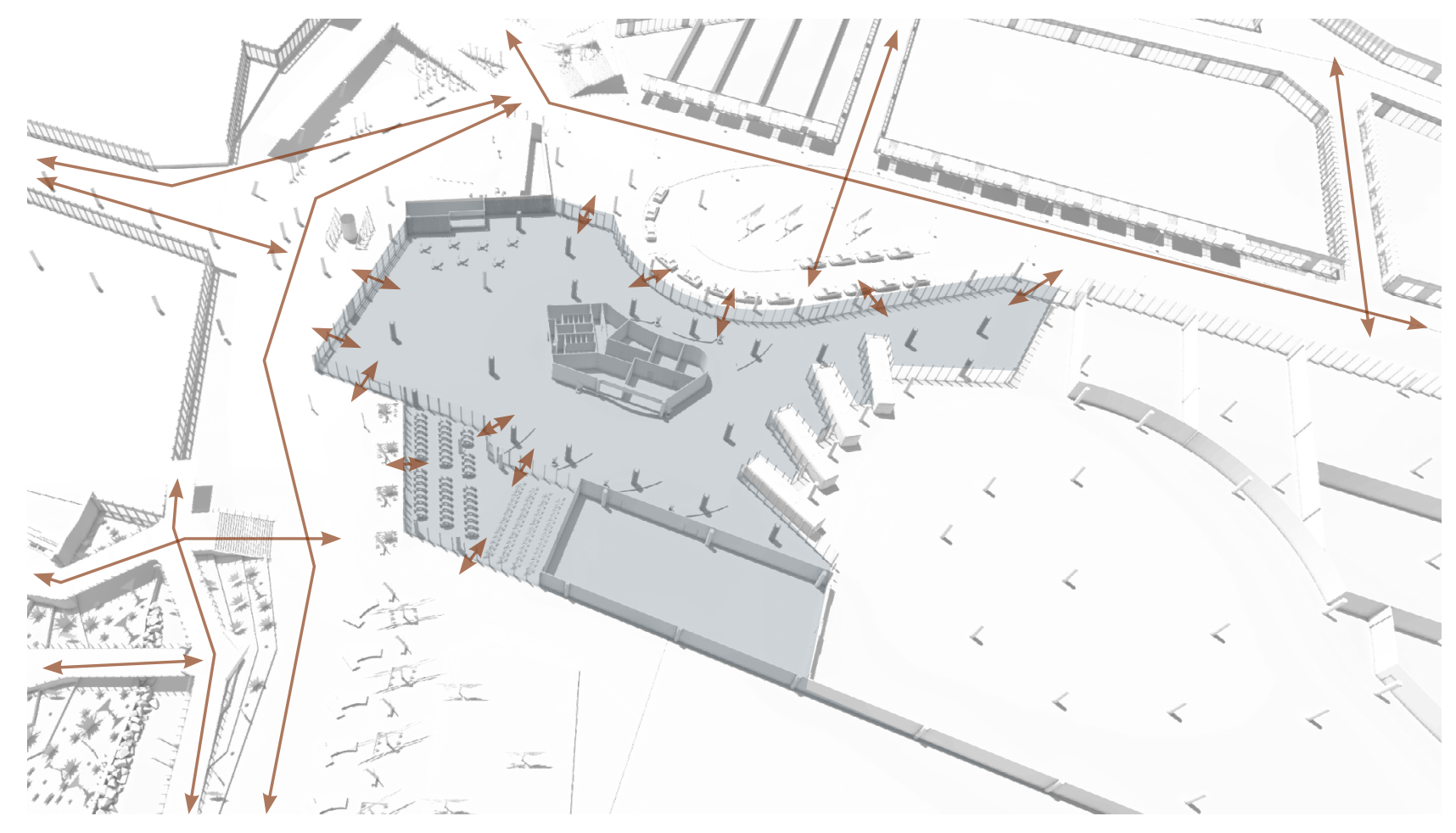

Ground Level

^ Figure 147-Integration of Transport Hub with surrounding public spaces. The Transport Hub should be considered as accessible by the public as any of the comparable outdoor spaces to ensure connectivity through the central site. 


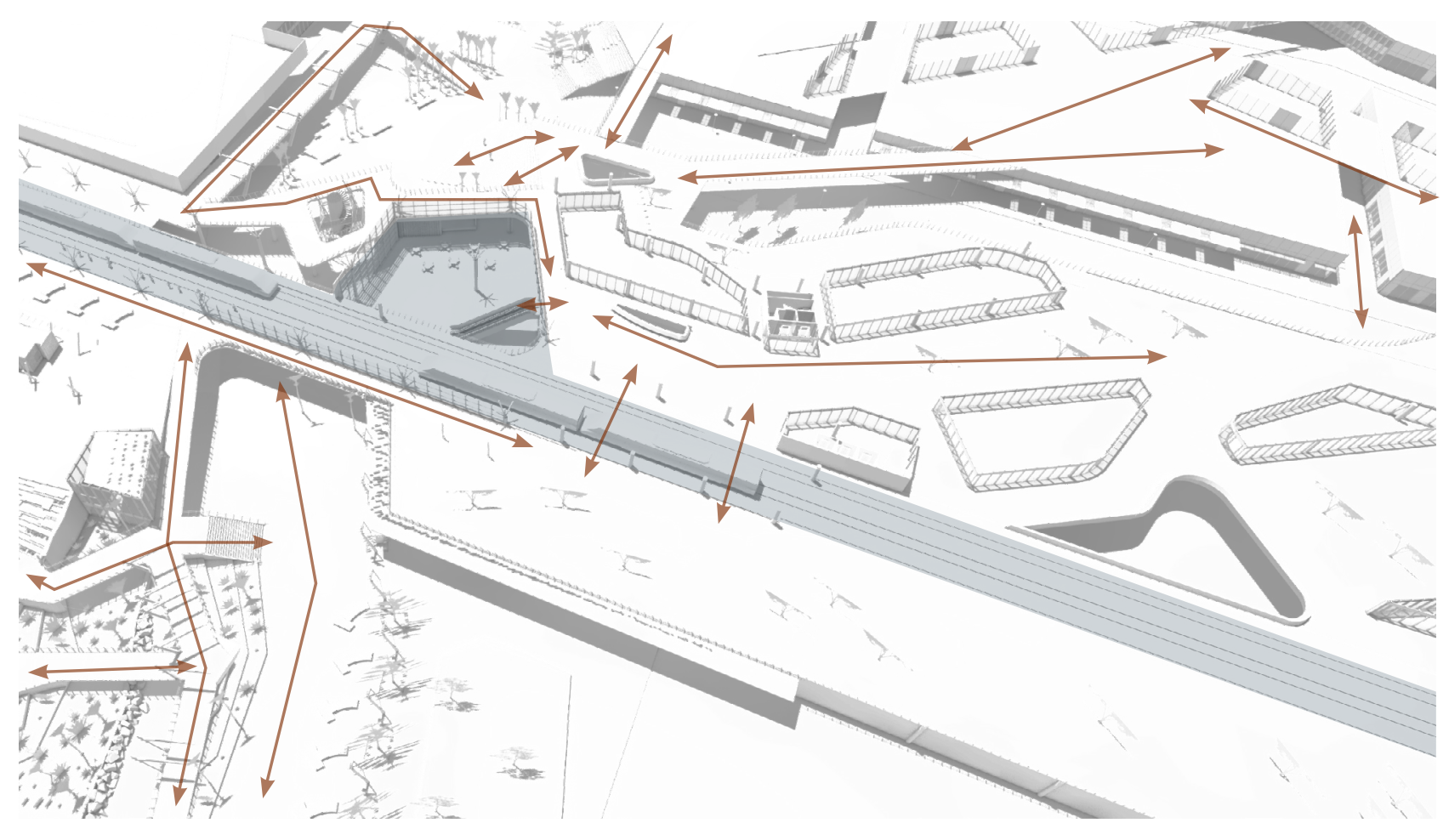

Podium Level

^ Figure 148 - Integration of Transport Hub with podium levels and linkages between podium and ground. Issues concerning sudden influxes of commuters from the elevated light rail were remedied by providing vertical circulation on both sides of the platform. 
The Tower

The twisting of views
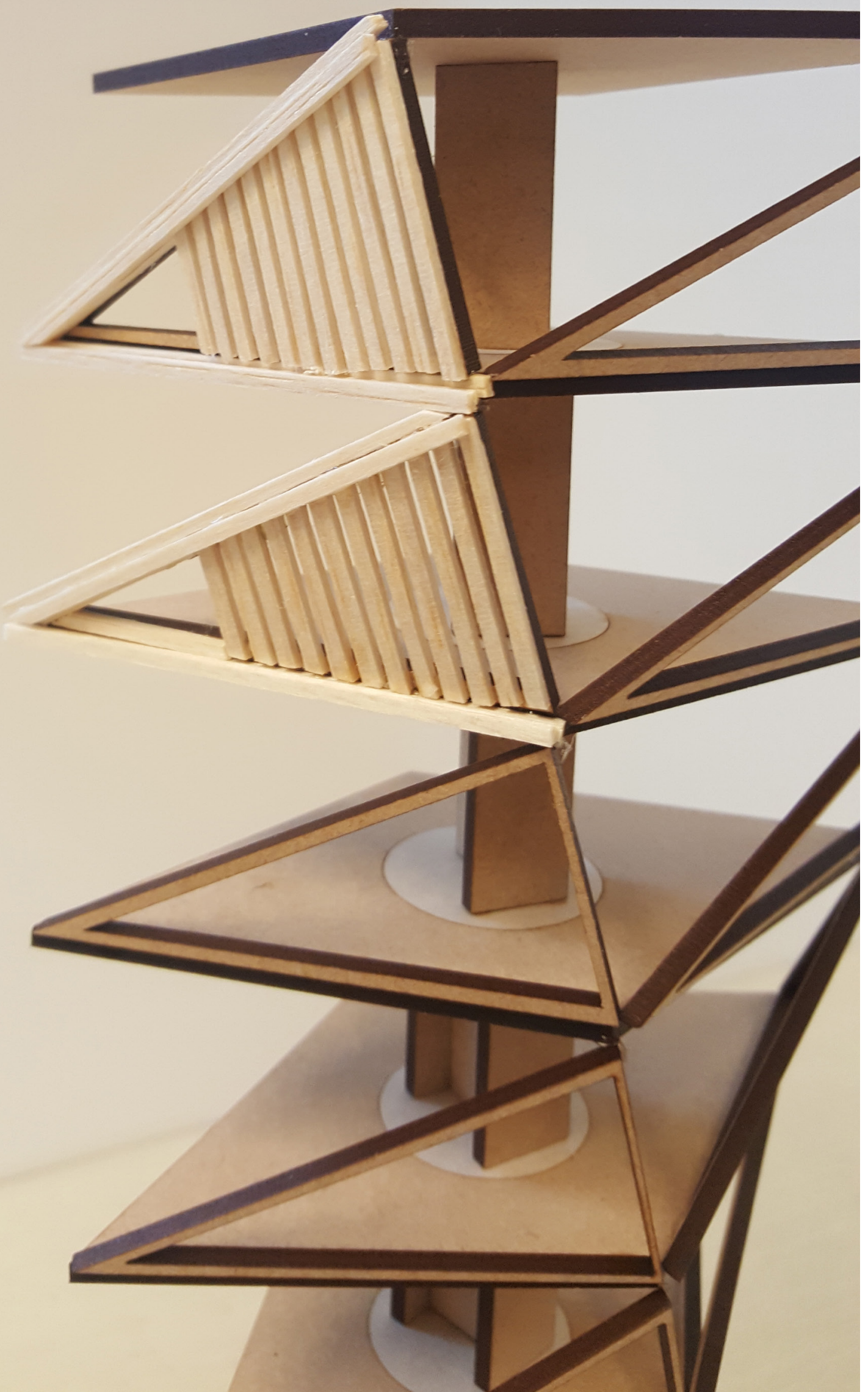

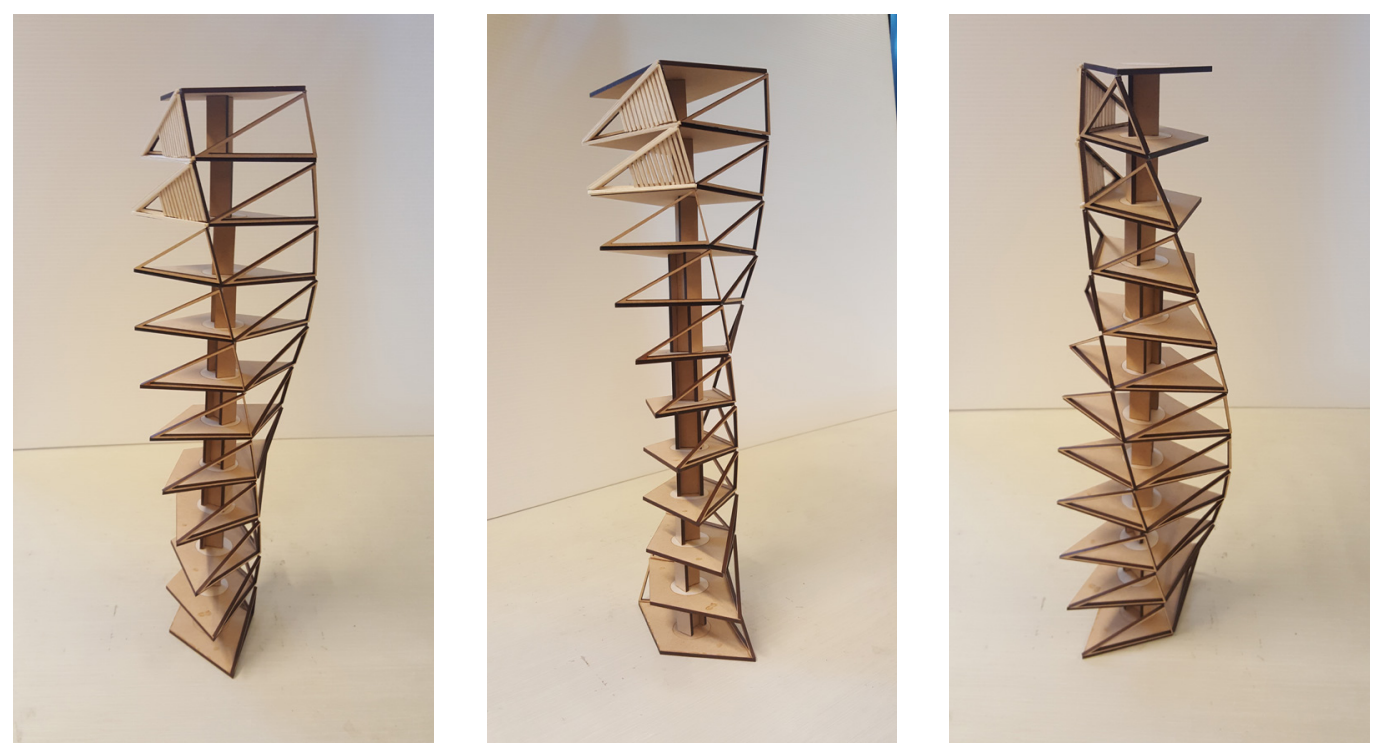

Figure 149 - Lookout Tower structure and cladding design exploration

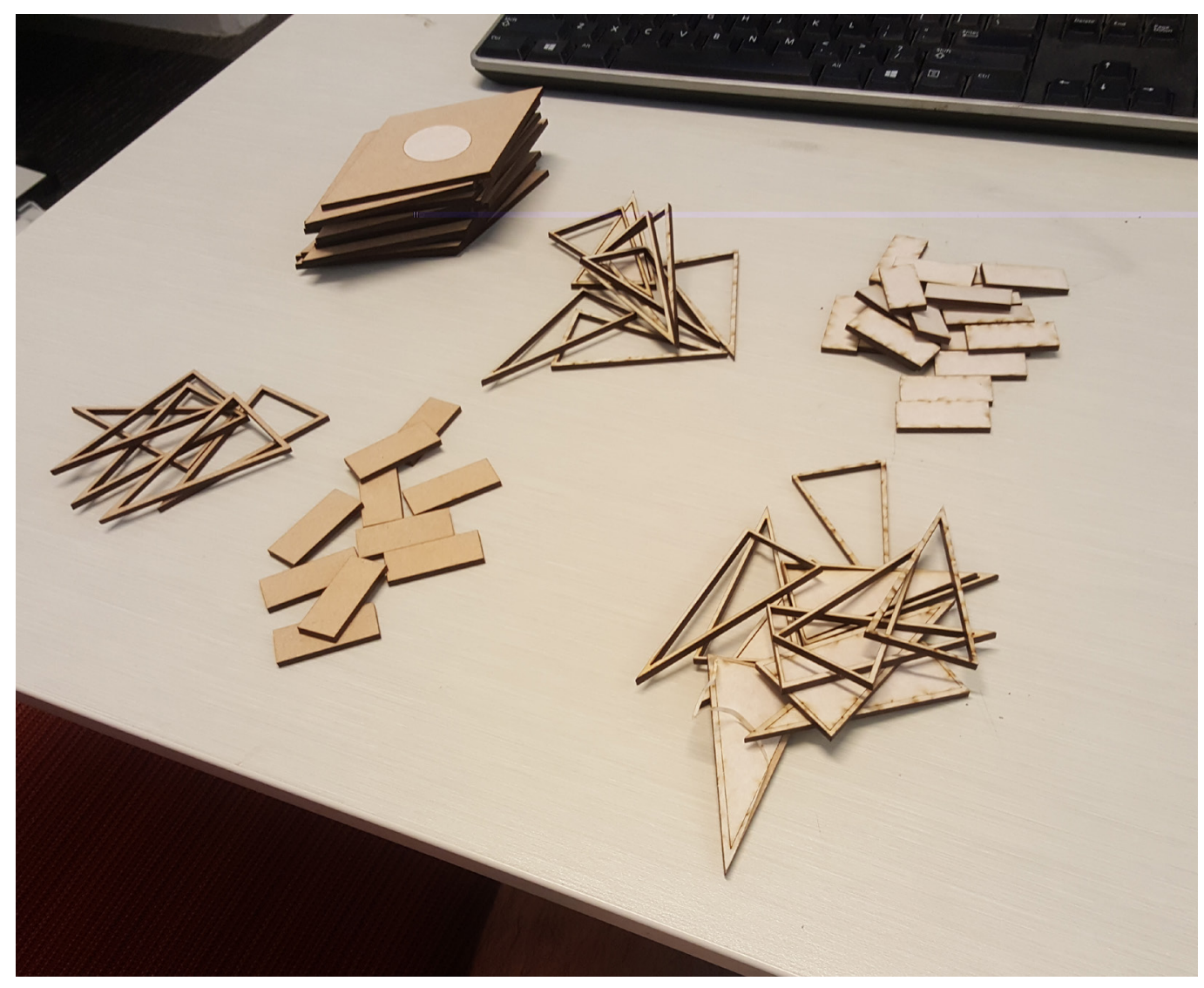

^ Figure 150 - Lookout Tower structural components

< Figure 151-Lookout Tower physical modelling of conceptual structural 

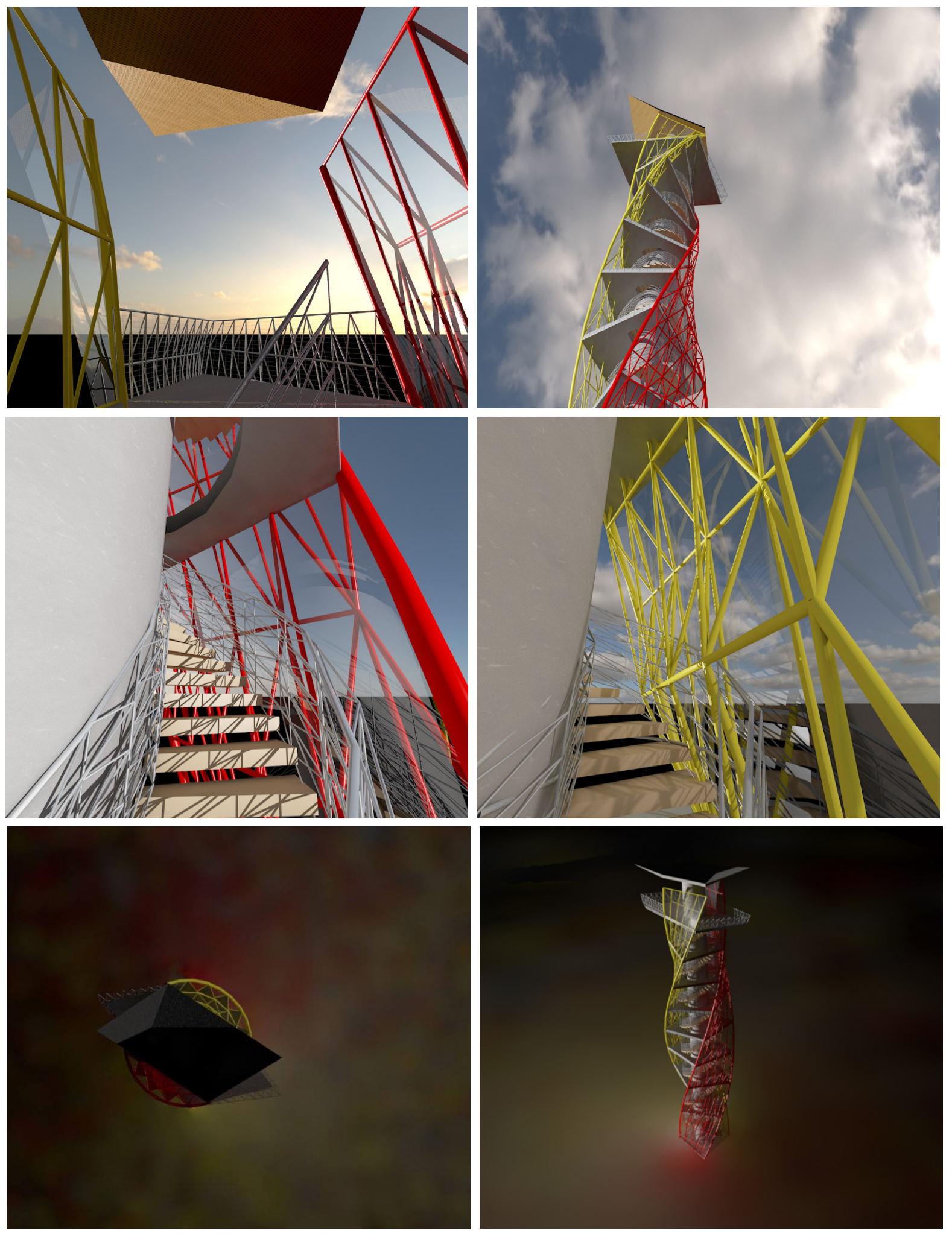

$\wedge$ Figure 152- Lookout Tower - Orientation of view, The Journey 


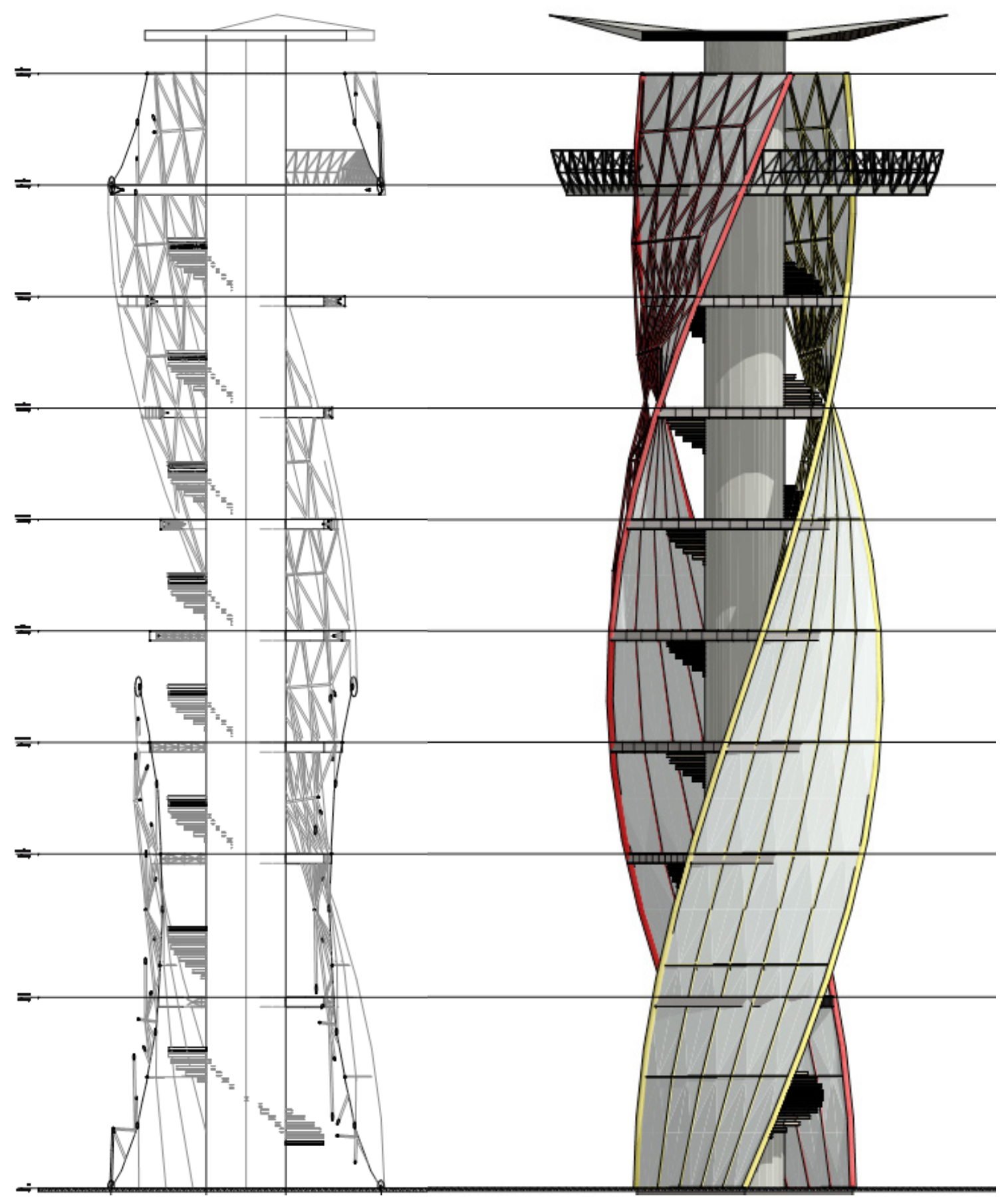

Figure 153 - Lookout Tower Elevation and Sectional drawings 